\title{
Thrombinoscopy : a method for the determination of prothrombinase activity in plasma, its application to the study of different types of heparin
}

Citation for published version (APA):

Béguin, S. (1987). Thrombinoscopy : a method for the determination of prothrombinase activity in plasma, its application to the study of different types of heparin. [Doctoral Thesis, Maastricht University].

Rijksuniversiteit Limburg. https://doi.org/10.26481/dis.19870605sb

Document status and date:

Published: 01/01/1987

DOI:

10.26481/dis.19870605sb

Document Version:

Publisher's PDF, also known as Version of record

Please check the document version of this publication:

- A submitted manuscript is the version of the article upon submission and before peer-review. There can be important differences between the submitted version and the official published version of record.

People interested in the research are advised to contact the author for the final version of the publication, or visit the DOI to the publisher's website.

- The final author version and the galley proof are versions of the publication after peer review.

- The final published version features the final layout of the paper including the volume, issue and page numbers.

Link to publication

\footnotetext{
General rights rights.

- You may freely distribute the URL identifying the publication in the public portal. please follow below link for the End User Agreement:

www.umlib.nl/taverne-license

Take down policy

If you believe that this document breaches copyright please contact us at:

repository@maastrichtuniversity.nl

providing details and we will investigate your claim.
}

Copyright and moral rights for the publications made accessible in the public portal are retained by the authors and/or other copyright owners and it is a condition of accessing publications that users recognise and abide by the legal requirements associated with these

- Users may download and print one copy of any publication from the public portal for the purpose of private study or research.

- You may not further distribute the material or use it for any profit-making activity or commercial gain

If the publication is distributed under the terms of Article $25 \mathrm{fa}$ of the Dutch Copyright Act, indicated by the "Taverne" license above, 


\section{THROMBINOSCOPY}





\section{THROMBINOSCOPY}

A METHOD FOR THE DETERMINATION OF PROTHROMBINASE ACTIVITY IN PLASMA, ITS APPLICATION TO THE STUDY OF DIFFERENT TYPES OF HEPARIN

\section{PROEFSCHRIFT}

TER VERKRIJGING VAN DE GRAAD VAN DOCTOR IN DE GENEESKUNDE AAN DE RIJKSUNIVERSITEIT LIMBURG TE MAASTRICHT, OP GEZAG VAN DE RECTOR MAGNIFICUS, PROF. DR. F.I.M. BOMKE, VOLGENS BESLUIT VAN HET COLLEGE VAN DEKANEN, IN HET OPENBAAR TE VERDEDIGEN IN DE AULA VAN DE UNIVERSITEIT OP VRIJDAG 5 JUNI 1987, DES NAMIDDAGS TE VIER UUR

door

Suzette BÉGUIN

GEBOREN TE SAINT-OUEN, FRAMKRIJK 
Promotor : Prof. Dr. H.C. Hemker

Referenten: Prof. Dr. P. van Breda Vriesman

Prof. Dr. P. Cornu

Prof. Dr. C. Haanen
Rijksuniversiteit Limburg Université Descartes, Paris Kath. Universiteit Nijmegen

Cover illustration by: Martin Linnartz

Printed by: Krips Repro Meppel 
L'esprit d'observation est rare. Quand on l'a reçu de la nature, $i 1$ est encore facile de se tromper par précipitation.

Denis Diderot

(Voyage en Hollande)

A la mémoire de mon père

A la mémoire de Françots Josso 
This work has been made possible by a grant from the "Thrombose Stichting Nederland".

Financial support by "La Fondation de France" is gratefully acknowledged. "De Nederlandse Hartstichting" contributed to the printing costs of this thesis. 


\section{CONTENTS}

\section{INTRODUCTION}

Chapter I

FEEDBACK REACTIONS IN THROMBIN

GENERATION

Chapter II

A COMPUTER ASSISTEO METHOD TO OBTAIN

THE PROTHROMBIN ACTI VATION VELOCITY

IN WHOLE PLASMA INDEPENDENT OF THROMBIN DECAY PROCESSES

Annexe: Mathematical analysis of the thrombin generation curve. (G.M. Willems and H.C. Hemker)

Chapter III

THE MDDE DF ACTION OF HEPARIN IN PLASMA

Chapter IV

THE MODE OF ACTION DF SOME LOW MOLECULAR WEIGHT HEPARINS IN PLASMA. RECOGNITION

OF TWD FUNCTIONALLY DIFFERENT TYPES

Chapter $V$

THE MODE OF ACTION OF PENTDSAN

POLYSULPHATE IN PLASMA.

Demonstration of the Josso pathway 
THE COOPERATIVE EFFECT DF TISSUE FACTOR AND THROMBOCYTES ON THROMBIN GENERATION;

A COMMON SITE OF ACTION FOR HEPARIN, LOW MOLECULAR WEIGHT HEPARINS AND OTHER ANTITHROMBOTIC DRUGS?

SUMMARY and CONCLUSIONS

SAMENVATTING EN CONCLUSIES

RESUME et CONCLUSIONS

REMERC IEMENTS 


\section{INTRODUCTION}

Thrombin is the pivotal enzyme of hamostasis and thrombosis. It cataiyzes many important reactions in these processes among which coagulation in the strict sense of the word, i.e. the enzymatic conversion of fibrinogen in fibrin by thrombin. The formation af thrombin in the blood results from a complicated series of chemical and physical interactions; its subsequent inactivation also. In vivo these opposite mechanisms (activationinactivation) are tuned so precisely that the blood remains fluid in the wessels but any leak is promptly mended. When this equilibrium is disrupted either bleeding or thrombosis will erisue.

Because of the enomous progress in modern coagulation biochemistry, resulting in the isolation and purification of the proteins of coagulation and detailed enzymological studies on their interactions, it is readily possible at this moment to give a plausible scheme of the biochenical reactions which contribute to the formation and to the disappearance of thrombin. Especially in the last ten years, kinetic studies of isolated steps of the coagulation mechanism revealed many details of the biochemical mechanisms involved. There is a consensus on the existence of two pathways that explain the mechanism of the coagulation of blood: the intrinsic pathway operative when coagulation is started by contact of blood with glass or other foreign surfaces, and the extrinsic pathway triggered by the addition of tissue thromboplastin. In both cases, calcium is essential. However, these standard schemes of blood coagulation proposed for in vitro situations will not necessarily apply in vivo. Thus some questions from the patho-physiology of blood coagulation remain even today without answer, e.g.: How to explain the importance of the intrinsic pathway in vivo in the obvious absence of foreign surfaces? or: Why do haemophllitacs bleed whereas the proband of Factor XII deficiency, Mr. Hageman had no bleeding problems and died of thrombosis? or: Why is it that heparin hardly influences the thromboplastin time and in the same concentration has a marked influence both on the thrombin time and the activated partial thromboplastin time? again: Why do some kinds of thrombopathies show clotting disorders whereas most do not? and: How to explain the origin of early traces of thrombin 
necessary to activate Factors $V$ and VIII? The answer to these questions does not readlly follow from the classical coagulation schemes. other interactions between the clotting factors must exist. In the course af the years many accessory reactions, not featuring in the classical schemes ("cross reactions") have been demonstrated to be possible in vitro but it remains difficult to see which of them are of importance in vivo and which are not.

Already in 1976, Hur let-Birk Jensen, Josso and Bëguin produced evidence for thrombin fomation in the very early stage of hamostasis before clotting occurred. This was done by means of the measurement of the activation of factors $V$ and $V \mathbb{I I}$ in the blood flowing fron a wound in nomal and congenitally deficient subjects. This type of experiments requires the presence of patients in the laboratory, because the activation of the factors is not stable and difficult to quantify if the determinations are not carried out immediately. This is one example of the importance of close collaboration between the clinics and the research laboratory for the study of haenostasis and thrombosis. The alder literature abounds with more examples but even today, patients like those exibiting abnormal prothrombin (prothrombin Metz, prothrombin Barcelona), abnarmal antithrombin III

(AT III Alger) or the Scott thrombopathy show that the experiments of nature, that can be found by attentive physicians among the patients under their care, are never to be neglected. In general, the (patho)physiology of haemostasis and thrombosis has a wider scope than the study of interactions of isolated coagulation factors. Having worked in a clinical research laboratory for ten years, then an other ten years in fundamental research in a universtiy haspital and being exposed to the surroundings of a highly specialized biochemistry department for the last few years, I should like this study to become a "trait dunilon" between biochemistry and blood coagulation (patho)physiology. The aim of the present thesis is to attempt a study of the coagulation mechanism in whole plasma under conditions as near as possible to the situation in vivo; using the classical thrombin generation test equipped with the assets of modern technology such as chromogenic substrates, computer aided automatic sample-timing, computing techniques for the interpretation of the results and, where necessary the use of highly purified clotting factors and well defined phospholipids. After a brief review of the classical coagulation mechanism, (chapter I) 
we will report on a new method that allows to obtain the prothrombin activation velocity in normal plasma independently of thrombin decay processes (chapter II). In the third chapter this methodology will be applied to the study of the action of heparin in plasma. In the fourth chapter the mode of action of low molecular weight heparins is investigated. In chapter five the anticoagulant, pentosan polysulphate (Hemoclar ${ }^{R}$ ) is used to demonstrate the role of Factor VIII in the extrinsic coagulation and hence the function of the Josso Loop. Finally, in the aim to mimic more clasely the physiological situation, we studied thrombin formation in platelet rich plasma, in the presence and absence of platelets activators or inhibitors and heparins (Chapter VI).

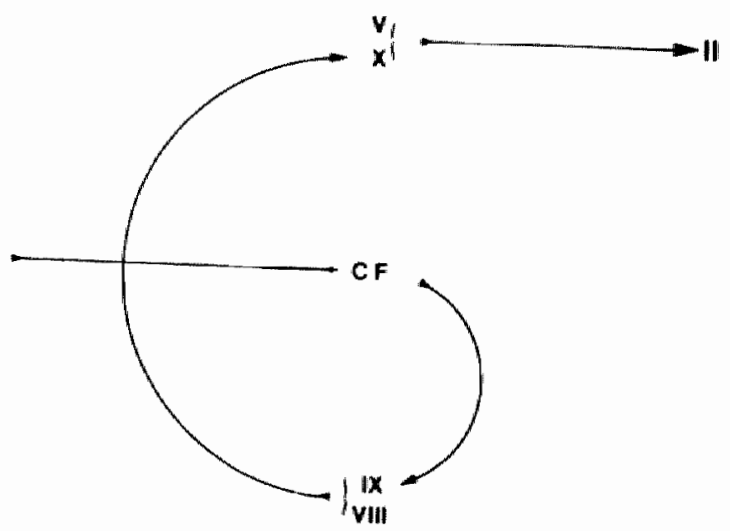

The classical intrinsic pattuay 
CONCENTRATIONS OF SOME PLASMA PROTEINS

\begin{tabular}{|c|c|c|c|}
\hline Abreviations & & Molecular weight & $\begin{array}{l}\text { Approximate conc. } \\
\text { nMolar }\end{array}$ \\
\hline 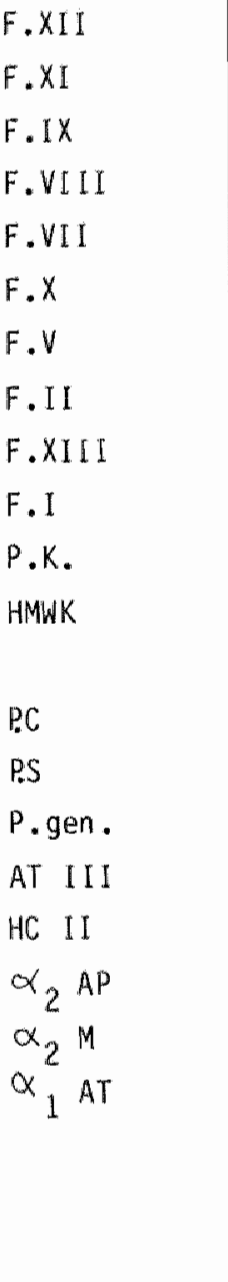 & $\begin{array}{l}\text { Factor XII } \\
\text { Factor XI } \\
\text { Factor IX } \\
\text { Factor VIII } \\
\text { Factor VII } \\
\text { Factor X } \\
\text { Factor V } \\
\text { Factor II } \\
\text { Factor XIII } \\
\text { Fibrinogen } \\
\text { Prekallikrein } \\
\text { High molecular } \\
\text { weight kininogen } \\
\text { Protein C } \\
\text { Protein S } \\
\text { Plasminogen } \\
\text { Antithrombin III } \\
\text { Heparin Co-factor In } \\
\alpha_{2} \text {-antiplasmin } \\
\alpha_{2} \text {-macroglobulin } \\
\alpha_{1} \text {-antitrypsin } \\
\text { inter- } \alpha \text {-trypsin inh } \\
\text { cl-inhibitor } \\
\text { S-protein }\end{array}$ & \begin{tabular}{|c}
80000 \\
170000 (dimer) \\
70000 \\
200000 \\
45500 \\
55000 \\
300000 \\
66000 \\
350000 \\
360000 \\
100000 \\
200000 \\
\\
60000 \\
$70-85000$ \\
92000 \\
65000 \\
$65-70000$ \\
65000 \\
750000 \\
52000 \\
160000 \\
150000 \\
74000
\end{tabular} & $\begin{array}{r}450 \\
30 \\
70 \\
0.5-1 \\
10 \\
180 \\
25 \\
1500 \\
\\
10000 \\
1100 \\
350 \\
\\
66 \\
130 \\
1400 \\
2000 \\
1200-450 \\
900 \\
3500 \\
25000 \\
3000 \\
2200 \\
6700\end{array}$ \\
\hline
\end{tabular}




\section{FEEDBACK REACTIONS IN THROMBIN GENERATION}

The basis of the physiology of the coagulation were established in the second part of $X_{I} x_{t h}$ century. After the discovery of thrombin (Buchanan 1836-1845, Schmidt 1861-1892) the definition of fibrinogen (Wirchow 1856; Denis 1859) and its isolation by Hammarsten (1876-1880), the demonstration of the important role of calcium in coagulation (Arthus and Pages 1890) and finally the discovery of "prothrombin" by Pekelharing in 1895, Morawitz in 1905 proposed the first coherent model of coagulation, which will then be maintained during some forty years. In 1940 Seegers purified "prothrombin" (i.e. What is now known to be a mixture of the factors II, VII, IX and $X$ ). This opened the era of modern biochemical coagulation research. Yet, still in 1947, only two proteins of coagulation were sufficiently defined: fibrinogen and prothrombin. In that year Owren published his study on Factor $V$ (proaccelerin). Concomitantly owren created a methodology which allowed the discovering of ten clotting factors. In 1964, the hypothes is of a "cascade" of enzymatic reactions was advanced by Mac Farlane. This was the trigger for many enzyme mechanistic studies that led to the establishment of a reaction sequence that we will discuss now.

\section{A. THE CLASSICAL COAGULATION MECHANISM.}

1. Activation by limited proteolysis.

The mechanism of activation by 1 imited proteolysis is central in the blood coagulation reaction sequence. Studies on digestive proteolytic enzymes ((chymo)trypsin, pepsin etc) and their zymogens have made proenzyme $\longrightarrow$ enzyme conwersions of proteolytic enzymes one of the main subjects of classical enzymology $(1,2)$.

The main chain of tissue thromboplastin induced proteolytic activations in blood is: * 
in blood is:

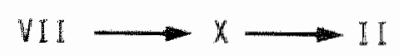

For intrinsic coagulation the main chain of activations is $(3)$ :

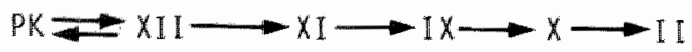

All the non-activated clotting factors participating in these chains are proenzymes of serine proteases, the activated enzymes consequently are serine proteases.

\section{Heterogenous biocatalysis.}

The proteolytic activations shown above can be obtained when the molecules encounter in free aqueous solution. They are accelerated up to 100.000 fold however by the presence of a phospholipid interface and specific protein cofactors. To illustrate this mechanism we will take the activation of prothrombin as an example. Factor $x_{a}$ is capable to generate thrombin from prothrombin in free solution, but only in a very ineffective mechanism $(4,5,6)$. Hanahan \& Papahadjopoulos (7) were the first to observe that an active prothrombinase exists only in preparations that contain the three components $F X_{a}$, FV and phospholipid. (The question of factor $V$ activation will be discussed later). Hemker et al (8) showed that the generation of prothrombinase activity can be described as the reversible fomation of a complex of $F X_{a}$, $F V$ and phospholipid. In a series of very elegant experiments Rosing et al (9) later showed that phospholipids diminish the $k_{m}$ for prothrombin

\section{* Footnote:}

Arrows indicate activation steps, double arrows mean mutual activation. Brackets indicate multienzyme complexes. $P K=$ Prekallikrein, TF = Tissue Factor, $P L=$ Phospholipids. Roman mumerals indicate the factors. 
conversion (a typical change would be from 3000 n to $30 \mathrm{~mm}$ ) whereas Factor $V_{a}$ increases the turnover number $\left(k_{c a t}\right)$ about 1000 fold. Further investigations (9-16) showed that the change in $K_{m}$ is caused by the fact that the lipid bound enzyme has a higher affinity for the substrate then the free enzyme has. The change in $k_{c a t}$ is probably brought about by an alignment of the active-site of Factor $x_{a}$ to the vulnerable sites of Factor II caused by their mutual interaction with Factor $V_{a}$.

In 1967 Hemker and Kahn (17) found that the Factor X activating enzyme is a complex of the Factors VIIIa and $\mathbb{I X}_{a}$ and phospholipid, completely comparable to the prothrombinase complex. Later, van Diejjen et al (18) showed that in this complex the kinetic effects of phospholipids (on $K_{m}$ ) and Factor VIII (an $k_{c a t}$ ) were similar to those of phospholipid and Factor $V_{a}$ in the prothrombinase complex. Apart from their kinetic effect on $k_{c a t}$, the factors $V_{a}$ and VIII a 1 so serve to better bind their respective enzymes $\left(F X_{a}\right.$ and $\left.F I X_{a}\right)$ to phospholipid $(19,20)$.

The available data, primarily those coming from the laboratory of Nemerson (21) indicate clearly that Factor VII and tissue thromboplastin form a complex that is again comparable to prothrombinase. In this case the protein cofactor and the phospholipid are intimately bound but the mechanistic role of the protein cofactor, ijke Factor $V_{a}$, seems to be to enhance the efficiency of the enzyme whereas the lipid serves to booster the affinity for the substrate. The most obvious difference with the other complexes resides in the fact that tissue thromboplastin does not arise from an on the spot combination of the protein cofactor and the lipid but is a tight lipoprotein complex, shed as such by wounded cells. We will not enlarge upon the surface reactions and cofactors of contact activation here for reasons that will be discussed later.

We can summarize the reactions of the classical coagulation pathways as foll lows: 
Extrinsic pathway:

$\left(V I I, T_{1} F_{*}, P L\right) \Longrightarrow\left(X, V_{a}, P L\right) \longrightarrow I I$

Intrinsic pathway:

$\mathrm{PK} \rightleftarrows \mathrm{XII} \rightarrow \mathrm{XI} \rightarrow(\mathrm{IX}, \mathrm{VIII}, \mathrm{PL}) \longrightarrow\left(\mathrm{X}, \mathrm{V}_{\mathrm{a}}, \mathrm{PL}\right) \longrightarrow \mathrm{II}$

An overview of the coagulation reactions is not complete if no account is given of the way in which thrombin formation is 1 imited. Apart from the trivial possibility of substrate exhaustion, more often then not silently assumed to be the clatting delimiter in the older literature, there are two main mechanisms to be considered: scavening of coagulation proteases by antithrombin III, $\alpha_{2}$ Macroglobul in and other antiproteases $\left(\alpha_{1}\right.$ antitrypsin) (Ref. 22 see for a review) and breakdown of the protein cofactors ( $F V_{a}$ and FVIII ${ }_{a}$ ) by activated protein $C$ (together with protein $S)(23,24)$. Protein $C$ and protein $S$ are vitamin $K$ dependent proteins circulating in the plasma, $(25,26)$. Protein $C$ is activated by thrombin adsorbed onto thrombomodulin (27). Because thrombomodulin occurs at the surface of intact endothelium this mechanism may help to limit thrombin formation to wounded areas.

Among the anti-proteases, AT III is extremely important because of the fact that its activity can be enhanced by heparins (28-30) which makes it the lever on which this important family of antithrombotic drugs acts.

\section{B. THE CROSS REACTIONS.}

1. Activation of clotting factors by thrombin.

It has been shown that both Factor VIII and Factor $V$ have to be activated before they can play their role as a protein cofactor, and that thrombin is the enzyme that brings about these activations (31-34). Thrombin-activated Factor $V\left(F, V_{a}\right)$ in a purified state, when kept under the right conditions is relatively stable. The active state of factor VIII always seems to be a transient phenomenon, ending in 
inactivation. The activation of factor $V$ has been described in terms of protein chemistry. The single chain molecule of factor $V$ is cleaved in three places by thrombin and two of the four resulting fragments recombine under the influence of $\mathrm{Ca}^{++}$to form Factor $V_{\mathrm{a}}$. The mode of interaction between Factor VIII and thrombin probably is a similar process (35). It has been described that in a human system Factor $X_{a}$ can activate Factor VIII (36).

At this moment it is established beyond any reasonable doubt that activation of the Factors $V$ and VIII is obligatory for their taking part in the coagulation mechanism. This does not mean however that we know wether these reactions are physiologically important. To be more exact: it is essential to know wether these activations play a rate limiting role under physiological conditions and what the physiological activator is. From the work of Hurlet et al (37) it may be concluded that the activation of $V$ and VIII does occur in vivo in the time course of normal haemostasis but this again does not allow conclusions as to its factual importance. Such conclusions might be drawn if an aberrant prothrombin were known that yield a thrombin incapable of activating Factor $V$, prothrombin Metz $(38,39)$ might be a candidate.

\section{Activation of platelets by thrombin.}

Thrombin is the most potent physiological platelet activator known (40), a concentration of 0.1 to $1.0 \mathrm{nM}$ will suffice to trigger a half maximal release reaction. All other activators of human platelets need concentrations that are one or more orders of magnitude higher if they are to cause the same response.

Anong the proteins released by platelets are factor $V$ and heparin neutralizing proteins (platelet factor 4). The amount of Factor $V$ sequestered in the platelets is roughly $20 \%$ of the amount present in the plasma (41). Thrombin, that causes the release reaction will also activate the released Factor $V$. It has been shown that this activation rather then the release reaction itself is the rate 1 imiting factor for the generation of Factor $V$ activity from triggered platelets (42). The concentration of Factor $V$ in platelet poor plasma is about 25 nM whereas that of its partner, Factor $X$ is around $200 \mathrm{nM}$. This may lead 
one to think that the contribution of platelet Factor $Y$ may be important in vivo. The aggregation of platelets at sites where the hemostatic mechanism is active will cause a further increase in the ratio of platelet-Factor V to plasma-factor V. Still patients with a storage pool deficiency that are unable to release Factor $W$ from their platelets do not have an important hemorrhagic diathesis (43). It seems that only patients lacking Factor $V$ in both platelets and plasma do show a hemorrhagic syndrome (44). This may be explained by the generally recognized fact that the normal level of any clotting factor represents a large functional excess. As a rule the level of any clotting factor must drop significantly below $10 \%$ before a decrease of the clotting function becomes apparent.

A second procoagulant function of platelets induced by thrombin together with collagen is the platelet "flip-flop" reaction discovered by Bevers et al. (45). This reaction consists of a transbilayer movement of the procoagullant, negatively charged phospholipids (primarily phosphatidyl serine) that as a rule are to be found almost exclusively at the inner face of the cell membrane. In the presence of collagen and thrombin, platelets produce these procoagulant phospholipids at the outside of the cell without the cell being disrupted. The precise molecular mechanism of this reaction is not yet clear. Anyhow, platelets thus activated, offer large amounts of binding sites for the Factors IX $X_{a}$ VIII,$X_{a}$ and $V_{a}$ at their outer surface so that prothrombinase and the Factor $X$ activating enzyme can readily form there. One patient has been described in which this mechanism is defective, she suffers from a mild haemorrhagic diathesis (46).

It has been reported that collagen activated platellets can start coagulation via a Factor XI dependent mechanism and that ADP activation of platelets triggers coagulation via Factor XII (47). These findings remain to be confirmed. The recent observation that platelets release a potent inhibitor of Factor $X_{\mathbb{a}}$, so that Factor IX activation by Factor $X_{I}$ hardly proceeds in the presence of activated platelets (48) makes one doubt the importance of contact activation for in vivo thrombin generation. 
3. The Josso loop.

In the classical view, contact factors and antihemophilic factors form the intrinsic pathway of thrombin formation and the importance of the role of the contact factors is derived from the recognized importance of the antihemophilic factors. The activating action of Factor VII on Factor $\mathbb{I} X$ invalidates this argument. The first indications that the action of the antihemophilic factors (FVIII and FIX) is not confined to the coagulation pathway started by the contact factors were obtained by Biggs and Nossel (49). Josso (50) was the first to postulate that Factor VII can activate Factor IX so that the antihemophilic factors play a role in thromboplastin triggered coagulation. This means that Factor $x$ can be activated either directiy by Factor VII and tissue

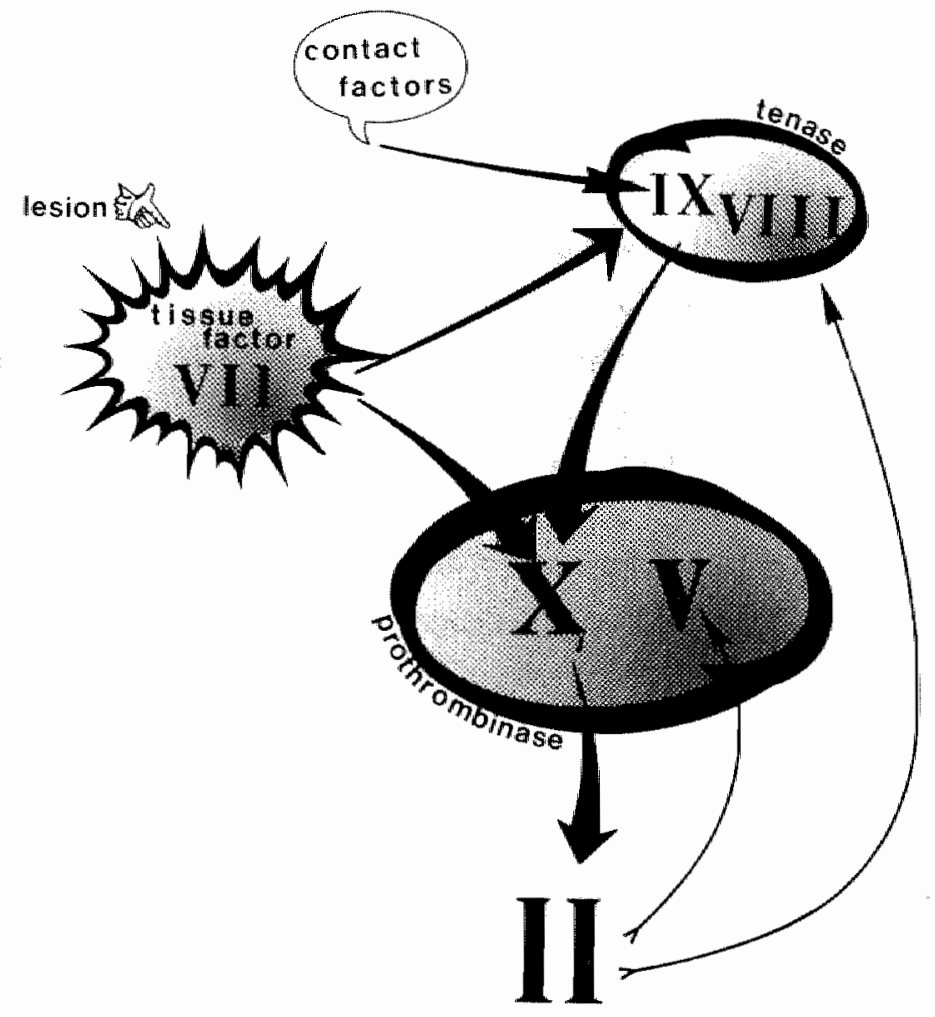

Fig. 1. A SCHEME OF THROMBIN GENERATION. 
thromboplastin or indirectly by factor $I_{a}$ (together with Factor VIII ) that, in its turn has been activated by Factor VII (see fig. 1). It is easy to see that the function of this pathway will anyhow be dependent upon the amount of thromboplastin available. The contribution of the direct, one-step action of Factor VII a Factor $x_{a}$ formation will be constant in time and roughy proportional to the concentration of thrombopiastin. The contribution via the pathway VII $\longrightarrow I X \longrightarrow X$ will be small in the beginning of the reaction but will increase proportionally with time as the Factor $x$ activating enzyme (i.e. Factor $\left.I X_{a}\right)$ builds up. Therefore the reinforcement loop constituted by the antihemophilic factors - which H.C. Hemker proposed to call the Josso loop after its discoverer (50) - will gain in importance when clotting is started by smaller amounts of thromboplastin.

The early observations on the interconnections between the extrinsic and the intrinsic pathway did not get the attention they deserved until Dsterud and Rappaport drew attention to the fact that the Factor VIIthromboplastin complex is capable of activating Factor IX in a partially purified system (51). Later Zur and Nemerson (52) Jesty and Silverberg (53) and Marlar and Griffin (54) established this pathway without any reasonable doubt.

The physiological importance of the Jasso loop is difficult to ascertain because of the thromboplastin dependent and hence time dependent effect discussed above. It is tempting to use the losso-loop mechanism as a tentative explanation for the clinical observation that hemophillacs tend to bleed in thromboplastin poor organs such as joints, but this can hardly be accepted as a proof of its importance. Jesty and Silverberg (53) calculate that the activation of Factor $x$ by Factor VII $\mathbb{I}_{a}$ is 6 to 7 times faster than the activation of Factor IX. Zur and Nemerson (52) find a ratio of 10 of the thearetical maximal velocities but argue that the actual ratio will be completely dependent upon the thromboplastin concentration. Van de Besselaar et al. (55) conclude from observations in deficient human plasmas that the Josso loop may be of no importance in human plasma. Clearly the issue is not settled as yet.

Kalousek et al. (56) have reported that Factor $X$ is able to activate Factor IX. This would constitute a mutual activation interaction that 
could enhance Factor $X$ activation even without activation of Factor $I X$ by Factor VII. Their experiments have been carried out in purified systems that did not contain protein cofactors (F.V anf F. VIII). Any indication as to the physiological significance of this interaction is. lacking at this moment.

\section{Activation of Factor VII.}

The current wiew on the starting mechanism of coagulation is based on the observation that the proenzyme Factor VII has a non-neglectible enzymatic activity $(57,58)$. Once it adsorb:s onto tissue thromboplastin, the activity of Factor VII is enhanced so as to become sufficiently important to start the clotting process. It has been observed however that there exists a more active form of Factor VII, the two

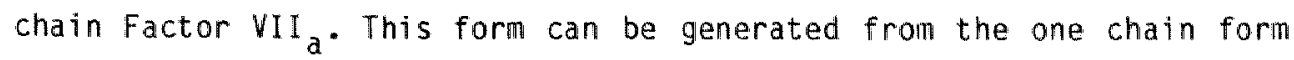
in a number of different ways. Altman and Hemker (59) showed, as early as 1967 , that the contact activation mechanism can enhance Factor VII activity in vitro. The cold activation of Factor VII, involving kallikrein and different other proteins has been well established. It has also been described that Factor VII can be activated by Factor IX and by Factor $x_{a}(60,61)$. A very interesting suggestion is made by Silverberg and Jesty (62), when they claim that a complex of Factor VII, tissue thromboplastin and Factor $x_{a}$ in the proteolytically active species.

If anywhere, then it is at the level of the activation of Factor VII that every conceivable reciprocal interaction of clotting factors has been described whereas any indication of their phystological importance is lacking. It is evident that all biochemical observations do not necessarily represent reactions that play a role in (patho) physiology. This being said, it must also be mentioned that often conclusions are drawn too quickly from clinical observations. Tradition has it that the scarce observations of a Factor VIl deficiency or of any other rare clotting factor deficiency prowoke speculations as to the physiological importance of a deficiency, of that specific factor. Now some observe a low Factor VII level $(<5 \%)$ without clinical symptoms whereas others find these patients severely handicapped. The same holds for Factor $X I$ 
deficiencies and others. In trying to interprete these data one should be aware of the following:

a) Any really important bleeding syndrome will lead to death either before or shortly after birth. Only the relatively mild syndromes survive. We remind of the and logy in thrombophilia: AT III and protein $c$ deficiencies are very rarely seen in the homozygous states, probably because complete deficiencies are lethal to the foetus.

b) Ary deficiency that does not lead to a clinically important syndrome will more often then not go unnoticed. It must be kept in mind that the physiological levels of clotting factors as a rule represent a large excess of that factor so that a decrease to as low as $m 15 \%$ of the nomal level will not cause any overt disease. The number of deficiencies that are recognized not to cause problems will therefore depend an chance findings and hence be under-estimated. This is illustrated by the fact that these disorders tend to cluster around laboratories that specialize in research on the blood coagulation and that are backed up by competent clinicians. We thus see that neither the really important deficiencies nor those without any clinical consequences will be recognized in routine medical practice. Therefore it is very hard - if not impossible - to draw conclusions on the mechanism of the blood coagulation process from the correlation between observed clinical symptoms and the accompanying clotting factor deficiencies.

\section{INHIBITORY REACTIONS.}

One may think of several crosslinks between the reactions that inhibit the clotting process and those that enhance thrombin formation.

The thrombin feedback reactions play an important role here. As we have discussed before, thrombin will enhance its own fomation by activating the factors $V$ and VIII as well as platelets. Any inhibition of thrombin formation and any reaction that inactivates thrombin therefore will interfere with this positive feedback. At the moment it is completely unknown in howfar ant thrombin III inhiblts thrombin formation because it modulates the extend of activation of Factor $V$ or Factor VIII etc. Because heparin acts via antithrombin III, this means that the mode of action of heparin in plasma is to a large extend unknown at this 
moment. Also diminution of the avallable amount of thrombin will cause a decreased rate of actiwation of protein $C$ and therefore prolong the mean 1 ifetime of the prothrombin and Factor $x$ activating complexes. Again no quantitative data are available that allow an estimate of the importance of this conceivable pathway.

In the second place one has to reckon with competition for clotting proteases between procaagulant complexes and protease scavengers. Here more data are available. It has been abserved for instance $(63,64)$ that antithrombin III will attack Factor $x_{a}$ less readily in the presence of phospholipids then in free solution and even less if both phospholipids and Factor $V_{(a)}$ are present. To what extend this phenomenon is operative in vivo is anybody guess. The fact that low molecular weight heparins are efficient antithrombotics and have an enhanced anti Factor $x_{a}$ activity suggests that anti-Factor $x_{a}$ scavening by AT III-heparin complexes might be of (patho)physiological importance. It has also been shown however that there is no direct relation between anti Factor $X$ action and antithrombotic properties (see chapter IV). What holds for Factor $x_{a}$ and antithrombin III, in principle holds for all surface bound proteases and all antiproteases. We do not know wether lipid binding of Factor $I_{a}$ or kaolin binding of kallikrein protects these enzymes from $\alpha_{2}$ macroglobulin or $\alpha_{1}$ antitrypsin etc.

Indeed, here as with the other cross reactions we have no data that allow us to determine which reactions are important in physiology and pathology and which are not.

A short overview Tike this already poses more questions then it answers. The main question that we are left with seems to be: How can we conceive an experimental approach to estimate the relative importance in vivo of different biochemical reactions that have been observed in vitro? We feel that an attempt should be made to attack the problem stepwise by first studying the ex viva situation, i.e. the clotting of platelet poor and platelet rich plasma. Different approaches are feasibile.

a) By computer aided mathematical analysis it must be possible to get the time course of prothrombinase activity from a thrombin generation curve, independently from the simultaneous breakdown of thrombin by protease inhibitors. This allaws to differentiate between effects on 
prothrombin activation and effects on thrambin breakdown. The development of this method is the subject of chapter II. In chapter VI we study thrombin generation in platelet rich plasma.

b) Heparins are known that have a more specific action then classical heparin has (65-66). A pentasaccharide has been found (67) that does not influence the AT III-thrombin interaction but enhances the breakdown of Factor $x_{\text {activity by } A T ~}$ III. Comparison of the action of this substance with that of classical heparin may inform us about the relative impartance of thrombin and factor $x_{a}$ inhibition (chapters III and IV). Also pentosan polysulphate, if it prevents activation of factor VIII (68), will inhibit specifically the Josso-loop. It thus might be used to demonstrate the importance of that pathway (chapter $V$ ).

c) Because in the specialized laboratories all the clotting factors are now avallable in a purified form it is possible to bypass and shortcut pathways in whole plasma by directly adding the purified activated intermediates. Also kinetic studies in whole plasma are now possible because the concentration of one specific factor can be modified between zero and very high concentrations by adsorbtion of that factor to a specific antibody or by adding the purified factor to the plasma.

d) Clotting factors that have properties different from the normal ones occur in rare congenital disorders or can be produced by chemical modification. If for example the prothrombin of normal plasma is replaced by aminidated prothrombin, thrombin will still be readily formed by prothrombinase but this aminidated thrombin will be unable to activate Factors V and VIII. In such a plasma the importance of feedback activation of these factors may be studied.

It thus appears that there are several passible ways to integrate the data from modern biachemical studies with the study of the clotting of plasma ex vivo. In this thesis we used the approaches mentioned under $a, b$ and $c$, to investigate the made of action of classical heparin (chapter III), of low molecular weight heparins (chapter IV) and of pentosan polysulphate (chapter V). Finally, in chapter VI, we study the generation of thrombin in platelet rich plasma. 


\section{REFERENCES}

1. Boyer, P. (ed.): The enzymes, Vol. III. Hydrolysis. Peptide Bands Academic press, New York, 1970

2. Neurath, H.: Structure and function of protedytic enzymes. In: edited by M. Sela, 28-79, "New perspectives in Biology", 28-79, Elsewier, New York.

3. Griffin, J.H., Cochrane, C.G.: Recent advances in the understanding of contact activation reactions. Seminars in Thrombosis and Hemostasis, vol. V 254-273, 1979

4. Esmon, C.T., Jackson, C.M.: The conversion of prothrombin. III: The Factor $x_{a}$, catalyzed activation of prothrombin. J. Biol. Chen. 249, $7782-7790,1974$

5. Jobin, F., Esnouf, M.P.: Studies on the formation of the prothrombinconverting complex. Biochem. J., 102, 666-674, 1967

6. Esmon, C.T., Owen, W.G., Jackson, C.M.: A plausible mechanism for prothrombin activation by Factor $x_{a}$, Factor $V_{a}$, phospholipid, and calcium ions. J. Biol. Chem., 249, 8045-8047, 1974

7. Papahadjopoulos, D.P., Hanahan, D.J.: Observations on the interaction of phospholipids and certain clotting factors in prothrombin activator formation. Biochim. Biophys. Acta, 90, 436-439, 1964

8. Hemker, H.C., Esnouf, M.P., Hemker, P.W., Swart, A.C.W.. MacFarlane, R.G.: Formation of prothrombin converting activity. Nature, 215, $248-251,1967$

9. Rosing, J., Tans, G., Govers-Riemslag, J.W.P., Zwaal, R.F.A., Hemker, H.C. The role of phospholipids and Factor $V_{a}$ in the prothrombinase complex. J. Biol. Chem. 255, 274-283, 1980

10. Nesheim, M.E., Eid, S., Mann, K.G.: Assembly of the prothrombinase complex in the absence of prothrombin. J. Biol. Chem. 256, 9874-9882, 1981

11. Van Rijn, J.L.M.L., Govers-Riemslag, J.W.P., Zwaal, R.F.A. Rosing, J.: Kinetic studies of prothrombin activation: Effect of factor $V_{a}$, phospholipids on the formation of the enzyme-substrate complex. Biochem. $23,4557-4564,1984$

12. Nelsestuen, G.L., Kisiel, W., Di Scipio, R.G.: Interaction of vitamin K dependent proteins with membranes. Biochem. 17, 2134-2138, 1978 
ann, K.G.: The kinetics and cofactor dependence of the volved in prothrombin activation. J. Biol. Chem., 258,

aswe 11, J.B., Mann, K.G.: The contribution of bovine ictor $V_{a}$ to the activity of prothrombinase. J. Biol. $-10962,1979$

, G., Govers-Riemslag, J.W.P., Zwaal, R.F.A., Hemker, of phospholipids and Factor $V_{a}$ in the mechanism of vation. Thromb. Haemostas. 42, 177 (abstract), 1979

, J. van Dieijen, G. Hemker, H.C.: Conjectures on the f Factor $V$ and VIII. In: The regulation of coagulation, ann and E. Taylor, 173-185, Elsevier North Holland, New

ahn, M.J.P.: Reaction sequence of blood coagulation. $1-1202,1967$

, Tans, G., Rosing, J., Hemker, H.C.: The role of Factor VIII ${ }_{a}$ in the activation of bovine Factor $X$. $56,3433-3442,1981$

overs-Riemslag, J.H.P., V.d. Waart, P., Henker, H.C. ;or $V_{a}$-Factor $x_{a}$ interaction. Effects of phospholipid ing composition. Biochem, 21, 5494-5502, 1982

van Rijn, J.L.M.L., Govers-Riemslag, J.W.P., Hemker, J.: Assembly of the intrinsic factor $X$ activating tions between factor $I X_{a}$, Factor VIII $I$, and phosphoaemos tas. 53, 396-400, 1985

-Nemerson, Y., Zur, M., Ostapchuk, P.: Kinetics of the bovine coagulation Factor $X$ by components of the y. Kinetic behavior of two-chain Factor VII in the ence of tissue factor. J. Biol. Chem., 252,8481-8488,

vesen, G.S.: Human plasma proteinase inhibitors. Ann. $52,655-709,1984$

eiss, A.J., Griffin, J.H.: Human protein C inactivation VIII in plasma by activated molecule. Ann. N.Y. Acad. 10,1981

flo, J., Dahlbäck, B., Teodorsson, B.: Inactivation of 
human coagulation Factor $V$ by activated protein C. J. Biol. Chenl., 258, $1914-1920,1983$

25. Stenflo, J.: A new vitamin K-dependent protein. Purification from bovine plasma and preliminary characterization. J. Biol. Chem. 251, $355-363,1976$

26. Stenflo, J., Jonsson, M.: Protein S. A new vitamin K-dependent protein from bovine plasma. Febs. Lett. 101, 377-381, 1979

27. Esmon, C.T., Owen, W.G.: Identification of an endathelial cell cofactor for thrombin-catalyzed activation of protein C. Proc. Natl. Acad. Sci. USA. 78, 2249-2252, 1981

28. Abildgaard, U.: Highly purified antithrombin III with heparin cofactor activity prepared by disc electrophoresis. Scand. J. Clin. Lab. Invest. $21,89-91,1968$

29. Biggs, R., Denson, K.W.E., Akman. N., Borrett, R., Hadden, M.: Antithrombin III, Antifactor $x_{a}$, and heparin. Brit. J. Haemat. 19, $283-305,1970$

30. Rosenberg, R.D., Damus, P.S.: The purification and mechanism of action of human anti-thrombin-heparin cofactor. J. Biol. Chem. 248, 6490-6505, 1973

31. Newcomb, T.F., Hoshida, M.: Factor V and thrombin. Scand. J. Clin. Lab. Invest. 17 suppl. 84, 61-69, 1965

32. Bergsagel, D.E., Nockolds, E.R.: The activation of proaccelerin. Brit. J. Haemat. 11, 395-410, 1965

33. Biggs, R., MacFarlane, R.G., Denson, K.W.E., Ash, B.J.: Thrombin and the interaction of Factors VIII and IX. Brit. J. Haemat. 11, 276-295, 1965

34. Suzuki, K., Dahlbäck, B., Stenflo, J.: Thrombin catalyzed activation of human coagulation Factor V. J. Biol. Chem. 257, 6556-6564, 1982

35. Vehar, G.A., Davie, E.W.: Preparation and properties of bovine factor VIII (antihemophilic factor). Biochemistry. 19, 401-410, 1980

36. Mertens, K., Bertina, R.M.: Activation of human coagulation Factor VIII by activated Factor $X$, the common product of the intrinsic and the extrinsic pathway of blood coagulation. Thromb. Haemostas. (Stuttgart) $47,96-100,1982$

37. Hurlet-Birk Jensen, A., Béguin, S., Josso, F.: Factor $V$ and VIII activation "in vivo" during bleeding. Evidence of thrombin fomation at 
the early stage of hemostasis. Path. Biol. 24,6-10, 1976

38. Rabiet, M.J., Jandrot-Perrus, M., Boissel, J.P., Elion, J., Josso, F.: Thrombin Metz: Characterization of the dysfunctional thrombin derived from z variant of human prothrombin. Blood, 63, 927-934, 1984

39. Josso, F., Rio, Y., Béguin, S.: A new variant of human prothrombin: prothrombin Metz, demonstration in a family showing double heterozy gosity for congenital hypoprothrombinemia and dysprothrombinemia. Haemostasis, 12, 309-316, 1982

40. Züicker, M.B., Nachmias, V.T.: Platelets activation. Arteriosclerosis, $5,2-18,1985$

41. Tracy, P.B., Eid, L.L., Bowie, E.J.W., Mann, K.G.: Radioimmunoassay of factor $V$ in human plasma and platelets. Blood, 60, 59-63, 1982

42. Baruch, D., Hemker, H.C., Lindhout, T.: Kinetics of thrombin induced release and activation of platelet factor V. Eur. J. Biochem. 154, $213-218,1986$

43. Weiss, H.J., Witte, L.D., Kaplan, K.L. et al.: Heterogenity in storage pool deficiency studies of granule bound substances in 18 patients including variants deficient in alpha granules platelet factor 4 , thromboglobulin and platelet derived growth factor. Blood, 54, $1296-1319$, 1979

44. Tracy, P.B., Giles, A.R., Mann, K.G., Eid, L.L., Hoogendoorn, H., Rivard, G.E.: Factor $V$ (Quebec) a bleeding diathesis associated with a qualitative platelet Factor $V$ deficiency. J. Clin. Invest. 74, $1221-1228,1984$

45. Bevers, E.M., Comfurius, P., van Rijn, J.L.M.L., Henker, H.C., Zwaal, R.F.A.: Generation of Prothrombin-converting activity and the exposure of phosphatidylserine at the outer surface of platelets. Eur. $J$. Biochem. 122, 429-436, 1982

46. Rosing, J., Bevers, E.M., Comfurius, P., Hemker, H.C., van Dieijen, G., Weiss, H.J., Zwaal, R.F.A.: Impaired Factor $X$ and Prothrombin activation associated with decreased phospholipid exposure in platelets from a patient with a bleeding disorder. Blood, 65, (2), 1557-1561, 1985

47. Walsh, P.N., Griffin, J.H.: Contributions of human platelets to the proteolytic activation of blood coagulation Factors XII and XI. Blood, $57,106-118,1981$

48. Soons, H.: Personal communication. 
49. Biggs, R., Nossel, H.L.: Tissue extract and the contact reaction in blood coagulation. Thromb. Diath. Haemorrh. 6, 1-14, 1961

50. Josso, F., Prou-Wartelle, 0.: Interaction of Tissue Factor and Factor VII at the earliest phase of coagulation. Thromb. Diath. Haemorr. Suppl. 17, 35-44, 1965

51. sterud, B., Rapaport, S.I. Activation of Factor $I X$ by the reaction product of tissue Factor and Factor VII: Additional pathway for initiating blood coagulation. Proc. Natl. Acad. Sci, USA, 74, $5260-5264,1977$

52. Zur, M., Nemerson, Y.: Kinetics of factor IX activation via the extrinsic pathway. J. Biol. Chem. 255, 5703-5707, 1980

53. Jesty, J., Silverberg, S.A.: Kinetics of the tissue factor-dependent activation of coagulation Factors $I X$ and $X$ in a bovine plasma systen. J. Biol. Chem. 254, 12337-12345, 1979

54. Marlar, R.A.. Griffin, J.H.: Alternative pathways of thromboplastindependent activation of human factor $X$ plasma. Annals New York Acad. Sciences. 370, 325-335, 1981

55. Van den Besselaar, A.M.H.P., Ram, I.E., Alderkamp, G.H.J., Bertina, R.M.: The role of factor $I X$ in tissue thromboplastin induced coagulation. Thromb. Haemostas. (Stuttgart) 48, 54-58, 1982

56. Kalousek, F., Konigsberg, W., Nemerson, Y.: Activation of factor IX by activated factor $X$ : a link between the extrinsic and intrinsic coagulation systems. Febs. lett. 50, 382-385, 1975

57. Jesty, J. Nemerson, Y.: Purification of Factor VII from bovine plasma. Reaction with tissue factor and activation of Factor X. J. Biol. Chem. $249,509-515,1974$

58. Nemerson, Y.: Regulation of the initiation of coagulation by Factor VII. Haemostas. 13, 150-155, 1983

59. Altman, R., Hemker, H.C.: Contact activation in the extrinsic blood clotting systems. Thromb., Diathes. Haemorrh. (Stuttgart) 18, 525-531, 1967

60. Nemerson, Y.: Biological control of Factor VII. Thrombos. Haemostas. (Stuttgart) 35, 96-100, 1976

61. Radcliffe, R. Nemerson, Y.: Activation and control of Factor VIl by activated Factor $X$ and thrombin. Isolation and characterization of a single chain form of Factor VII. J. Biol. Chem. 250, 388-395, 1975 
62. Morrisson-Silverberg, S.A., Jesty, J.: The role of activated Factor $X$ in the control of bovine coagulation Factor VII. J. Biol. Chem. 256, $1625-1630,1981$

63. Marciniak, E.: Factor $x_{a}$ inactivation by antithrombin III. Evidence for blological stabilization of Factor V. J. Biol. Chem. 256, 1625-1630, 1573

64. Josso, F., Bëguin, S.: Changes in the antithrombin III activity at the interface plasma-phospholipids. Thromb. Haemostas. 46, 285 (abstract), 1981

65. Dckelford, P.A., Carter, C.J. Cerskus, A., Smith, C.A., Hirsh, J.: Comparison of the in vivo hemorrhagic and antithrombatic effects of a low antithrombin II affinity heparin fraction. Thromb. Res. 27, $679-690,1982$

66. Barrowcliffe, T.W., Merton, R.E., Havercroft, S.J., Thunberg, L., Lindahi, U., Thomas, D.P.: Low affinity heparin potentiates the action of high-affinity heparin oligosaccharides. Thromb. Res. 34, 125-133, 1984

67. Choay, J., Petitou, M., Lormeau, J.C., Sinay, P., Casu, B., Gatti, G.: Structure-activity relationship in heparin: a synthetic pentasaccharide with high affinity for antithrombin III and eliciting high anti-factor $X_{a}$ activity. Biochem and Biophys. Res. Comm. 116, 492-499, 1983

68. Wagenvoord, R., Hendrix, H., Soria, C., Hemker, H.C.: Determination of the non-antithrombin III dependent inhibitor site of pentosane polysulphate in the blood coagulation. (to be published).

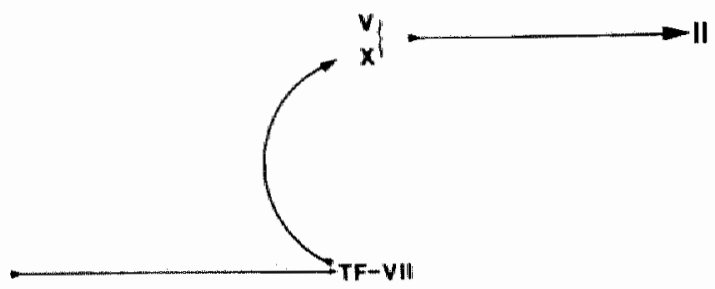

The classical extrinsic pattway 


\section{A COMPUTER ASSISTED METHOD TO OBTAIN THE PROTHROMBIN ACTIVATION VELOCITY IN WHOLE PLASMA INDEPENDENT OF THROMBIN DECAY PROCESSES.*}

\section{Summary}

A methad is descmibed that, on basis of the time course of amidotytio activity after the triggering of thrombin generation in nomat plabma, allows the calculation of the veloctty of prothrombin conversion independent of thrombin inativating processes.

It is shown how the reaction constants for the $\alpha_{2} M$-dependent and the $\alpha_{2}^{\prime}{ }^{M-}$ independent thrombin inactivation processes necessary for the calaulations can be obtained in a sample of whote plasma.

The method is verified by demanstrating that the experimentally observed time courses of residuat prothrombin and of $\alpha \mathrm{g}^{\mathrm{M}}$-thrombin complex coincide with those alduzated from the time coumge of amidotytic activity, and by showing that the course of prothrombin conversion in plasma without $\alpha_{2}$-Macroglobulin or AT III is adequately desemibed if the $\alpha_{2} M$ or AT IIIdepenient breakdown constants are taken zero in the calculations.

It appears that the inactivation of thrombin, endogenousty generated in whote plasma, is about half as fast as that of exogenows thrombin added to the plasma.

A computer program is presented that carmies out the relevant calculations.

* This chapter is based an an article of the same name published in Thrombosis and Haemostasis (1986) 56, 9-17 by H.C. Hemker, G.M. Willems and S. Béguin. 
The thrombin generation curve is one of the oldest tools of the coagulation trade. It is the basis of the so called two-stage prothrombin estimation $(1,2,3)$ but its roots go as far back as the very discovery of prothrombin (4). The rise and fall of thrombin concentration after triggering of coagulation in plasma results from the combined activity of the prothrombin activating enzyme complex (prothrombinase) and the thrombin inactivating processes, i.e. the binding of thrombin by antithrombins, such as antithrombin III and $\alpha_{2}$-macroglobulin $(5,6)$.

The general shape of the curve shows a short lag time and a fairly quick rise. After the maximum has been reached a gradual decline is observed that, if the clotting of fibrinogen is used to estimate thrombin, will eventually approach a zero level. Because the complex of a protease with $\alpha_{2}$-Macroglobulin has a persistent activity towards small molecular weight substrates $(6-10)$ the end of the level of activity will not be zero if the thrombin concentration is determined with the aid of chromogenic substrates.

The classical thrombin generation test suffers from an important drawback: the samples from the mixture in which thrombin is generated have to be tested immediately on a fibrinogen containing reagent. Estimation of low concentrations of thrombin tends to be very imprecise and time consuming when clotting methods are used. It therefore is virtually impossible to achieve in this way a sampling pattern with enough measuring points and of sufficient accuracy over the whole time range. A detailed analysis of the thrombin generation curve obtained by this method is therefore impossible.

This chapter describes a methad to obtain thrombin generation curves with sampling intervals that can be as small as 5 seconds. The thrombin is measured by its action on a chromogenic substrate. It is shown how these curves can be used to compute the time course of the process that generates thrombin (prothrombinase) independently of the processes that inactivate thrombin (antithrombins). These calculations can be carried out with the aid of a personal computer.

The following abrevations will be used: AT III = Antithrombin III; $\alpha_{2} M=\alpha_{2}$-macroglobulin; Tris = tris (hydroxymethyl) - aminomethane; EDTA = Ethylenediamino tetracetate; SBTI = Soybean Trypsin Imhibitor. 
Plasmas

Blood from healthy donors was collected on $0.13 \mathrm{M}$ trisodium citrate; nine parts of blood to one part of citrate solution.

A first and a second centrifugation were perfomed at $3000 \mathrm{~g}$, at $15^{\circ} \mathrm{C}$ for 15 minutes. A third centrifugation was done at $4{ }^{\circ} \mathrm{C}$, for one hour at. $23000 \mathrm{~g}$. The platelet free plasma thus obtained was stored at $-80{ }^{\circ} \mathrm{C}$. It was checked that the clotting factors and the antiproteases were in the normal range. The clotting factors were determined according to ref. 11 and 12. Radial immuno diffusion was used to estimate $\alpha_{2}$-macroglobulin and $\alpha_{1}$-antitrypsin (M. Partigen, Behring Werke, Germany). Antithronbin III was determined according to ref. 13 .

Defibrinated plasma was obtained by mixing an aliquot of plasma with 1 : 50 volume of a reptilase solution, letting a clot form for $10 \mathrm{~min}$ at $37{ }^{{ }^{O}} \mathrm{C}$ and keeping the clotted plasma at $0{ }^{o_{C}}$ for $10 \mathrm{~min}$. The fibrin formed was discarded by centrifugation $\left(10 \mathrm{~min}, 5000 \mathrm{~g}, 0^{\circ} \mathrm{C}\right)$ or by winding an a small plastic spatula. The concentrations of factors II, V, VII, VIII, IX, $X, X I$, and $X I I$ did not significantly change by the reptilase treatment. For the factors $V$ and VIII a series of dilution $(1-10 \%)$ of the plasma before and after the treatment were compared. They showed clotting times that were identical with in the limits of experimental error thus concluding the possibility that the combined effect of activation and inactivation of the factors accidently mimicked as identical clotting factors.

The euglobulin fraction from defibrinated plasma was obtained by acid precipitation at low ionic strenght as described in ref. 11. The precipitate was dissolved in Michaelis buffer $\mathrm{pH} 7.35$ containing $0.02 \mathrm{M}$ trisodium citrate, so as to obtain a concentration of the clotting factors II, V, VII and $X$ that was not lower than $50 \%$. No antithrombin activity could be demonstrated in this mixture.

Thrombin was formed in the euglobulin fraction by the addition of human thromboplastin (1:240 final dilution) and $\mathrm{CaCl}_{2}$ (16 mM final conc.). The development of thrombin activity was measured as described later in this section.

Human brain thromboplastin was prepared as described in ref 14 . It was 
Subsequently centrifuged at $2000 \mathrm{~g}$ for 15 minutes and stored in $0.1 \mathrm{ml}$ allquots at $-20^{\circ} \mathrm{C}$. It was thawed and incubated at $37{ }^{\circ} \mathrm{C}$ for one hour, then diluted as indicated with buffer containing $100 \mathrm{~mm}$ of CaCl, and kept at room temperature. In this way it remained stable for at least 4 hours.

Reptilase was obtained from Laboratoires Stago (Asnières, France), and prepared according to the indications of the manufacturer.

Soybean trypsin inhibitor (batch no 43 F-800) was obtained from Sigma

(St. Louis, USA.). A $10 \mathrm{mg} / \mathrm{ml}$ solution in buffer A was used.

Staphylocoagulase, was prepared as described in Hendrix et al. (15). Chromogenic substrate for thrombin was H.0.-phe-pip-arg-pHA. 2HCL (S2238, from KABI, Sweden).

other chemicals were the highest grade commercially available.

\section{Buffers}

A: $0.05 \mathrm{MTris-HCl}, 0.1 \mathrm{M} \mathrm{NaCl} \mathrm{pH} 7.35$, with $0.5 \%$ egg albumin (Sigma)

B: Buffer A with $20 \mathrm{mM}$ EDTA pH 7.9 .

Inhibitor-Deficient Plasmas.

Plasma without $\alpha_{2} M$ was obtained by addition of anti- $\alpha_{2} M$ globulin to normal plasma and elimination of the immunoprecipitate. The globulins were isolated according to Steinbuch et at (16) from the serum of rabbits immunized agä̈nst purified human $\alpha_{2} M$ (gift from J. Tapon-Bretaudière). No $\alpha_{2} M$ could be demonstrated by an immunoelectrophoretic method that would detect $\alpha_{2} M$ at concentration $>2 \%$ of the normal plasma concentration. Plasma without AT III was prepared by gently stirring $2 \mathrm{ml}$ of normal human plasma with $0.8 \mathrm{ml}$ of a slurry of sepharose to which anti AT II was bound (gift: from Dr. Tran Huu Tri, Basel) for 18 hours at $4{ }^{\circ} \mathrm{C}$. The antithrombin activity in the plasma after adsorption was not influenced by the addition of $10 / \mathrm{ml}$ of heparin.

\section{Determination of the Time Course of Amidolytic Activity}

An aliquot of plasma is defibrinated as indicated above. To $200 \mu$ of defibrinated plasma is added $50 \mu l$ of buffer $A$, that may contain the substances of which the influence on thrombin generation has to be investigated (e.g. heparins). 
At zero time, thrombin generation is triggered by the addition of $50 \mu l$ buffer A containing $100 \mathrm{~mm}$ of $\mathrm{CaCl}_{2}$ and a suitable trigger of coagulation. In the experiments described here human brain thromboplastin, diluted as indicated, was used as a trigger. If necessary the volumes indicated may be proportionally altered. At fixed intervals $(10,15,20,30$ or 60 secs) after zero time, a $10 \mu \mathrm{l}$ aliquot of the mixture is added to a disposable plastic microcuvette containing $465 \mu \mathrm{r}$ of buffer $\mathrm{B}$ and $25 \mu$ l of a $4 \mathrm{mM}$ solution of $\mathrm{S} 2238$ at $37^{{ }^{\circ} \mathrm{C} \text {. }}$

The aliquots are handled with a Microman pipette (Gilson, France). It is essential to keep the plunger of the pipette down after subsampling and to wipe the pipette tip carefully in order to avoid contamination of the incubation mixtures with EOTA from the buffer in the cuvette. Plastic tubes can be used instead of cuvettes but glass tubes adsorb thrombin and give unpredictable results.

A $15 \mathrm{sec}$. rythm is easily managed, $10 \mathrm{sec}$. intervals require some practice. If shorter intervals are required one can make use of pipettes equipped with a pushbutton connected to an input gate of a personal computer (Apple IIe) programmed to record the moment of sampling. After sampling the cuvette is quickly and rigourously mixed on a Vortex mixer.

After 120 seconds the reaction in the cuvette is stopped by adding 0.3 $\mathrm{ml}$ of concentrated (98\%) acetic acid, the cuvette is again thoroughly mixed and can be kept at room temperature until reading. If a pushbutton pipette and automatic time recording is used for sampling, then stopping the reaction is also carried out with a time recording pipette.

The cuvettes are read at $405 \mathrm{nM}$ in a suitable spectrophotometer (LKBU1trospec). The generation of p-Nitroaniline was linear in time up to an 0.D. of 0.900 . If necessary incubation times longer or shorter than two minutes can be used so as to obtain a sultable sensitivity and not to exceed 0.90 .0 .

The thrombin concentration data are processed by a computer program to obtain the time course of prothrombin conversion velocity. A full description of this procedure is to be found in the annexe.

\section{Determination of the Thrombin Breakdown Constant}

The same mixture as for thrombin generation curves is used, but with a volume of $44 \mu 1$ of buffer $A$ instead of $50 \mu 1$. After 2 to 8 minutes, at a 
moment that sufficient thrombin is formed, $6 \mu$ of SBTI solution $(10 \mathrm{mg} / \mathrm{ml})$ is added to the main incubation mixture, so as to stop further prothrombinase activity. SBTI at this concentration could be shown to stop completely the activity of prothrombinase and not to influence the amidolytic activity of thrombin (17).

At the shortest possible intervals after addition of the SBTI solution, 10 all aluots of the incubation mixture were added to cuvettes by the use of a time recording pipette. The cuvettes were further treated as described for the thrombin generation curves.

Activation by Staphylocoagulase

A solution of staphylocoagulase of $50 \mathrm{nM}$ is used. Of this solution 100 Hl was added to $100 \mu 1$ of a suitably diluted plasma sample. Normal plasma can be diluted 1:50. The incubation mixture remaining after a thrombin generation experiment is best diluted 1:5 or 1:10. The thrombin activity resulting from the formation of coagulase-thrombin is measured by adding 10 $\mu l$ of the mixture to a cuvette containing buffer B and chromogenic substrate as used for the thrombin generation curves. The staphylocoagulaseprothrombin complex has the same molar activity towards small molecular weight substrate as thrombin $(15,18)$. Commercially available staphylacoagulase preparations can be used. In that case the own amidolytjc activity of the preparation should be determined and its activating capacity has to be checked on nomal pooled plasma.

\section{EXPERIMENTAL}

The method that we propose here has the purpose to determine the velocity of prothrombin conversion in whole plasma. To this end we determine the amidolytic activity that generates and disappears in plasma after suitable triggering of the coagulation process, using a substrate specific for thrombin. Then we analyse the time-activity curve by a mathematical procedure that separates the process of thrombin formation (prothrombinase activity) and trombin inactivation (antithrombin activity). In order to carry out the calculations it is necessary to know the reaction constants of the breakdown processes. In the first part of this section we will discuss how these data are abtained. In the second part we verify the mathematical model. 
Figure 1 shows the thrombin activities generated in normal plasma by diffent dilutions of tissue thromboplastin. As a rule the standard error of each point is belaw $4 \%$ except for the points lacated in the steep rising parts of the generation curve. With the aid of pipettes provided with a signalling pushbutton connected to an input port of an Apple lle computer we could estimate the experimental error in the sampling time to be between 0.4 and $1 \mathrm{sec}$. In the horizontal parts of the curve the coefficient of variation of the thrombin determination is $2.75 \%$. When the tangent of the curve is steep, the time error adds significantly to the overall error so as to make it $15-18 \%$ at tangents exceeding 1.0000 .0 .4$. min $^{-1}$.

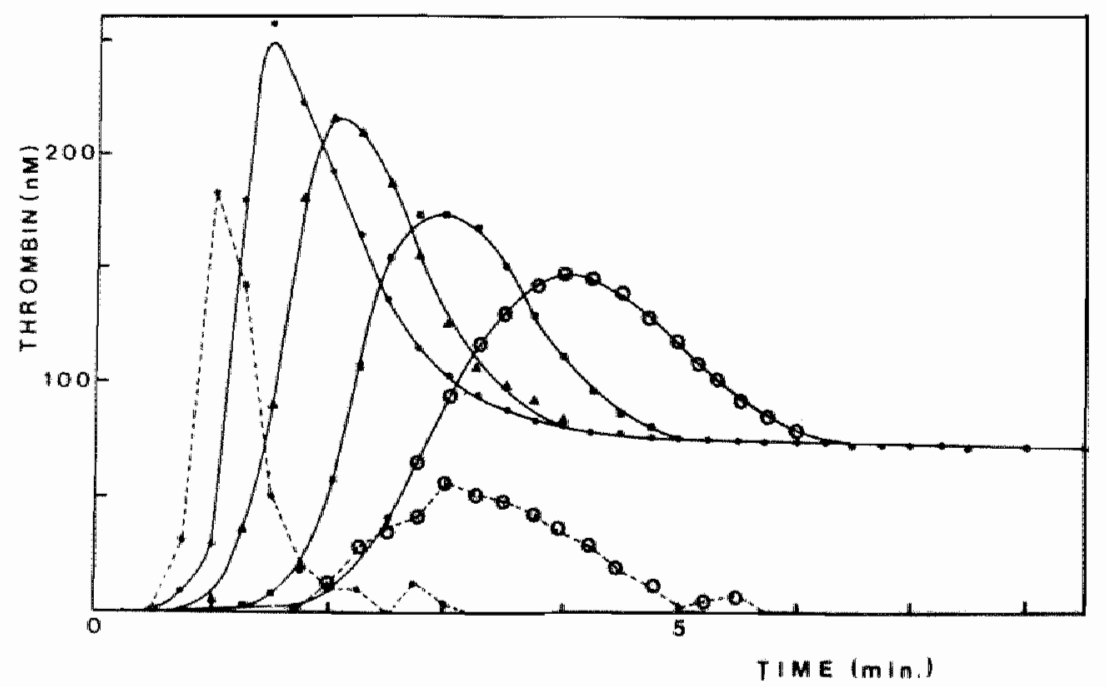

Fig. 1. THROMBIN GENERATION AND THE RATE OF THROMBIN FORMATION IN NORMAL PLASMA TRIGGERED WITH DIFPERENT DILUTIONS OF THROMBOPLASTIN.

Thromboplastin diluted as follows $1 / 40(-1 / 1 / 100(\Delta) ; 1 / 200$ (1) ) $1 / 400(\mathrm{O})$. The dotted lines represent the thrombin generation velocities of the $1 / 40$ and $1 / 400$ curves resp. The scale for these curves is the thrombin generation velocity in $n M \mathrm{~min}^{-1}$. 
With the aid of the time recording pipettes it is possible to eliminate the time error and to obtain almost perfectly overlapping curves in repeated experiments.

The amounts of residual prothrombin left in the mixtures after the amidolytic activity has reached a steady end-level, were determined with staphylocoagulase (table l). They are apparently not dependent upon the vartations in velocity of thrombin generation induced by ditution of thromboplastin.

\section{Table $\mathbb{1}$}

ACTIVITIES AND CONCENTRATIONS OF $\alpha 2^{M-T H R O M B I N ~ A N D ~ P R O T H R O M B I N ~ I N ~ S E R U M . ~}$

\begin{tabular}{|c|c|c|c|c|c|}
\hline & & \multicolumn{2}{|c|}{$\begin{array}{l}\text { Activities } \\
\text { (nM thrombin aeq) }\end{array}$} & \multicolumn{2}{|c|}{ Concentrations ( $n M)$} \\
\hline $\begin{array}{l}\text { Thromboplastin } \\
\text { dilution }\end{array}$ & $n$ & $\begin{array}{c}\alpha_{2}^{M-T} \\
(1)\end{array}$ & $\alpha_{2} m-T+s c$ & $\frac{\alpha_{2}-T}{(2)}$ & F.II res. \\
\hline $1: 40$ & 10 & $65(+2)$ & $265(+5)$ & $117(+6)$ & $200(+5)$ \\
\hline $1: 100$ & 4 & 69 & 280 & 123 & 211 \\
\hline $1: 200$ & 4 & 61 & 273 & 109 & 212 \\
\hline $1: 400$ & 10 & $62( \pm 5)$ & $266( \pm 8)$ & $111( \pm 7)$ & $204( \pm 9)$ \\
\hline
\end{tabular}

The activaties were detemined in the reaction mixtures of the expemiments shown in fig. 1. between $t=10$ and $t=20$, they are expressed as the equivalunt anownt of thrombin that would give the same rate of converion of chromogente substmite. $\alpha_{2} M-T$ (1) is the spontareous activity, $X_{2} M-T+S C$ in the total activity that could be elicited by addition of an excess of staphyloooagulase, $\alpha_{2}^{M-m}$ (2) is the concentration of the $\alpha_{2}$ M-Thrombin complex obtained by multiplying the $\alpha_{2} M-T$ activity with the retevant constant ( $f$, aes text), F.II is the prothrombin concentration obtained by atubtraction of the first two columne SEM are indicated when $n=10$. 
From Figure 2 it appears that thrombin generation can be resumed in the course of the experiment if purified human prothrombin is again added. The method thus determines thrombin generation velocities that are dependent upon both prothrombin concentration and prothrombinase activity.

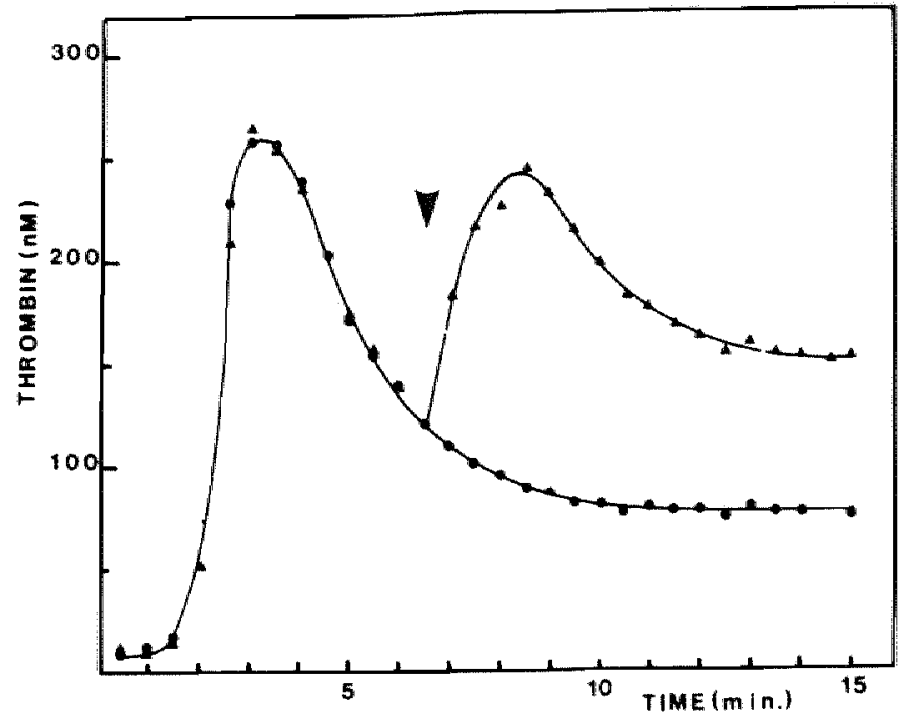

Fig. 2. EEPECT OF ADDITION OP PROTHROMBIN DURING THROMBIN GENERATION.

To a thrombin generation expemiment as in fig. 1 (thromboplastin dilution $1 / 40$ ) at $7 \mathrm{~min}$ (armow) $1500 \mathrm{nH}$ of purified human prothrombin were added.

Figure 3 shows experiments in which the breakdown constant of thrombin in plasma was determined. The decay curve of thrombin generated endogenously in plasma was obtained by stopping the factor $x_{\text {a }}$ activity in thrombin generating plasma by addition of SBTI and measuring the thrombin disappearance (see methods section). Alternatively $200 \mathrm{nM}$ of thrombin that had been formed in a euglobulin mixture was added at zero time to defibrinated plasma diluted in the same way as the reaction mixture, SBTI included. In the latter case the decay was two fold quicker. The slower decay of endogenously formed thrombin cannot be attributed to ungoing thrombin formation because the amount of prothrombin that can be demonstrated with staphylocoagulase in the plasma does not change after the moment of stopping the reaction with SBTI (results not shown). 


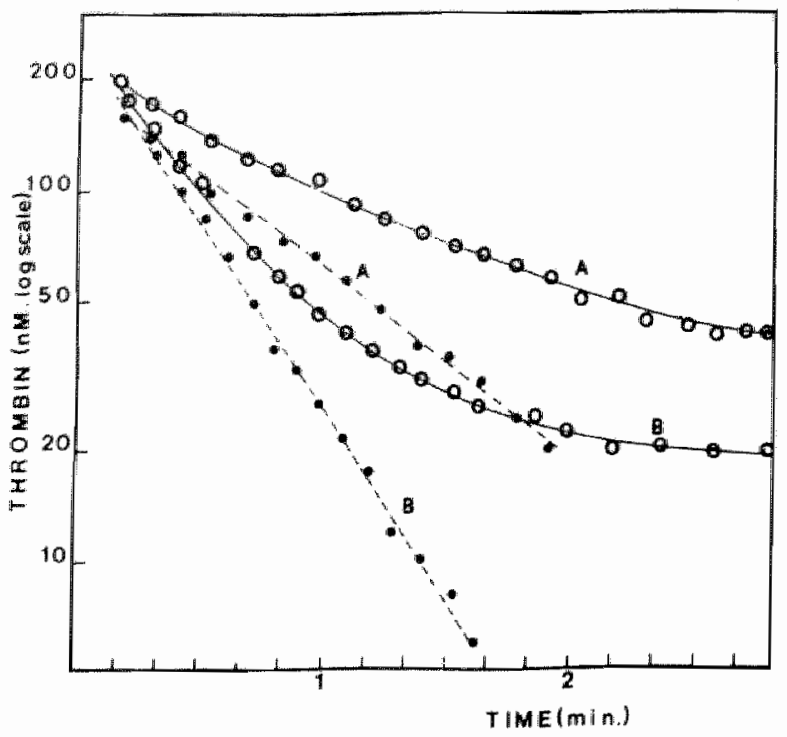

Fig. 3. THROMBIN INACTIVATION IN PLASMA

A. (O-O) Decay of endogenous amidolytic activity after addition of SBTI in a standard thrombin generation experiment, 3 min after triggeming the reaction with thromboptastin $1 / 40(-$.$) ). The same data after$ subtraction of the steady end-level of activity.

B. (0-O) Decay of amidolytio activity of $200 \mathrm{nM}$ exogenous thrombin. ( -... ). The same data after subtraction of the steady end-levez of activity.

During the course of thrombin generation the decay constant of thrombin does not change (fig. 4), showing that, in the course of the experiment there is not a time dependent change in the properties of thrombin that could explain the difference in half life time. For the moment we have no explanation for this phenomenon (see discussion).

The form of the decay curve is adequately described by a logarithmic approach to a steady end level (figs 3 and 4 ). From experiments like these 


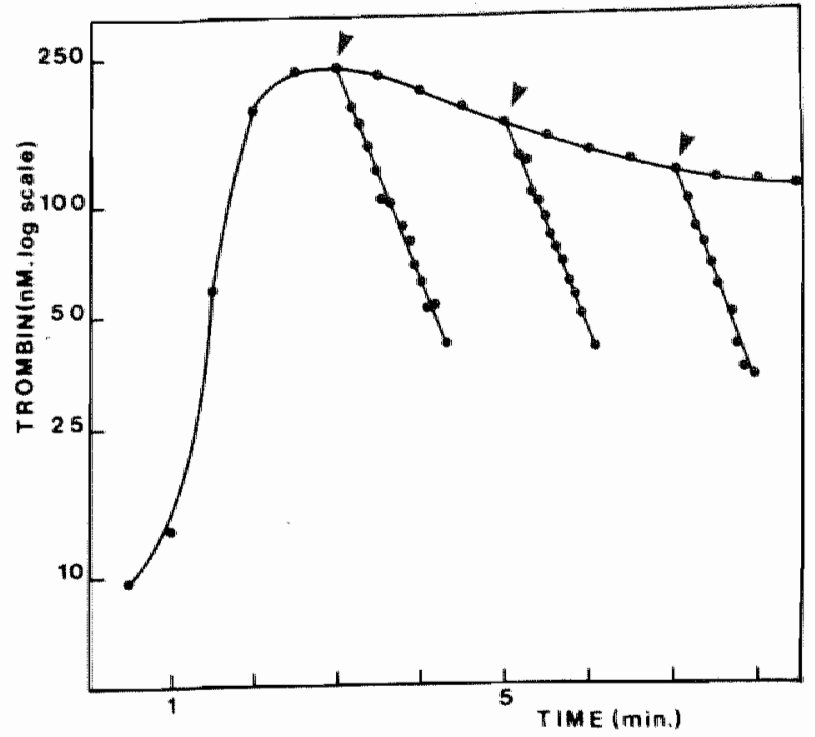

Pig. 4. DECAY OF ENDOGENOUS THROMBIN AT DIFFERENT INTERVALS AFTER THE START OF THROMBIN GENERATION.

In thrombin generation experiments triggered with thromboplastin $1 / 40$, SBTI was added at $t=3,5$ and 7 min. The decay constants observed were 1.24, 1.17 and 1.23 respectively. The data are plotted on a log scale after subtraction of the steady end-levels.

overall decay constants can be obtained. This overall constant ( $\left.k_{\exp }\right)$ is equal to the sum of the $\alpha 2 M-d e p e n d e n t$ decay constant $\left(k_{2}\right)$ and the nonQ2M-dependent constant $\left(\mathrm{k}_{1}\right)$, mainly due to antithrombin III.

Table II lists these constants for various kinds of normal and deficient plasmas. Also in this table the ratio of the amount of prothrombin consumed during the experiment (i.e. the total amount of thrombin formed) and the amount eventualiy taken up by $\alpha_{2} M$ is given, as well as the vallues of $k_{2}$ and $k_{1}$ that were calculated from these data. For this calculation it is necessary to know the value of $f ; i . e$. the ratio of the amidolytic activity of one mole of the $\alpha_{2} M-t h r a m b i n$ complex to one mole of free thrombin. This value was obtained by preparing thrombin in a euglobulin precipltate of 
defibrimated plasma and estimating its activity. Then an excess of an $\alpha_{2}-$ macroglobulin preparation devord of AT III activity was added and the residual amidolytic activity was detemined, f was estimated to be 0.558 t $0.043\left(\mathrm{~m}=10 ; 5 . \mathrm{E}_{\mathrm{H}}\right)$.

\section{Table II}

REACTION CONSTANTS OF INACTI VATION IN PROTEASE-INHIBITOR DEF ICIENT PLASMAS.

\begin{tabular}{|c|c|c|c|c|c|}
\hline Plasma & Di1. & $\begin{array}{c}k \exp \\
\left(\min ^{-1}\right)\end{array}$ & $\mathrm{R}$ exp & $\left(\min ^{k_{2}}\right)^{-1}$ & $\left(\min ^{k}-1\right)$ \\
\hline Controll & 1.00 & 1.260 & 0.271 & 0.342 & 0.920 \\
\hline $\begin{array}{l}\alpha_{2}{ }^{M} \text { def. } \\
\text { control }\end{array}$ & 0.78 & $\begin{array}{l}0.733 \\
0.856\end{array}$ & $\begin{array}{c}- \\
0.236\end{array}$ & $\begin{array}{c}- \\
0.200\end{array}$ & $\begin{array}{l}0.733 \\
0.756\end{array}$ \\
\hline $\begin{array}{l}\text { AT III def. } \\
\text { Control }\end{array}$ & 0.45 & $\begin{array}{l}0.249 \\
0.630\end{array}$ & 0.270 & 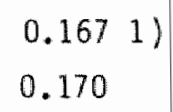 & $\begin{array}{l}0.0822) \\
0.460\end{array}$ \\
\hline $\begin{array}{l}\text { Double def. } \\
\text { Control }\end{array}$ & 0.32 & $\begin{array}{l}0.058 \\
0.462\end{array}$ & 0.240 & $\begin{array}{c}- \\
0.111\end{array}$ & $\begin{array}{l}0.058 \\
0.352\end{array}$ \\
\hline
\end{tabular}

Dil: Ditution dite to immunodsomption, the control plasmas were dituted to extend

$K$ exp: Overall decay constant observed $\left(\mathrm{min}^{-1}\right)$

Rexp: Ratio of $\alpha_{2} M-T$ to AT IIT-T in the controt ptabma

$k_{2}$ and $k_{1}$ : Pseudo first order reaction constants of the complexation of thromin with $\alpha_{2} M$ and non- $\alpha_{2}$ Mespectively $\left(\min ^{-1}\right)$

1) Obtained from the dowb defioient plasma lacounting for the difference in ditution!

2) Obtained by subtracting $\mathrm{K}_{2}$ from $K$ exp. 


\section{I1. Verification of the model}

The adequacy of our model was tested in two fundamentally different ways a) by comparing the time course of reaction products as predicted by the model with those actually found. b) by studying the effect of selective elimination of AT III and/or $\mathrm{O}_{2}$ M.

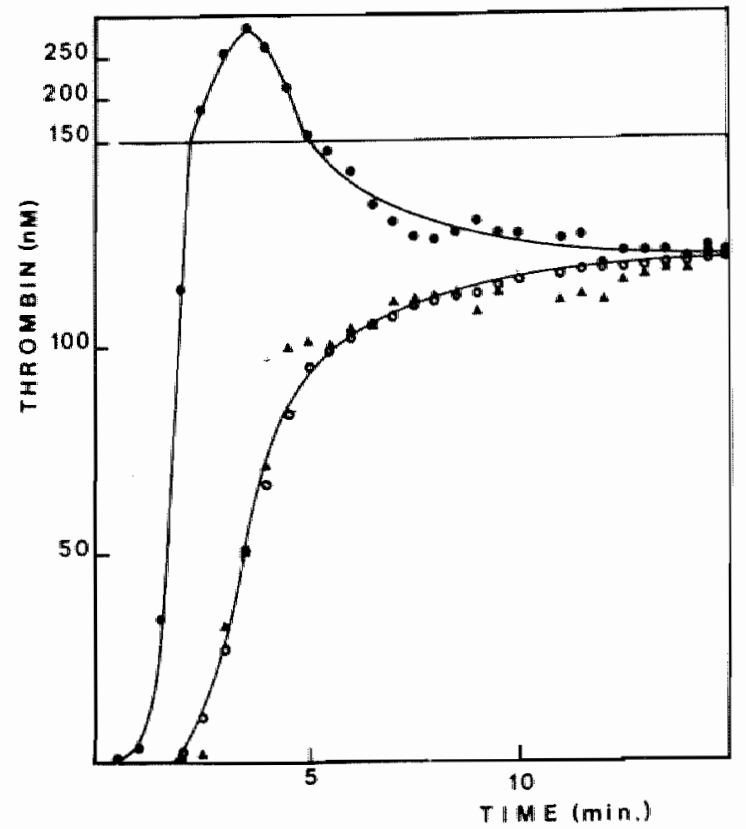

Fig. 5. COMPARISON OF OBSERVED AND COMPUTED LEVELS OF THE $\propto 2 M-$ THROMBIN COMPLEX.

A standard thrombin generation experiment was carpied out. Thromboplastin diluted 1:40 was used as trigger. From the amidolytic activity $(\bullet)$ the concentration of $\propto 2 M-$ complex was computed ( 0 ). The levels of $\alpha_{2^{M-T}}$ complex found experimentally are represented by $(\boldsymbol{\Lambda})$.

In figure 5 two sets of experimental data are plotted: the overall amidolytic activity as determined by our standard procedure (•) and the level of $\alpha_{2} M-$ Thrombin $(\boldsymbol{\Delta})$. The latter was determined by subsampling from the reaction mixture into a solution containing an excess $(1 U / m 1)$ of heparin and $20 \mathrm{mM}$ EDTA. In this mixture the generation of thrombin stops iminediately and, because the half life of thrombin is $<10 \mathrm{sec}$, the residual activity measured after 10-20 $\min$ is due to the amount of $\alpha_{2}{ }^{M-b o u n d ~ t h r o m b i n ~}$ that was present at the moment of subsampling. From the data on amidalytic activity with the formulas derived from the mathematical model, one can also calculate the time course of the $\alpha_{2} M-T h r o m b i n$ concentration ( 0 ). From fig. 5 it is seen that the calculated values and the values actually determined coincide within the limits of experimental error. 


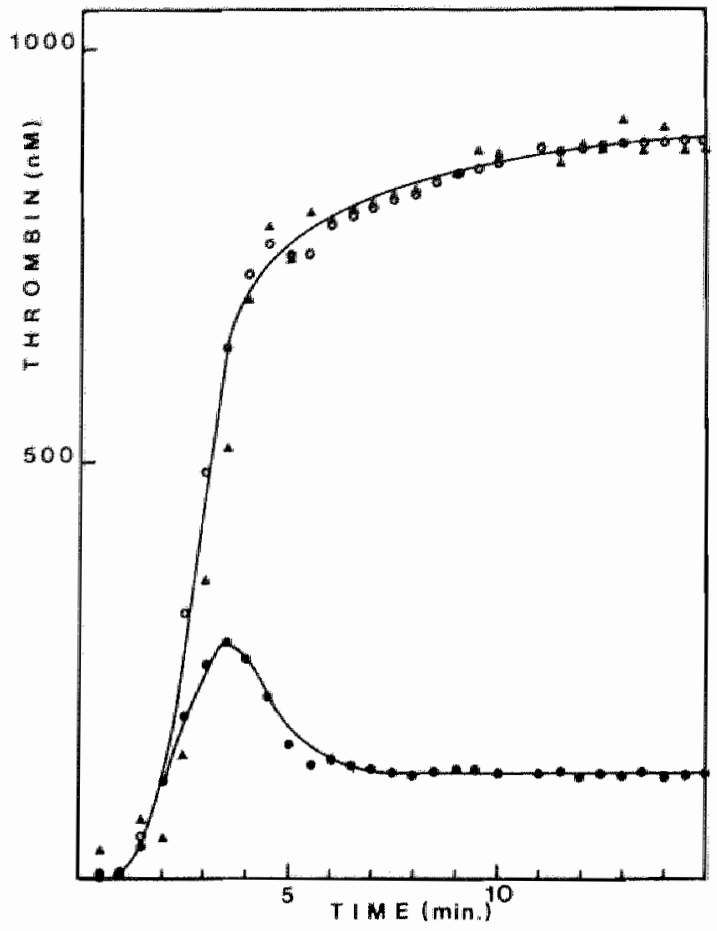

Eig. 6. COMPARSON OF OBSERVED

AND COMPUTED LEVELS OP CONSU-

MED PROTRROMBIN.

In a standand thrombin generation experiment (trigger: thromboplastin 1:40) the amount of prothrombin converted (O) was computed from the amidolytic activities (O) and compared to the difference between the original amount of prothrombin and anount remaining during the time course of activation $(\Delta)$.

Figure 6 also shows the equivalence of a set of experimental and calculated concentrations, viz. those of the tatal amounts of prothrombin converted into thrombin. Experimentally these concentrations were determined by subsampling into a mixture containing $20 \mathrm{mM}$ EDTA, $1 \mathrm{U} / \mathrm{ml}$ of heparin and $2 \mu \mathrm{M}$ of staphylocoagulase. In this mixture prothrombin conversion into thrombin stops, the thrambin present is inactiwated by AT III and the prothrombin present converts quickly (second order rate constant $3.3 \times 10^{6} \mathrm{M}^{-1} \mathrm{~s}^{-1}$ ) (12) into the anidolytically active prothrombin-staphylocaagulase complex that is not inactivated by AT III. Thus one obtains the amount of residual prothrombin (after subtraction of the activity due to $\alpha_{2} M$-thrombin determined independentily) while the amount of prothrombin converted into thrombin is found by subtraction from the starting level. The equivalence between the concentrations found experimentally and those derived from the amidolytic activity via the kinetic model is again satisfactory. 


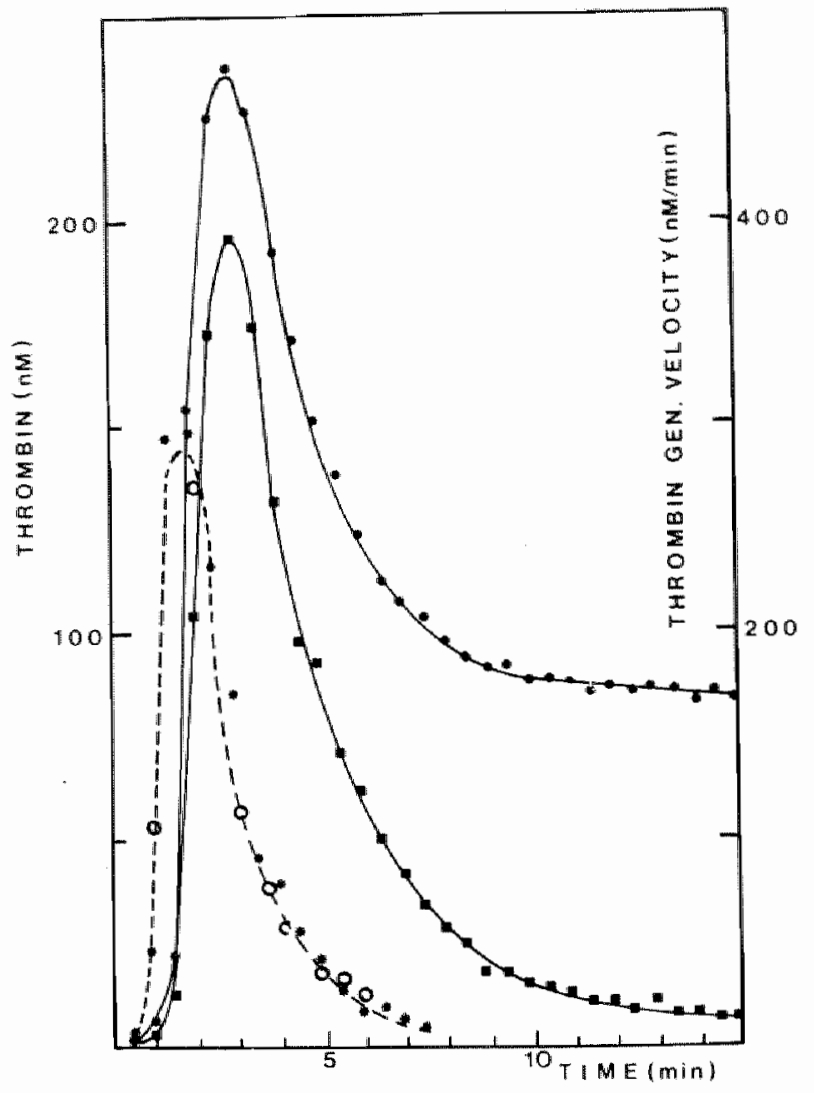

Fig. 7. COURSE OE ANLDOLYTIC ACTIVITY IN Q8- MACROGLOBULIN DERICIENT PLASMA.

Amidolytic aotivity in $\alpha$ IM deficient plasma.

- Amidolytic activity in control plasma. Dotted Iine: thrombin generation velocity alculated from the amidolytic activity curves.

O points obtained from the $\propto 2 M$ defiaient plasma.

* points obtained from the controt plasma. The constant used for calculation are given in Table II.

A different approach to test the validity of the model is shown in figures 7 and 8 . Here the inactivation system of the plasma was modified by selective immunaadsorbtion of $\alpha_{2}$-macroglobulin and AT III respectively. Control plasmas were obtained by treating normal plasma in a comparable way with a gamaglobulin fraction from serum from non-immunised rabbits and adjustment of the dilution if necessary.

In table II it is shown that the decay constants calculated for the non-deficient plasmas are identical to those found experimentally in the deficient plasmas, if one allows for a small amount of inhibition that is due to neither $\alpha_{2} M$ or AT III.

In figure 7 the thrombin activity curves obtained with the $\alpha_{2} M$ deficient plasma and its contral are shown as well as the thrombin generation velocity curves obtained from them, using the relevant constants from Table II. 
In fig. 8 the same is done for the AT 111 deficient plasma. In both figures 7 and 8 the thrombin generation velocity curves obtained with the deficient and the control plasmas superimpose within the limits of experimental error, as would be expected from the model.

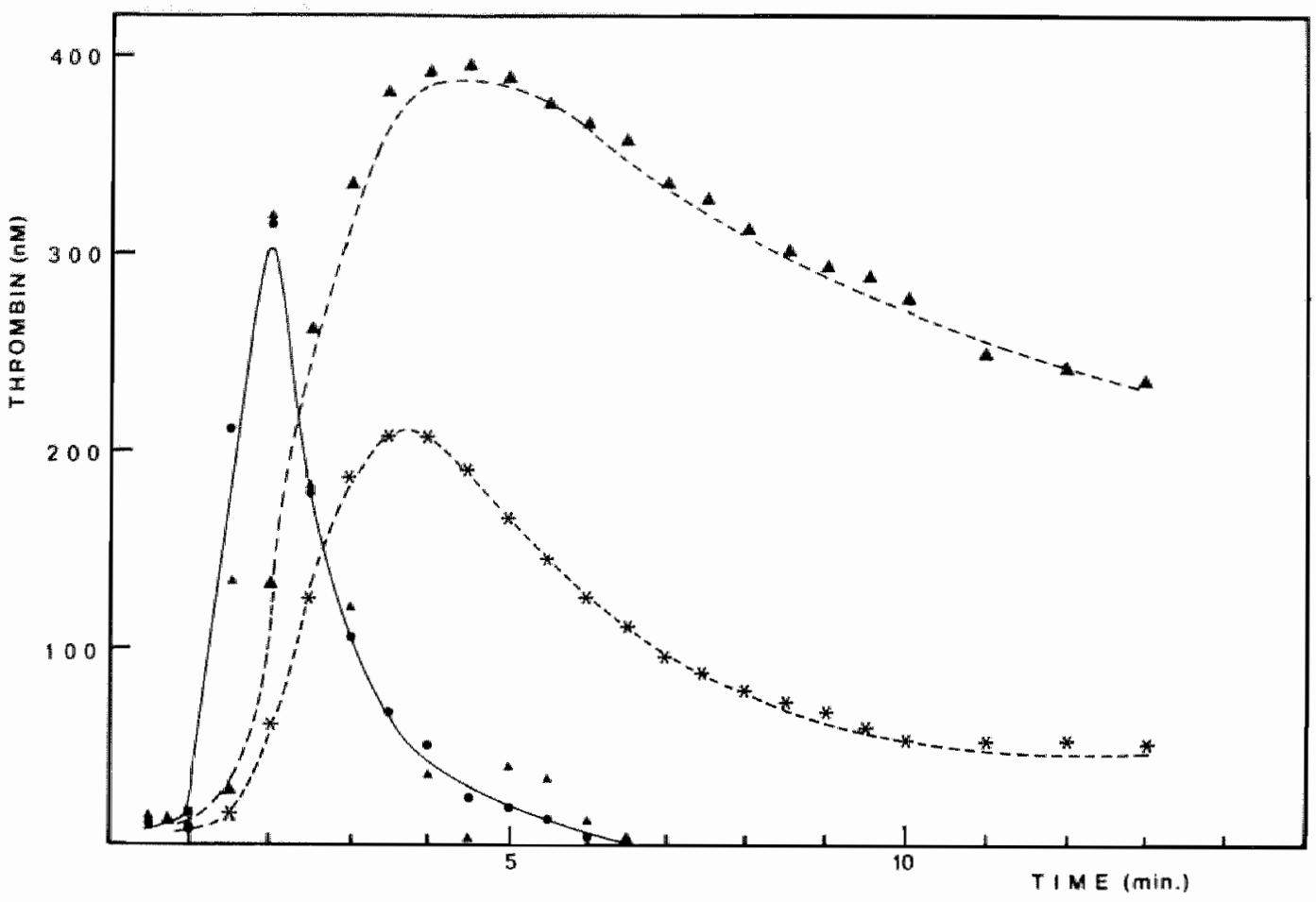

Fig. 8. COURSE OF AMTDOLYTIC ACTIVITY IN AT III DEFICIENT PLASMA.

- A Amidolytio activity in AT III deficient plama. *--* Amidolytio activity in control plasma. Drawn line: thrombin generation velocity caloulated from the amidolytic activity arves.

$\Delta$ : pointa obtained from the AT III deficient plasma.

- paints obtained from the control plasma. The constants used for calculation are given in Tabte II. 
For the study of the mechanism of thrombin formation in plasma the two classical methods of enzymolagy are open, kinetic analysis and isolation of enzymes with partial reconstruction of the system from its components. In the last ten years the latter approach has yielded important results and the main mechanisms of activation of clotting factors are well known by now. It remains difficult however to answer in this way questions about the relative physiological importance of mechanisms that have been shown to be biachemically possible. What is the importance in vivo of the extrinsic activation of factor $I X, ?$ of the feedback activation of factors $V$ and VIII by thrombin? The question of whether heparin and its derivates inhibit the formation of thrombin in vivo or only accelerate its inactivation is not settled either. As a first step to approach the in vivo situation we developed a method in which the generation of thrombin in whole plasma ("ex vivo") can be studied independent of its breakdown by antiproteases. The method consists of measuring the course of amidolytic activity after triggering thrombin fomation in a sample of defibrinated plasma and then eliminating the effect of the breakdown processes by compensating for their velocities, that are calculated from the concentration of thrombin and the breakdown constants. The calculations are easily carried out on a personal computer.

The problem with this approach is that the acceptability of the results obtained is entirely dependent upon the acceptability of the model and the mathematical procedure. Therefore it is important to test extensively the validity of the method.

We assume that the situation in the plasma when thrombin generates can be depicted by the following diagram:

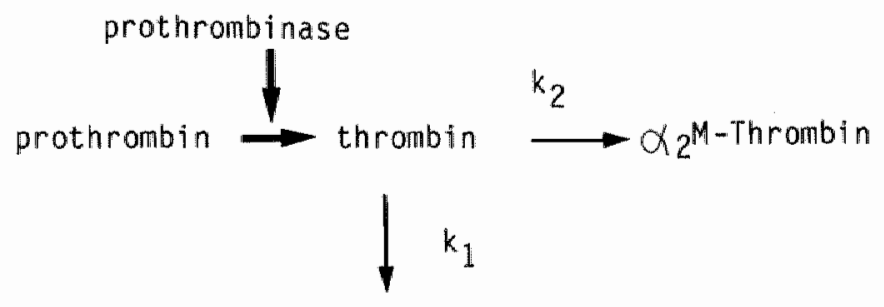

inactive thrombin 
The assumptions at the basis of the kinetic model are:

1. Thrombin breakdown occurs via two processes, one (caused by AT III and others antiproteases) leading to inactive products, the other

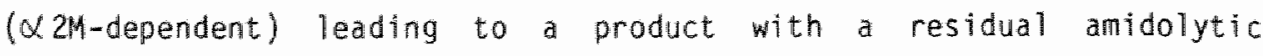
actînity.

2. Both reactions are pseudo first order with regard to thrombin.

It has been demonstrated that the interaction of AT III with thrombin is a bimolecular reaction and shows second order kinetics $(19,20)$. Under the conditions prevailing in our experiments there is at least a ten-fold excess of AT III over free thrombin and the excess of $\propto 1$-antitrypsin is a hundred-fold. It therefore seemed reasonable to try whether a model for this reaction based on pseudo first order kinetics would stand verification. The case of $\alpha 2 M-d e p e n d e n t$ inactivation is more complex. Here the stoichiometry of the reaction is variable and the kinetics of the reaction are complicated $(20,6-10)$, yet second order reaction kinetics describe the situation if the $\alpha_{2} M$ to thrombin ratio is higher then 2 to 1 (20). The initial concentration of $\alpha^{2} 2 \mathrm{M}$ is $2 \mu \mathrm{M}$. No more than $300 \mathrm{nM}$ af this is complexed in the course of the experiment (fig 1 and 5). As a first approximation we therefore again assumed pseudo first order kinetics. If, ar to what extent it is indeed an adequate description of this situation must follow from the experiments.

The translation of the reaction model into rate equations, the solution of these equations and their utilization in a computer program is a technical problem in mathematics, that is explained in the annexe and will not be discussed here.

The following qualitative arguments support the correctness of the model:

a. The partition between the AT III-II complex and the X2M-II complex of the thrombin generated in an experiment is independent of the course of thrombin generation. This can be seen in fig. 1 and Table $I$, where the total amount of prothrombin as well as the levels of $\alpha 2 M-I I$ a eventually obtained are independent of the dilution of thromboplastin used. Our model predicts such behaviour (formula 8 ).

b. The decay of thrombin activity is characterized by a logarithmic approach to a steady end-level (fig. 3). This proves the pseudo first order character of the breakdown constants (formula $4 \mathrm{C}$ ).

c. The breakdown constant of thrombin does not change over the experiment (fig. 4) 
d. The level of activity remaining in the plasma after activation is explained by the level of $\alpha_{2} M-I I$ a present (fig. 5), in the absence of $\alpha_{2} M$, the actiwity approaches the zero level (fig. 7).

In the absence of both $\alpha_{2} M$ and $A T I I I$ there is a residual antithronbin activity of about $18 \%$ of the total. (Table II). This activity is not heparin dependent and consumes thrombin in a pseudo first order process (results not shown). In our formulas this decay is included in the AT III dependent decay $\left(k_{1}\right)$. Thisinhibition activity is presumably due to $\alpha_{1}$ antitrypsin and other antiproteases.

From the observations (a to d) it can be concluded that the qualitative features of our model are supported by the experiments. The validity of our model is further corroborated by the similarity of the concentration courses calculated and those actually observed. In principe the time courses of all the reactants can be computed from the time course of the amidolytic activity. In practise the amounts of remaining prothrombin and of the $\alpha_{2} M$-thrombin complex can be determined independent of amidolytic activity, thus offering the opportunity to compare the results of the calculation with the time-course of cancentrations actually found. Figures 5 and 6 show. that the observed and the computed points seem to follow the same curve.

Further qualitative arguments for the correctness of our procedure can be derived from figs. 7 and 8 . Here it is seen that the velocities of thrombin generation computed from plasma specifically deficient in either $\alpha 2 M$ or in AT III coincide with those of the control plasma if the respective breakdown constants are eliminated from the computation. We conclude that, within the limits of experimental error our model gives a satisfactory description of the situation in plasma and that our procedure can be used to obtain thrombin generation velocities from amidolytic activities. The use of the computer in this procedure is not unlike that of the microscope in that it can reveal experimental features not apparent at direct inspection.

Several observations awalt explanation:

1. The lag time always observed when thromboplastin is used as a trigger. It has to be determined whether feedback activations by thrombin of factor $V$ and/or factor VIII contribute to this process. 
2. The difference in breakdown velocity of endogenously generated thrombin and of exogenous thrombin. The generation of meizothrombin $(21,17)$ or any other anidolytic thrombin precursor with a low affinity to antiproteases does not offer an explanation because it would, in the course of the experinent, convent into thrambin, so that the apparent decay constant found would increase during the experiment and approach that of free thrombin, which it does not (fig. 4). One can surmise that part of the freshly formed thrombin is inaccessible to antiprotease action because it still interacts with elements of the prothrombinase complex and/or its own activation peptides. The strong noncovalent interactions between the $N$ terminal half of prothrombin (fragment 1,2 ) and the $C$ terminal half (prethrombin 2, thrombin) (22) make such interactions not a priori unlikely. This problem is at present under imvestigation. The same phenomenon probably explains why the pseuda order rate constants that we find for endogenous thrombin breakdown in whole plasma are below the lower 1 imits of ranges found in the literature with free thrombin and in (partiy) purified systems. For $\alpha_{2} M$ we found $0.342 \mathrm{~min}^{-1}$ (Table II) compared to $0.4-0.8 \mathrm{~min}^{-1}$ in the literature. For AT III the value was $0.920 \mathrm{~min}^{-1}$ compared to 1.4-3.6 $\min ^{-1}(6-10,23)$. The value of 0.09 for the decay constant of thrombin in the presence of the normal plasma concentration of $\alpha 2 \mathrm{M}$ that can be calculated from ref 20 , has been supposed by others to be based on an underestimation of the second order rate constant of this intibition (10).

3. The model behaves as if the inhibitory capacity of $\alpha_{2} M$ is immediately availlable, although it is known that this molecule has to be activated by a proteolytic enzyme, e.g. by the proteolytic enzyme that it will complex with $(5,6$ and references therein).

4. Even though prothrombinase is not exhausted (fig. 2) the reaction comes to a stop when 5-10\% of the original prothrombin is left. This suggests the possibility of product inhibition of prothrombin activation in whole plasma.

Our results indicate that in $2: 3$ diluted normal platelet free plasma (our standard system) the pseudo fïst order rate constant of $\propto 2 \mathrm{M}$, AT III and non- $\alpha 2 M-n o n-A T I I I$ antiproteases contribute $23 \%, 64 \%$ and $13 \%$ to the overall disappearance rate of endogenous thrombin. This is in accordance with the $20-30 \%$ of plasma antithrombin activity assigned to $\alpha 2 M$ by several authors $(10,19,20)$. 
We think that our method may be a valuable means to investigate the physiology of thrombin generation in whole plasma and to study the in fluence of antithrombotic drugs on, as well as the pathological changes of this process. In the latter case additional studies, such as the estimation of prothrombin activation peptides may be necessary.

The procedure we propose can also be applied to the study of the factor $X$ generating enzyme (Factor $I x_{a}$ - Factor VIII ${ }_{a}$ - Phospholipid)in plasma on basis of the factor $x_{a}$ levels observed.

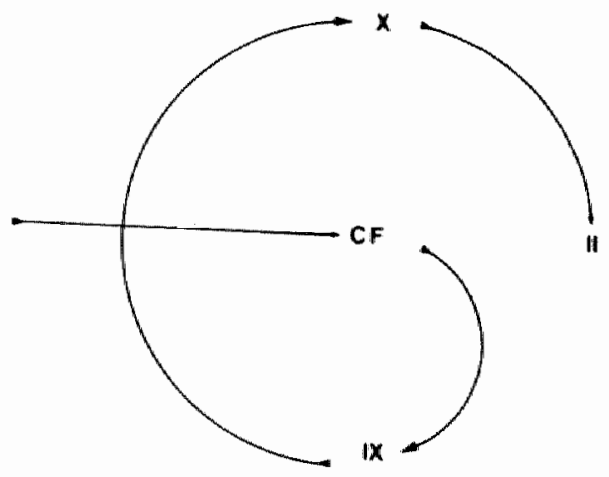

The intrinsic lag phase pathway 
1. Wagner, R.H., Graham, J.B, Penick, G.D, Brinkhous, K.M.: Estimation of prothrombin by the two stage method. In: Blood coagulation, Hemorrhage and Thrombosis. Edited by Dr. M. Leandra Tocantins and L.A. Kazal. 1965.

2. Biggs, R., Macfarlane, R.G.: Human blood coagulation and its disorders. Biackwell Scientific Publications, Dxford. 1967.

3. Henker, H.C., Hemker, P.W., V.d. Torren, K., Devilee, P.P., Hermens, W. Th., Loeliger, E.A.: The evaluation of two stage prothrombin assay. Thromb. Diathes. haemorrh. (Stuttg.) 25, 545-554, 1971

4. Pekelharing, C.A.: Over de betrekking van het fibrineferment van het bloedserum tot de nucleoproteide van het bloedplasma. Versl. Kon. Acad. wetensch. Aristerdam. 3, 272-297, 1895

5. Travis, J., Salvesen, G.S.: Human plasma proteinase inhibitors. Ann. Rew. Biochem. 52, 655-709, 1983

6. Harpel, P.C., Rosenberg, R.D.: $\alpha_{2}$-Macroglobulin and antithrombinheparin cofactor: modulators of hemostatic and inflammatory reactions. Progress in hemostasis and thrombosis. 3, 145-189, 1976

7. Barret, A.J., Starkey, P.M.. The interaction of $\alpha_{2}$-Macroglobulin with proteinases. Biochem. J. 133, 709-715, 1973

8. Harpel, P.C.: Studies on human plasma $\alpha_{2}$-Macroglobulin enzyme interactions. Evidence for proteolytic modification of the subunit chain structure. J.Exp. Med. 138, 508-521, 1973

9. Rinderknecht, H., Feling, R.M., Geokas, M.C.: Effect of $\alpha_{2}$-Macroglobulin in some kinetic parameters of trypsin. Biochim. Biophys.Acta $377,150-165,1975$

10. Fischer, A.M., Tapon-Bretaudière, J., Bros, A., Josso, F.: Respective roles of Antithrombin III and $\alpha_{2}$-Macroglobulin in thrombin inactivation. Thromb. Haemostas. (Stuttg.) 45, 51-54, 1981

11. Josso, F., Prou-Wartelle, 0.: Exploration de l'hémostase. In: Techniques en hëmatologie, D. Alagille et al. edts. Flammarion Paris. $101-208,1972$

12. van Dam-Mieras, M.C.E., Muller, A.D., Hemker, H.C.: Methods of enzymatic analysis. Vol. V. Enzymes 3: Peptidases, proteinases and their inhibitars. 3.2 Proenzymes, enzymes, inhibitors, cofactors. 3.2.1 
Blood coagulation factors $I I, V, V I I, V I I I, I X, X$ and $X 1$. Determination by clotting assays. Verlag Chemie GmbH, D-6940 Weinheim 365-394, 1984

13. Ddegard, 0.R., Lie, M.: On the use of chromogenic substrates for studies of coagulation inhibitors. Haemostasis. 7, 121-126, 1978

14. Owren, P.A., Aas, K.: The control of dicumarol therapy and the quantitative determination of prothrombin and proconvertin. Scand. U. Cl in. Lab. Invest. 3, 201-218, 1951

15. Hendrix, H., Lindhout, T., Mertens K., Engels, W., Hemker, H.C.: Activation of human prothrombin by stoichiometric levels of staphylocoagulase. J. Biol.Chem. vol. 258, 3637-3644, 1983

16. Steinbuch, M., Audran, R.: I solement de l'immunoglobul ine IgG du plasma humain à l'aide de l'acide caprylique. Revue Franc. de Clin. Biol. 14, $1054-1058,1969$

17. Lindhout, T., Baruch, D., Schoen, P., Franssen, J., Hemker, H.C.: Thrombin generation and inactivation in the presence of antithrombin III and heparin. Biochemistry, 25, 5962-5969, 1986

18. Kawabata, S., Morita. T., Iwanaga, S., Igarashi, H.: StaphylocoagulaseBinding Region in Human Prothrombin. J. Biochem. 97, 325-331, 1985

19. Rosenberg, R.D., Damus, P.S.: The purification and mechanism action of human antithrombin-heparin cofactor. J. Biol.Chem. 248, 6490-6505, 1973

20. Downing, M.R., Bloom, J.W.., Mann, K.G.: Comparison of the inhibition of thrombin by three plasma protease inhibitors. Biochemistry 17 , $2649-2653,1978$

21. Rosing, J., Zwal, R.F.A., Tans, G.: Formation of meizothrombin as intermediate in Factor $X_{a}$-catalyzed prothrombin activation. J. Biol. Chem. 261, 4224-4228, 1986

22. Esmon, C.T., Jackson, C.M.: The conversion of prothrombin to thrombin. IV. The function of the fragment 2 region during activation in the presence of factor V. J. Bial. Chem. 249, $7791-7797,1974$

23. Jesty, J.: The kinetics of inhibition of thrombin by antithrombin in the presence of components of the hemostatic systems. Blood. 66, $1189-1195,1985$

24. Hemker, H.C., Willems, G.M., Bëguin, S.: Thrombinoscope, a personal computer program for the analysis of thrambin generation curves. Computers in Biol. and Med. (Submitted). 


\section{Mathematical analysis of the thrombin generation curve.}

(G.M. Wi17ems, H.C. Hemker).

The amidolytic activity that we observe in the experiment is the sum of the activities of free thrambin and $\alpha_{2} M$-bound thrombin. The experimental procedure gives this activity at a series of points in time. It is our purpose to obtain the velocity of thrombin generation alone as a function of time $\mu \mathrm{g}(t) \beta$, independent of the breakdown processes.

We can make no assumptions as to the form of $g(t)$ because the enzyme that causes prothrombin activation (prothrombinase) itself increases and decreases as an unknown function of time. We describe the disappearance of thrombin as the sum of two pseudo first order reactions, one giving the inactive product of the interaction of antithrombin III and thrombin (AT III-T) and minor amounts of other inactive forms of thrombin and the other the amidolytically active complex of $\alpha_{2}$-macroglobulin and thrombin $\left(\alpha_{2} M-T\right)$. (see discussion for experimental justification).

The chenical model can be represented by a set of differential equations that describes the relations between the reaction velocities and the concentrations of the reactants in the system. We will use the follawing symbols: 
$A(t)=$ amidolycic activity found at time $t$

$\mathbb{P}(t)=$ prothrombin concentration at time $t$.

$T(\tau)=$ thrombin concentration at time $t$

$M(t)=\alpha_{2}$ M-thrombin concentration at time $t$

$g(t)=$ thrombin generation from prothrombin as a function of time

$k_{2}=$ pseudo first order rate constant for the binding of thrombin to $\alpha_{2}{ }^{M}$

$k_{1}=$ pseudo first order rate constant for the binding of thrombin to AT III.

$\mathbb{E}=$ the ratio of the enzymatic activity of one mole of $\alpha_{2}{ }^{M-T}$ over that of one molle of thrombin.

The subcripts thr and mcr will indicate tha activities due to thrombin and to $\alpha_{2} M-t h r o m b i n$ respectively, the total activity is unsubscripted.

The amidolytic activity w11 be expressed in thrombin equivalent-amounts, so that $A=T$ in a solution containing only thrombin and $A=F \cdot M$ in the presence of $\alpha_{2}$ M-thrombin only.

At any moment the net velocity of thrombin formation will be equal to the sum of the velocity of thrombin generation from prothrombin and the velocity of thrombin breakdown:

$$
\frac{d}{d t} T(t)=g(t)-k_{2} T(t)-k_{1} T(t) \quad(T(0)=0)
$$

The velocity of the formation of $\alpha_{2}$-thrombin 1 s proportional to the concentratior of free thrombla,

$$
\frac{d}{d t} M(t)=k_{2} T(t) \quad(M(0)=0)
$$

and the activity measured is the sum of the activities of thrombin and $\alpha_{2}$ M-thrombin:

$$
A(t)=T(t)+f(t)
$$


These equations have the solution

$$
g(t)=\frac{d}{d t}\left[A(t)+\left[(1-f) k_{2}+k_{1}\right] \int_{0}^{t}-e^{-f k_{2}(t-r)} A(\pi) d r\right)
$$

In order to use this formula we need estimates of $k_{2}$, $k_{1}$ and $f$ separately. The value $f$ can be obtained by comparing the amidolytic activity of Thrombin with that of $\alpha_{2}$ M-Thrombin (see experimental gection). If, at any moment a during thrombin generation we stop the conversion of prothrombin (e.g. by the addition of SBTI) then the course of the remaining activity is given by:

$\frac{d}{d t} T(t)=-\left(k_{2}+k_{1}\right) T(t) ; T(B)=T_{\mathbf{B}}$

$$
\frac{d}{d t} m(t)=k_{2} T(t)
$$

$$
\mathbf{M}(\mathbf{s})=\mathbf{m}_{\mathbf{B}}
$$

$A(t)=T(t)+r(t)$

where $t$ is counted from moment $s$ on and $M_{s}$ in the amount of 2M-Thrombin present at moment $s$.

From the formulas 3 it ca: be derived that:

$$
A(t)=T_{B} e^{-\left(k_{2}+k_{1}\right)(t-s)}+f\left\{\frac{k_{2}}{k_{2}+k_{1}} T(s)\left[1-e^{-\left(k_{2}+k_{1}\right)(t-s)}\right]+M(s)\right\}
$$

for $t \rightarrow \infty$ this gives

$A(-)=f\left(\frac{m k_{2}}{k_{2}+k_{1}} \quad T(s)+M(s)\right.$

so that 
$\log [A(t)-A(\infty)]=\log \left|\frac{(1-f) k_{2}+k_{1}}{k_{2}+k_{1}}\right| T(s)-\left(k_{2}+k_{1}\right)(t-s)$

from which it follows that $k_{2}+k_{1}$ can be obtalned from the slope of the plot of $\log [(A(t)-A(0))$ against time. The activity found at some late point(s) in the time curve are taken as $A(\infty)$. In order to obtain $k_{1}, k_{2}$ separately we integrate (2):

$P(0)-P(\infty)=\int_{0}^{\infty} g(\tau) d(\tau) d \tau=A(\infty)+\frac{(1-f) k_{2} k_{1}}{f k_{2}} A(\infty)$

from which it follows that:

$A(\infty)=\frac{f k}{k_{2}+k_{1}} \int_{0}^{t} f(\tau) d \tau=\frac{f k_{2}}{k_{2}+k_{1}}[P(0)-P(\infty)]$

where $P(\infty)$ is the amount of prothrombin present after the activation 18 over, so that $P(0)-P(\infty)$ is the total amount of thrombin that has been formed during the experiment from formula (6), and equal to the amount of prothrombin converted during the experiment. We calculate $k_{2}$ as

$$
k_{2}=\frac{\left(k_{2}+k_{1}\right) A(-)}{r[P(0)-P(\infty)]}
$$

and k1 from:

$$
k_{1}=\left(k_{2}+k_{1}\right)-k_{2}
$$

Once the constants $f, k_{2}$ and $k 1$ are known we cam ube the following rearrangement of formula 2 to calculate $g(t)$ :

$\int_{0}^{t} g(\tau) d \tau=A(t)+\frac{\left(k_{2}+k_{1}\right)-f \cdot k_{2}}{k_{2}+k_{1}} e^{-f k_{2} t} \int_{0}^{t} A(t) e^{+f k_{2} t} d \tau$ 
In practice $A(n)$ is obtained at a series of times, $t(n)$; $n$ being the runalng number of the observation. The integral in the right hand term of formula $(g)(I(n))$ cin be obcained as the area under the curve generated by ploteling

$S(n)=A(n) e^{t k \cdot t(n)}$

againgt $t(n)$, so that

$$
r(n)=x \sum_{1}^{n}[(t(n)-t(n-1)) \cdot(s(n)+s(n-1))]
$$

The amount of thrombin that would have been formed at the moment of observatton if no inactivation had taken place then is obtalned as:

$$
T(n)=A(n)+\left[\left(k_{2}+k_{1}-f k_{2}\right) /\left(k_{2}+k_{1}\right)\right] \cdot e^{-f k_{2} \cdot t(n)} \cdot I(n)
$$

The following series of Basic commands, operating on the arrays $A(n)$ and $t(n)$ carries out these calculations.

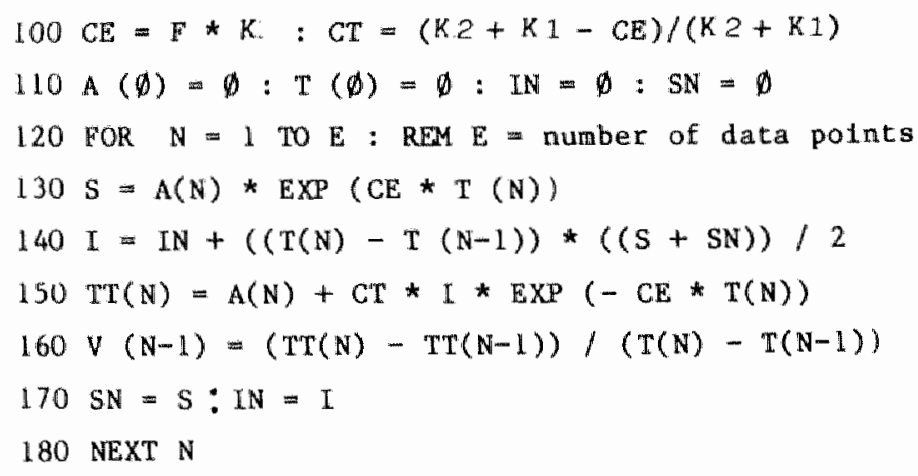


It will yield the arrays TT(N) and $V(N)$ that, when plotted against $T(N)$ (sampling time) give the total amount of prothrombin activated and the velocity of prothrombin conversion as a function of time.

This routine is the core of the program "Thrombinoscope" (24) that

a) stores the experimental data on disk b) calculates prothrombinase activity c) stores the results of the calculation on disk and d) displays the data and results in graphic and/or alphanumeric format on the monitor or the printer. The program was developed in Applesoft Basic on an Apple Ile personal computer with $128 \mathrm{k}$ RAM and Applesoft in ROM. Both data obtained at regular and at irregular intervals can be accomodated. It also contains the subprogram "Stopwatch" that is used to record sampling and stopping times from pipettes provided with a pushbutton.

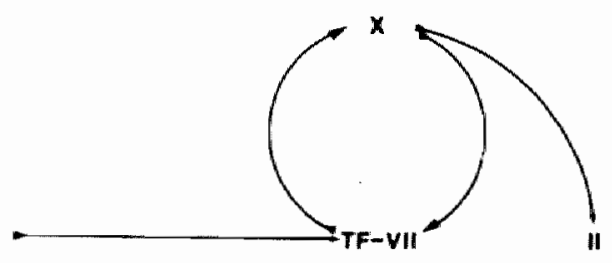

The extrinsic lag phase pathwey 


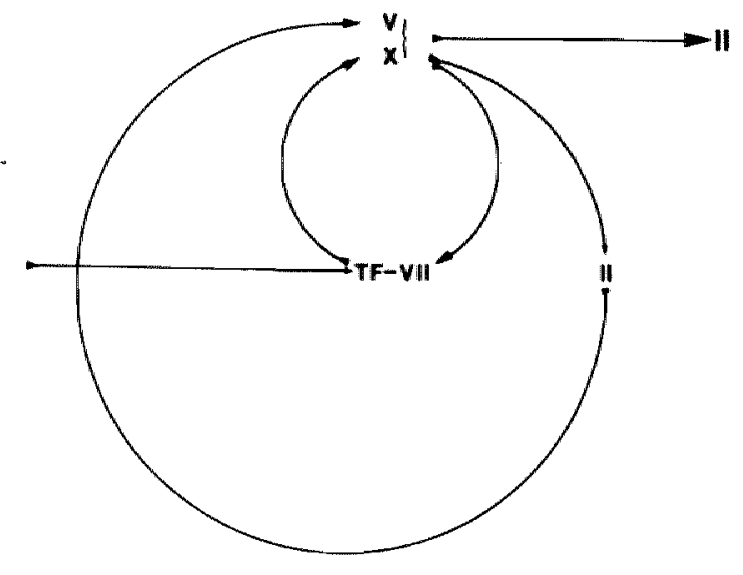

The PT pattway 
THE MDDE OF ACTION OF HEPARIN IN PLASMA.

\section{Sumary}

The generation of thrombin in plasma triggered via the extrinsic and the intrinsie pathway has been anatyzed in the presence and absence of comentionat heparins. The prothrombin conversion rate was estimated in two ways: a) by measuring the disappearance of prothrombin with the aid of staphyzocoagulase and b) by calculation from the thrombin found, compensating for the simultaneous thrombin inactivation by AT-III, $\alpha_{2}$ macrogtobutin and minor thrombin inhibitors.

In the extrinsic system, concentrations of hepamin up to $0.0750 / m t$ inhibit the veloaity of thrombin fomation for about $85 \%$ white prothrombin conversion is inhibited less then 10\%. At higher heparin concentrations prothrombinase is inhibited. This may be due either to inactivation of factor $x_{a}$ or to defective feedback activation of factor $V$ by thrombin.

In the intrinsic system, triggered by kaolin, prothrombinase aotivity is inhibited by low concentrations of heparin. It could be show that this must be attributed to defective activation of factor VIII, aused by the Low anow of active thrombin that is available. The ohortage of factor VIII entaits a secondary lose of factor. IX in the intrinsio system, because factor IX ${ }$, when not bound to factor VIII and phosphotiptd is susceptible to AT III-heparin activation.

We conclude that both in the extminsic and in the intrinsio system the action of conventional heparin an be explained by its thrombin scavenging action. No direct action of heparin on prothrombinase or the factor $X$ activating system needs to be assumed if one takes into acoount the secondary effect of thrombin deptetion on the detivation of factor VIII and $V$. 


\section{Introduct ion}

The anticoagulant effect of heparin is considered to be primarily due to the enhancing action of this drug on the inactivation of clotting proteases by antithrombin III (AT III). It has been demonstrated that the actlvated foms of the factors II, IX, X, XI and XII as well as kallikrein are susceptible to this action (1-11). Which of the various possible inactivations are instrumental in causing the anticoagulant effect of heparin in plasma is essentially unknown however. Yet this question is not without theoretical and practical interest. It has been hypothesized for instance that the anti-factor $x_{a}$ action of heparins might be related to their antithrombotic properties while the anti-thrombin action might correlate with bleeding complications $(12-15)$. This hypothesis, based on observations with low molecular weight heparin fractions (LMw heparin), is probably not tenable in its umamended form $(16-22)$. Nevertheless it would be interesting to know what the influence of heparin is an the generation of factor $x_{a}$, on the level of factor $x_{a}$ and on the level of the product of factor $x_{a}$ action i.e. thrombin. This question cannot be answered by comparing the rate constants of the inactivation reactions between purified proteases and AT II 1 and their dependence upon heparin concentrations. There exist numerous plasma proteins that interact with heparins and/or the clotting proteases and AT III. Therefore in plasma the concentrations of the free reactants are changed to an unknown extent (23-29). Moreover classical unfractionated heparin is a complex mixture of different products with different affinities for heparin binding proteins. When complexed with AT III the different heparins induce different activities towards the various proteases. This situation is so complifated that it must be considered impossible to obtain the quantitative details of the effect of heparin in plasma from anything ellse then from direct observations in plasma.

Data on the decay of activated clotting factors added to plasma and on the influence of heparin on this process are readily and frequently obtained $(1-11)$. For two reasons they cannot be used to judge the situation in clotting plasma. In the first place it has been found that the decay constant of thrombin generated endogenously in plasma is different from that of thrombin added to plasma (30). In the second place, and more important, it has been shown that clotting proteins such as factor $x_{a}$, that 
exert their physiological function when bound to phospholipid and a cofactor (factor $V_{a}$ ), are probably to a certain axtend protected fron AT III and heparin action (31-39). Data on the magnitude of this effect obtained in purified systems are difficult to extrapolate to the situation in plasma. In clotting plasma the concentrations of the reactants $V_{a}$ and $x_{a}$ change continously. Factor $V_{a}$ has a considerable influence on the binding of factor $x_{a}$ to phospholipid. Therefore the amount of factor $x_{a}$ bound to lipid in clotting plasma can hardly be calculated. The same holds, mutatis mutandis, for factors VIII a and $I X_{a}(40)$. Also it has been described that heparin interferes with the binding of clotting factors to phospholipid in purified systems whereas in plasma this effect is negligible (41-45). In order to know how heparin influences thrombin generation in plasma, one therefore has to study plasma.

The course of thrombin generation in whole plasma can be easily determined spectrophotametrically by subsampling into mixtures containing a chromogenic substrate specific for thrombin. The rate of thrombin generation thus observed at any moment results from two processes: a) the conversion of prothrambin into thrombin by prothrombinase and b) the decay of thrombin by the action of plasma antiproteases. There is no doubt that the latter process is influenced by heparin. The question we want to approach in this chapter is: Is prothrombinase activity in clotting plasma influenced by heparin, and if so, is this due to factor $x_{a}$ inactivation or to inhibition of factor $x_{a}$ generation?

Dur approach is a simple one. From the thrombin generation curve we know the net rate of thrombin fomation over the course of the experinent. The decay rate at any moment can be calculated from the concentration of thrombin and the pseudo first order reaction constants of the inactivation of thrombin by antithrombin III $\left(k_{1}\right)$ and $\alpha_{2}$-macroglobulin $\left(k_{2}\right)$. The fact that the $\alpha_{2}$-macroglobulin-thrombin complex has a residual amidalytic activity is accounted for. The effect of minor antiproteases (such as $\alpha_{1}-$ antitrypsiny is included in $k_{1}$. The rate of prothrombin conversion can then be computed from the net rate of thrombin generation observed and the decay rates. The reader is referred to the previous chapter for full details on this method. 


\section{Plasmas}

Blood from healthy donors was collected on 0.13 trisodium citrate; nine parts of blood to one part of citrate solution. A first and a second centrifugation were performed at $3000 \mathrm{~g}$, at $15^{\mathrm{a}} \mathrm{C}$ for 15 minutes. A third centrifugation was done at $4^{\circ} \mathrm{C}$, for one hour at $23000 \mathrm{~g}$. The platelet free plasma thus obtained was stored at $-80{ }^{\circ} \mathrm{C}$. It was checked that the clotting factors and the antiproteases were in the normal range. The clotting factors were determined according to ref. 46 and 47 .

Defibrinated plasma was obtained by mixing an aliquot of plasma with 1 : 50 volume of a reptilase solution, letting a clot form for 10 min at $37{ }^{\circ} \mathrm{C}$ and keeping the clotted plasma at $0{ }^{\circ} \mathrm{C}$ for $10 \mathrm{~min}$. The fibrin formed was discarded by centifugation (10 min, $\left.5000 \mathrm{~g}, 4^{\circ} \mathrm{C}\right)$ or by winding it on a small plastic spatula. The concentrations of factors II, V, VII, VIII, $I X, X, X I$, and $X I I$ did not significantly change by the reptilase treatment as has been shown before (30).

Humam brain thromboplastin was prepared as described in ref. (47). It was homogenated in a Potter Elvehjem homogeniser for 3 minutes, centrifugated at $2000 \mathrm{~g}$ for 15 minutes and stored at $-20{ }^{\circ} \mathrm{C}$ in $0.1 \mathrm{ml}$ aliquots. Before the experiments it was thawed, diluted $1: 40$ with $0.05 \mathrm{M}$ Tris $\mathrm{HCl}$ $\mathrm{pH} 7.35$ containing $100 \mathrm{mM}$ of $\mathrm{CaCl}_{2}$, so as to obtain a clotting time of 90 sec when incubated with normal non defibrinated plasma under the same conditions as used for the thrombin generation experiments $(1: 30-1: 50)$. The dilution was incubated at $37{ }^{\circ} \mathrm{C}$ for one hour and kept at room temperature. In this way it remained stable for at least 4 hours.

Reptillase was obtained from Laboratoires Stago (Asnières, France).

Soybean trypsin inhibitor (batch no 43 F-800) was obtained from Sigma (St. Louis, USA.). A $10 \mathrm{mg} / \mathrm{ml}$ solution in buffer A was used.

Staphylocaagulase, was prepared as described in Hendrix et al (48) or obtained from Laboratoires Stago (Asnières, France) and prepared according to the indications of the manufacturer.

Chromogenic substrate for thrombin was H.D-phe-pip-arg-pNA. 2 HCl (52238, from KABI, Sweden).

The phospholipid vesicle preparation contained $20 \%$ phosphatidylserine and $80 \%$ phosphatidylcholine and was prepared according to ref. 49 . 
Kaolin was "Kaolin lëger" provided by B.L.B. Laboratoires du Bois de Boulogne" (Puteaux-France).

Buffers: $A-0.05 \mathrm{M}$ Tris $-\mathrm{HCl}, 0.1 \mathrm{M} \mathrm{NaCl} \mathrm{pH} 7.35$, with $0.5 \%$ ovalbumin (Sigma); B - Buffer A with $20 \mathrm{mM}$ EDTA pH 7.9

Heparins: Four kinds of heparin were investigated: Tromboquinine ${ }^{R}$ manufactured by Organon-Technika (the Netherlands), Liquemine Roche from Hoffman La Roche (Basle, Switzerland), Heparine Lêo ${ }^{R}$ from Laboratoires Lëo (Paris, France) and the $4^{\text {th }}$ international standard from the National Bureau of Standards (London, Great Britain)(165 U/mg).

Purified proteins: Human $\alpha$-thrombin was prepared according to Pletcher et al (50), active site titrated and used for establishing a standard curve.

Factors $V, V_{a}$ and Factor $x_{a}$ were obtained as described by Lindhout et a). (51).

Factor VIII was prepared according to Vehar and Davie (52) with the modifications by van Dieijen et al (40).

Factor $I X$ was prepared according to Fujikawa et al (53) and activated by incubation with purified contact factor (54).

Determination of the Time Course of Amidolytic Activity

All plasma handling is carried out in/with plastic material. An aliquot of plasma is defibrinated as indicated above. To $200 \mu 1$ of defibrinated plasma is added $50 \mu 1$ of buffer $A$ with heparin at the desired concentration. The tube is put at $37{ }^{\circ} \mathrm{C}$ for $5 \mathrm{~min}$. At zero time, thrombin generation is started by the addition of $50 \mu 1$ of a solution containing $100 \mathrm{~mm}$ of $\mathrm{CaCl}_{2}$ and a suitable trigger of coagulation, for the extrinsic systern this human brain thromboplastin 1 : 40, for the intrinstc system 1 MM phospholipid and $0.25 \mathrm{mg}$ kaolin (final concentrations), other mixtures as indicated in the legends. At intervals a $10 \mu 1$ aliquot of the mixture is sampled into a disposable plastic cuvette containing $0.465 \mu 1$ of buffer $B$, and

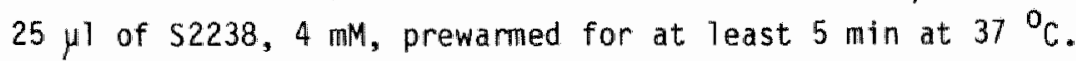

A $25 \mu 1$ micropipette (A) and a $1000 \mu 1$ pipette (B) Gilson were provided with pushbuttons and connected to the game control switches of an Apple Ile computer. A program was written that recorded the moment of sampling (pipette $A$ ) and the moment of stopping the amidolytic reaction with acetic acid (B) in a loop with a cycle time of 35 ms. The clock contained in a 
LKB Ultrospec II spectrophotometer was used. In this way sampling times as short as 3 sec can be obtained.

After 120 seconds the reaction in the cuvette is stopped by adding 0.3 ml of concentrated acetic acid with pipette B. Both after sampling and stopping the cuvette is rigorously stirred on a Vortex mixer. The cuwette is kept at room temperature until reading. The cuvettes are read at $405 \mathrm{nM}$ in a suitable spectrophotometer (L.K.B. Ultrospec II). The D.D. readings are entered into the computer that calculates $0.0 / m i n$ from the 0.0 . and the time interval between sampling and stopping. The generation of p-Mitroaniline was linear in time up to an 0.D. of 0.900. The development of the prothrombin conversion velocity in time is calculated from the thrombin generation curve by the computer according to the principles exposed in the introduction and discussed in detail in the previous chapter.

\section{Measurement of Prothrombin}

A solution of staphylocoagulase of $2 \mu M$ is used to activate prothrombin. Of this solution $10 \mu 1$ are added to $10 \mu l$ of a suitably diluted serum or plasma. The coagulase-thrombin activity after 2 min incubation at $37{ }^{\circ} \mathrm{C}$ is measured in the same manner as indicated for thrombin. The coagulase-thrombin has the same molar activity towards small molecular weight substrate as thrombin has (48). For residual prothrombin in the serum the spontaneous activity of $\alpha 2 M$-thrombin is subtracted. The amount of prothrombin consumed $(P)$ is obtained by subtracting the residual amount in the serum from the original prothrombin concentration of the plasma.

Determination of the Thrombin Breakdown Constant.

The same mixture as for the thrombin generation curves was used, but with a volume of $34 \mu 1$ of buffer $A$ instead of $50 \mu 1$. After 2 to 8 minutes, at a moment that sufficient thrombin was formed, $6 \mu 1$ of Soybean trypsin inhibitor (SBTI) solution $(10 \mathrm{mg} / \mathrm{ml})$ were added. In the same pipette $10 \mu$ l of buffer were taken that contained the heparin to be tested. SBTI at this concentration was shown to stop completely the activity of prothrombinase and not to influence the activity of thrombin (30).

At suitable time intervals after addition of the SBTI solution, $10 \mu 1$ aliquots of the incubation mixture were added to cuvettes by the use of the 
time recording pipette. The cuvettes were further treated as described for the thrombin generation curves.

The half life of thrombin in plasma may be as short as 6 seconds when heparin is present. In order to detennine the thrombin decay curves with sufficient precision it may therefore be necessary to subsample at the shortest interval possible.

The concentration at the moment of adding the SBTI $\left(C_{0}\right)$ was determined as well as a series of concentrations $\left(C_{t}\right)$ at later monents. The data obtained were fitted to the formula $C_{t}=C_{R}+C_{0} e^{-k t}$, which gave the level at the moment of adding SBTI $\left(C_{D}+C_{R}\right)$, the steady end-level $\left(C_{R}\right)$ and the decay constant $(k)$. The parameters are determined by means of an ordinary least squares fit of the model to the data. The parameter values that minimize the sum squared residuals are calculated using the Box-Kanemasu modification of Gauss' method (55). The linear equations are solved by means of Haussholder transformations. The decay comstant thus obtained is the sum of the $\alpha_{2} M$ dependent decay constant $\left(k_{2}\right)$ and the AT III dependent decay constant $\left(k_{1}\right)$. We have shown before that the amounts of thrombin complexed to $\alpha_{2}{ }^{M}$ and AT III are proportional to the rate constants. The amount complexed to $\alpha_{2} M$ can be determined directly from the residual amidolytic activity $\left(C_{R}\right)$ because the $\alpha_{2} M$-thrombin complex has a catalytic activity of $0.525 x$ that of free thrombin (30). If $S$ is the spontaneous activity after the experiment and $P$ is the amount of prothrombin consumed then $k_{2}=k(1.95 / P)$ and $k_{1}=k-k_{2}$.

\section{EXPERIMENTAL}

\section{Choice and Evaluation of the Method}

In order to assess the influence of heparin on the course of prothrombin conversion in plasma one can follow two different approaches. Either one determines directly the course of prothrambin conversion or one measures the rate of thrombin appearance while compensating for the simultaneous disappearance by calculating its velocity and adding that to the observed thrombin generation rate. Monitoring the rate of formation of prothrombin activation peptides (41) is an example of a method of the first type. We choose an alternative and measured the time course of the 
renaining prothrombin. This was executed by subsampling, at 1 min intervals, $20 \mu l$ aliquots of the reaction mixture into $20 \mu l$ of buffer $B$ containing $2 \mathrm{U} / \mathrm{ml}$ of heparin. In this way thrombin was inhibited almost instantaneous1y. In one part of the sample we measured directly the activity of $\alpha_{2}$-thrombin complex $\left(\mathbb{A}_{t}\right)$. To another part we added an excess of staphylocoagulase and determined the activity of the staphylacoagulaseprothrombin complex and the $\alpha_{2} M$-thrombin complex together $\left(B_{t}\right)$. The concentration of prothrombin at time $t$ was calculated from the difference between those two activities $\left(B_{t}-A_{t}\right)$. The rate of change of the prothrombin concentration $\left(W_{t}\right)$ in the reaction mixture could then be calculated directly from the course of the prothrombin concentration $v_{t}=\left[\left(B_{t 2}-A_{t 2}\right)-\left(B_{t 1}-A_{t 1}\right)\right] /\left(t_{2}-t_{1}\right)$.

This procedure invalves calculations on the differences between large figures. Even though the standard error of each of the deteminations can be reduced to $3-4 \%$, the standard error of the resulting prothromin disappearance rate was calculated to be between 9 and $15 \%$. Also the method is laborious and hardly suited to test larger series of heparin concentrations. The alternative possibility is to compute the rate of thrombin formation per se as the sum of the rate of observed thrombin formation and the calculated rate of thrombin disappearance. This method can be easily executed and the experimental error of the resulting figures is not greater than that of the thrombin concentrations entered in the computation $(2-4 \%)$.

However, the calculations are based on the assumption of pseudo first order reaction kinetics between thrombin and its scavengers. This simplifying assumption could be shown to be acceptable within the limits of experimental error in the absence of heparin (30). To check whether this method could be used to investigate the influence of heparin on the prothrombin conversion in plasma we checked the first order character of thrombin decay in the presence of heparin (Fig. 1) and we compared the indirect with the direct method in the presence and the absence of heparin (Fig. 2). It is seen that a) the decay of thrombin can not be distinguished from a logarithmic approach to a steady end level, showing that the process can in good approximation be described as the sum of two pseudo first order reactions, one inactivating thrombin completely 


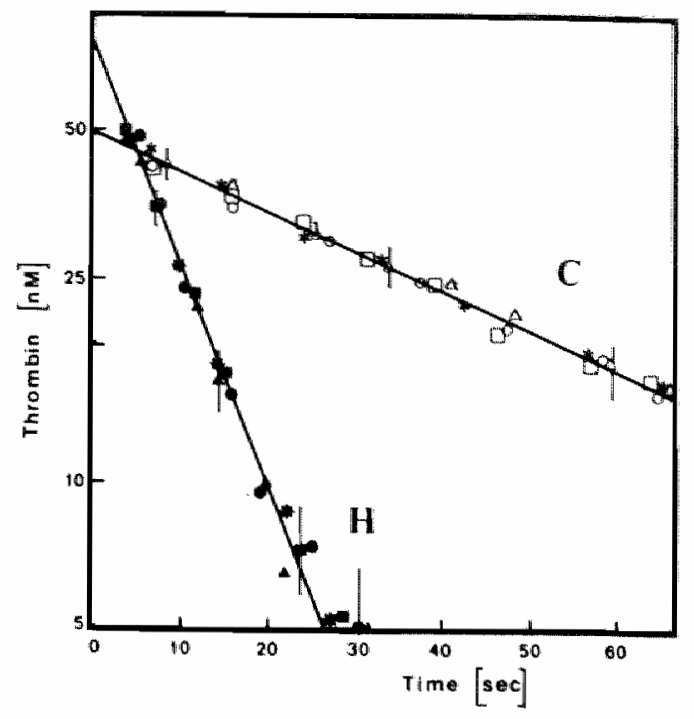

Fig. 1. THE DECAY OF ENDOGENOUS THROMBIN IN THE PRESENCE AND ABSENCE OF HEPARIN.

Zero time is the moment of stopping thrombin generation with SBTT. Along the ordinate is plotted $\left(T_{t}-T_{R}\right)$ i.e. the difference between the thrombin concentration at time $T_{t}$ and the final steady level of residuat activity $T_{R}{ }^{*} T_{R}$ is the mean of five estimations taken between $t=150$ and $t=600$. Line $C \square, \Delta, O$, * : control without heparin. Line $\boldsymbol{B} \mathbf{\square}, \boldsymbol{\Lambda}, \boldsymbol{0}$, * $0.1 \mathrm{U} / \mathrm{ml}$ of heparin. In each series the data from four different experimente were entered.

(complexing by AT III and thrombin inhibitors of minor importance) and the other yielding a product with a persisting amidolytic activity (complexing by $\alpha 2 M$ ) (see annexe to chapter II, ref. 30), (Fig. 1) and b) that the computed prothrombin conversion velacities coincided tolerably with the velocities found directly at two different heparin concentrations. 


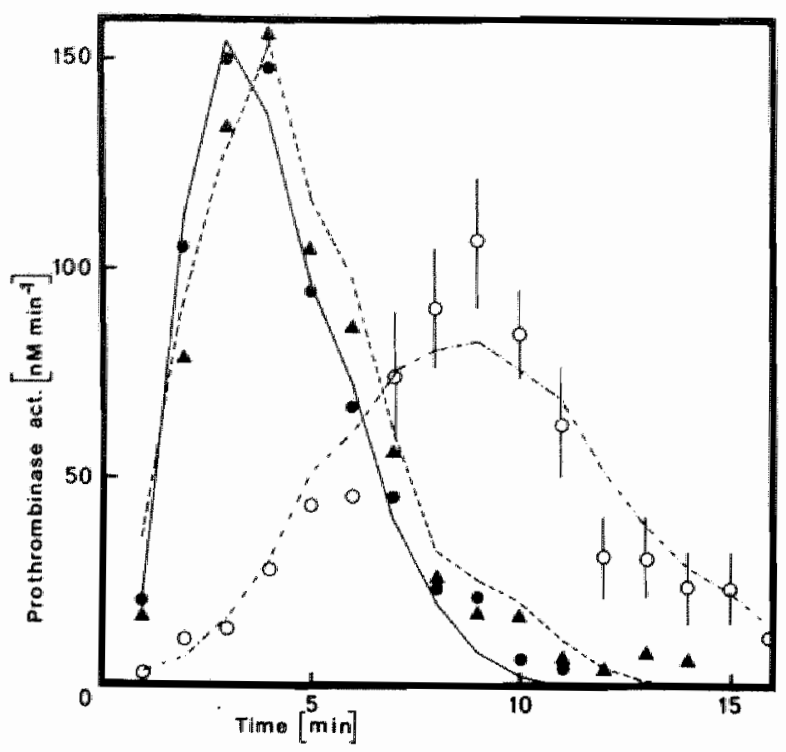

Fig. 2. PROTHROMBIN CONVERSTON RATES IN WHOLE PLASMA, INELUENCE OF HEPARIN.

The points indicate the prothrombin conversion rates found directly with the staphyloooagulase method. The drawn lines join the points conputed with the indirect method. - control with buffer; heparin $\mathrm{U} / \mathrm{ml}: \Delta 0.02,00.1$

We conclude that our method of calculation gives an acceptable picture of the velocity of prothrombin conversion in the absence as well as in the presence of heparin. We cannot exclude the possibility of a slight systematic aver estimation of the velacities in the descending limb of the curve (Fig. 2). This does not, however, influence the interpretation of the observations.

Influence of heparin an the breakdown of endogenous thrombin

In order to compute the prothrombin conversion velocity curves at at a series of heparin concentrations it is necessary to determine the breakdown constants of thrombin in plasma in the presence of different concentrations 
AT III -DEPENDENT DECAY CONSTANTS AND HEPARIN CONCENTRATION

\begin{tabular}{|c|c|c|}
\hline $\begin{array}{l}\text { Heparin } \\
\text { Concentration } \\
U / m i\end{array}$ & $n$ & $k_{1}(m i n-1) \pm$ S.E.M. \\
\hline 0 & 10 & $1.034 \pm 0.029$ \\
\hline 0.01 & 4 & 1.166 \\
\hline 0.02 & 4 & 1.797 \\
\hline 0.03 & 4 & 2.323 \\
\hline 0.04 & 4 & 2.830 \\
\hline 0.05 & 4 & 3.426 \\
\hline 0.06 & 2 & 3.751 \\
\hline 0.075 & 2 & 4.821 \\
\hline 0.10 & 10 & $5.858 \pm 0.190$ \\
\hline
\end{tabular}

of heparin. This was done as shown in Fig. 1 for $0.1 \mathrm{u} / \mathrm{ml}$ of heparin. In all instances curves were obtained that showed a logarithmic approach to a steady end level.

The time constant of the experimental decay curve gives $k_{1}+k_{2}$, where $k_{2}$ is the pseudo first order rate constant of the interaction between thrombin and $\alpha_{2}$ macroglobutin and $k_{1}$ that for AT III dependent thrombin inactivation. The ratio of $k_{2}$ and $k_{1}$ can be obtained from the ratio of the amount of $\alpha 2 M$ bound thrombin to that of AT III-bound thrombin (30). The concentration of $\alpha 2 M$-thrombin can be estimated directly in the serum by its persisting activity towards $\$ 2238$ taking into account that the molar activity of the $\alpha 2 M$-thrombin complex under our experimental condittons is $0.525 \times$ that of thrombin. The concentration of AT III-bound thrombin is calculated as that amount of prothrombin which disappeared from the plasma and that is not accounted for by $\alpha 2 M$-thrombin (see ref. 30 for full details). In our nomal plasma $k_{2}$ was $0.232 \pm 0.004$ (S.E.M.; $n=25$ ). 


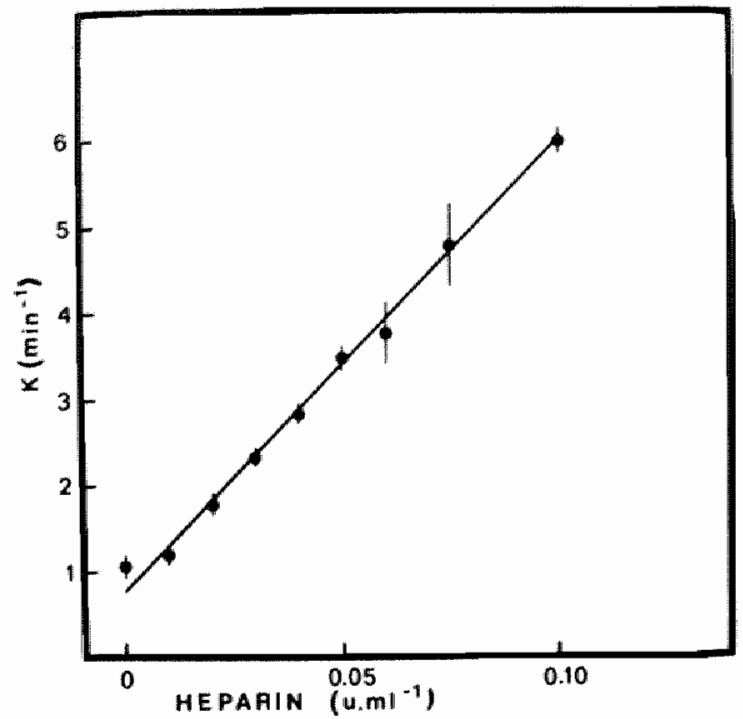

Fig. 3. AT III DEPENDENT DECAY CONSTANTS AND HEPARIN CONCENTRATION.

The line drawn $i s$ the best fit through the points obtained in the presence of heparin. $K=0.728+53.6(H)$, where $(H)$ is the concentration of heparin in $U / m l$.

It was independent of the heparin concentration. We determined the AT III dependent decay canstant for a series of concentrations of heparin (Fig. 3, Table I). No essential differences were found when heparins from different sources were tested.

Heparin and the extrinsic pathway.

We determined the course of thrombin generation triggered by thromboplastin in the presence of different concentrations of heparin. As expected heparin had a clearcut inhibitory effect both on the maximal amount of thrombin formed and on the velocity of thrombin formation (Fig. 4). Inhibitions of about $90 \%$ of the thrombin formation velocity were found at $0.10 \mathrm{U} / \mathrm{ml}$ of heparin. 


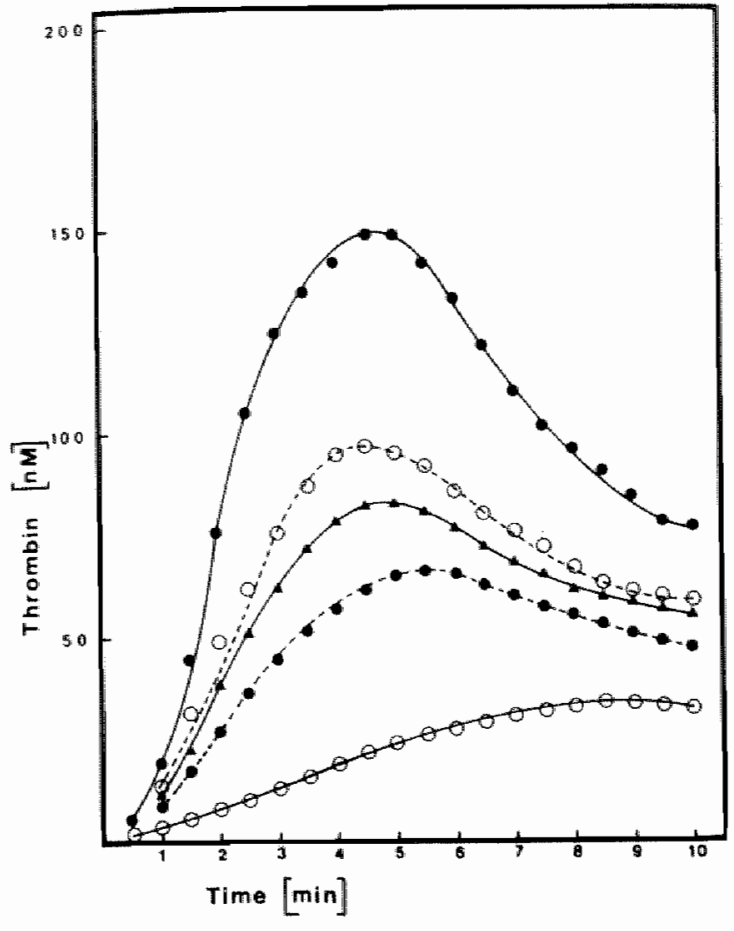

Fig. 4. THE INELUENCE OE HEPARIN ON THROMBIN GENERATION VIA THE EXTRTNSTC PATHEAY.

mean of 4 different aurver at each concentration.

buffer, control heparin $U / \mathrm{ml}$ :
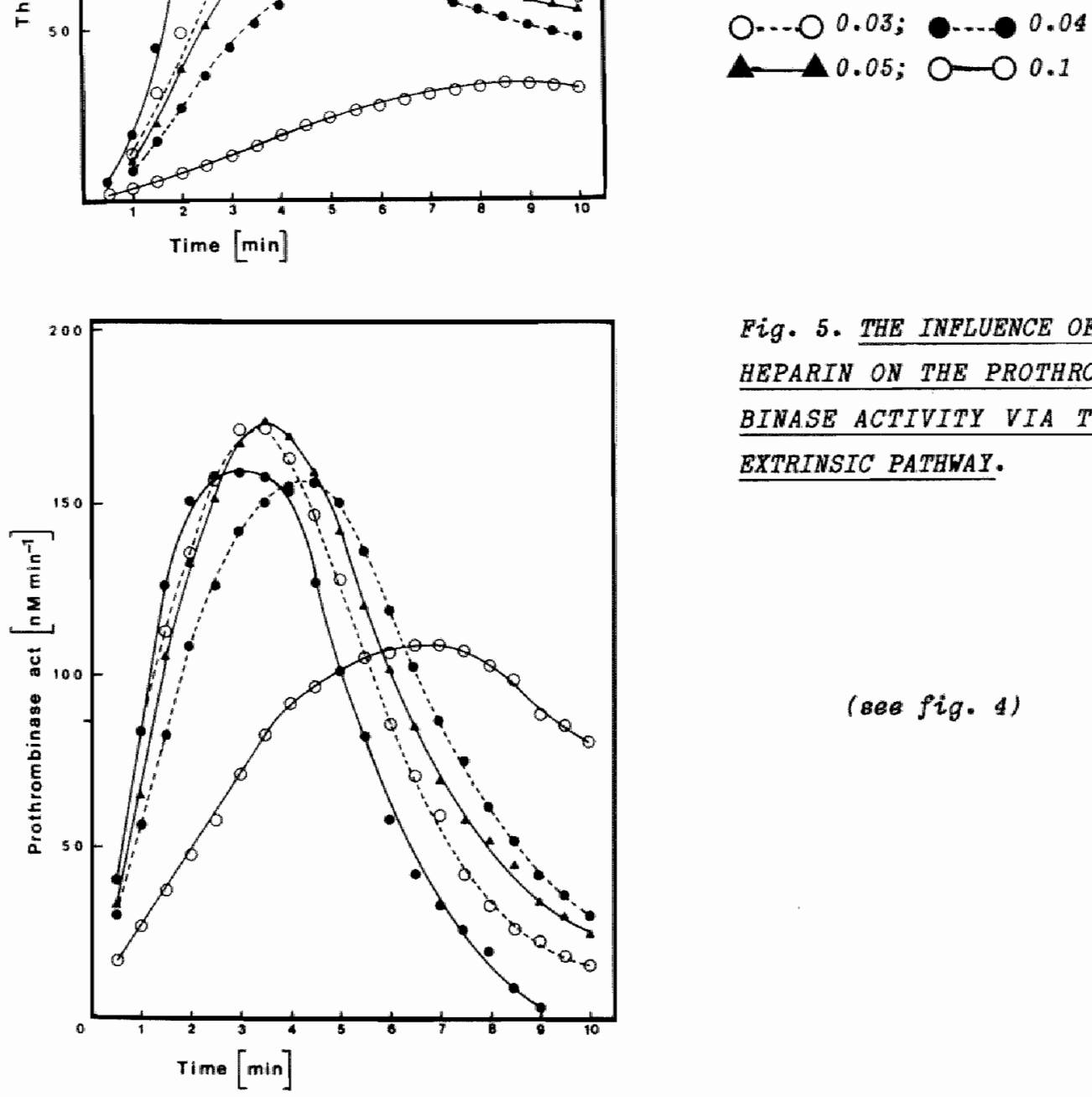

Fig. 5. THE INFLUENCE OF HEPARIN ON THE PROTHROMBINASE ACTIVITY VIA THE EXTRINSIC PATHWAY.

(see fig. 4) 


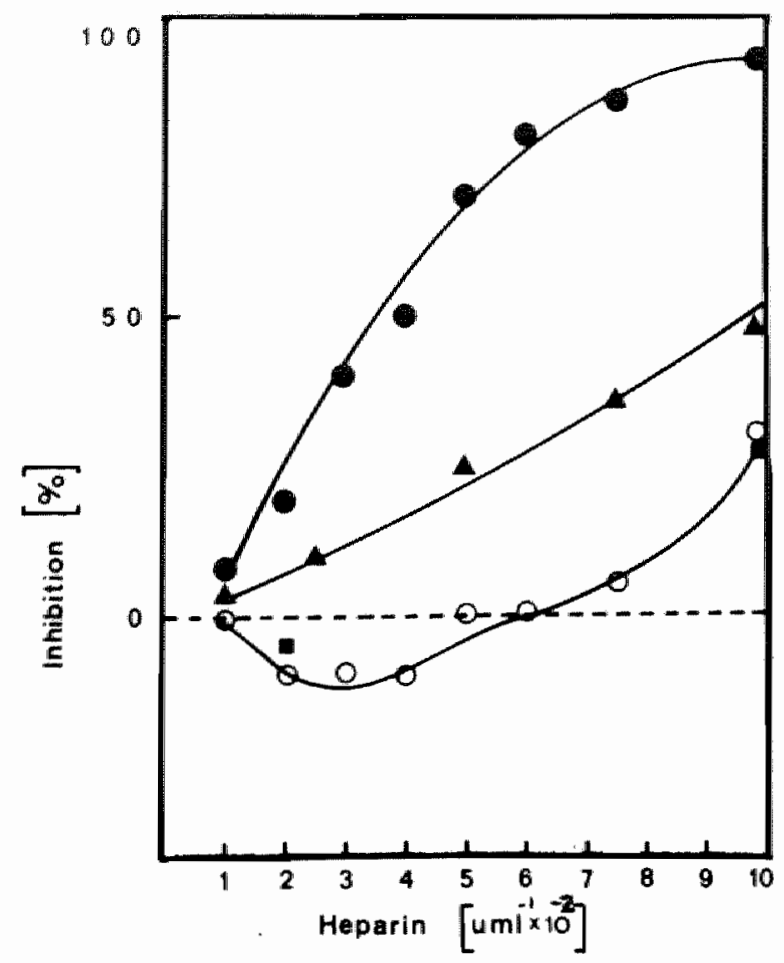

Fig. 6. THE INHIBITION OF THROMBIN GENERATION VELOCITY AND PROTHROMBINASE ACTIVITY BY HEPARIN.

- thrombin generation velocity; 1 prothrombinase extrinsic, direct method; Oprothrombinase extminaic, $\Delta$ prothrombinase intrinsic, computed method.

From the thrombin curves of fig. 4, with the use of the appropriate breakdown constants (Table 1) we computed the course of the prothrombin conversion velocity (Fig. 5). Fig. 6 sumnarizes the results obtained at eight heparin concentrations.

The most salient feature is that the enhancenent of thrombin scavenging is the main effect of heparin in plasma. In thromboplastin triggered thrombin formation, it is much more important than inhibition of the prothrombinase activity. In fact a concentration of $0.075 \mathrm{~J} / \mathrm{m} 1$ heparin inhibits the peak velocity of thrombin formation for $85 \%$, whereas the effect on the peak prothrombinase activity is less then $10 \%$. 
In the concentration range of $0.03-0.04 \mathrm{U} / \mathrm{mi}$ heparin seems even to have a slight enhancing action on the peak prothrombinase activity (Fig. 5,6). On the other hand the velocity at which the prothrombinase activity builds up is slightly slowed down (ascending slopes of fig 5). It must be stressed that our observations are on the overa11, net effect of heparin on prothrombinase activity in the plasma. We cannot exclude that the net effect observed is the sum of an activation and an inmibition. At $0.1 \mathrm{U} / \mathrm{ml}$ heparin there is a clear inhibition of both prothrombinase generation and peak prothrombinase activity.

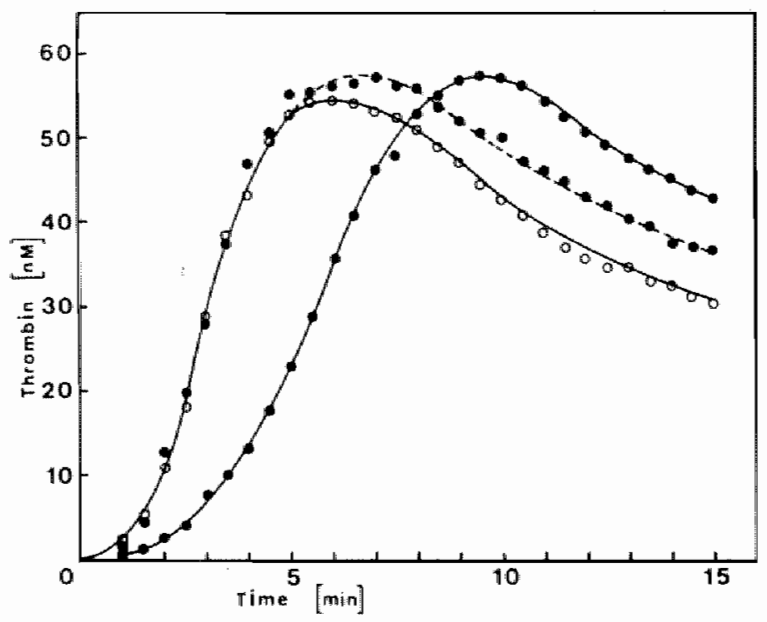

Fig. 7. THE INELUENCE

OF PURTEIED FACTOR Va

ON THE THROMBIN GENE-

RATION TRIGGERED BY

TISSUE THROMBOPLASTIN.

O control, no F.V added.

dotted line; $10 \mathrm{nM} \mathrm{P} \cdot \mathrm{V}$

- 10 nM Eactor Va

If the ambient thrombin concentrations are decreased then one expects the activation of factor $V$ to be decreased as well. In an attempt to see whether this affects prothrombinase generation we added purified factor $v_{a}$ to the plasma. To our surprise factor $v_{a}$ inhibited thrombin generation (fig 7). In a purified system consisting of factor $x_{a}$, phospholipid and prothrombin the same factor $v_{a}$ preparation had the expected accelerating activity on factor $x_{a}$ action and did not cause any inhibition. Factor VIII a also had a slight inhibitory effect in whole plasma (results not shown). The same amounts of unactivated factors $V$ and VIII were without innibiting effect. 


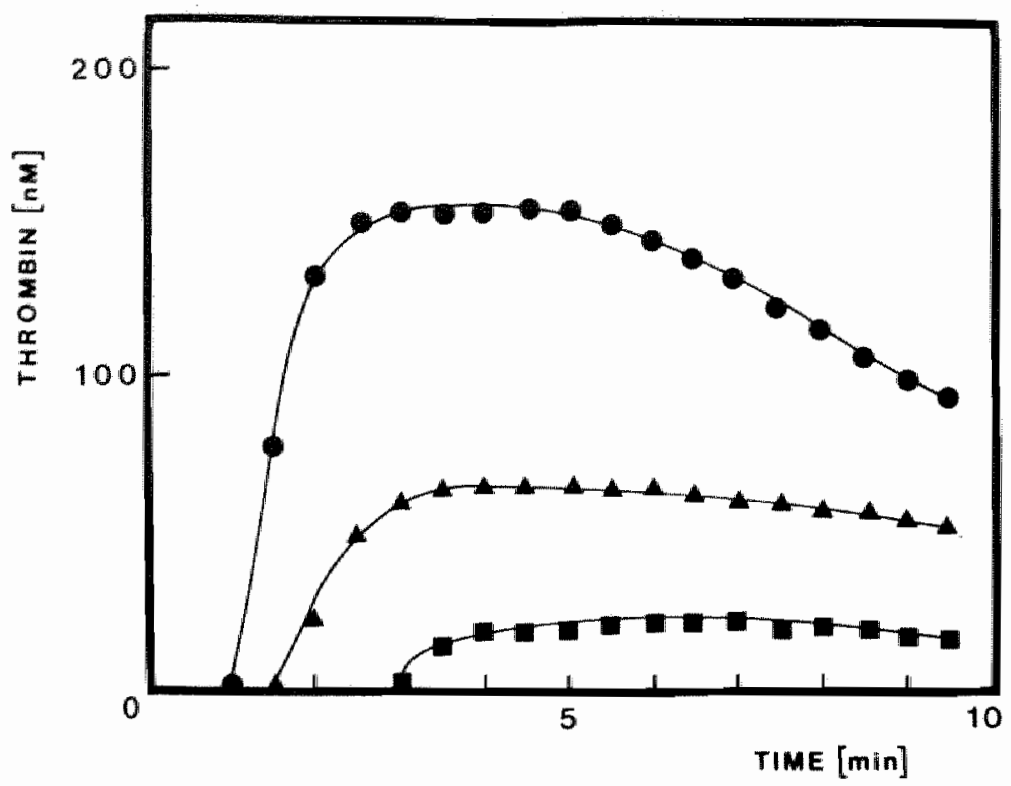

EZ̈g. 8. THE EFEECT OF HEPARIN ON THROMBIN FORMATION INDUCED BY CONTACT ACTIVATION.

no hepamin; $\Delta 0.03 \mathrm{U} / \mathrm{ml}$ heparin, $0.1 \mathrm{U} / \mathrm{ml}$

Influence of heparin on the intrinsic pathway of thrombin generation

After the thromboplastin induced thrombin generation, we studied the intrinsic pathway as triggered by kaolin in the presence of phospholipid. As shown in fig. 8, a definite effect of heparin could be observed, not only on the amount of thrombin formed but also on the lag time of thrombin formation. When we calculated the effect of heparin on the time course of prothrombin activation a significant inhibition of the prothrombinase activities was observed (fig. 9). In contrast to the prothrombinase activity that is triggered by thromboplastin, the prothrombinase formed via the intrinsic system seems to be inhibited by heparin even at low concentrations (Fig. 6). There is no reason to assume that the prothrombinase itself is different in the two cases, so it is likely that the intrinsic factor $X$ activating pathway is inhibited by heparin. 


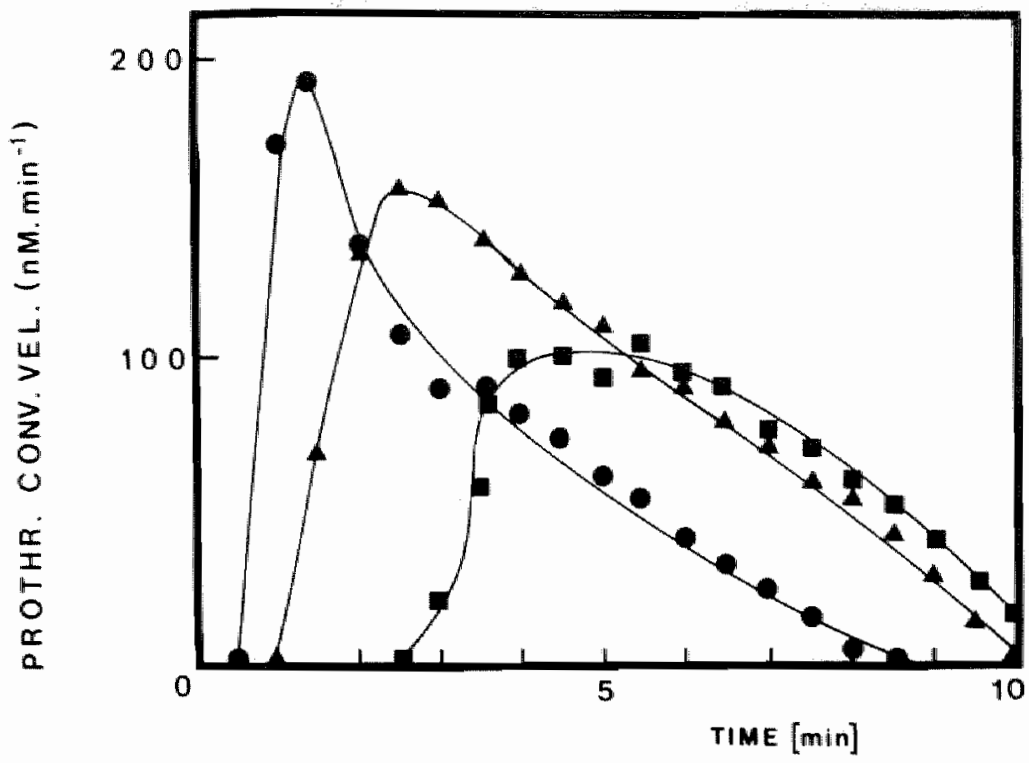

Fig. 9. THE ERPECT OF HEPARTN ON THE PROTHROMBINASE ACTIVITY INDUCED BY CONTACT ACTIVATION.

The data were computed from the data in fig. 8 as indicated under methods. - no heparin, $\mathbf{\Delta} 0.03 \mathrm{~J} / \mathrm{ml}$ heparin, $0.1 \mathrm{U} / \mathrm{mL}$

In an attempt to differentiate between an effect on the factor $X$ activating complex itself (FVIIL ${ }_{a}, F I X_{a}$, phospholipid) and an effect on the activators of factors VIII or IX, we started coagulation with the factor $X$ activating complex, consisting of the purified factors VIII ${ }_{a}$ and $i X_{a}$, phospholipid and $\mathrm{Ca}^{++}$. The factor VIII, was generated by the addition of a small amount of thrombin ( $4 \mathrm{nM}$ ) to the activating mixture. It was checked that the final concentration of thrombin in the reaction mixture $(0.67 \mathrm{nM})$ had no influence on the intrinsic thrombin generation triggered with kalin.

Thrombin formation triggered by the intrinsic factor $x$ activating complex was inhibited by heparin but the lag time had disappeared (Fig 10). 


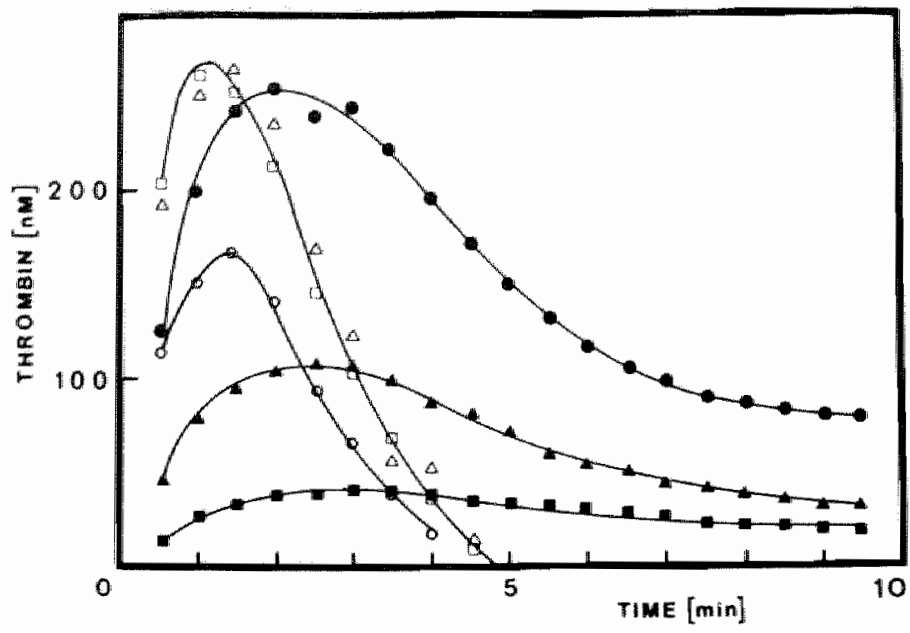

Fig. 10. THE EFPECT OF HEPARIN OF THROMBIN FORMATION INDUCED BY FACTOR X ACTIVATING COMPLEX.

Activation mixture: $25 \mu \mathrm{L} 200 \mathrm{mM} \mathrm{CaCl} 2$ and $25 \mu \mathrm{t}$ of a mixture of factor IXa $(20 \mathrm{nM})$; Factor VIIIC $(10 \mathrm{U} / \mathrm{mL})$, Factor IIa $(4 \mathrm{nM}) ; \mathrm{Ca}^{++} 5 \mathrm{mM}^{\mathrm{M}}$ in buffer $\mathrm{A}$.

\section{- control; heparin U/ml; O $0.1 ; \Delta \boldsymbol{\Delta} 0.05$}

The white symbols give the prothrombinase activity in $n M$ thrombin-min ${ }^{-1}$.

Like in the case of the extrinsic pathway, the inhibition of thrombin formation must be mainly attributed to the scavenging of thrombin, because when the course of prothrombinase activity was calculated no inhibition was seen at concentrations of up to $0.075 \mathrm{U} / \mathrm{ml}$ of heparin and $35 \%$ inhibition was caused by at $0.1 \mathrm{U} / \mathrm{ml}$ of standard heparin (Fig. 10). From these results we concluded that it was likely that in the case of kaolin activation, the formation of one of the constituents of the intrinsic factor $x$ activator must be inhibited by heparin. We therefore added one or the other constituent in preactivated form. When clotting is started by activated factor IX and phospholipid, the inhibition by a heparin concentration of $0.05 \mathrm{U} / \mathrm{m}$ is overwhelming (Fig. 11). 


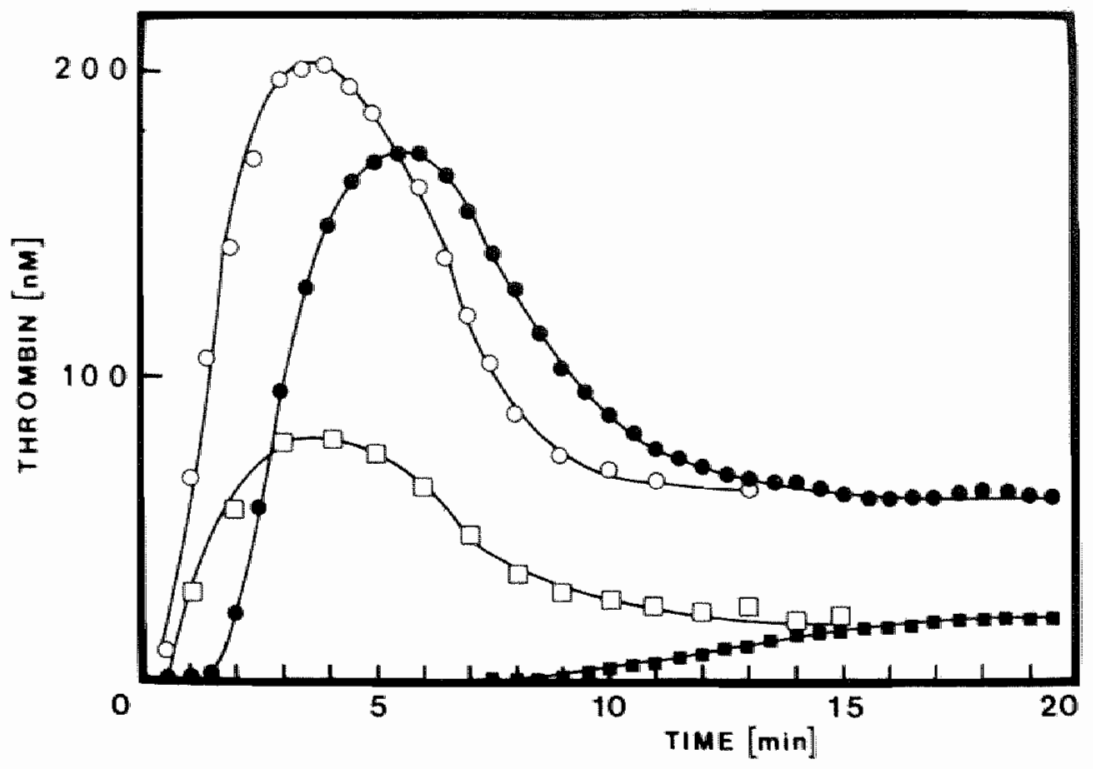

Fig. 11. THE EFPECT OF HEPARIN ON THROMBIN FORMATION INDUCED BY EACTOR IXa OR BY KAOLIN IN THE PRESENCE OF FACTOR VIIIa.

Triggers: F.IXa, phospholipid: controt, Deparin $0.05 \mathrm{u} / \mathrm{ml}$ Kaolin, phospholipid, 5 u factor VIIIc and $2 \mathrm{nM}$ factor IIa O control, $\square$ hepamin $0.05 \mathrm{u} / \mathrm{ml}$.

When activated factor VIII is added to a plasma in which thrombin generation is started by kaolin (Fig. 11) the inhibition of thrombin formation that was observed is comparable to that seen in the extrinsic system and can be explained by thrombin scavenging; also no lag phases are observed. We concluded that the generation of factor $I X_{a}$ as such was probably not inhibited by heparin, but that in the absence of factor VIII $a$, factor $I_{a}$ is easily inactivated by heparin-AT III.

When the factor VIII used in this experiment was not preactivated with thrombin, then the inhibition by heparin reappeared, as did the lag phases (results not shown). 
Ever since it has been reported that phospholipids and factor $\gamma_{a}$ can protect factor $x_{a}$ from the action of AT-III (-heparin) it has remained an open question what the importance of this phenomenon is for the coagulation of plasma, especially in the presence of heparin (31-38). It was our purpose to investigate to what extent factor $x_{a}$ and the factor $x_{\text {activating }}$ proteases are inhibited by AT III (-neparin) during thrombin generation triggered via the extrinsic and the intrinsic pathway in the complex medium of whole plasma.

\section{Choice of the method.}

The problem of the action of heparin in plasma can hardly be solved by studies on purified factors. During coagulation in plasma the kinetic and the binding parameters of the enzymes and substrates change continuously, a.o. because of the variations of the concentration of factor $V_{a}$ and VIII ${ }_{a}$. Neither can the problem be approached by measuring the course of the concentration of factors $I x_{a}$ or $x_{a}$ in clotting plasma because these factors contribute to thrombin formation only in so far as they are bound to procoagulant phospholipids and to their protein cofactors. Only a decrease of the bound fraction will inhibit thrombin generation. Direct measurement of activities of factors $I X_{a}$ and $X_{a}$ in plasma will measure both phospholipidbound and free factors. One cannot automatically assume a simple relationship between the total amount and the bound fraction, because no equilibrium conditions need to exist. The only possibility to estimate the level of factor $x_{a}$ that is active in converting prothrombin in clotting plasma seems determining prothrombinase activity, i.e. prothrombin conversion as a function of time. We used two independent methods for determining prothrombinase activity. a) estimation of the level of residual prothrombin in the course of time with the aid of stapylocoagulase and b) computation of the prothrombin conversion velocity from the experimentally observed veloclty of thrombin formation, correcting it for the simultaneous thrombin decay caused by AT III (-heparin) and other protease scavengers (30).

The two methods appear to give similar results both in the absence and in the presence of heparin (Fig. 2). The direct method is relatively cum- 
bersome and, because the velocities are calculated by subtraction of four activities tends to large experimental errors. We therefore used the indirect method in further experiments.

Working with whole plasma entails all the complex interactions that can exist in whole plasma. Our attempts to explain the phenomena that we observed are therefore necessarily in terms of minimal hypotheses.

\section{Heparin and the extrinsic pathway.}

It follows from the results shown in $\mathrm{fig} .4,5$ and 6 . that the main action of heparin in thromboplastin induced coagulation is on thrombin. The amount of prothrombinase activity triggered by thromboplastin and $\mathrm{Ca}^{\text {t+ }}$ is hardly inhibited by heparin in concentrations that inhibit the velocity of thrombin formation as much as $85 \%$.

The rate of development of prothrombinase activity is however slowed down to some extend by low concentrations of heparin, as can be seen from the ascending slopes in fig. 5. This is not likely to be caused by factor $x_{a}$ scavenging because in that case one would expect the peak amounts of prothrombinase activity to be decreased as well. Alternative explanations are a) the inhibition of factor $X$ activation by the factor VII (a)-thromboplastin complex and $b$ ) inhibition of the activation of factor $V$ by lack of active thrombin. In an attempt to distinguish between these possibilities was added purified preactivated factor $V$ to the reaction mixture. To our surprise this slowed down thrombin formation (Fig. 7). Factor VIII a had the same effect be it to a lesser extend. Trivial explanations for this phenomenon seem excluded because a) control experiments with the same preparations in unactivated form had no inhibiting effect and b) the activated preparations were perfectly functional in a purified systen. Our working hypothesis for the moment is, that in the presence of factor $v_{a}$ (factor VIII ${ }_{a}$ ) the first amounts of factor $x_{a}$ (factor $I X_{a}$ ) that are generated by the factor VII-tissue factor complex are strongly bound to phospholipid by the factor $V_{a}$ (factor VIII ${ }_{a}$ ) present ( $c f$. ref. 40,49,51) and thus are to a lesser extend available for the feedback activation of factor VII. This hypothesis is at present under investigation.

We must conclude that we cannot distinguish in an unequivocal way between the possible mechanisms of the retardation of prothrombinase 
generation by low concentrations of heparin $(20.05 \mathrm{U} / \mathrm{ml})$. In view of the fact that inhibition of factor VII (a) -thromboplastin by heparin has not been described in the literature (1-11) we think that inhibition of the feedback actiwation of factor $W$ by thrombin is the most likely explanation of this phenomenon. The minimal hypothesis that explains the action of heparin on thromboplastin induced thrombin formation is that heparin increases thrombin scavenging. Although is cannot be completely excluded, there is no need to assume that heparin up to concentrations of about 0.075 $\mathrm{U} / \mathrm{ml}$ influences the activities of factors VII and $x_{a}$. At $0.1 \mathrm{U} / \mathrm{ml}$, it seems that inhibition of factor $x$ a starts to play a role because the peak activity of prothrombinase starts to be inhibited.

\section{Heparin and the intrinsic pathway.}

Heparin, at concentrations that do not inhibit prothrombin activation induced via the extrinsic pathway, does inhibit the development of prothrombinase activity when thrombin formation is triggered wia the intrinsic system by kaolin, phospholipid and $\mathrm{Ca}^{++}$(figs. 8 and 9). It is hard to see why this could be the result of factor $x_{a}$ inactivation if the extrinsically generated prothrombinase is not significantly inhibited by the same concentrations of heparin. The inhibition of the intrinsic system therefore is more likely to be caused by inhibition of the phospholipid-Ca ${ }^{++}$-factor IX $X_{a}$-factor VIII complex itself or by inhibition of the generation of one of its constituents. The generation of factor IX $X_{a}$ can be inhibited by heparin when the contact factors are inhibited, which might be readily possible $(6,9,10)$. The action of thrombin on factor VIII, a compulsory process for its activation (56-59), might evidently also be influenced by the decrease of thrombin induced by heparin. In platelet rich plasma the scavenging of thrombin might inhibit the unmasking of procoagulant phospholipids (60) but this process is not operative in our experimental setup. From fig. 10 it follows that the prothrombinase activity triggered by the complete factor $X$ activating complex is not inhibited by a heparin concentration of $0.05 \mathrm{U} / \mathrm{ml}$ (Fig. 9). It therefore appears reasonable to assume that not the complex itself but rather the formation of factor Ix or of factor VIII is inhibited by heparin. To distinguish between these possibilities we did experiments in which efther one or the other factor 
was present in its activated form from zero time, whlle the other had to be generated during the process. We found that factor IX $X_{a}$ is very sensitive to heparin action, but only as long as no factor WIII is present (Fig. 11). In the presence of factor VIII however, the prothrombinase level is not influenced by heparin so that it appears that factor IX then is stable. The primary action of heparin at this level therefore seens to be an inhibition of factor VIII activation caused by a decrease of the ambient concentration of thrombin. The lack of factor VIII then causes factor $\mathbb{I X}_{a}$ to be subjected to AT III-heparin inactivation.

This view is corroborated by the observations on the lag times of thrombin generation (Figs. $4,7,9,10$ ). There is hardly any lag time in the extrinsic system. In the intrinsic system a lag time is seen only when no factor VIII is added to the mixture and then the lag times increase when increasing amounts of heparin are added. The lag time probably represents the time necessary for a sufficient amount of factor VIII to be activated. If this time is long, then part of the factor IX that is formed by the contact activation system is inactivated by AT-III (-heparin) and less factor $x$ activating complex can eventually form, resulting in smaller amounts of prothrombinase being formed.

This again suggests that heparin does inhibit the intrinsic coagulation pathway because it inactivates factor IX until the moment that the traces of thrombin have appeared that can activate factor VIII, after which the activated factor VIII protects factor IX from further inhibition.

Heparin concentrations in vivo, ex vivo and in vitro.

The concentrations of heparin that we studied are relatively low. We do think that they are relevant for the situation in patients that receive heparin because such levels are routinely encountered in preventive heparim treatment. Also if platelets are present, considerable amounts of heparin can be neutralized by platelet factor 4, so that even in the presence of high plasma levels of heparin, at the site of a hemostatic or thrombotic process the effective heparin concentration may well be in the range we studied here. Concentrations of heparin higher then $0.1 \mathrm{U} / \mathrm{ml}$ anyhow could not be tested with our method because we need a minimal velocity of thrombin formation of about $10 \%$ of normal to apply our calculations. We 
tested heparin from four different sources, three conventional heparin preparations that are in current clinical use and the international standard heparin and did not find significant differences between these preparations.

In a purified system, when AT III is present in excess, the pseudo first order rate constant of thrombin inactivation is proportional to the heparin concentration it equais $38.7 \mathrm{~min}^{-1} / \mu \mathrm{g} / \mathrm{ml}$. For a heparin containing $168 \mathrm{U} / \mathrm{mg}$ this is equivalent to $232 \mathrm{~min}^{-1} \mathrm{~N} / \mathrm{ml}$. (Th. Lindhout, personal communication). In plasma between 0.005 and $0.010 \mathrm{U} / \mathrm{ml}$ of heparin seem to be inactivated, probably by high affinity binding to a plasma protein, possibly $s$-protein (28).

After compensating for this effect one finds a change of $k$ with the heparin concentration of $8.6 \mathrm{~min}^{-1} / \mu \mathrm{g} / \mathrm{ml}$. This is considerably lower then that is found in purified systems $\left(38.7 \mathrm{~min}^{-1} / \mu \mathrm{g} / \mathrm{m} 1\right)$. At least two phenomena may explain this difference.

a) Heparin may bind reversibly to various plasma proteins and thus its effective concentration may be lower than the amount added would predict.

b) Thrombin generated in situ is less vulnerable to AT III (-heparin) than exogenous thrombin is (30). This holds also for thrombin fomed by prothrombinase from prothrombin in a purified system (39).

Dur observations pertain to the difficult problem of standardisation of heparin preparations. If heparin in clotting biood acts primarily on thrombin, then its estimation should be based on its effect on thrombin. The best parameter for this action is probably the heparin dependent pseudo first order decay constant $\left(k_{1}\right)$ of thrombin, generated endogenously in whole plasina. Test for clinical use therefore should be based upon the effect of heparin on endogenously generated thrombin rather then an added thrombin or even added factor $X$.

It is interesting to see that our results explain a well known paradox from the clinical laboratory: Although both the thrombin time and the activated partial thromboplastin time (APTT) are sensitive to heparin, the prothrombin time is not. When we carried out experiments with non defibrinated plasma it appeared that coagulation is always seen at the start of the explosive fomation of thrombin. This means that the APTT actually measures the lag time of thrombin formation in the intrinsic system. As we argued, this lag time is determined by the availability of thrombin for the 
activation of factor WIII. The APTT therefore must be considered to be influenced primarily by the action of AT III (-heparin) on thrombin just like the thrombin time is.

Dur results are al so in agreement with the observations of ofosu et al. who showed that the effective inhibition of the generation of thrombin activity appears to require sulphated polysaccharides which can potentiate the inactivation of thrombin $(61,62)$. They also report inhibition of prothrombinase by standard heparin in antithrombin 111 depleted plasma and by heparin with a low affinity to antithrombin III in nomal plasma (11,60). However, these effects are seen at heparin concentrations $(0.2-3 \mathrm{U} / \mathrm{m}$ ) that are appreciably higher then those used here.

We do not exclude the possibility that tissue thromboplastin neutralizes heparin, as forwarded by Gomperts \&ucker (63) and 0fosu (11). This effect cannot explain our results however, because a) the thromboplastin is used here in dilutions that are more then $100 \times$ higher them those in a normal Quick test and b) the effect of heparin on the decay of endogenous thrombin (figs. 2,3, table I) was measured in the presence of the same amount of thromboplastin as that used in the thrombin generation curves.

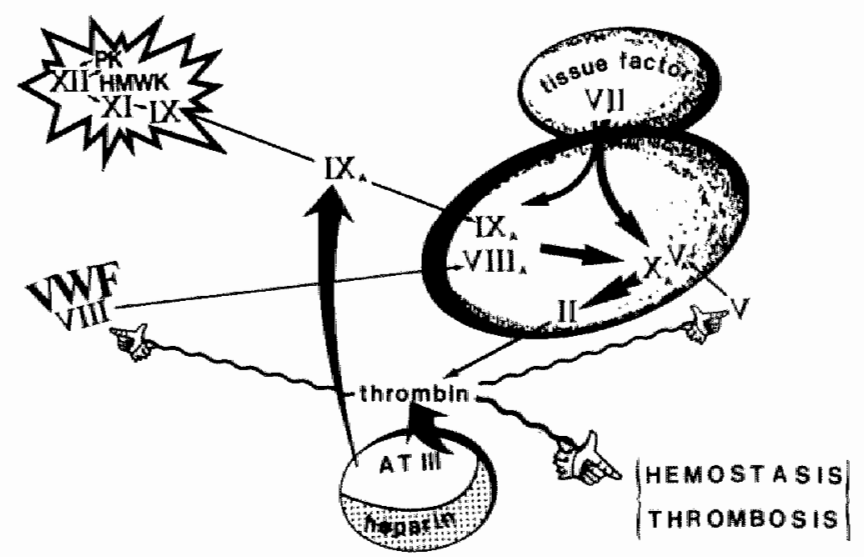

Fig. 12. A SCHEME OF THE ACTION OF AT III-HEPARIN IN PLASMA. 
We are unable to explain why heparin inhibition of the feedback activation of thrombin is more important at the level of factor Ixa and WIIl then at the level of factors $x_{a}$ and $V_{a}$. At this moment we tend to nypothesize that factor $x_{a}$ formation vid the extrinsic pathway is completely confined to the phospholipid surface, and therefore protected from AT III action. On the contrary the factor $x_{a}$ formation induced by contact activation requires partition of factor $\mathbb{I} X_{a}$ between the kalin surface, free solution and phospholipid. In free solution AT III(-heparin) may readily inhtbit factor $\mathbb{I} X_{a}$. Fig. 12 sumarizes our hypotheses.

A sufficiently standardised and accurate APTT would be a logical candidate for monitoring the effect of heparin on the thrombin generation in patient plasma.

\section{Conclusions.}

In order to explain up to $85 \%$ of the inhibition of the rate of thrombin fomation by heparin ( $0.075 \mathrm{U} / \mathrm{m} 7)$ in wholle plasma, it suffices to assume that heparin acts by increasing AT III-dependent thrombin scavenging only.

Because of the feedback activation ex.erted by thrombin on its own formation, thrombin scavenging can however indirectly inhibit the prothrombin conversion rate. It could be shown that this mechanism is operative when coagulation is started via the intrinsic pathway. Whether it al so explains inhibition of the extrinsic pathway at higher concentrations of heparin (i.e. at $85 \%$ inhibition of the thrombin formation rate) could not be decided. In the intrinsic system the scavenging of trace amounts of thrombin that activate factor VIII during the lag phase of thrombin generation induces an important secondary effect on the stability of factor $\mathbb{I}_{a}$.

Our results partly agree with the observation reported by Teltel \& Rosenberg (41) who saw that the process of thrombin generation becames less vulnerable to heparin as the conversion of prothrombin proceeds. We would tend to explain this in tems of activation of factor VIII and protection of factor IX $X_{a}$ by factor VIII . On the other hand we did observe a protective effect by phospholipids, whereas Teitel \& Rosenberg saw this effect anly in the presence of platelets. At the high heparin concentration used by these authors $(2 \mathrm{U} / \mathrm{ml})$ the protection by phospholipid could be overcame al so in our system and inhibition of prothrombinase can be observed, unless the heparin is neutralized by activated platelets. 
1. Seegers, W.H., Cole, E.R., Hamison, C.R., Monkhouse, F.C.: Neutralization of autoprothrombin C activity with antithrombin. Can. $J$. Bi ochem. 42, 359-364, 1964

2. Abilldgard, $U$.: Purification of two progressive Antithrombins of Human plasma. Scand. J. CTin. Lab. Invest., 19, 190-195, 1967

3. Biggs, R., Densan, K.W.E., Akman, N., Borrett, R., Hadden, M.: Antithrombin III, antifactor $x_{a}$ and heparin. Brit. J. Haenatol., 19, $283-305,1970$

4. Yun, E.T. Wessler, S., Stoll, P.J.: Rabbit plasma inhibitor of the activated species of blood coagulation factor $x$. J. Biol. Chem. 246, $3694-3702,1971$

5. Rosenberg, R.Q., Damus, P.S.: The purification and the mechanism of action of human antithrombin-heparin cofactor. J. Biol. Chem. 248, $6490-6505,1973$

6. Stead, N., Kaplan, A.P., Rosenberg, R.D.: Inhibition of activated factor XII by antithrombin-heparin cofactor. 2. Biol. Chem. 251, $6481-6488,1976$

7. Kurachi, K., Fujikawa, K., Schmer, G., Davie, E.W.: Inhibition of bovine factor $I X_{a \alpha}$ and factor $X_{a \beta}$ by antithrombin III. Biachenistry, $15,373-377,1976$

8. Andersson, L.0., Barrowcliffe, J.W. Holmer, E., Johnson, E.A., Sims, G.E.C.: Anticoagulant properties of heparin fractionated by affinity chromatography on matrix-bound antithrombin III and by gel filtration. Thromb. Res., 9, 575-583, 1976

9. Kurachi, K., Davie, E.W.: Activation of human factor XI (Plasma thromboplastin antecedent) by factor XIIa (activated Hageman factor). Biochemistry, 16, 5831-5839, 1977

10. Holmer, E., Kurachi, K., Söderström, G.: The molecular weight dependence of the rate enhancing effect of heparin on the inhibition of thrombin, factor Xa, factor IXa, factor XIa, factor XIla or kallikrein by antithrombin. Biochem. J., 193, 395-400, 1981

11. Ofosu, F.A., Blajchman, M.A., Modi, G., Cerskus, A.L., Hirsh, d.: Activation of factor $X$ and prothrombin in ATIII depleted plasma: the effects of heparin. Thrombosis Research, 23, 331-345, 1981 
12. Fusst, F., Girolami, A., Cella, G.: Low molecular heparins and their effects in vitro, in experimental models and in humans. in: Chemistry and biollogy of Heparin. R.L. Lundblad e.a. edts. Elsevier/North Holland New York. 535-546, 1980

13. Thomas, D.P., Merton, R.E., Lewis, W.E., and Barrowcliffe, T.W.: Studies in man and experimental animals of a low molecular weight heparin fraction. Thrombos. Haemostas. (Stuttg.) 45, 214-218, 1981

14. Holmer, E., Mattson, C., and Nilsson, V.S.: Anticoagulant and antithrombotic effects of heparin and low molecular weight heparin fragments in rabbits. Thromb. Res., 25, 475-485, 1982

15. Bergquist, D., Hedner, U., Sjörin, E., Holmer, E.: Anticoagulant effects of two types of molecular weight heparin administered subcutaneously. Thromb. Res., 32, 381-391, 1983

16. Carter, C.J., Kelton, J.G., Hirsh, J. Cerskus, A., Santos, A.V., Gent, M.: The relationship between the hemorrhagic and antithrombotic properties of low molecular weight heparin in rabbits. Blood, 59, $1239-1245,1982$

17. Ockelford, P.A., Carter, C.J., Mitchel1, L., Hirsh, J.: Discordance between the anti- $x_{a}$ activity and the antithrombotic activity of an ultra-low molecular weight heparin fraction. Thromb. Res. 28, 401-409, 1982

18. Thomas, D.P., Merton, R.E., Barrowcliffe, T.W., Thunbergh L., Lindahl, U.: Effects of heparin oligosaccharides with high affinity for antithrombin III in experimental venous thrombosis. Thromb. Haemostas. (Stuttg.) 47, 244-248, 1982

19. Cade, J.F., Buchanan, M.R., Boneu, B., Dckelford, P., Carter, C.J., Cerskus, A.L., Hirsh, J.: A comparison of the antithrombatic and haemorrhagic effects of low molecular weight heparin fractions: the influence of the method of preparation. Thromb. Res., 35, 613-625, 1984 20. Merton, R.E., Thomas, D.P., Havercroft, S.J., Barrowcliffe, T.W., Lindahl, $U$ : High and low affinity heparin compared with unfractionated heparin as antithrombotic drugs. Thromb. Haemostas. (Stuttg.) 51, $254-256,1984$

21. Buchanan, M.R., Boneu, B., Ofosu, F., Hirsch, J.: The relative importance of thrombin inhibition and factor $x_{a}$ inhibition to the antithrombotic effects of heparin. Blood, 65, 198-201, 1985 
22. Boneu, B., Buchanan, M.R., Cade, J.F., Van Rijn, J., Femendez, F.F., Dfosu, F.A., Hirsh, J.: Effects of heparin, its low molecular weight fractions and other glycosaminoglycans on thrombus growth in vivo. Thromb. Res., 40, 81-89, 1985

23. Gentry, P.W., Alexander, B.: Specific coagulation factor adsorption to insoluble heparin. Biochem. Biophys. Res. Comm., 50, 500-509, 1973

24. Stathakis, N.E., Mosesson, M.W.: Interactions among heparin, cold insoluble globulin and fibrinogen in formation of the heparinprecipitable fraction of plasma. J. C1 in. Invest., 60, 855-865, 1977

25. MacGregor, I.R., Lane, D.A., Kakkar, V.V.: The anti-heparin properties of human low-density lipoprotein. Biochem. Biophys. Acta, 617, 472-479, 1980

26. Mckay, E.J., Laurell, C.B.: The interaction of heparin with plasma proteins. Demonstration of different binding sites for antithrombin III complexes and antithrombin III. J. Lab. Clin. Med., 95, 69-80, 1980

27. Lijnen, H.R., van Hoef, B., Collen, D. Interaction of heparin with histidine-rich glycoprotein and with antithrombin $\mathbb{1} 1$. Thromb. Haemostas. (Stuttg) 50, 560-562, 1983

28. Freissner, K.T., Wassmuth, R., Müller-Berghaus, G.: Physicochemical characterization of human S-protein and its function in the blood coagulation system. Biochem. J., 231, 349-355, 1985

29. Podack, E.R., Dahlbäck, B., Griffin, J.H.: Interaction of S-protein of complement with thrombin and antithrombin III during coagulation.

J. Biol. Chem., 261,7387-7392, 1986

30. Henker, H.C., Willems, G.M., Béguin, S.: A computer assisted method to obtain the prothrombin activation velocity in whole plasma independent of thrombin decay processes. Thromb. Haemostas. (Stuttg.) 56, 9-17, 1986

31. Marciniak, E.: Factor Xa inactivation by antithrombin III: evidence for biological stabilization of factor $x_{a}$ by factor $V$-phospholipid complex. Brit. J. Haem., 24, $391-400,1973$

32. Walsh, P.N., Biggs, R.: The role of platelets in intrinsic factor $x_{a}$ formation. Brit. J. Haem. 22, 743-760, 1972

33. Miletich, J.P., Jackson, C.M., Majerus, P.W.: Properties of the factor $x_{a}$ binding site on human platelets. J. Biol. Chem., 253, 6908-6916, 1978 
34. Josso, $F_{.}$, Bëguin, $S_{\text {. }}$ : Changes in the antithrombin III activity at the interface plasma-phospholipids. Thramb. Haemost., 46, 285, 1981 (abstract)

35. Ellis, V., Scully, M.F., Kakkar, V.V.: Inhibition of prothrombinase camplex by plasma proteinase inhibitors. Biochemistry, 23, 5882-5887, 1984

36. Barrowcliffe, T.W., Havercroft, S.J., Kemball-Cook, G.: Effects of calcium, phospholipid and Factor $V$ on inactivation of Factor $x_{a}$ by antithrombin III. Personally communicated

37. Dfosu, F.A., Cerskus, A.L., Hirsh, J., Smith, L.M., Modi, G.J., Blajchman, M.A.: The inhibition of the anticoagulant activity of heparin by platelets, brain phospholipids and tissue factor. British Journal of Haematology, 57, 229-238, 1984

38. Walker, F.J., and Esmon, C.T.: The effects of phospholipid and factor $v_{a}$ on the inhibition of factor $x_{a}$ by antithrombin III. Biochem. Biophys. Res. Commun., 90, 641-647, 1979

39. Lindhout, T., Baruch, D., Schoen, P., Franssen, J., Hemker, H.C.: Thrombin generation and inactivation in the presence of antithrombin III and heparin. Biochemistry, 25, 5962-5969, 1986

40. van Dieijen, G., van Rijn, J.L.M.L., Govers-Riemslag, J.W.P., Hemker, H.C., Rosing, J.: Assembly of the intrinsic factor $X$ activating complex; interactions between factor $I X_{a}$, factor VIIIa and phospholipid. Thrombosis and Haemost. (Stuttg.) 53, 396-400, 1985

41. Teitel, J.M., and Rosenberg, R.D.: Protection of factor $x_{a}$ from neutralization by the heparin-antithrombin complex. J. Clin. Invest., $71,1383-1391,1983$

42. Walker, F.J., Esmon, C.T.: Interactions between heparin and factor $X_{a}$ inhibition of prothrombin activation. Biochim. Biophys. Acta, 585, $405-415,1979$

43. Brown, J.E., Baugh, R.F., Hougie, C.: The inhibition of the intrinsic generation of activated factor $X$ by heparin and nirudin. Thrombos. Res., 17, 267-272, 1980

44. Ofosu, R., Blajchman, M.A., and Hirsh, J.: The inhibition by heparin of the intrinsic pathway activation of factor $X$ in the absence of antithrombin-III. Thrombos. Res., 20, 391-403, 1980 
45. Ofosu, F.A., Modi, G., Cerskus, A.L., Hirsh, J., and Bllajchman, M.A.: Heparin with low affinity to antithrombin III inhibits the activation of prothrombin in nomal plasma. Thrombos. Res., 28, 487-497, 1982

46. Josso, F., Prou-Wartelle, 0.: Explaration de I'hemostase. In: Techniques en hëmatologie. (eds)., $101-208,1972$ Flammarion, Paris.

47. van Dam-Mieras, M.C.E., Muller, A.D., wan Dieijen, G., Hemker, H.C.: In: Methods of enzymatic analysis. Enzymes 3: Peptidases, proteinases and their inhibitors. Vol. V, 352-394, 1984, Verlag Chemie, Weinheim, edited by H.U. Bergmeyer.

48. Hendrix, H., Lindhout, T., Mertens, K., Engels, W., Henker, H.C.: Activation of human prothrombin by stoichiametric levels of staphylocoagulase. J.B.C., 258, 3637-3644, 1983

49. Rosing, J., Tans, G., Govers-Riemslag, J.W.P., Zwaal, R.F.A., Henker, H.C.: The role of phospholipids and factor $V_{a}$ in the prothrombinase camplex. J. Biol. Chem., 255, 274-283, 1980

50. Pletcher, C.H., and Nelsestuen, G.L.: The rate detemining step of the heparin-catalyzed antithrombin-thrombin reaction is independent of thrombin. J. Biol. Chem., 257, 5342-5345, 1982

51. Lindhout, T., Govers-Riemslag, J.W.P., van de Waart, P., Hemker, H.C., Rosing, J. Factor $W_{a}$-factor $x_{a}$ interaction. Effects of phospholipid vesicles of varying composition. Biochemistry, 21, 5494-5502, 1982

52. Vehar, G.A., Davie, E.W.: Preparation and properties of bovine factor VIII. Biochemistry, 19, 401-410, 1980

53. Fujjikawa, K., Thompson, A.R., Legaz, M.E., Meyer, R.G., Davie, E.W.: Isolation and characterization of bovine factor $\mathbb{I} X$ (Christmas Factor). Biachemistry, 12, 4938-4945, 1973

54. Fujikawa, K., Legaz, M.E., Kato, H., Davie, E.W.: The mechanism of activation of bovine factor $I X$ (Christmas factor) by bovine factor XI (activated plasma thromboplastin antecedent). Biochemistry, 13 , $4508-4516,1974$

55. Beck, J.V., Arnold, K.J.: Parameter estimation in engineering and science. J. Wiley and Sons, New York, 1977

56. Seegers, W.H.: Multiple protein interactions as exhibited by the blood clotting mechanism. J. Phys. Colloid. Chem., 51, 198-206, 1947 
57. Rapaport, S.I., Hjort, P.F., Patch, M.d.: Further evidence that thrombin activation of factor VIII is an essential step in intrinsic clotting. Scand. J. Clin. Lab. Invest., 17, 84-88, 1965

58. Biggs, R., Denson, K.W.E., Ash, B.J. Macfarlane, R.G.: Thrombin and the interaction of factors VIII and IX. Brit. J. Haemat. $11,276-295,1965$

59. Dsterud, B., Rapaport, S.I., Schiffman, S., Chong, M.M.Y.: Formation of intrinsic factor $X$ activator with special reference to the role of thrombin. Br. J. Haematol., 21, 643-660, 1971

60. Bevers, E.M., Comfurius, P., van Rijn, J.L.M.L., Henker, H.C., Zwal, R.F.A.: Generation of prothrombin-converting activity and the exposure of phosphatidylserine at the outer surface of platelets. Eur. J. Biochem., 122, 429-436, 1982

61. Ofosu, F.A., Blajchman, M.A., Modi, G.J., Smith, L.M., Buchanan, M.R., Hirsh, J.: The importance of thrombin inhibition for the expression of the anticoagulant activities of heparin, dermatan sulphate, low molecular weight heparin and pentosan polysulphate. Brit. J. Haemat., $60,695-704,1985$

62. Dfosu, F.A., Modi, G., Ceskus, A.L., Hirsh, J., and Blajchman, M.A.: Heparin with low affinity to Antithrombin III inhibits the activation of prothrombin in normal plasma. Thromb. Res. 28, 487-497, 1982

63. Gomperts, E.D., and Zucker, M.N.: Heparin, brain thromboplastin and the insensitivity of the prothrombin time to heparin activity. Thromb. Res., 12, 105-117, 1978

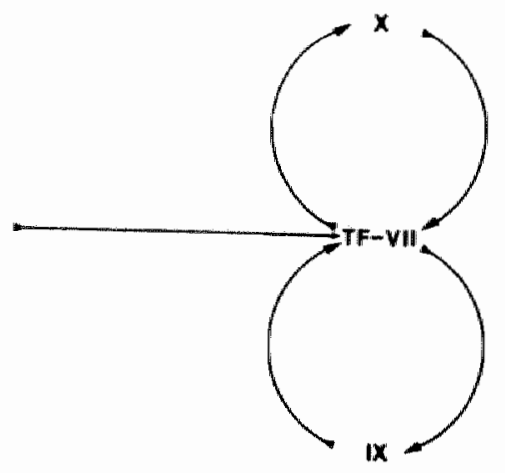

The actions of tissue factor 
CHAPTER IV

\section{THE MODE OF ACTION OF SOME LOW MOLECULAR WEIGHT HEPARINS IN PLASMA, RECOGNITION OF TWO FUNCTIONALLY DIFFERENT TYPES.}

\section{Sumnamy}

We investigated the action of a series of low motecular weight hepamin as to their action in plasma on endogenously generated thrombin and prothrombinase activity bath in the extrinsic and intminsic system." The materials tested were: Pentasacchamide (CY 234), CY 216 (Fraxtanin) and CY 222 (Choay) and PK 10169 (Enoxaparind, EMT 966 and EMT 967 (Pharmuka). Of these the pentasacharide and the EMT's had no signifiaant influence on the AT III dependent decay of thrombin but they did inhibit both the extminsically and the intminsically generated prothrombinase. In sharp contrast CY 216 and CY 222, like classical heparin, do strongly influence the AT III dependent decay of thrombin but have no influence on prothrombinase. We thus recognize, two fundamentally different groups of heparins, those ating on thrombin, which we called s type heparine (after their Standand hepamin prototype) and thase which we alzed $p$ type hepamins (after thetr prototype Pentasaccharide) acting on prothrombinase. From this it followe that the standarization of 5 type heparins can be meadily admind out by comparison of a $P$ type hepamin with a standard from the other group witz be essentially impossible.

* The experiments with purified factors reported in Tables II, III have been carried out by T. Lindhout, J. Pieters, P. Schoen and H. Soons. 
The separation of crude heparin in high and low molecular weight fractions and in fractions with a high and low affinity for antithrombin III (AT III) made it clear that the properties of the crude material are not unifomaly distributed over the different molecular species that it contains $(1-10)$.

The best documented example to this is that a specific synthetic pentasaccharide binds to AT III and enhances the inactivation of factor $x_{a}$ by this protein but does not influence the inactivation of thrombin (11-12). Longer molecules of heparin that contain this pentasaccharide sequence obtain an antithrombin action. In general the ratio of antithrombin activity to anti $x_{a}$ activity decreases with decreasing molecular weight $(4,6,9)$.

This shift of functions with chemical structure opens the possibility that the therapeutic function of heparin, i.e. its antithrombotic activity, could be separated from its main side effect: bleeding (13-20).

In fact it has been hoped that the antifactor $x$ action would parallel the antithrombotic action and that the antithrombin action could be an indicator of the bleeding-risk provoked by a heparin preparation.

In its original form this thesis has been proven untenable. Several investigations showed that in practice there is no strict paralellism between the in vitro action against factor $x_{a}$ and antithrombotic action of a heparin and neither is there a good correlation between antithrombin activity and bleeding (21-28).

Moreover, we were able to demonstrate that classical heparin, when tested in whole plasma, for its action on activated clatting factors generated in that plasma had no anti factor $x_{a}$ action of any importance (Chapter III).

Evidently, it would be helpful for the development of better heparins if the invitro correlaties of in vivo antithrombotic or haemorrhagic action could be found. To this end it is necessary to document precisely what the in vitro actions are in a series of heparins and to compare them to the antithrombotic c.q. haemorrhagic properties of these drugs. Dur observation that no action of heparin is demonstrable on factor $x_{a}$ that takes part in the prothrombinase complex generated in whole plasma, even 
though it is readily found on free factor $x_{a}$ illustrates that some reactions encountered in vitro are not relevant in clotting plasma and therefore in all probability not in vivo either.

It is not even clear that the relevant property of heparin can be found in studies on plasma as this drug has been shown to act at several other targets like e.g. on endothelial cells $(29,30)$, on cell adhesion and movement (31), on blood platelets $(32,33)$, on fibrinolysis $(34,35)$, on liprotein lipase (36) etc.

Nevertheless, in view of the fact that the two most potent antithrombotics i.e. oral anticoagulants and heparin have their anticoagulant action as a common feature, it seems a reasonable quess that inhibition of the coagulation mechanism has a therapeutic effect on thrombosis. It therefore seems good strategy to make a thorough investigation of the interactions of heparin with the blood coagulation mechanism first.

This, in view of the results described in the previous chapter has to be done under conditions as near ta the in vivo situation as possible. In this chapter we therefore study the action of a set of low molecular weight heparins on the thrombin generation in plasma.

The effects that we may find in this way are not necessarilly pertinent to the therapeutic situation, but any effects that we can demonstrate not to play a role are very unlikely to be important, even though they may have been demonstrated to occur in more purified systems. In this way clotting plasma can be regared as an "ex vivo" model and to be one step nearer to physiological reality then "in vitro" systems using purified factors.

\section{Materials and Methods}

Unless otherwise indicated the materials were the same as in the previous chapter.

Hepartins

The heparins were supplied by Or. T.W. Barrowcliffe $\left(4^{\text {th }}\right.$ International Standard Heparin), Choay Laboratories (Pentasaccharide, CY 216, CY 222) and Pharmuka Laboratories (PK 10169, EMT 966 and EMT 967). CY 216 is an ethanol precipitated heparin fragment, $C Y 222$ is a fragment abtained by nitrous acid depolymerization, PK 10169 also is a nitrous acid depolymerization product of crude heparin and EMT 966 as well as EMT 967 are fractioms of 
this substance obtained by gel flltration. The average molecular weight, antifactor II and antifactor $x_{a}$ activities as given by the manufacturers are shown in Table 1 .

$$
\text { Table I }
$$

DATA ON THE HEPARINS USED

\begin{tabular}{|c|c|c|c|c|}
\hline Compound & $\begin{array}{l}M W \\
K D\end{array}$ & $\begin{array}{l}\text { USP act } \\
U / m g\end{array}$ & $\begin{array}{c}\text { anti I la act } \\
U / \mathrm{mg}\end{array}$ & $\begin{array}{c}\text { anti Xa act } \\
U / m g\end{array}$ \\
\hline St. heparin & $1.5-30$ & 168 & 168 & 168 \\
\hline Pentasaccharide & 1.7 & 0 & 0 & 4000 \\
\hline CY 216 & 4.5 & 50 & $10-20$ & 200 \\
\hline CY 222 & 2.5 & 25 & $5-15$ & 250 \\
\hline PK 10169 & 4.5 & - & 30 & 120 \\
\hline EMT 966 & 6.5 & - & 70 & 160 \\
\hline EMT 967 & 3.3 & - & 0 & 160 \\
\hline
\end{tabular}

Purified clotting factors.

Human factor $X$ and prothrombin were purified as described by Miletich et al. (37). Thrombin was purified as a prothrombin activation product as described earlier for bovine thrombin (38). Factor $x_{a}$ was abtained by activating factor $X$ with $R W W-X$ and $\mathrm{CaCl}_{2}$ and then separating the factor $X_{a}$ from the activator by chromatography on DEAE-Sephadex (39).

The functional molar concentrations of the proteases were determined by active site titration and were found to be at least $95 \%$ of the calculated total concentration. A11 preparations were homogeneous on SDS-polyacrylamide gels. Factor $I X_{a}$ and factor $X_{a}$ were obtained as described in ref. 40 and 41 .

\section{Methods}

The methods were the same as in the previous chapters but the standard procedure for estimating intrinsic thrombin generation has been modified in the amount of kaolin used. This was diminished from $0.25 \mathrm{mg} / \mathrm{ml}$ to 0.025 
$\mathrm{mg} / \mathrm{ml}$ because of the adsorption of several LMW heparin onto kaolin (see results section). This turned out to cause essentially the same thrombin generation as the original concentration of kaolin and not to adsorb heparins to an undue extent (see results section). As a rule, both in the intrinsic and in the extrinsic system, the control experiment was carried out in parallel with two experiments containing the inhibitor.

Inhibition of the peak amount of thrombin or prothrombinase activities relative to the control experiment was calculated using the mean of the three highest values obtained as an arbitrary top level.

The decay constants in purified systems were obtained by incubating the activated clotting factors AT III and the heparins at the concentrations indicated. Then at regular intervals samples were taken and the activities tested. In all instances a semilogarithmic breakdown was observed. The decay constant was calculated from the slope of the semilogarithmic decay curve $(42)$.

Thrombin was tested on S 2238 as indicated in the previous chapter. Factor $X a$ was tested like thrombin, substituting $S 2222$ as the chromogenic substrate. Factor IXa and Factor XIa were tested as given in (43).

\section{EXPER IMENTAL}

Breakdown Constants of Endogenous Thrombin

In order to be able to calculate the time course of prothrombinase activity from the course of amidolytic activity one has to know the AT III dependend decay constant $\left(k_{1}\right)$ as well as the $\alpha_{2} M$ dependent decay constant $\left(k_{2}\right)$. The effects of $\alpha_{1}$ antitrypsin and possible other minor proteases are included in $k_{1}$. We determined the owerall pseudo first order decay constant (k) at a series of concentrations of the different heparins tested (figs. $1,2)$. Then the ratio $(R)$ of $2 M$ bound thrombin to AT III bound thrombin was determined at various concentrations of the heparins and $k_{1}$ and $k_{2}$ were determined from the relations $R=k_{1} / k_{2}$ and $k=k_{1}+k_{2}$. It appeared that $k_{2}$ in the presence of heparins was not significantly different from that in its absence. With the presence batch of normal plasma $k_{2}=0.23 \pm 0.04$ (s.e.) 


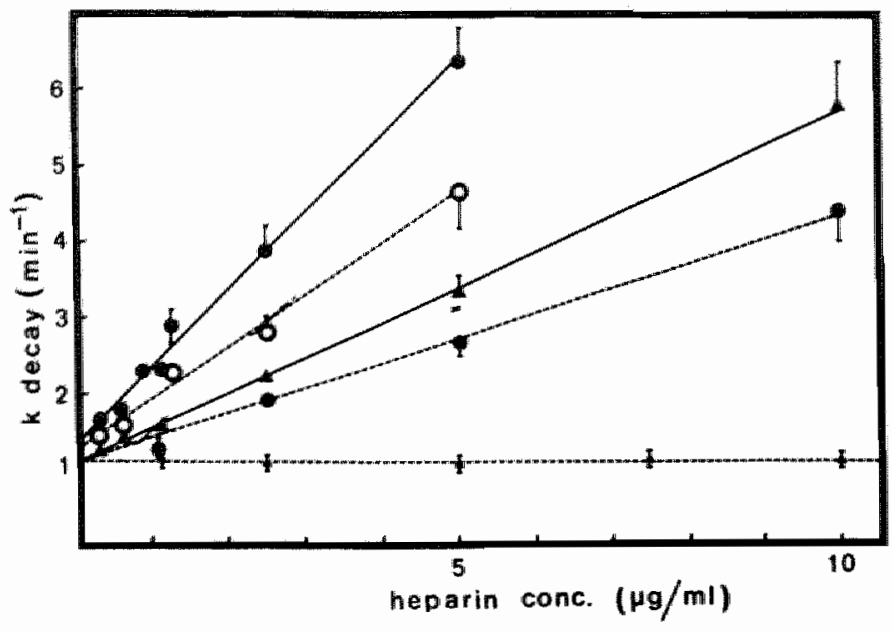

Pig. 1. THE CONCENTRATION DEPENDENCY OF THE DECAY CONSTANT OF ENDOGENOUS THROMBIN FOR PENTASACCHARIDE, CY 216 AND CY 222.

$\Delta-\Delta$ pentabaccharide; $\Delta$ CY 216 extminsic syatem; - CY 216 intminsic system;- C $C Y 222$ extrinsic aystem;O OCY 222 intminsic system.

This value was independentiy verified by the fact that the prothrombinasetime graphs always approached the zero level, which would not be the case if a wrong value of $k_{2}$ is used in the calculations (Figs. $7,9,12$ ).

Already from the inspection of the figs. 1 and 2 it is clear that the LMW Heparins come in two groups: Those that, like heparin, do increase the AT III dependent breakdown constant of endogenous thrombin and others that do not. The first group consists of PK 10169, CY 216 and $C Y 222$. In the second one, we find the pentasaccharide, EMT 966 and EMT 967. In the first group the concentration dependancy of $k$ could not be distinguished from a straight line. From the slopes of these lines one can calculate the increase of $k$ per $\mu g$ of heparin/ml c.q. per pM of heparin/ml. In Table II these data are given and compared to the constants obtained in a purified system.

We determined the breakdown constants both in the intrinsic and in the extrinsic system. For $C Y 216$ and $c Y 222$ there was a substantial difference 


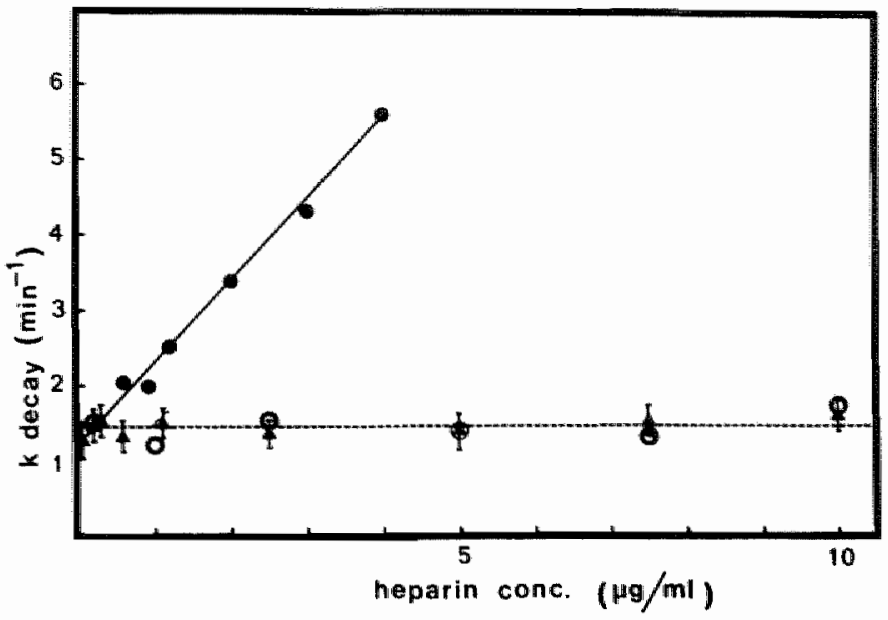

Pig. 2. THE CONCENTRATION DEPENDENCY OF THE DECAY CONSTANT OF ENDOGENOUS THROMBIN FOR PK 10169, EMT 966 and ENT 967.

\section{$P K 10169 ; 0 \cdots O E M T 966 ; \Delta-\triangle E M T 967$.}

between the two systems. It appeared that $C Y 216$ and $C Y 222$, but also the pentasaccharide as well as EMT 967 were adsorbed onto kaolin.

In fig. 4 it is seen for instance that reducing the amount of kaolin in an experiment to $1 / 10$ of its usual concentration increases the inmibition by pentasaccharide, clearly demonstrating the effect of the adsorption of the pentasaccharide onto kaolin. On the other hand, PK 10169, that is not adsorbed onto kaolin, has the same slope of the k-concentration line in the intrinsic and the extrinsic system. The low concentration of kalin (0.025 $\mathrm{mg} / \mathrm{m}$ !) still adsorbed about half of the $C y$ heparins in the concentration ranges used (results not shown). We therefore attribute the different slopes of the $k$-concentration lines, seen with the $C Y$ heparins, to their adsorption onto kaolin.

In Table II we compare the breakdown canstants found in a purified system with those found for endogenous thrombin in plasma. In plasma the rate constants are always lower. The low molecular weight heparins have only a few percent of the activity of heparins. This is expecially clear when the results are expressed on a molar basis. The activity of heparin 
THE CONCENTRATION DEPENDENCY OF THE DECAY CONSTANT OF THROMBIN FOR VARIOUS HEPARINS

\begin{tabular}{|c|c|c|c|c|c|c|c|}
\hline \multirow{2}{*}{ Heparin } & \multicolumn{3}{|c|}{ A) $k$.min $n^{-1} / \mu g / m !$} & \multicolumn{3}{|c|}{ B) $k \cdot \mathrm{min}^{-1} / \mathrm{mM} / \mathrm{m} 1$} & \multirow{2}{*}{$\begin{array}{r}\text { ratio } k \text { (plasina) } \\
k \text { (purified) }\end{array}$} \\
\hline & pur. & plasma & $\%$ & pur. & plasma & $\%$ & \\
\hline Standard & 38.7 & 8.57 & 100 & 542 & 120 & 100 & 020 \\
\hline PK 10169 & 7.3 & 1.11 & 13 & 33 & 5.0 & 4.2 & 0.15 \\
\hline CY 216 & 2.0 & 0.47 & 5.5 & 9 & 2.12 & 1.8 & 0.24 \\
\hline CY 222 & 1.9 & 1.02 & 12 & 4.8 & 2.55 & 2.1 & 0.54 \\
\hline
\end{tabular}

In section $A$ the data are on a weight basis, in section $B$ they are calculated on basis of the molar concentration, using the molecular weights from Tabte $I$.

in plasma is about, $20 \%$ of that observed in a purified system except for cy 222 where it is $50 \%$.

This can be attributed to the lower susceptibility of endogenous thrombin to AT III-heparin action and to the presence of heparin binding proteins in plasma.

In Table III we summarize the data on the breakdown constants of factors IIa, IXa, Xa and XIa in a purified system. For all heparins, except for the pentasaccharide and EMT 967, the activity decreases in the order IIa - Xa - IXa - XIa. The two exceptions are explained by the absence of antithrombin activity in pentasaccharide and EMT 967. 
THE BREAKDOWN CONSTANTS OF VARIOUS CLOTTING PROTEASES WITH DIFFERENT HEPARINS IN A PURIFIED SYSTEM

\begin{tabular}{l|c|c|c|c} 
Heparin & IIa & IXa & Xa & XIa \\
& & & & \\
Standard & & & & \\
PK 10169 & 38.7 & 0.180 & 4.1 & 0.021 \\
CY 216 & 7.3 & 0.109 & 0.8 & 0.002 \\
CY 222 & 2.87 & 0.101 & 0.27 & 0.001 \\
Pentasaccharide & 0 & 0.032 & 11.4 & 0.003 \\
EMT 966 & 1.91 & 0.058 & 0.45 & 0.002 \\
EMT 967 & 0 & 0.158 & 1.3 & 0.006 \\
& & 0.020 & 0.4 & 0.001 \\
\hline
\end{tabular}

$\mathrm{k}$ is expressed in $\mathrm{min}^{-1} / \mu \mathrm{g} / \mathrm{ml}$

Expemimental conditions:

a) AT III: $400 \mathrm{nM} ;$ II $: 20 \mathrm{nM}$; heparin: $0-300 \mathrm{ng} / \mathrm{ml}$

b) AT III: $400 \mathrm{nM}$; IX $280 \mathrm{nM}$; heparin: $1 \mathrm{\mu g}$

c) AT III: $400 \mathrm{nM} ; X_{a}$ : $20 \mathrm{nM}$; heparin: $0-300 \mathrm{ng} / \mathrm{mL}$

d) AT III: $400 \mathrm{nM} ; X_{a}$ : $4 \mathrm{nM}$; hepamin: $5 \mu \mathrm{g} / \mathrm{mL}$ 


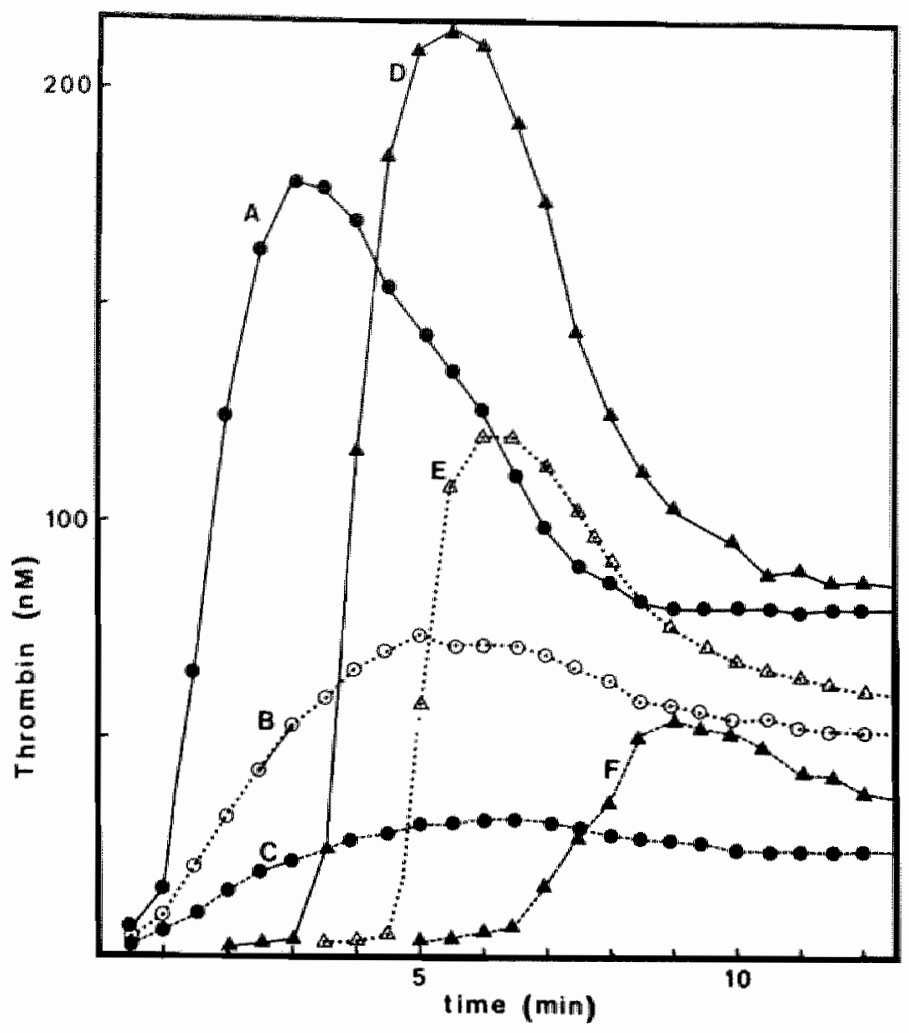

Fig. 3. THE INFLUENCE OF PENTASACCHARIDE ON THROMBIN GENERATION.

extrinsic aystem: $A$ : control $B: 0.1 \mu \mathrm{g} / \mathrm{mL} \quad C: 0.3 \mu \mathrm{g} / \mathrm{mZ}$ intrinato aystem: $D$ : control $E: 0.1 \mu \mathrm{g} / \mathrm{mL} \quad F: 0.3 \mu \mathrm{g} / \mathrm{ml}$

Influence of LMW heparins on thrombin generation and prothrombinase

In fig 3 the influence of pentasaccharide on thrombin generation is shown. There is an evident, dose dependent inhibition both in the intrinsic and in the extrinsic system. Because thrombin decay is not influenced (Fig. 1) this inhibition must be attributed to the inhibition of prothrombinase or to a decreased prothrombinase generation. Either factor $x_{a}$ is scavenged or its formation is inhibited. Prothrombinase activities need not to be calculated. 


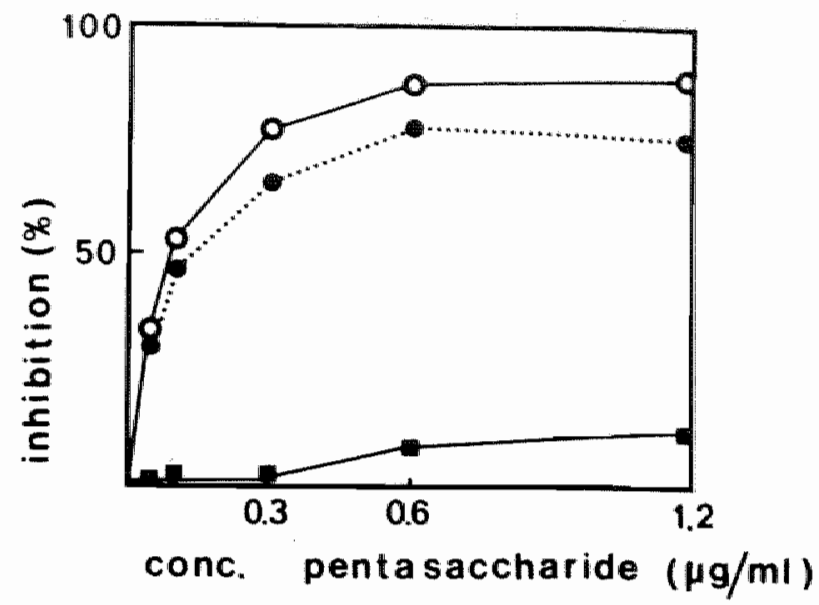

Pig. 4. INHIBITION OF THROMBIN BY PENTASACCHARIDE.

Triggers; O human brain thromboplastin; kaolin $0.25 \mathrm{mg} / \mathrm{mt}$

- $0.025 \mathrm{mg} / \mathrm{ml}$

They will show the same inhibitions as the thrombin activities because the breakdown constant does not vary with the pentasaccharide concentration. In fig. 4 it is seen that the intrinsic system seems not to be inhibited if the usual amount of kaolin, $0.25 \mathrm{mg} / \mathrm{ml}$, is used. This is due to adsorption of the pentasaccharide onto kaolin. The effect is largely abolished by using kaolin at $0.025 \mathrm{mg} / \mathrm{ml}$. This concentration was therefore used in our standard procedure. From figure 5 it is clear that pentasaccharide also inhibits when coagulation is started with purified tenase and when it is started with factor $I X_{a}$ and phospholipid. The difference between the two triggers is in the lag phases rather then in the inhibition of the amount of thrombin generated. This illustrates again that the lag phase is the time during which factor VIII is activated so that it can participate in the tenase complex (see also the previous chapter). 


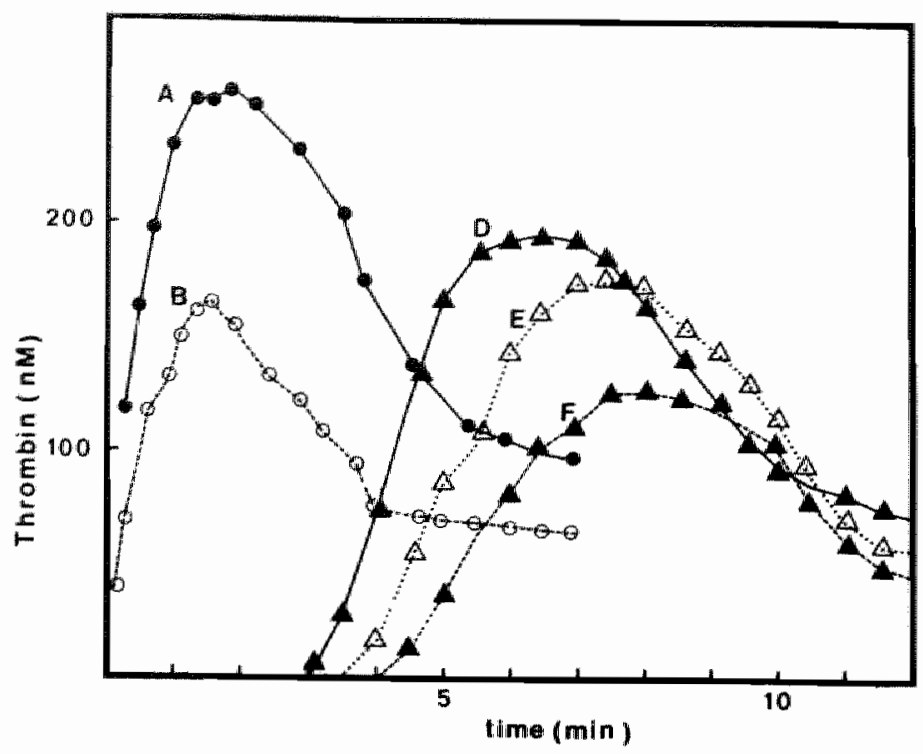

Pig. 5. THE INFLUENCE OF PENTASACCHARIDE ON THROMBIN FORMATION TRIGGERED WITH THE FACTOR IXA - EACTOR VIIIA - PHOSPHOLIPID COMPLEX AND WITH FACTOR IXa.

Trigger: tenase, A: Control; $B: 0.200 \mu \mathrm{g} / \mathrm{ml}$

Trigger: factor IXa D: Control; $E: 0.050 \mu \mathrm{g} / \mathrm{ml} ; \mathrm{F}: 0.200 \mu \mathrm{g} / \mathrm{mL}$

Curves $A$ and $B$ are obtained at irregular intervals at the highest possible sample frequency.

The CY heparin show a behaviour that is completely different from pentasaccharide (figs. 6-9). Like unfractionated heparin they cause inhibition of thrombin scavenging, without inducing an important inhibition of prothrombinase. CY 222 is indeed very similar to classical heparin in its behaviour towards thrombin generation, in that at high concentrations it starts inhibiting prothrombinase to a certain extend. 


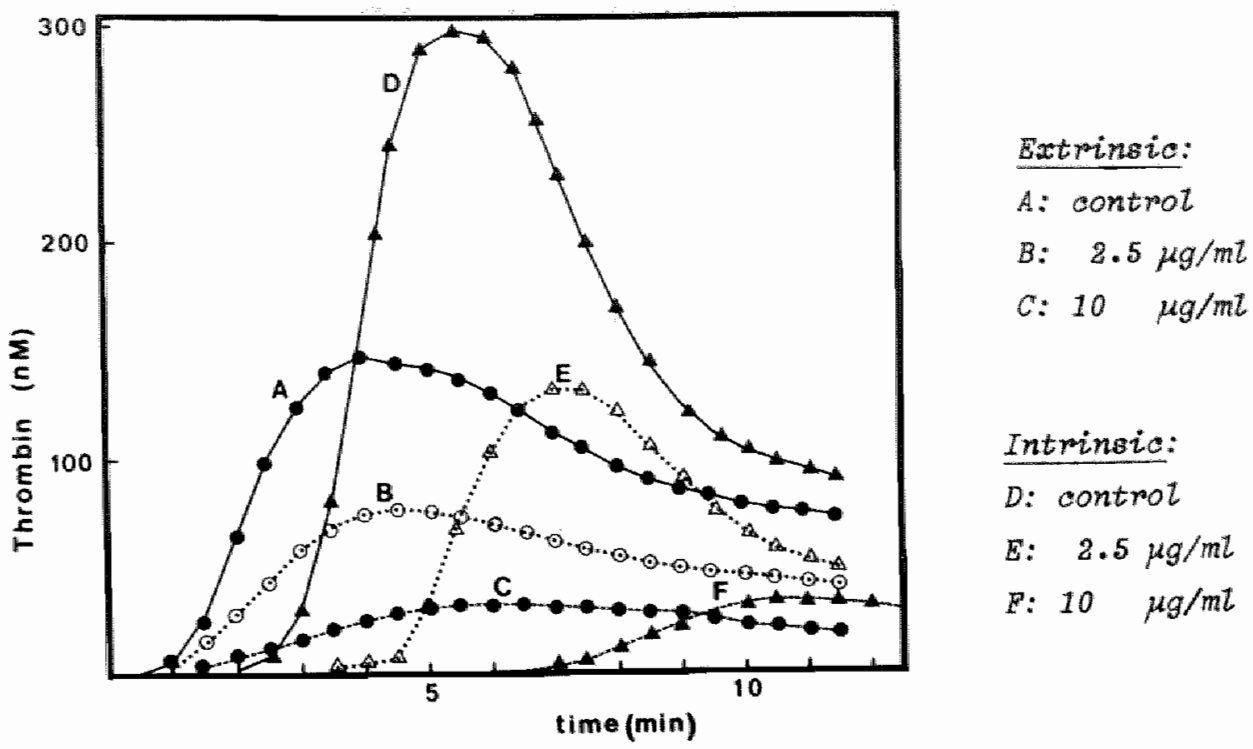

Fig. 6. THE INRLUENCE OF CY 216 ON THROMBIN GENERATION.

Extminsic:

A: control

$B: 2.5 \mu \mathrm{g} / \mathrm{ml}$

C: $10 \mu \mathrm{g} / \mathrm{ml}$

Intrinsic:

D: control

E: $\quad 2.5 \mu \mathrm{g} / \mathrm{ml}$

F: $10 \mu \mathrm{g} / \mathrm{mt}$

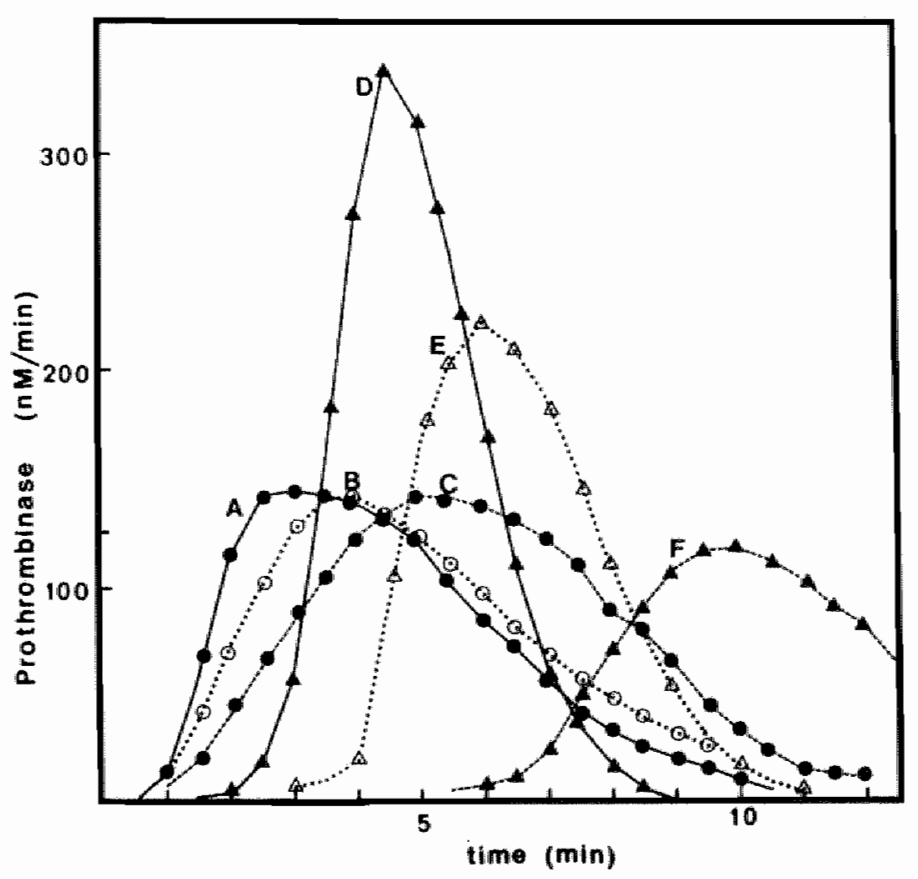

Fig. 7. THE INFLUENCE OF CY 216 ON PROTHROMBINASE ACTIVITY. 


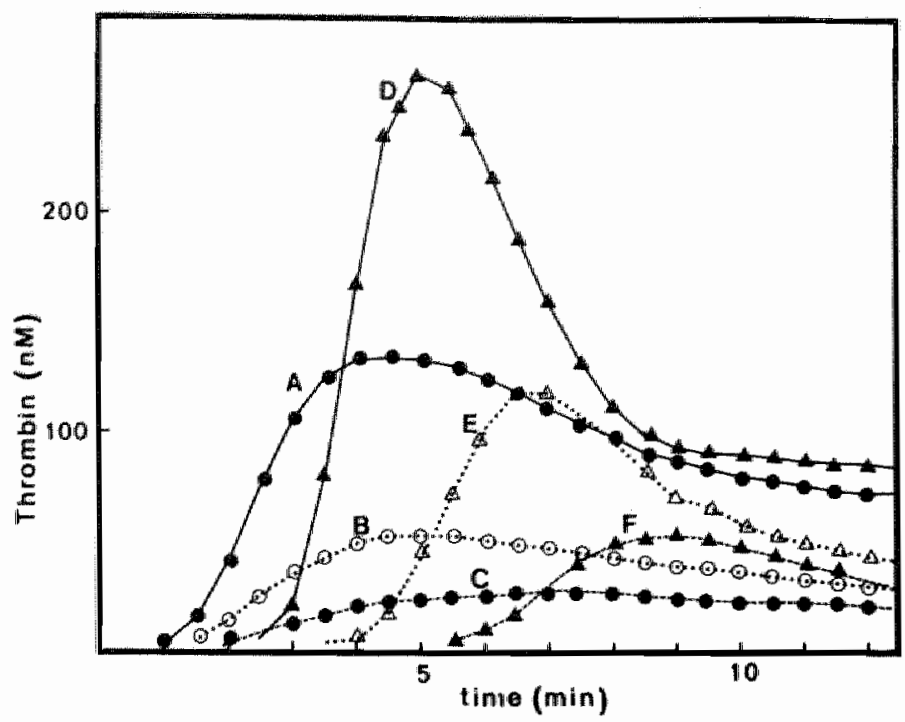

Extminsia:

A: control

$B: 2.5 \mu g / m L$

C: $5 \mu g / \mathrm{mL}$

Intminsic:

D: control

E: $2.5 \mu \mathrm{g} / \mathrm{mL}$

F: $5 \mu \mathrm{Mg} / \mathrm{ml}$

Fig. 8. THE INELUENCE OF CY 222 ON THROMBIN GENERATION.

Extmingia:

A: control

$B: 2.5 \mu \mathrm{g} / \mathrm{mL}$

C: $5 \quad \mu g / m L$

Intminato:

D: control

$E: 2.5 \mu g / m l$

P: $5 \mu g / m L$

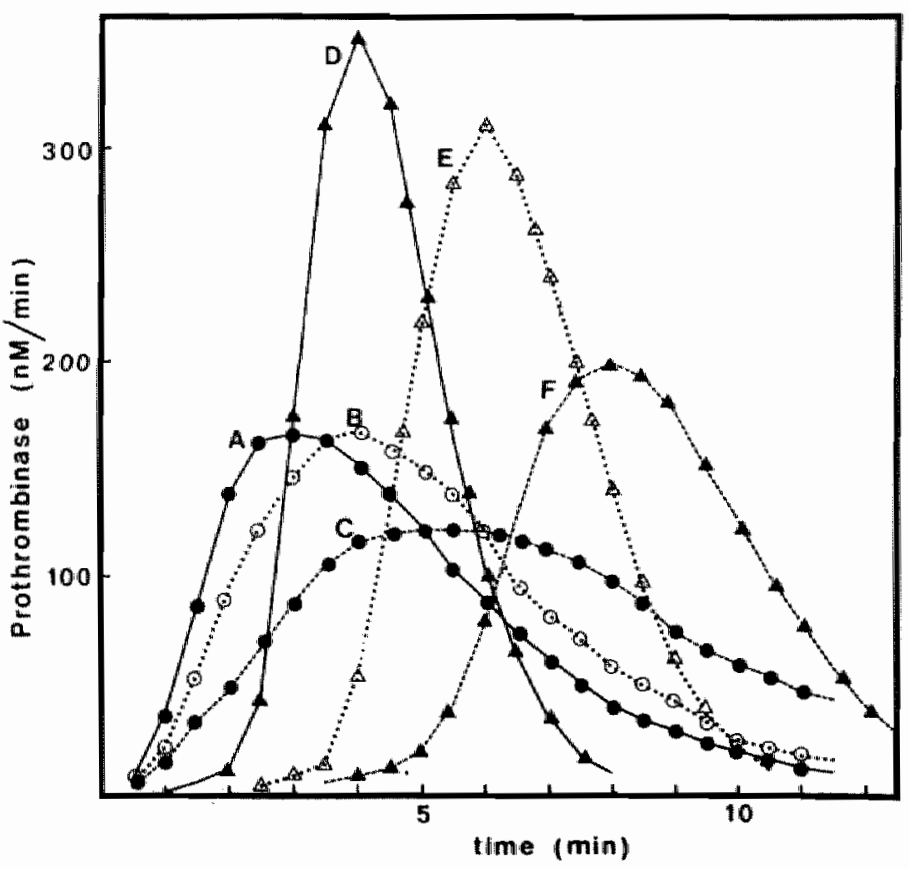

Fig. 9. THE INFLUENCE OF CY 222 ON PROTHROMBINASE ACTIVITY* 


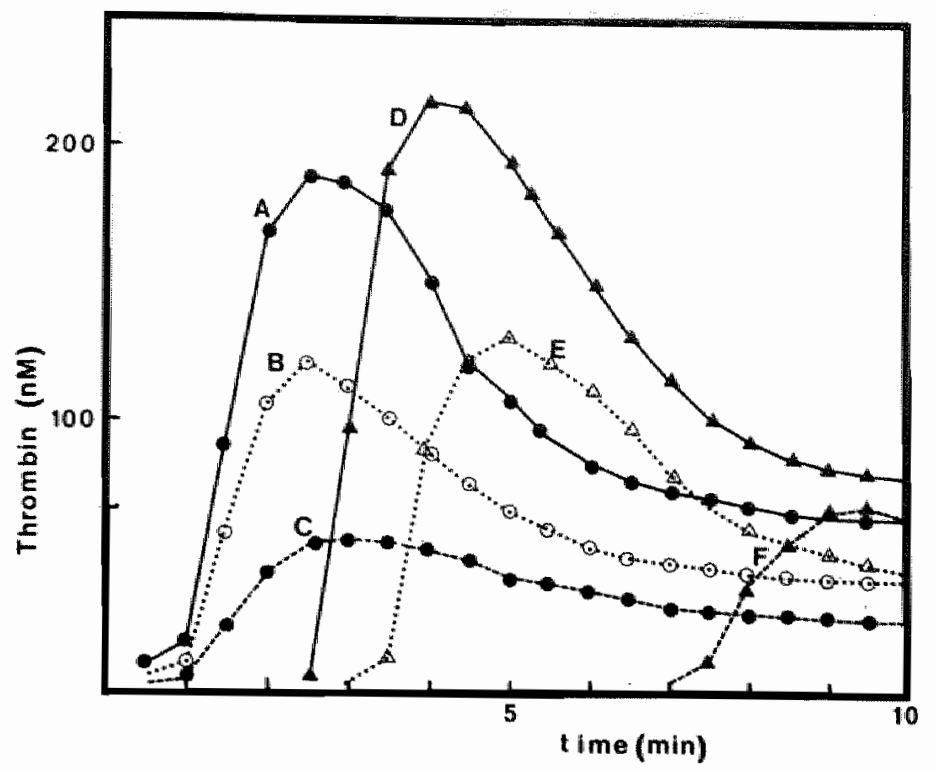

Fig. 10. THE INFLUENCE OF EMT 966 ON THROMBIN GENERATION.

extminsic: $A$ : control; $B: 0.2 \mu \mathrm{g} / \mathrm{mL} \quad \mathrm{C}: 0.6 \mu \mathrm{g} / \mathrm{mL}$ intrinsic: D: control; $E: 0.2 \mu \mathrm{g} / \mathrm{ml} F: 0.6 \mu \mathrm{g} / \mathrm{ml}$

In fig 10 the results obtained with EMT 966 are shown. This substance, like EMT 967 and pentasaccharide, has hardly any influence on the decay constant of thrombin and like in the case of pentasaccharide the inhibition of the formation of thrombin must be mainly attributed to the inhibition of prothrombinase, $i . e$. to factor $x_{a}$ inactivation or to inhibition of factor $x_{a}$ formation. PK 10169 on the other hand does influence thrombin inactivation, but not sufficiently to account completely for the observed inhibition of thrombin formation. Here prothrombinase inhibition occurs simultaneously with enhancement of AT III-dependent breakdown (figs 11 and 12). 


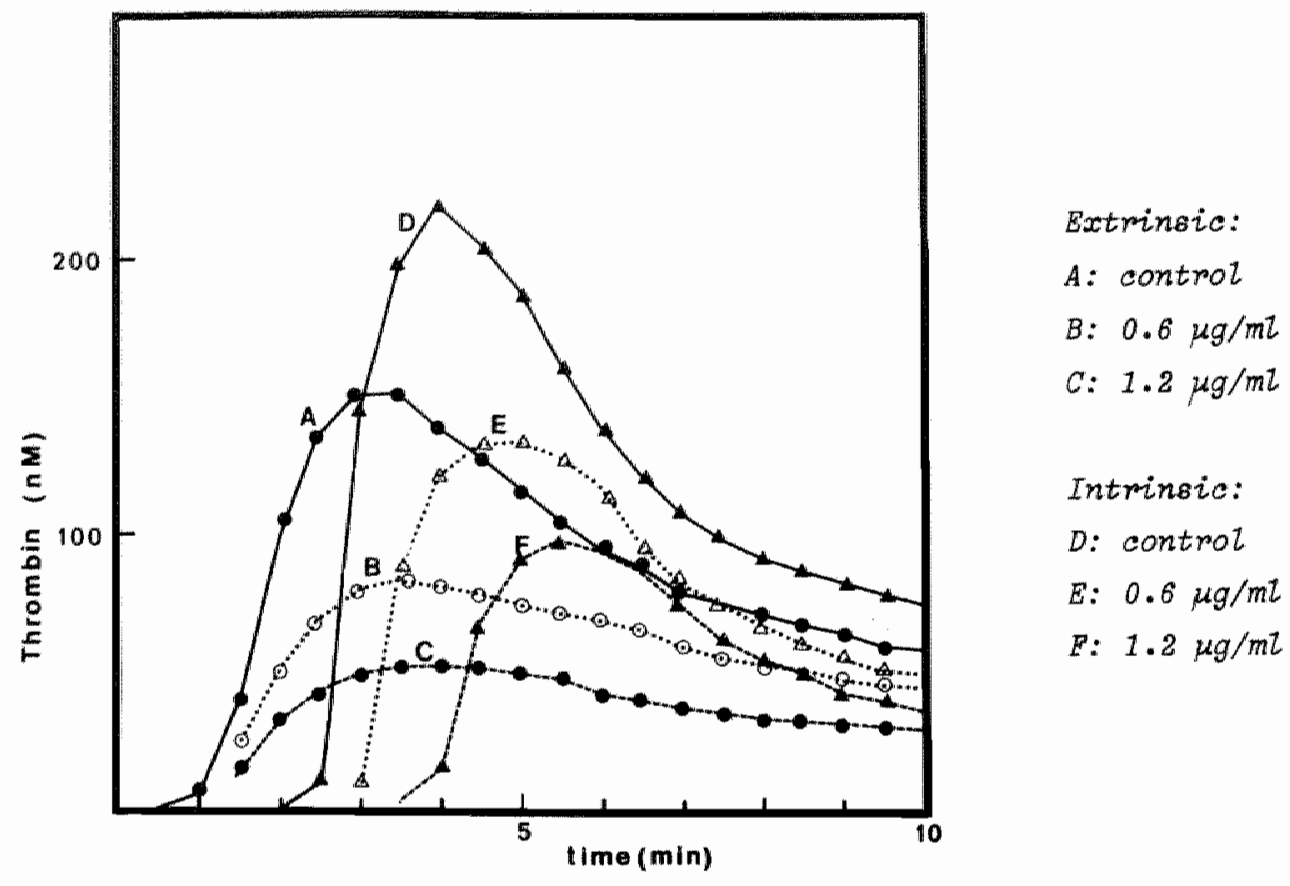

Pig. 11. THE INELUENCE OF PK 10169 ON THROMBIN GENERATION.

Extrinsic:

A: control

$B: 0.6 \mu \mathrm{g} / \mathrm{mL}$

C: $1.2 \mu \mathrm{g} / \mathrm{mt}$

Intrinaic:

D: control

E: $0.6 \mu g / m L$

F: $1.2 \mu g / m t$

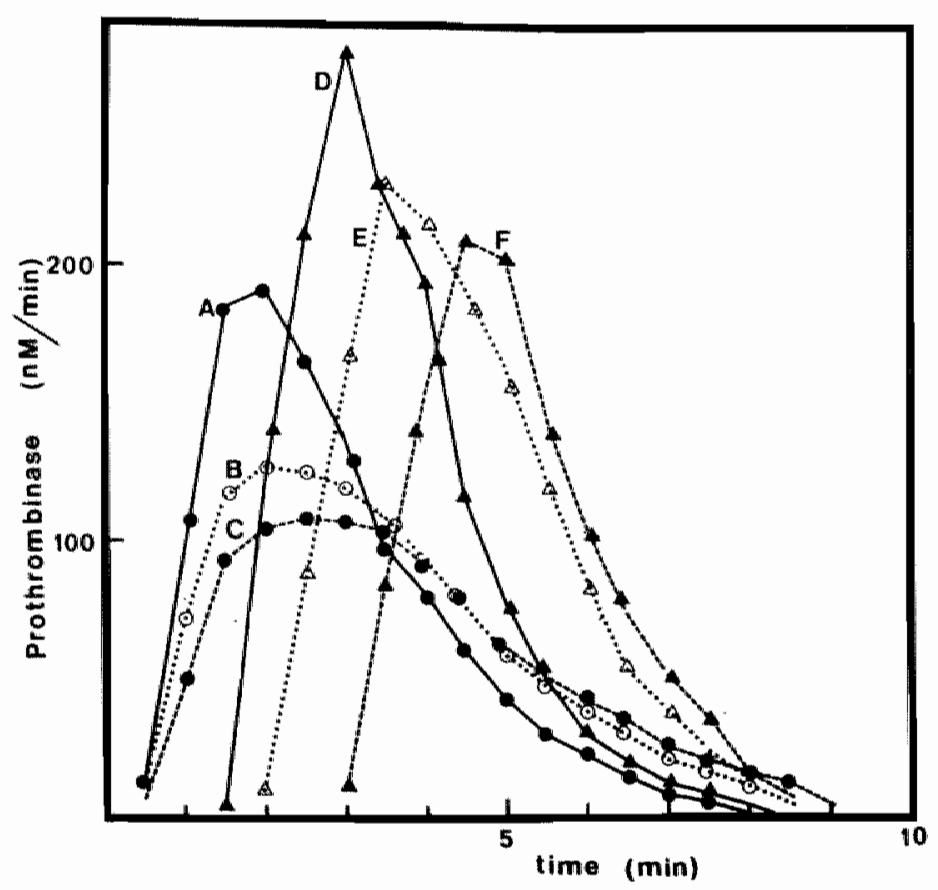

Fig. 12. THE INFLUENCE OF PK 10169 ON PROTHROMBINASE ACTIVITY. 


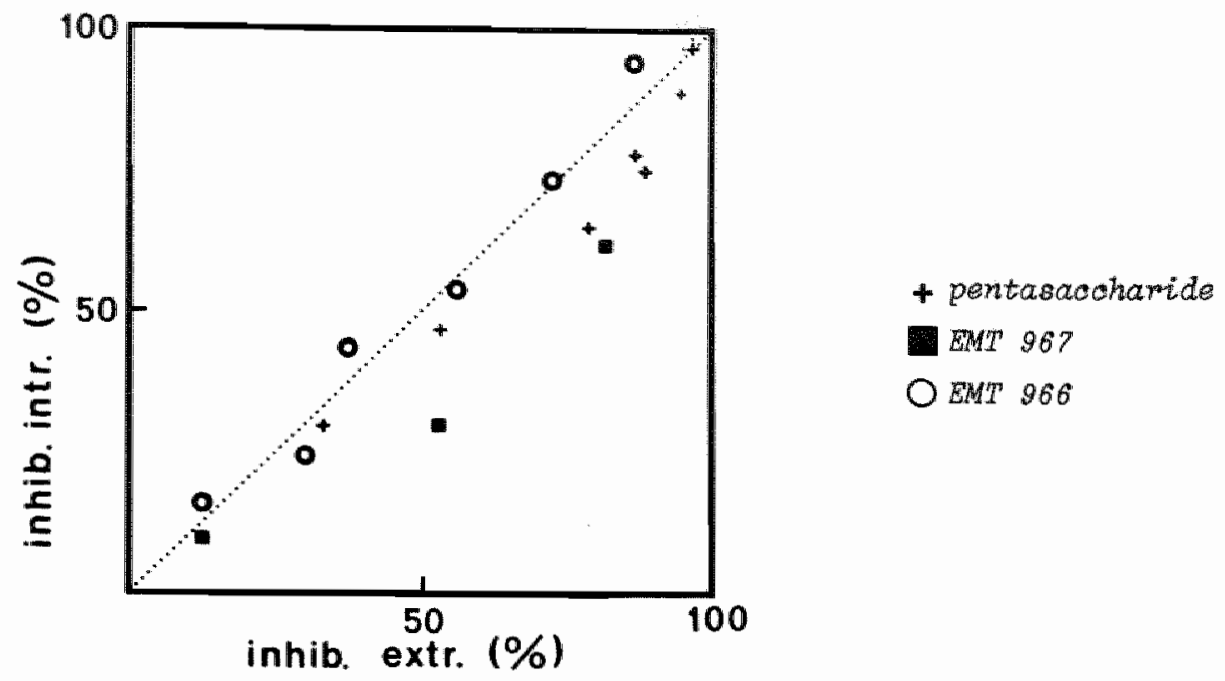

Fig. 13. COMPARISON OF INTRINSIC AND EXTRIMSTC INHIBITION WITH P TYPE HEPARTNS.

Fig. 13 compares the inhibition of intrinsic and extrinsic thrambin formation by those heparins that do not influence thrombin scavenging. EMI 966 , that is not adsorbed onto kaolin gives identical inhibition in both systems. The pentasaccharide and EMT 967, that do adsorb onto kaolin, show a somewhat lower inhibition in the intrinsic system. This we may attribute to a partial adsorption onto kaolin. We summarize that for these heparins the inhibition of the intrinsic and the extrinsic system is essentially equal. In Table IV we have summarized the results abtained with the various heparins.

In order to substantiate the impression that there exist two classes of heparin, those that inhibit prothrombinase and those that enhance thrambin breakdown, we plotted the experimentally found values of $k$ against the inhibition of prothrombinase (fig. 14) and we see that the points obtained with the two types of heparin occupy two different domains in the plain. 
SUMMARY OF THE INHIBITIONS OBSERVED

A.

\begin{tabular}{|c|c|c|c|c|c|c|c|c|c|c|}
\hline \multirow{3}{*}{$\begin{array}{l}\text { conc. } \\
\mathrm{ug} / \mathrm{m} \text { i }\end{array}$} & \multirow{2}{*}{\multicolumn{2}{|c|}{$\frac{\text { PENTA }}{\text { EXTR. INTR. }}$}} & \multicolumn{4}{|c|}{ CY 216} & \multicolumn{4}{|c|}{ CY 222} \\
\hline & & & \multicolumn{2}{|c|}{ EXTR. } & \multicolumn{2}{|c|}{ INTR. } & \multicolumn{2}{|c|}{ EXTR. } & \multicolumn{2}{|c|}{ INTR. } \\
\hline & Thr. & Thr. & Thr. & P.ase & Thr. & P.ase & Thr. & P.ase & Thr. & P.ase \\
\hline 0.05 & 33 & 30 & 8 & 5 & - & - & 0 & 0 & - & - \\
\hline 0.10 & 53 & 47 & - & - & - & - & - & - & - & - \\
\hline 0.30 & 78 & 65 & - & - & - & - & - & - & - & - \\
\hline 0.60 & 87 & 78 & - & - & - & - & 19 & 4 & - & - \\
\hline 0.90 & - & - & - & - & - & - & 22 & 0 & - & - \\
\hline 1.25 & 88 & 75 & 29 & 5 & - & 46 & 36 & 10 & 4 & - \\
\hline 2.5 & 95 & 84 & 55 & 3 & 56 & 32 & 67 & -2 & 61 & 10 \\
\hline 5 & 98 & 98 & 72 & 8 & 80 & 51 & 88 & 25 & 85 & 40 \\
\hline 10 & - & - & 87 & 2 & 92 & 63 & - & - & - & - \\
\hline
\end{tabular}

B.

\begin{tabular}{|c|c|c|c|c|c|c|c|c|}
\hline & & 966 & EMT & & & PK 10 & & \\
\hline conc. & EXT & I NTR & EXTR. & INTR. & EXT & & & TR. \\
\hline & Thr & Thr. & Thr. & Thr. & Thr. & P.ase & Thr. & P.ase \\
\hline 0.05 & 12 & 17 & - & - & 13 & 20 & 16 & 5 \\
\hline 0.10 & 29 & 24 & - & - & - & - & 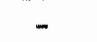 & - \\
\hline 0.20 & 37 & 44 & - & - & - & - & - & - \\
\hline 0.30 & 56 & 54 & - & - & 26 & 19 & 23 & 9 \\
\hline 0.60 & 72 & 74 & - & - & 50 & 28 & 40 & 18 \\
\hline 0.9 & - & - & - & - & 56 & 32 & 52 & 23 \\
\hline 1.2 & 86 & 95 & 11 & 10 & 68 & 42 & 58 & 26 \\
\hline & 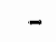 & - & 53 & 30 & 85 & 45 & 80 & 31 \\
\hline 10 & - & - & 81 & 62 & - & & - & - \\
\hline
\end{tabular}

The inhibitions are expresed in $\%$ of an unhibited control run in parallet.

Only PK10169 shows a mixed type of inhibtion. This may be due to the presence of a $\underline{P}$ type heparin and $\underline{S}$ type heparin in this product. From Table $V$ it can be seen that the presence of pentasaccharide does not inhibit the influence of standard heparin on thrombin decay. Mixtures of $S$ and $P$ type heparins therefore may show a mixed type inhibition. 
THE EFFECT OF HEPARIN ON THROMBIN DECAY IN WHOLE PLASMA IN THE PRESENCE OF PENTASACCHARIDE
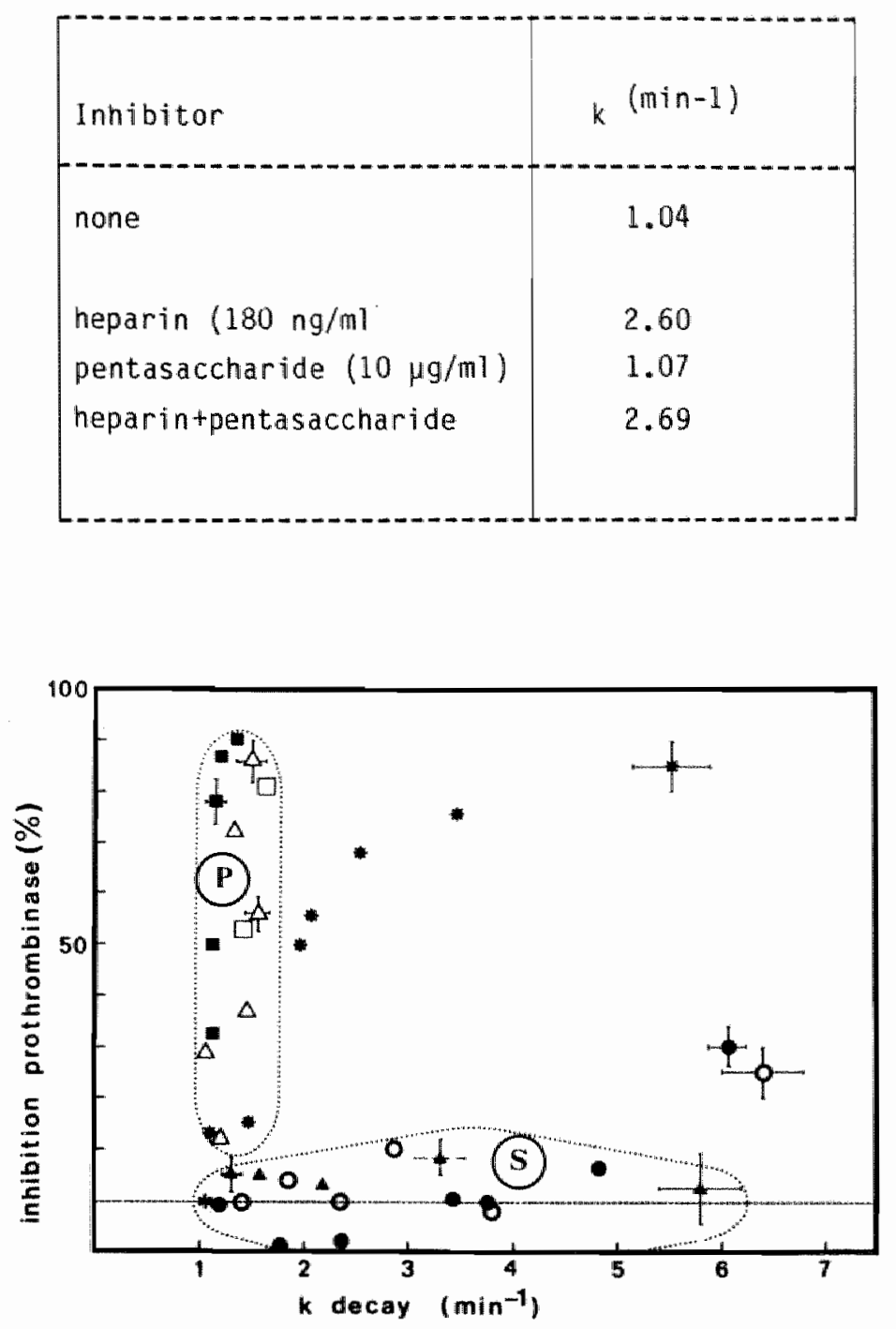

Fig. 14. RELATTON OF THE THROMBIN DECAY CONSTANT TO PROTHROMBINASE INHIBITION FOR DIFEERENT HEPARINS.

- pentasaccharide; $\triangle E M T$ 966; $\square$ EMT 967; $\$$ PK 10169

- standard hepamin; $\triangle C Y$ 216; OCY 222 
The general picture that arises from numerous publications is, that with decreasing molecular weight heparins tend to loose their activity towards thrombin but retain their activity against factor $x_{a}$; activity being defined here as the enhancement of AT III dependent inactivation. The experiments leading to this concept have been carried out either in partial purified systems containing the activated clotting factor, antithrombin III and heparin, or in plasma to which the activated clotting factor is added.

From Table III it appears that, with the notable exception of pentasaccharide, the activities of LMW heparins are always lower than those of standard heparin. For sane (CY 222, EMT 967, pentasaccharide) the ratio of the activities shifts in favour of factor $X a$ breakdown. For others (PK 10169 , CY 216, EMT 966) the ratio appears not to change. This is not in agreement with the generally accepted picture of increasing anti-factor xa activity with decreasing malecular weight. This discrepancy might be due to the experimental conditions.

In that case it seems compulsary to investigate the influence of a set of LMW heparins on the generation and the disappearance of thrombin in plasma, under conditions as near as possible to the in vivo situation. One approach is to reconstitute the physiological situtation by constructing mixtures of increasing complexity that contain the relevant reactants (i.e. clotting factors, antiproteases, phospholipids, thrombocytes) and investigating the behaviour of the system (42). Alternatively one can try and analyze the situation as it is encountered in the complex mediun of plasma, as we try to do here. The two approaches are complementary, in that a sufficient description of the system may be said to exist if the experiments with purified systems explain the phenomena observed in plasma.

In the previous chapter we already showed that classical heparin, although it reportedly has a considerable anti factor $x_{a}$ action, does hardly exert this action against factor $x_{a}$ that is incorporated in the prothrombinase of clotting plasma but acts almost entirely via the enhancement of AT III dependent thrombin decay. Here we report that also for a set of low molecular weight heparins the mode of action in plasma differs significantly from what might be expected from observations on (partially) purified systems. 
The way in which different low molecular weight heparins influence the AT III dependent inactivation of thrombin generated in plasma appears to be fundamentally different for $\mathrm{Cr} 216, \mathrm{CY} 222$ and $P K$ on the one hand and pentasaccharide, EMT 966 and EMT 967 on the other. The former group, like standard heparin, causes a clearcut, dose dependent increase of the pseudo first-order reaction constant of thrombin decay. Those of the second group, with pentasaccharide as the prime example, do not influence the inactivation of thrombin by AT III. They still do inhibit the fomation of thrombin in plasma though. Therefore they must act at a higher level in the coagulation cascade, either by increasing factor $x$ inactivation or by inhibiting factor $X$ activation or both. Standard heparin and pentasaccharide therefore act via two fundamentally different mechanisms in that the latter does not act on thrombin and the former hardly acts on prothrombinase.

From the literature one could expect other LMW heparins to take an intermediate position between standard heparin and the pentasaccharide. It came therefore as a surprise that $C Y 216$ and $C Y 222$ are essentialiy like standard heparin in their behaviour. If $90 \%$ inhibition of thrombin fomation is obtained with these products, less then $15 \%$ of it is due to inhibition of prothrombinase. We propose to call the heparins that show this mode of action $S$ type heparins, after their prototype: standard heparin. The two products EMT 966 and EMT 967 on the other hand, like pentasaccharide, inhibit thrombin fomation mainly via inhibition of prothrombin conversion, i.e. via diminution of the amount of active prothrombinase. These heparins we propose to call $\underline{p}$ type heparins, the pentasaccharide being their prototype. PK 10169 cannot easily be accredited to one of the two groups, because its action is of a mixed type.

One can raise the interesting question whether a mixed type heparin is indeed a mixture of $\mathbb{P}$ and $S$ type heparins. This question can not be answered at the monent. It is interesting to see that the subfractions of PK 10169 that are EMT 966 and EMT 967 do no longer show a mixed type inhibition. A component with $S$ type heparin activity might be lost during the fractionation. From the experiment described in Table $V$ one sees that the pure pentasaccharide does not inhibit the action of standard heparin, this leaves open the possibility that mixed type inhibitors are indeed mixtures. 
The experiment of Table $V$ shows the absence of any competition between pentasaccharlde and standard heparin at a concentration of pentasaccharide (10 $\mu \mathrm{g} / \mathrm{ml})$ that may be considered to saturate virtually all the pentasaccharide binding sites in AT III $\left(K_{d}=1 \mu g / m l\right)$ (44). This means that standard heparin either binds to AT III via a binding site different from the pentasaccharide or via multiple binding sites that have a cooperative effect, so that the pentasaccharide is chased from AT III by heparin even at concentrations that are below the $k_{d}$ of heparin.

Whether the slight prothrombinase inhibition seen with standard heparin and $C Y 222$ should be attributed to inhomogeneity of the preparation remains to be investigated.

\section{LMW heparins and the intrinsic system}

In the previous chapter we showed that a decrease of the levels of thrombin during the lag phase of intrinsic coagulation will cause retardation of explosive thrombin formation because it inhibits the positive feedback effect that thrombin has on its own formation via activation of factor VIII. As all heparins tested decrease the amount of thrombin available, we expect them all to retard the appearance of prothrombinase generated via the intrinsic pathway. In figs. 3 and $6-12$, it is seen that indeed the lag times in the intrinsic system are prolonged by $a 11$ heparins tested. The peak levels of prothrombinase found are also inhibited in all instances.

From our experiments with standard heparin (chapter III) it follows that $S$ type heparins can be expected to inhibit intrinsically fomed prothrombinase secondarily, because the low amblent thrombin concentrations retard factor VIII, activation and factor IX in absence of factor VIII is subject to AT III-dependent decay. Indeed in figs 7 and 9 and Table IV it is seen that intrinsic prothrombinase in the $S$ type heparins (CY 216 and Cy 222) is inhibited to a significantly higher extend then extrinsic prothrombinase is; $P$ type heparins show essentially the same inhibition in the intrinsic and in the extrinsic system (fig. 13). The slightly lower inhibition of the intrinsic system seen with pentasaccharide and EMT 967 finds an unstrained explanation in the partial adsorption of these substances by kaolin (see also fig. 3 ).

From fig. 5 it is clear that direct inhibition of intrinsically 
generated prothrombinase by pentasaccharide must exist because the thrombin generation provaked by ready made tenase is inhibited. Also the indirect inhibition caused be scavenging of free factor IX cannot be very important because, contrary to standard heparin, pentasaccharide allows considerable thrombin formation to be triggered by factor $I X_{a}$ alone. To what extend the final inhibition of the intrinsic system by $P$ type heparins is due to direct inhibition of factor $x_{a}$ or to indirect inhibition of factor $x_{a}$ formation remains to be investigated.

\section{Determination and standardization of LMW Heparins}

One of the main problems in the clinical application of low molecular weight heparins is the absence of a reliable test that monitors their activity in plasma(45). With heparin more then half a century of trial and error have established dosage schemes and laboratory values, like the APTT, that vary with the dosage given. We do not know if the action of heparin that prolongs the APTT the same one as its antithrombotic action, but we make use of the experimentally established correlation. In LMW heparins a dissociation is induced between the various activities of heparin and the established correlations existing in standard heparin are lost. It is an unattractive prospect that for each type of LMW heparin the save and efficient doses and the laboratory data that go with it will have to be established by trial and error, yet there are indications that this might be the case $(46,47)$. We think that the results we present here indicate a partial solution of this question.

We maintain the assumption, in common for all laboratory testing of heparin, that the effect on the clotting system is related to the therapeutic effect.

Previously we have shown that the effect of standard heparin in piasma is for all practical purposes restricted to an effect on thrombin (chapter III). Here we show that there is a class of low molecular weight heparins that in this respect does not differ from standard heparin. This means that they can be compared to a standard heparin. It stands to reason that they should be compared by a method that is based upon their action in plasma, i.e. on the decay of endogenous thrombin. Table II gives this comparison. This indicates a solution of the standardization problem for the $S$ type heparins. One has to remember that the figures cannot be completely exact 
because low concentrations of standard heparin $(<0.01 \mathrm{U} / \mathrm{ml})$ tend to influence $k$ to a lesser extend then comparable concentrations of low molecular weight $S$ type heparins do. This is alledgedly due to the binding of standard heparin by plasma proteins other then AT III. This causes a shift of the concentration - $k$ lines of 0.005 to $0.01 \mathrm{U} / \mathrm{ml}$ for heparin. This will not influence the active heparin concentrations very much. It will be shown later that this holds for platelet free plasma only. As soon as platelet factor 4 starts to play a role the situation may change dramatically.

The $P$ type heparins do not have a mechanism of action in common with the $S$ type heparins. If one wants to compare $P$ type heparins to a standard heparin one has to reckon with the fact that the result of the comparison will be arbitrary and completely dependent on the test system used. They should therefore be considered as new drugs. The best defined one of them (pentasaccharide) may be used as a standard. The range in which the standard is therapeutically active - if it is active - should be established experimentally in in vivo experiments and clinical trials, because we have no comparison with an established drug as a basis for a dosage scheme.

In vivo studies on mixed type heparins (PK 10169) might better be postponed untill the effects of $\mathbb{P}$ type heparins are known. For $S$ type heparins this is not the case as long as the test system is based on thrombin generation in plasma.

\section{Canclusions}

As long as the therapeutic action of heparin has not been demonstrated to be dissociable from its action on coagulation, its action on thrombin generation in whole plasma is probably the best guide for judging its effective concentration, and this for two reasons: a) Thrombin inhibition is the common denominator of every effective type of pharmacological antithrombotic therapy known until this mament (for a discussion on aspirin see chapter III). b) Thrombin generation in plasma comes nearer to the situation in vivo than thrombin generation in artificial systems.

In contrast to the common bel jeve at this moment there is a set of LMW heparins, viz. the $S$ type heparins (CY 216, Cr 222) that, in their action on thrombin generation in plasma, do not differ from standard heparin. 
Their favourable antithrombotic properties may be explained by a) more favourable bioavallability and other pharmacodynamic differences with classical heparin b) less important neutralization by platelet factor 4 (see chapter VI) and other physiological antiheparins $c$ ) action on other systems than blood coagulation. There exists another type of heparins, the P type heparins (Pentasaccharide, EMT 966, EMT 967) that do act primarily on prothrombinase and not directly on thrombin decay. p type heparins still have to be shown to be therapeutically active. If they are, their action may differ from that of standard heparin not only for the reasons (a,b and c) mentioned above but also because they have fundamentally different action on blood coagulation. 


\section{REFERENCES}

1. Lane, D.A., MacGregor, I.R., Michalski, R., Kakkar, V.V.: Anticoagulant activities of four unfractioned and fractioned heparins. Thromb. Res. $12,257-271,1978$

2. Barrowcliffe, T.W. Johnson, E.A. Eggleton, C.A. Kemball-Cook, G., Thomas, D.P.: Anticoagulant activities of high and low molecular weight. heparin fractions. Brit. J. Haemat. 41, 573-583, 1979

3. Andersson, L.0., Barrowcliffe, T.W., Holmer, E., Johnson, E.A., Söderstrom, G.: Molecular weight dependency of the heparin potentiated inhibition of thrombin and activated factor $x$. Effect of heparin neutralization in plasma. Thromb. Res. 15, 531-541, 1979

4. Holmer, E., Kurachi, K., Söderström, G.: The molecular-weight dependence of the rate-enhancing effect of heparin on the inhibition of thrombin, factor $X_{a}$, factor $I X_{a}$, factor $X I_{a}$, factor XII and kallikrein by ant ithrombin. Biochem. J. 193, 395-400, 1981

5. Ofosu, F.A., Modi, G., Cerskus, A.L., Hirsh, J., Blajchman, M.A.: Heparin with low affinity to antithrombin III inhibits the activation of prothrombin in nomal plasma. Thromb. Res, 28, 487-497, 1982

6. Björk, I., Lindahl, U.: Mechanism of the anticoagulant action of heparin. Mol. Cel1. Biochem. 48, 161-162, 1982

7. Sache, E. Majllard, M., Bertrand, H., Maman, M., Kunz, M., Choay, J., Fareed, J., Messmore, H.: Studies an a highly active anticoagulant fraction of high molecular weight isolated from porcine sodium heparin. Thr omb. Res. 25, 443-458, 1982

8. Thomas, D.P., Merton, R.E.: A low molecular weight heparin compared with unfractionated heparin. Thromb. Res. 28, 343-350, 1982

9. Lane, A., Denton, J., Flynn, A.M., Thunberg, L. Lindahl, U.: Anticoagulant activities of heparin oligosaccharides and their neutralization by platelet factor 4. Biochern. J. 218,725-732, 1984

10. Choay, J., Lomeau, J.C., Petitou, M., Sinay, P., Casu, B., Oreste, P. Torri, G., Gatti, G.: Anti-X active heparin oligosaccharides, Thromb. Res. $18,573-578,1980$ 
11. Choay, J., Petitou, M., Lomeau, J.C., Sinay, P., Casu, B.J., Gatti, G.: Structure-activity of relationship in heparin: a synthetic pentasaccharide with high affinity for antithrombin III and eliciting high anti-factor $x_{a}$ activity. Biochem. Biophys. Res. Comm. 116, 492-499, 1983

12. Casu, B., Oreste, P., Torri, G., Zoppetti, G., Choay, U. Lormeau, J.C., Petitou, M., Sinay, P.: The structure of heparin oligosaccharide fragments with high anti-(factor $x_{a}$ ) activity containing the minimal antithrombin III-binding sequence. Biochem. J. 197, 599-609, 1981

13. Wessler, S., Yin, T.Y.: On the antithrombotic action of heparin. Thromb. Diath. Haemorrh. 32, $71-78,1974$

14. Wessler, S.: Small doses of heparin and a new concept of hypercoagulability. Thromb. Diath. Haemorrh. 33, 81-86, 1974

15. Johnson, E.A., Kirkwood, T.B.L., Stiring, Y., Perez-Requejo, J.L., Ingram, G.I.C., Bangham, D.R., Brozovia, M.: Four heparin preparations: anti-X potentiating effect of heparin after subcutameous injection. Thromb. Haemostas. 35, 586-591, 1976

16. Kakkar, V.V., Djazaeri, B., Fok, J., Fletcher, M., Scully, M.F., Westwick, J.: Low molecular weight heparin and prevention of postoperative deep vein thrombosis. Br. Med. J. 284, 375-379, 1982

17. Fussi, F., Girolami, A., Cella, G.: Low molecular heparins and their effects in vitro, in experimental models and in humans. in: Chemistry and biology of Heparin. R.L. Lundblad e.a. edts. Elsevier/North Holland New York. 535-546, 1980

18. Thomas, D.P., Merton, R.E., Lewis, W.E., Barrowcliffe, T.W.: Studies in man and experimental animals of a low molecular weight heparin fraction. Thromb. Haemostas. (Stuttg.) 45, 214-218, 1981

19. Holmer, E., Mattson, C., Nilsson, S.: Anticoagulant and antithrombotic effects of heparin and low molecular weight heparin fragments in rabbits. Thromb. Res. 25:475-485, 1982

20. Berquist, D., Hedner, U., Sjörin, E., Holmer, E.: Anticoagulant effects of two types of molecular weight heparin administered subcutaneously. Thromb. Res. 32:381-391, 1983

21. Carter, C.J., Kelton, J.G., Hirsh, J. Cerskus, A., Santos, A.V., Gent, M.: The relationship between the hemorrhagic and antithrombotic properties of low molecular weight heparin in rabbits. Blood 59, 1239-1245, 1982 
22. ockelford, P.A., Carter, C.J., Mitchell, L., and Hirsh, d.: Discordance between the anti-x activity and the antithrombotic activity of an ultra low molecular weight heparin fraction. Thromb. Res. 28,401-409, 1982

23. Thomas, D.P., Merton, R.E., Barrowcliffe, T.W., Thunberg, L., Lindahl, U.: Effects of heparin aligosaccharides with high affinity for antithrombin III in experimental venous thrombosis. Thromb. Haemostas. (stuttg.) 47, 244-248, 1982

24. Cade, J.F., Buchanan, M.R., Boneu, B., Dckelford, P., Carter, C.J., Cerskus, A.L., Hirsh, J.: A comparison of the antithrombotic and haenorishagic effects of low molecular weight heparin fractions: the influence of the method of preparation. Thromb. Res. 35, 613-625, 1984

25. Merton, R.E., Thomas, D.P., Havercroft, S.J., Barrowcliffe, T.W., Lindahl, $ا$.: High and low affinity heparin compared with unfractionated heparin as antithrombotic drugs. Thromb. Haemostas. (Stuttg.) 51, $254-256,1984$

26. Buchanan, M.R., Boneu, B., Dfosu, F., Hirsh, J.: The relative importance of thrambin inhibition and factor $x_{a}$ inhibition to the ant thrombotic effects of heparin. B1ood 65, 198-201, 1985

27. Boneu, B., Buchanan, M.R., Cade, J.F., Van Rijn, J., Fermendez, F.F., Ofosu, F.A., and Hirsh, J.: Effects of heparin, its low molecular weight fractions and other glycosaminoglycans on thrombus growth in vivo. Thromb. Res. 40, 81-89, 1985

28. Thomas, D.P., Barrowcliffe, T.W., Curtis, A.D.: Low molecular weight heparin: A better drug? Hemostasis 16,87-92, 1986

29. Glimelius, B., Busch, $C_{*}$, Hook, M.: Binding of heparin on the surface of cultured human endathelial cells. Thromb. Res. 12, 773-782, 1978

30. Barzu, T., Molho, P., Tobelem, G., Petitou, M., Caen, J.: Binding and endocytosis of heparin by human endothelial cells in culture. B. B.A. $845,196-203,1985$

31. Turley, E. A role of glycosaminoglycans in cell adhesion and movement. Chemistry and Biology of heparin. Lundblad et al. Elsevier North Holl and, New York, 121-131, 1981

32. Besterman, E.M.M., Gillet, M.P.T. Heparin effects on plasma lysoclecithin formation and platelet aggregation. Artherosclerosis 17, 503-513, 1973 
33. Salzman, E.W., Rosenberg, R.D., Smith, M.H., Lindon, U.N., Favreau, L.: Effect of heparin and heparin fractions on platelet aggregation. J. Clin. Invest. $65,64-72,1980$

34. Vairel, E.G., Bouty-Boye, H., Toulemonde, F., Doutremepuich, C., Marsh, N.A., Gaffney, P.J.: Heparin and a low molecular weight fraction enhances thrombalysis and by this pathway exercises a protective effect against thrombosis. Thromb. Res. 30, 219-224, 1983

35. Bounameaux, H., Lijnen, H.R., Hellemans, H., Verstraete, M.: Effect of standard and low molecular weight heparin fractions on fibrinolysis and platelet aggregation in patients undergoing hysterectomy. Thromb. Haemostas. (Stuttg.) 55, 298, 1986

36. Harenberg, J., Schwarz, F., Zimmerman, R.: Severe heparin-induced immune thrombocytopenia and thrombosis anticoagulated effectively with a new heparin analog. Thromb. Haemostas. (Stuttg.) 50, 64, 1983 (Abstract)

37. Miletich, J.P., Jackson, C.M., Majerus, P.W.: Properties of the factor $X_{a}$ binding site on human platelets. J. Biol. Chem. 253, 6908-6916, 1978 38. Rosing, J. Tans, G., Govers-Riemslag, J.W.P., Zwaal, R.F.A., Hemker, H.C. The role of phospholipid and factor $V_{a}$ in the prothrombinase complex. J. Biol. Chem. 255, 274-283, 1980

39. Fujikawa, K., Legaz, M.E., Davie, E.W. Bovine factor X, (Stuart Factor). Mechanism of activation by a protein from Russell's viper venam. Biochemistry 11, 4892-4899, 1972

40. Fujikawa, K., Thompson, A.R., Legaz, M.E., Meyer, R.G., Davie, E.W.: Isolation and characterization of bovine factor IX. (Christmas Factor). Biochemistry, 12, 4938-4945, 1973

41. Fujikawa, K., Legaz, M.E., Kato, H., Davie, E.W.: The mechanism of activation of bovine factor IX (Christmas factor) by bovine factor $\mathrm{XI}_{\mathrm{a}}$ (activated plasma thromboplastin antecedent). Biochemistry, 13 , $4508-4516,1974$

42. Lindhout, T., Baruch, D., Schoen, P., Franssen, J., Hemker, H.C. Thrombin generation and inactivation in the presence of antithrombin III and heparin. Biochemistry. 25, 5962-5969, 1986

43. Soons, H., Janssen-Claessen, T., Hemker, H.C., Tans, G.: The effect of platelets in the activation of human blood coagulation Factor IX by Factor $X I_{a}$. B1ood, 68, 140-148, 1986 
44. Lindhout, T., Schoen, P.: Personal comunication.

45. Bara, L., Samama, $M_{x}$ : The need for standardization of low molecular weight heparin (LMWH). Thromb. Haemostas. 56, 418, 1986

46. Schmitz-Huebner, U., Bünte, H., Freise, G., Reers, B., Rüschemeyer, C., Scherer, R., Schulte, H., van de Loo, J.: Clinical efficacy of low molecular weight heparin in postoperative thrombosis prophylaxis. Klin. Wochenschr. 62, 349-353, 1984

47. Koller, M., Schoch, U., Buchmann, P., Largiadèr, F., Felten von, A., Frick, P.G.: Low molecular weight heparin (KABI2165) as thromboprophylaxis in elective visceral surgery. A randomized, double-blind study versus unfractionated heparin. Thromb. Haemostas. 56, 243-246, 1986

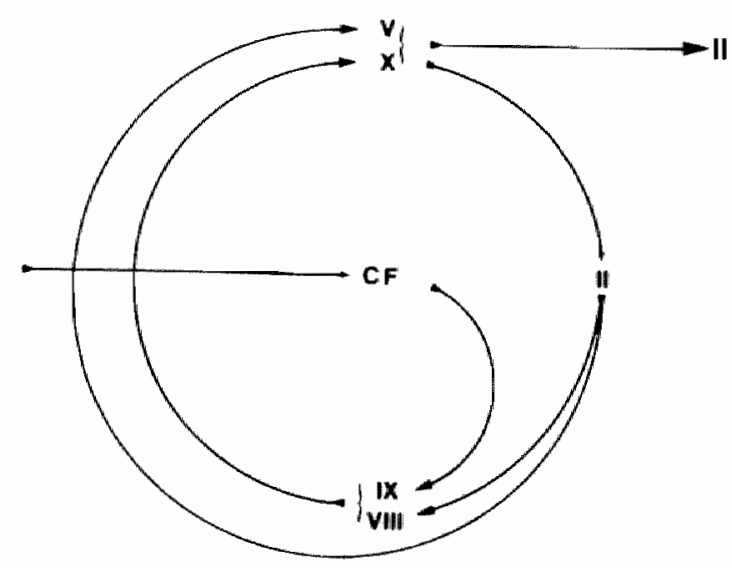

The APTT pettway 


\section{Demonstration of the Josso pathway}

\section{Summary}

Pentosan potysulphate (PPS) when added to normal plasma in the concentration range of $0-8 \mu \mathrm{g} / \mathrm{ml}$ induces a dose dependent increase of the pseudo first order decay constant of endogenous thrombin, 1 Mg of PPS baing equivatent to $0.045 \mathrm{Hg}$ of heparin. Contramy to heparin thïs action is partly $(\sim 65 \%)$ dependent upon AT III and partzy ( 35\%) upon another plasmatic cofactom, in all probability heparin cofactor II (HC II).

In nomal plasma PPS causes an inhibition of both extminsic and intminsic prothrombinase fomation. Only in the intminsic system an indrease of the lag time of prothrombinxse appearance is abserved, in atl probabiLity due to imhibition by PPS of the activation of factor VIII by thrombin.

The inhibition of extrinsic prothrombinase formation by PPS increases with progressive dilutions of thromboplastin and is not seen in hamophiliac $A$ or $B$ plasmas. This indicates a factor VITI and IX depentent process in extrinsic coagulation the Josso pathway.

Besides its imhibitory ation PPS, causes an whexplximed thorexae of prothrombinase under certain conditions. This, together with the fact that one cannot abtain complete inhibition of factor VIII activation with PPS makes that one annot use this inhibitor as a means to quantitate the contribution of the Josso pathway to extrinato prothrominase fomatiom. 
Pentosan polysulphate (PPS, SP54, PZ68, Hémoclar ) is a semi-synthetic heparin like material. The natural material, obtained from beechwood is a poly 0-xylose with lateral uronic acid side chains, sulphonated to a mean of 1.9 sulphate group per saccharide, with a mean molecular weight of 4500 daltons (see ref. 1,2 for further detalls on the structure). Its mode of action on blood coagulation is composite. One recognizes an antithrombin action, not unlike that of heparin and an AT III-independent action, the precise mechanism of which is still a matter of debate. Fischer et al. found PPS to inhibit intrinsic factor $X$ activation and located the site of inhibition at the level of factor $I X_{a}(3)$. Wagenvoord et al. found that PPS inhibits the activation of factor VIII by thrombin (4). Scully and kakkar showed that PPS acts on thrombin via the potentiation of heparin cofactor II (5), that the material is not homogeneous and that fractions separated according to molecular weight exhibit a different spectrum of activities (6).

In this chapter we quantitated the effect of PPS on the decay of endogenous thrombin in plasma. We tried to analyze the cofactor dependancy of the antithrombin action and to locate the inhibition of the intrinsic pathway. We used PPS as a tool to demonstrate the activity of the factor IX and VII dependent pathway in thromboplastin triggered thrombin formation: the Josso pathway.

\section{Materials and Methods}

Pentosan polysulphate (PPS, Hëmoclar ${ }^{R}$ ) was abtained from Clin Midy, Toulouse, France). All other materials and methods are described in the previous chapters.

Haemophiliac plasmas A or B were prepared as the normal plasma described in chapter II. 
We determined the influence of PPS on the decay of thrombin generated in normal plasma. From fig. 1 it is clear that there is a dose dependent antithrombin action. $4 \mu \mathrm{g} / \mathrm{ml}$ of PPS is roughly equivalent to $0.03 \mathrm{U} / \mathrm{ml}$ $(0.18 \mu \mathrm{g} / \mathrm{ml})$ of standard heparin.

He then investigated the decay of thrombin in plasma that, by immune adsorption, was specifically depleted of AT III and $\alpha 2 M$ and to an euglobulin fraction of normal plasma. This fraction was for all practical purposes devoid of thrombin inhibitors, because the thrombin activity elicited by recalcification in the presence of thromboplastin ( $1: 240$, final concentration) showed a decay constant of $<0.01$ even in the presence of heparin or P.P.S. The prothrombin concentration of the euglobut in preparation was adjusted to $2 \mu M$. In one series of experiments AT III was added to the preparation at a final concentration of $3 \mu M$. The results are summarized in Table I.



Fig. 1. THE CONCENTRATTON DEPENDENCY FOR PPS OF THE DECAY CONSTANT OF ENDOGENOUS THROMBIN.

It is seen that the antithrombin activity of PPS is completely cofactor dependent (lane D). Comparison of lanes $B$ and $C$ indicates that roughly $1 / 3$ of the action of PPS is dependent upon a non AT III, non $\alpha 2$ M plasma factor in all probability Heparin Cofactor II. Comparison between lanes A and $E$ suggests that roughly $2 / 3$ are dependent upon AT III. 
THE INFLUENCE OF PPS ON THROMBIN BREAKDOWN IN THE PRESENCE DF VARIDUS THROMBIN SCAVENGING PROTEINS

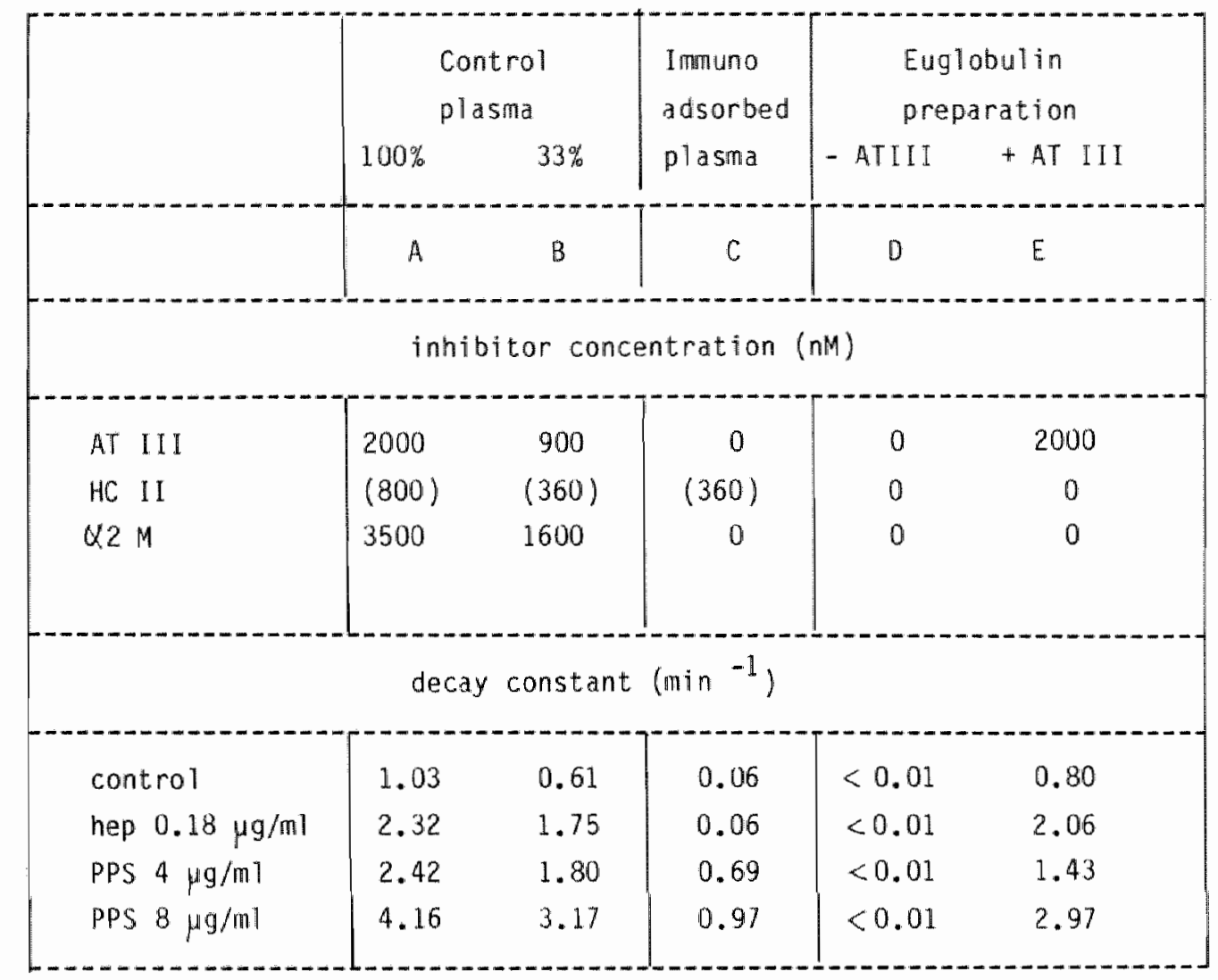

The inmumo adsorbed plasma had a protein content of $32 \%$ of the originat control plasma. We therefore used two controls, nomat plasma (Lane A) and 1 and 3 diluted normal plasma (lane B). The H.C. II concentrations given are based upon the assumptions that the undiluted nomal plasma contains $800 \mathrm{nM}$.

It must be stressed that these are only semiquantitative estimates and that further experiments will be necessary to obtain a more exact quantitation. 


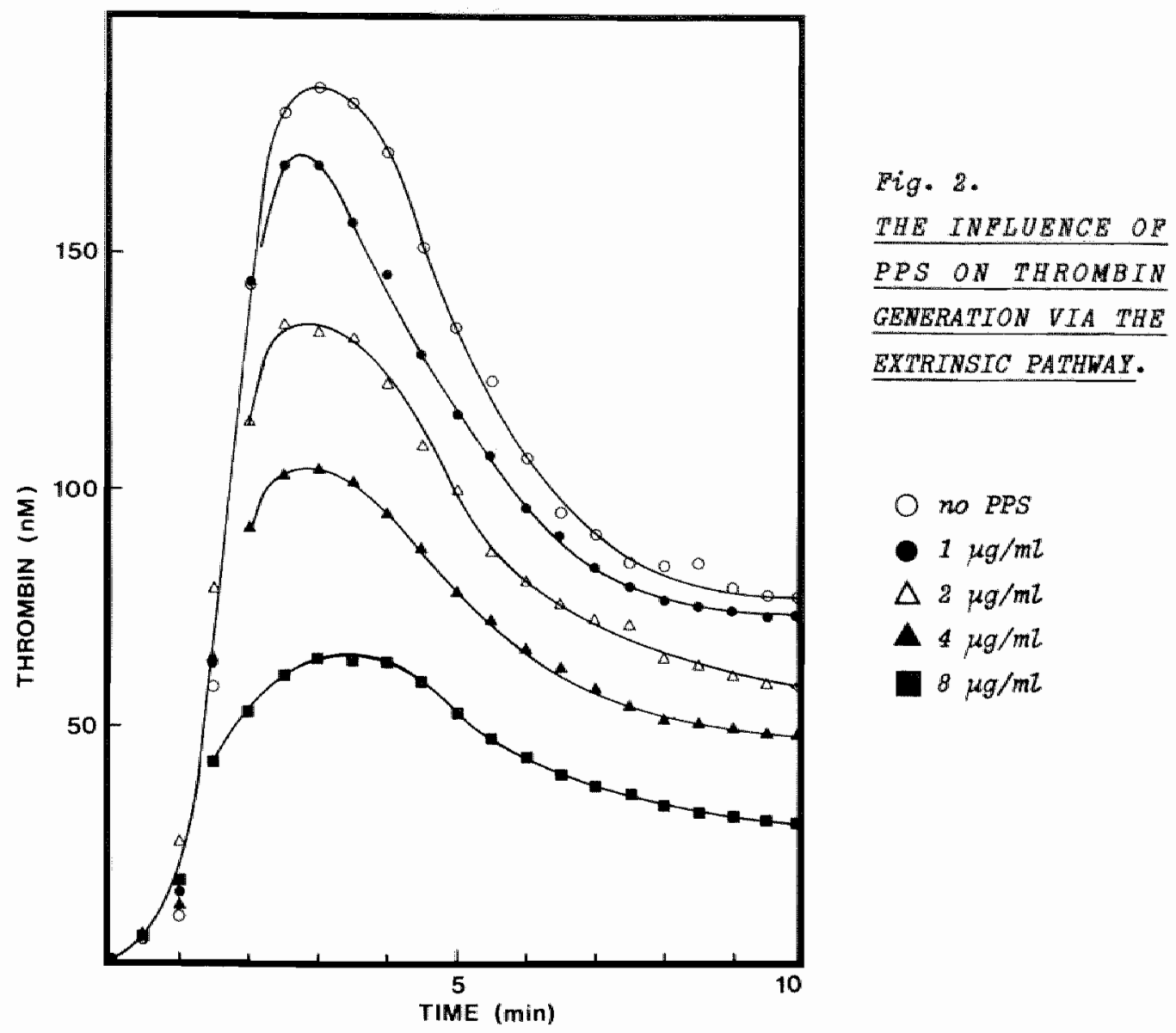

The influence of PPS on the extrinsic system is depicted in fig. 2 and summarized in fig. 4. There is a dose dependent inhibition of the velocity of thrombin formation that must be largely attributed to an increased thrombin decay, because the prothrombinase activity is inhibited to a limited extent only (fig. 4). In the concentration range of $2-8 \mu \mathrm{g} / \mathrm{ml}$ the inhibition of prothrombinase seems to level off at a maximum of about 20\%

In the intrinsic system, triggered with kaolin, PPS inhibits to the same extend as in the extrinsic system and a retardation of thrombin formation is observed as well (figs. 3 and 4 ). 


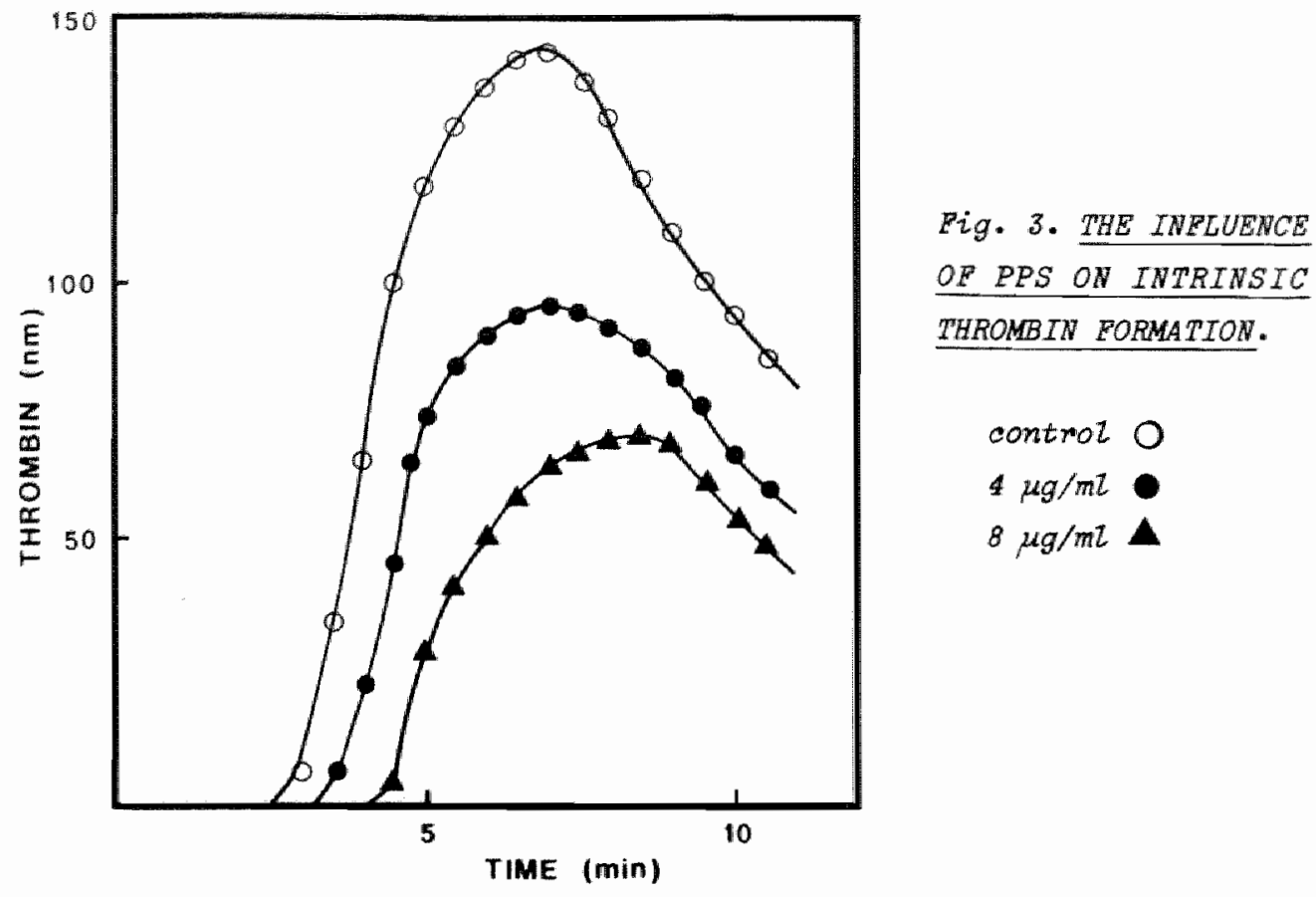

Pig. 4. THE INHIBITION OF THROMBIN GENERATION VELOCITY AND PROTHROMBINASE ACTIVITY BY PPS.

thrombin genenation velocity extminsic o prothrombinase extmingio

$\Delta$ thrombin genemation velocity intminete $\triangle$ prothrombinase intrineic.

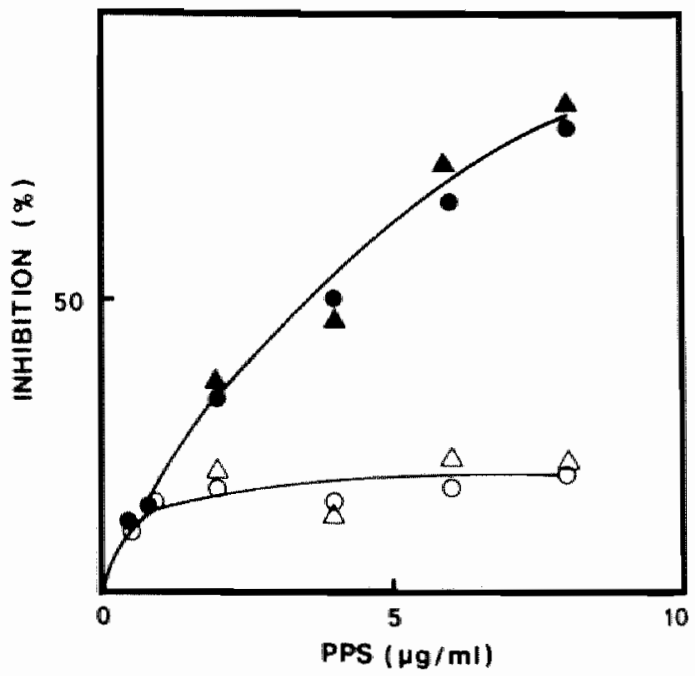

The increase in the lag time before thrombin formation starts must, as in the case of heparin, be explained by the time necessary to form the temase complex, because it is not seen when thrombin formation is triggered with the complete tenase complex (results not shown). On bas is of the 


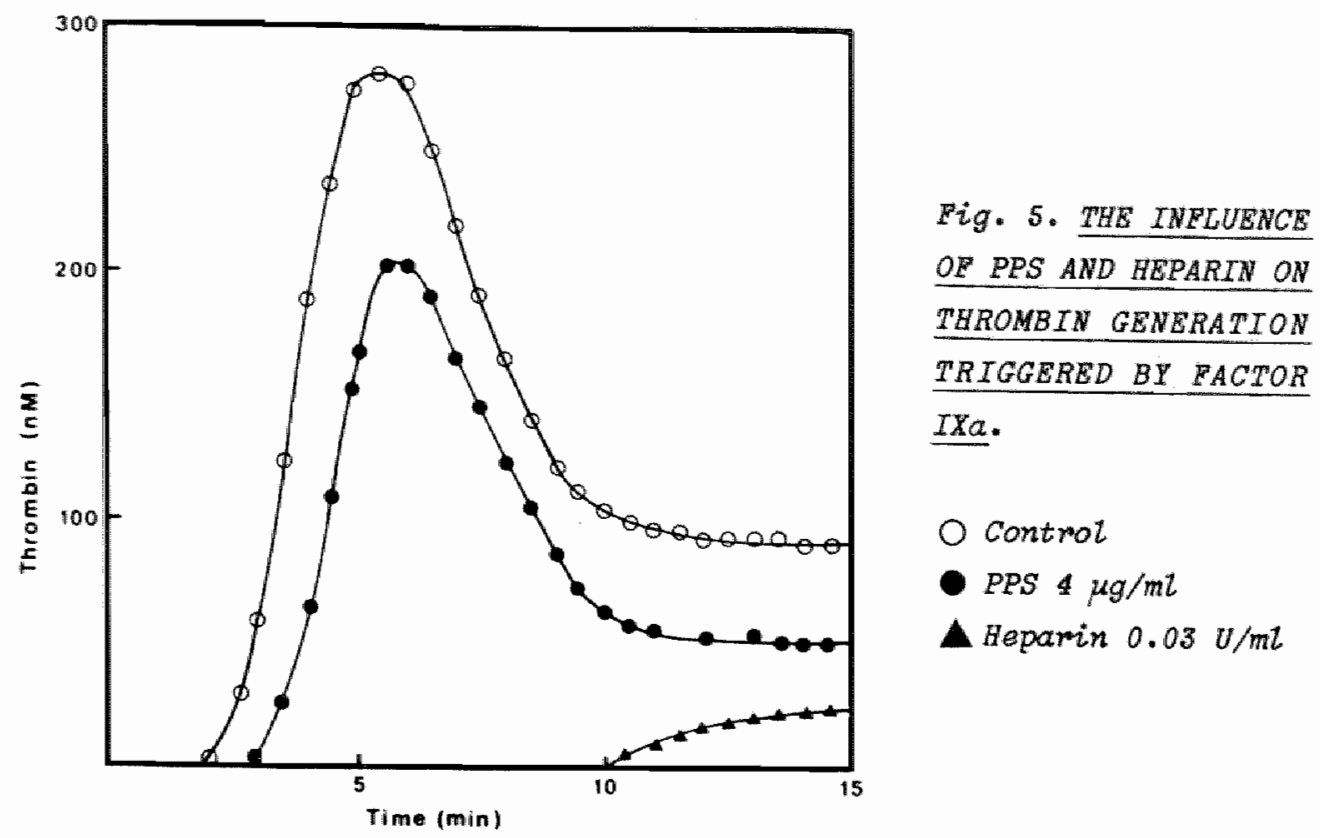

experiments of Wagenvoord et a1., (ref. 4) we expect the lag time to be caused by inhibition of factor WII activation. It might however, as in the case of heparin (chapter III), also be brought about by inactivation of factor $I X_{a}$. From fig. 5 it becomes clear that PPS does inhibit factor IX triggered thrombin formation only to an extent that can be explained by its anti-thrombin action. The increase of the lag time thus can be attributed to the dual effect of PPS on the activation of factor VIII: a) less thrombin is available because of its increased decay and b) the available thrombin will not properly activate factor VIII.

We thought that this action of PPS on the activation of factor VII might be used as a means to inhibit the Josso 10op, i.e. the indirect activation of factor $x$ in the extrinsic system by tissue factor activated factor IX, together with factor VIII. The factor IX generated by the action of factor VII will not be able to function if the activation of factor VIII is inhibited. One therefore expects that the inhibition of extrinsic prothrombinase formation by PPS will be primarily due to the inhibition of the VII $\rightarrow($ VIII \& IX) $\rightarrow X$ pathway. Dne also expects that this route will become more important when the concentration of tissue factor decreases (see also the introduction). 


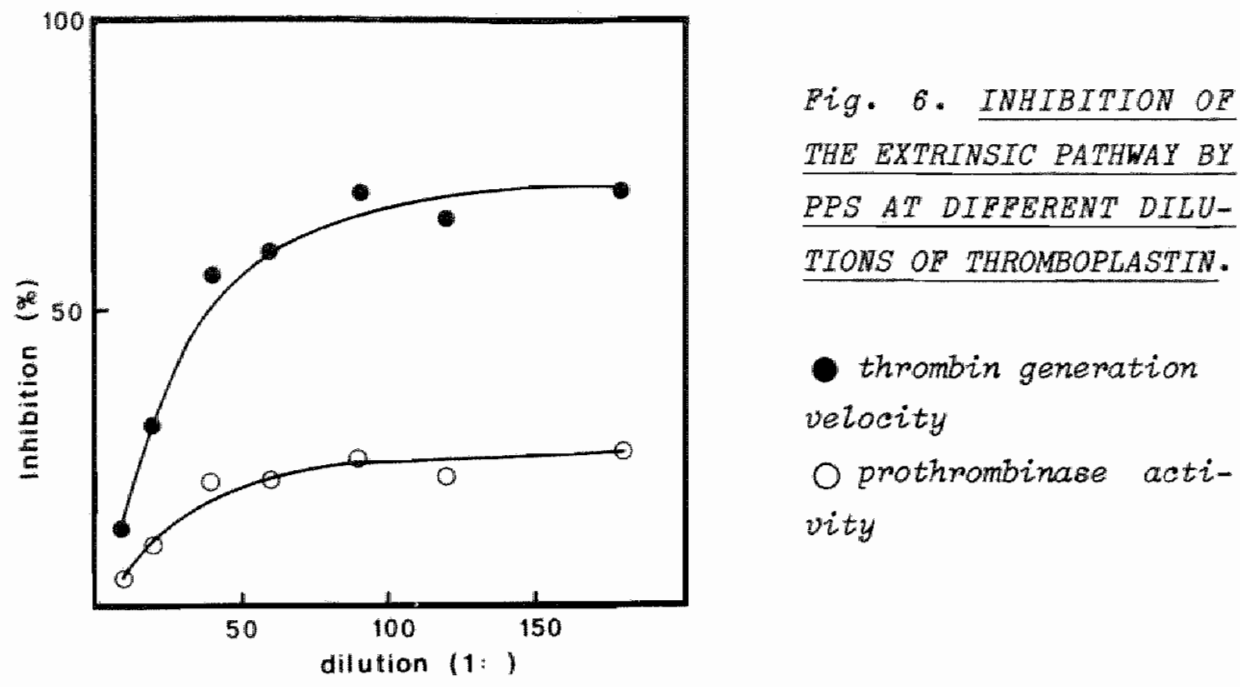

Indeed the extend of inhibition by PPS could be shown to be dependent upon the concentration of thromboplastin used (fig. 6).

It is tempting to interprete the upper limit of inhibition of prothrombinase seen in fig. $6(\sim 20 \%)$ as the maximum contribution of the Josso pathway to thramboplastin triggered factor $x$ activation. This however, is not justified for two reasons. In the first place we can see from the experiments in the absence of tissue thrombopllastin (figs. 3 and 4 ) that the inhibition of factor VIII activation does lead to a retardation of thrombin fomation but that the inhibiting effect on the peak prothrombinase activity is partiy overcome in the course of time. We therefore can expect that the inhibition of the Josso pathway in the experiments of fig. 6 will be progressively less important as the experiment proceeds. This precludes exact quantitation of the contribution of the F.IX -VIII $_{a}$ complex to factor activation.

The second reason is more intriguing. Reasoning that in the absence of factor VIII or IX the Josso pathway will not operate, we did control experinents in haemophiliac plasma (Table II). To our surprise here the addition of PPS caused an increase of prothrombinase activity. The same effect, be it quantitatively less important, had already been observed on normal plasma with heparin and some LMW heparins (chapters III and IV). Indeed with heparin in haemophiliac plasma it was also observed (Table II). 


\section{TABLE II}

THE EFFECT OF PPS AND HEPARIN ON THE EXTRINSIC PATHWAY

IN HAEMOPHILIAC PLASMAS

\begin{tabular}{|c|c|c|c|c|}
\hline \multirow{2}{*}{ Plasma } & \multicolumn{2}{|c|}{ Heparin $0.03 \mathrm{U} / \mathrm{ml}$} & \multicolumn{2}{|c|}{ PPS $4 \mu g / m 1$} \\
\hline & thromb in & pr. ase & thromb & pr. ase \\
\hline Norma 1 & -38 & +9 & -50 & -16 \\
\hline Haem. A & $-\quad 33$ & $+\quad 32$ & -33 & +36 \\
\hline Haem. B & $-\quad 31$ & * 34 & -40 & +17 \\
\hline
\end{tabular}

Activation $(+)$ or inhibition (-) are expressed in percent relative to the same plasma without inhibitor.

At the moment we cannot explain this phenomenon. It is clear, however, that any inhibition by PPS observed in normal plasma must be the sum of an inhibition and an activation. This aborts further attempts to quantitate the Josso pathway by the use of PPS. In an attempt to make a preliminary guess we may consider the $20 \%$ of intribition (fig. 6) as the lower linit of the contribution of the Josso pathhway to the peak prothrombinase formation at thromboplastin dilutions of $1: 40$ or higher.

\section{Discussion}

Most authors agree that the activation of factor IX by factor VII and tissue thromboplastin is possible and probably plays a role when thrombin generation is triggered by tissue thromboplastin. From the existing data in the literature it cannot be decided whether the pathway via factor IX is an important means of factor $X$ activation in vivo or not (see chapter I). To approach this problem we attempted to inhibit the contribution of the factor $I X$ and VIII dependent extrinsic factor $X$ activation with PPS. 
We first analyzed the antithrombin effect of PPS in nomal plasma. It appeared that PPS has a completely cofactor-dependent antithrombin action, $1 \mu \mathrm{g} / \mathrm{ml}$ of PPS being equiwalent to about $0.045 \mu \mathrm{g} / \mathrm{ml}$ of standard heparin. Both AT III and HCII can act as a cofactor. We estimate that roughly $1 / 3$ of the antithrombin effect is mediated wia HCII. Qualitatively this is in accordance with Scully et al, but quantitatively it is not, as they expect $>80 \%$ of the antithrombin action to be mediated by HCII $(5,6)$.

Once the antithrombin action of PPS had been quantitated, we could calculate its effect on prothrombinase. Dur experiments (fig. 5) do not support the idea that PPS inhibits factor $I X_{a}$ or the factor IX $X_{a}$ phospholipid interaction (3) but rather confinm the mechanism suggested by Wagenvoord i.e. inhibition of the activation of factor VIII by thrombin (4). One therefore expects that it can specifically inhibit the factors VIII-IX dependent pathway. From fig. 3 and 4 it appears, however, that in plasma the extent of inhibition obtained in both pathways is approximately equal. This is an unexpected result, because the intrinsic pathway is exclusively factor WIII dependent whereas the extrinsic pathway is not. The differences between the effect on the two pathways appears to reside rather in the fact that PPS influences the lag time of thrombin fomation in the intrinsic system and not in the extrinsic system.

We may attempt to explain the lack of inhibition of the intrinsic pathway by considering the quantitative aspects of thrombin conversion in our experiments. The maximal prothrombinase activity observed is in the order of $300 \mathrm{mM} \mathrm{min}{ }^{-1}$. The turnover number of factor $x$ in the presence of phospholipid and factor $V_{a}$ is about $2000 \mathrm{~min}^{-1}$ (7). This means that in our system the maximum concentration of active prothrombinase is in the order of $0.2 \mathrm{nM}$. The required amount of factor $x_{a}$ is formed in the course of about $1 \mathrm{~min}$, $1 . e$. In the ascending branch of the prothrombinase curve. The turnover number of the complete factor $x$ activating enzyme is between 200 and $500 \mathrm{~min}^{-1}$ (8). This means that the amount of active factor $I_{a}$ and VIII necessary to obtain the activity observed will be about 1 pM. This is a small fraction of the factor VIII in plasma $(0.5$ - 1nM). Moreover, unlike heparin, PPS will not enhance factor $\mathbb{I X}$ a inactivation (fig. 5 ).

Inhibition of the activation of factor VIII therefore has to be practically complete in order to prevent the eventual generation of a sufficient amount of factor VII a. Incomplete inhibition will cause a 
retardation of the production of "tenase", but will hardly be able to prevent that, in the course of time, enough tenase generates to ensure the production of sufficient amounts of prothrombinase. Complete inhibition of factor VIII activation by PPS is impossible without affecting factor $V$ activation (4) and without inducing an unconveniently rapid decay of thrombin. This leads to the conclusion that PPS in applicable concentrations cannot block the Josso pathway but only can retard its action. This means that we cannot use PPS to quantitate the contribution of the Josso pathway. Yet we can arrive at a qualitative appreciation.

\section{Conclusions}

The following evidence can be brought farward in favour af the operation of the Josso pathway in clotting plasma: a) The inhibition of the extrinsic pathway by PPS increases with a decrease of the thromboplastin concentration. At high thromboplastin concentrations the activity of the direct pathway will provide the necessary prothrombinase directly, as shown by the fact that haemophiliacs have a nomal quick time. At low concentrations of thromboplastin the direct pathway will be slaw and factor $I X_{a}$ will, with time, obtain an increasingly large share in the activation of factor $x$. b) The inhibition of the extrinsic prothrombinase by PPS is absent in haemophiliac ( $A$ and $B$ ) plasma. Further inhibition by PPS will not matter because in haemophiliac plasma the Josso pathway is already completely blocked.

It came as a surprise that, in haemophiliac plasma, pPs causes an activation of prothrombinase. This effect is not specific for PPS because it is also seen with heparin (Table II). In fact it can sometimes be observed with low concentrations of $S$ type heparins added to nomal plasma (see also chapter III and IV) but its significance was difficult to asses there. In haemophiliac plasma there is no doubt as to its existence. We were not yet able to elucidate the mechanism behind this phemomenon. The lack of free thrombin is a common denominator of the experimental conditions in which the actiwation is observed. Dur first guess for a working hypothesis would be a feedback inhibition of thrombin on prothrombinase activity. 
Anyhow, the fact that PPS causes activation when factors VIII and $\mathbb{I}$ cannot play a role, stresses the fact that the factor VIII dependent pathway is inhibited by PPS in normal plasma and suggests that it is underestimated.

We conclude that our experiments support the existence of the Josso pathway in normal plasma and suggest that it contributes more then $20 \%$ of the total prothrombinase activity at thromboplastin dilutions superior to $1: 40$. 


\section{REFERENCES}

1. Raveux, R., Gros, P., Briot, M.: Etudes des polyesters sulfuriques des $x y l a n e s$ naturels extraits du bois de hetre $I$ Composition et structure génèrale. Bull. Soc. Chim. Fr. 33, 2744-2749, 1966

2. Maffrand, J.P. Gachon, M., Bayol, A.: Comparison of structures of pentosan polysulphate and other sulphated polysaccharides. Premier Symposium International, Polysulfates de Pentosane. Clin-Midy, Paris, June 1985

3. Fischer, A.M., Barrowcliffe, T.W., Thomas, D.P.: A comparison of pentosan polysulphate (SP54) and heparin I. Mechanism of action on blood coagulation. Thromb. Heamostas. (Stuttg.) 47, 104-108, 1982

4. Wagenvoord, R., Hendrix, H., Soria, C., Hemker, H,C.: Detemination af the non antithrombin III-dependent inhibition sites of pentosan polysulphate in blood coagulation. In press.

5. Scully, M.F., Kakkar, V.V.: Identification of heparin cofactor II as the principal plasma cofactor for the antithrombin activity of pentosan polysullphate (SP54) Thromb. Res. 36, 187-194, 1984

6. Scully, M.F., Ellis, E., Kakkar, V.V.: Pentosan polysulphate: Activation of heparin cofactor II or antithrombin III according to molecular weight fractionation. Thromb. Res, 41, 489-499, 1986

7. Rosing, J., Tans, G., Govers-Riemslag, J.W.P., Zwaal, R.F.A., Henker, H.C.: The role of phospholipids and factor $V_{a}$ in the prothrombinase complex. J. Biol. Chem., 255, 274-283, 1980

8. Van Dieijen, G., Tans, G., Rosing, J., Henker, H.C.: The role of phospholipid and Factor VIII in the actiwation of bovine Factor $X$. $J$. Biol. Chem. 256, 3433-3443, 1981 


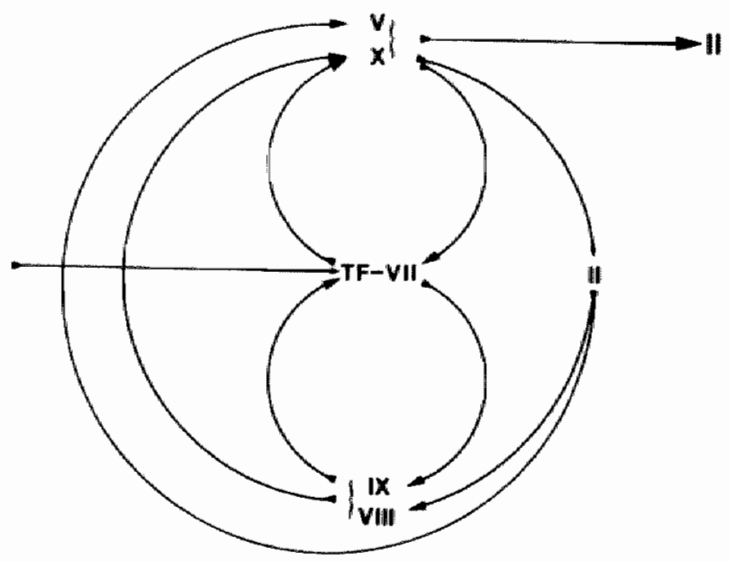

A clotting scheme for 1987 


\section{THE COOPERATIVE EFFECT OF TISSUE FACTOR AND THROMBOCYTES ON THROMBIN GENERATION; A COMMON SITE DF ACTION FOR HEPARIN, LOW MOLECULAR WEIGHT HEPARINS AND OTHER ANTITHROMBOTIC DRUGS?}

\section{Summar"y}

Amounte of tissue factor that do not stimulate thrombin generation in platelet poor plasma, were shown to advance by about 4 min the explosive formation of 200-300 nM of thrombin in the presence of blood platelets. This effect is inhibited by the specific thrombin inhibitor hirulin and it is mimicked by adding low amounts $(\sim 5 \mathrm{nM})$ of thrombin to platelet mich plasma. It is mediated by small anounts of thrombin generated under the influence of tissue factor. The phenomenon appears to be caused by the thrombin induced exposure of procoagulant phospholipids by blood platelets. Heparin inhibits this cooperative effect and retards the explosive thrombin formation. It does not, however, diminish the amount of thrombin eventually formed. This is attributed to the release of platelet factor 4.

Low molecular wight heparins of jarious kinds (Pentasacharide, CY 216, CY 222, PK 10169, EMT 966, EMT 967) do cause a retardation of thrombin formation and an inhibition of the amount of thrombin formed as welt. Orat anticaagutation has the same effeot.

In a semies of pilot expriments it appeared that some drugs that are known to act on platelets (ABpimin, $2 K 36374$ ) do inhibit the cooperative effect betwen platolets and thromboplastin. Wo hypothesize that the thromboplastin-platelet cooperation might be the target of antithrombotio therapy. 
Thrombin formation and blood platelet reactions are intimately linked both in hamostasis and in thrombosis. Thrombin is the most potent biological platelet activator and activated platelets have important procoagulant properties. The concentration of thrombin necessary to trigger a half maximal platelet reaction is significantly lower compared to other physiological activators (ADP, thromboxane $A_{2}$, PAF-acether) $(1,2)$. Platelets can show a transbilayer rearrangement of the phospholipids in the cell membrane ("flip-flop") that makes procaagulant phospholipids available at the surface of the intact cell. In washed platelets at a concentration of $10^{6}$ platelets per $m$, thrombin plus collagen is the specific trigger for this process. At higher platelet concentrations thrombin or collagen alone provoke this reaction to a significant extent (2.3). Activated platelets release a variety of substances, among which coagulation factor $V$ and platelet factor 4, (pf 4) a protein that neutralizes heparin $(4,5,6,7)$. From these phenomena, observed with isolated platelets, it can be surmised that in wivo there must exist a cooperation between the blood coagulation system and platelets.

In vivo, haemostasis will usually be started by the release of tissue factor from wounded cells. Tissue factor is a lipoprotein, present in most mammalian cells but not in blood platelets. It activates factor VII and thus starts the reaction sequence that leads to thrombin fomation ( 8 ). In order to investiglate the interplay between tissue factor, blood platelets. and the plasmatic coagulation factors, we have compared the influence of tissue factor on thrombin generation in platelet rich and platelet poor plasmai.

We found a cooperative effect of thromboplastin and platelets. Concentrations of thromboplastin that were without effect on platelet poor plasma significantly advanced the generation of thrombin in platelet rich plasma. We also investigated the influence of heparin, low molecular weight heparins and various other recognized or potential antithrombotics on this phenomenon. 
Platelet rich plasma was obtained by centrifugation $(900 \mathrm{~g}, 15 \mathrm{~min}$ ) of freshly drawn citrated blood. The platelet count was adjusted to $3.10^{8} / \mathrm{ml}$ with homologous platelet poor plasma (centrifuged for 15 min at $10.000 \mathrm{~g}$ ). Plastic tubes were used throughout the experiment so as to minimize contact activation. As a source of tissue factor we used human brain thromboplastin $(9,10)$. The phospholipid content of the undiluted thromboplastin used was $2.5 \mu \mathrm{M}$. The samples consisted of $240 \mu \mathrm{l}$ platelet rich plasma and $60 \mu 1$ of buffer, containing the substances to be tested. The samples were kept at $37{ }^{\circ} \mathrm{C}$ and could be magnetically stirred. Thrombin formation was started by addition of $60 \mu \mathrm{l}$ of $\mathrm{CaCl}_{2}$ (final concentration $16 \mathrm{mM}$ ) to which the thromboplastin was added.

In order to overcome the effect of platelet ageing, three incubation mixtures were run in paralel. At $10 \mathrm{sec}$ intervals a $10 \mu 1$ sample was taken from each of the mixtures and tested for thrombin as indicated in chapter II. In this way the sampling interval for each curve is $30 \mathrm{sec}$. The computerised registration of sampling times as described in chapters II and III was used. The plasma could not be previously defibrinated as this would cause loss of the platelets. A plastic rod was placed in the samples and as soon as the clot tended to interfere with sampling it was wound on the rod and removed. Vascular anticoagulant protein (VAC) was a kind gift of Dr. C. Reutelingsperger and prepared as described in ref. 11. PGE 1 was gift of $\mathrm{Dr}$. S. Levy-Toledano (Paris). ZK 36374 was a gift of Schering A.G. (Berlin) (12). All other materials and methods were as described in the previous chapters. 
By diluting the thromboplastin we determined which concentration of thromboplastin would cause less then $10 \mathrm{nM}$ of thrombin to be fomed in the course of $20 \mathrm{~min}$ in platelet poor plasma. With the preparation used this turned out to be 1 : 2000 (final dilution). We decided to use a somewhat lower amount ( 1 : 2400) in the following experiments. The effect of such a subthreshold amount of thromboplastin on thrombin formation is shown in fing. 1.



Pig. 1. THROMBIN GENERATION IN PLATELET RICH AND IN PLATELET POOR PLASMA.

$\longmapsto$ platelet mich plasma,-m-mplatelet poor plasma; A: thromboplastin 1:240, B: $1: 2400$ (final concentration); $C:$ no thromboplastin. only the values obtained with platelet poor plasma and thromboplastin $1: 2400$ are represented in the tow range of thrombin concentration ( $110 \mathrm{nM})$ in order not to overtoad the figure. 


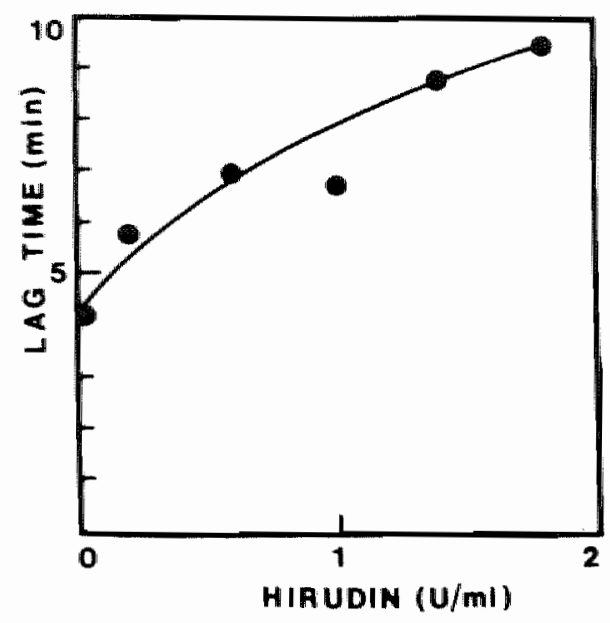

Fig. 2. INPLUENCE OF GIRUDIN ON THE LAG TIME OP EXPLOSIVE THROMBIN FORMATION.

The protongation of the lag time by hirudin in the presence of thromboplastin (1: 2400) is shown.

In the platelet rich plasma without thromboplastin, a burst of thrombin formation is seen after a lag time of 8-10 min. The lag time is read at the point where a line drawn through the main ascending $1 \mathrm{imb}$ of the thrombin generation curve cuts the abcissa. This lag time is shortened to 3-5 min in the presence a subthreshold amount of thromboplastin. If no platelets are present, less then $20 \mathrm{nM}$ thrombin is formed at this thromboplastin concentration. At higher thromboplastin concentrations $(1: 240)$ the difference between platelet rich-and poor plasma vanishes.

Sametimes it appears as if the thrombin concentration rises in two waves (Figs. $4,8,13,14,15$ ). We have not been able to obtain this phenomenon in a reproducible way, yet we have seen it too often to attribute it to mere experimental noise. Further investigations will be necessary here.

When hirudin, a specific inhibitor of thrombin is added to the mixture, the lag phase in the presence of thromboplastin is prolonged in a dose dependent way (Fig. 2). This suggests that the shortening of the lag phase is brought about by thrombin. As $1 \mathrm{U} / \mathrm{m}$ l of hirudin neutralizes $8-10 \mathrm{nM}$ of thrombin, the shortening of the lag time seems to be caused by low concentrations of thrombin produced under the influence of thramboplastin. Indeed, if thromboplastin is replaced by nanomolar amounts of thrombin the lag phase is shortened in platelet rich plasma (Fig. 3). In platelet poor plasma these quantities of thrombin do not trigger further thrombin formation. 


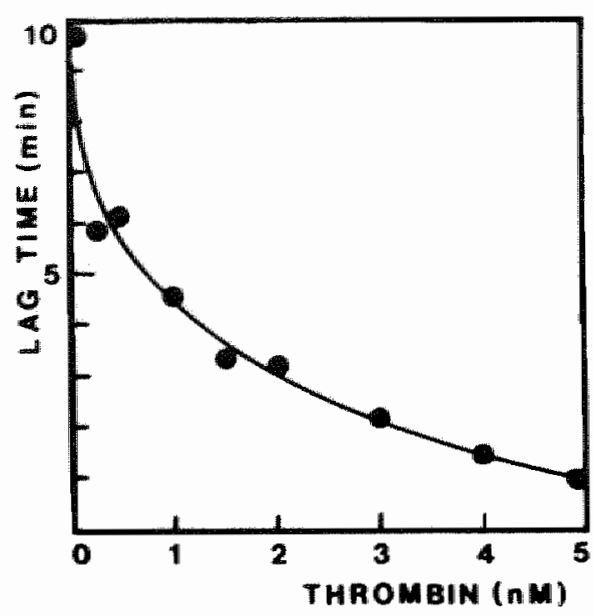

Pig. 3. INFLUENCE OF THROMBIN ON

THE LAG TTME OF EXPLOSTVE THROMBIN PORMATION.

We tried to detemine what procoagulant agent from the platelets is responsible for the effect observed. There are two obvious candidates, the factor $V$ that is released and the procoagulant phospholipids that are exposed upon platelet activation. We mimicked the effect of either of these by adding $10 \mathrm{nM}$ factor $V$ (or activated factor $V$ ) or $40 \mu \mathrm{M}$ phospholipid ( $20 \%$ phosphatidylserine and $80 \%$ phosphatidylcholine) to the platelet rich plasma. These amounts can be considered to be roughiy equivalent to the contribution of $3 \cdot 10^{8}$ activated platelets per $m 1(2,3,4)$.

Factor $V$ did not have a large effect on the lag times observed with or without thromboplastin. factor $v_{a}$ increase the peak amount of thrombin observed in the burst by about $10 \%$ and shortened the 1 ag time by $1 / 2-1$ min (fig. 4). The phospholipids doubled the thrombin peak and shortened the 1 ag time by about 3 minutes in the absence of thromboplastin as well as in its presence (fig. 4). Adding both factor $v_{a}$ and phospholipids did not change the thrombin generation pattern any further. This suggests that phospholipids are rate 1 imfting to the thrombin generation in nomal plasma and that they are provided by thrombin triggered blood platelets. It is known that, in order to expose significantly procoagulant phospholipids isolated platelets require stirring and the stimultaneous presence of both collagen and thrombin (2). In our setup neither stirring nor collagen seemed necessary. A7 so ADP 1-5 $\mu$ M did not cause any change in the thrombin generation pattern (results not shown). 


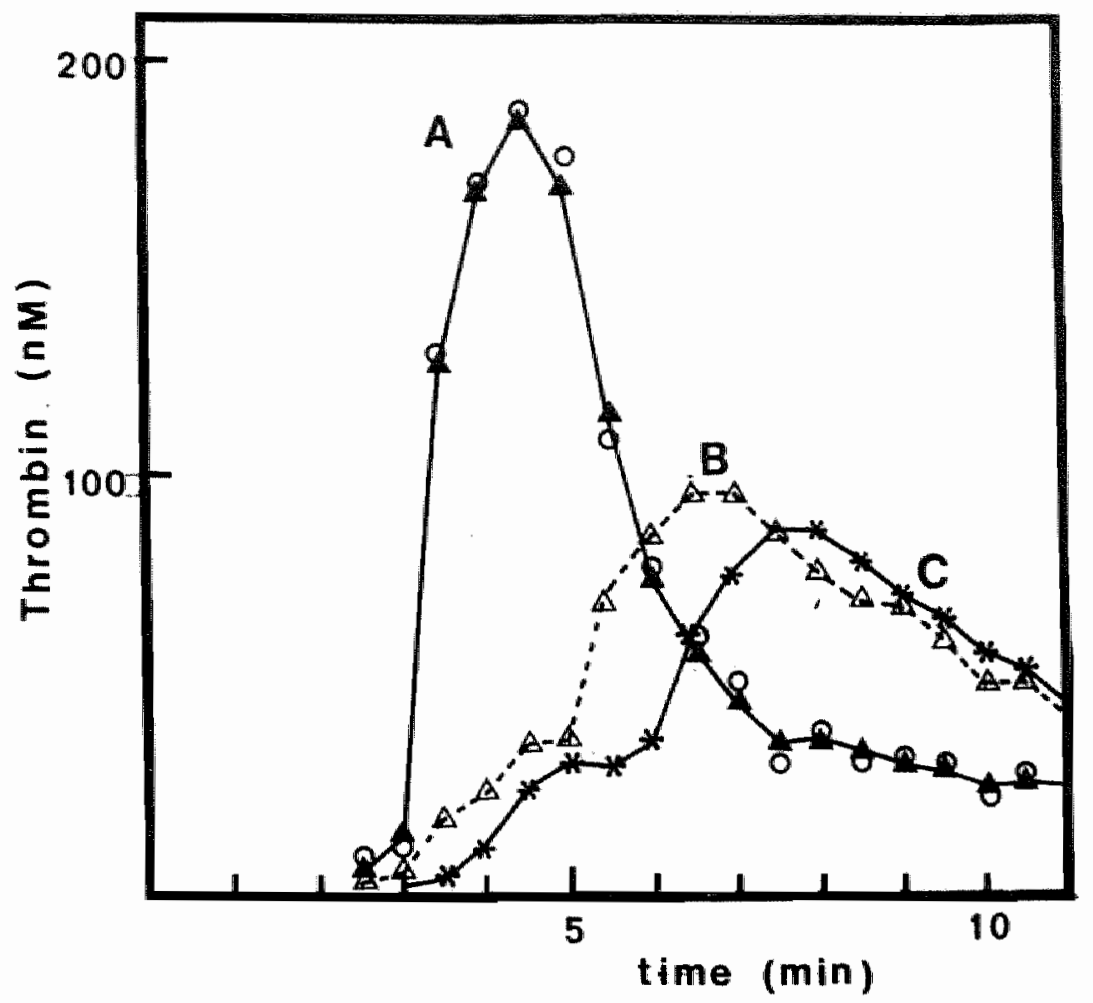

Fig. 4. THE INELUENCE OF FACTOR V AND PHOSPHOLIPID ON THE THROMBIN GENERATION IN PRP.

A: 40 HM PS/PC 20:80; $\Delta$ no thromboplastin; O with thromboplastin B: $10 \mathrm{nM}$ Factor Va $\triangle$; : no addition *

Thromboplastin $1: 2400$

The $\mathrm{Ca}^{++}$ionophore $\mathrm{A} 23187$ is known to induce a "flip flop" reaction in washed platelets (13). Indeed when $10 \mu M$ of $A 23187$ was added to plasma the lag time was reduced to $21 / 2$ minutes in the absence of thromboplastin as well as in its presence (fig. 5 ).

It thus seems that thrombin, in concentrations of $\sim 5 \mathrm{nM}$, generated under the influence of small amounts of thromboplastin, provokes a reaction in blood platelets that provides phospholipids and enables the plasmatic clatting factors to produce a burst of thrombin formation of 200-300 nM. 


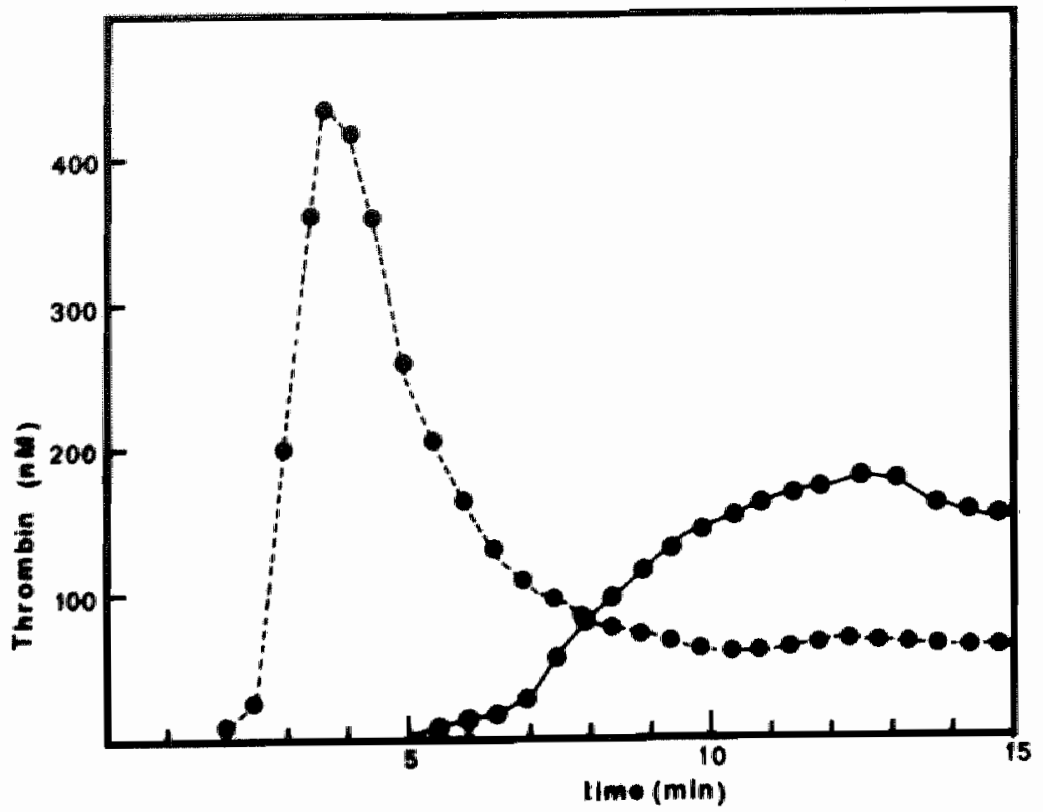

Fing. 5. THE INELUENCE OF Ca ${ }^{++}$IONOPHORE (A23187) ON THE THROMBIN GENERATION IN P.R.P.

Thromboplastin 1:2400

$(-)$ control (-..) $10 \mu M$ A23187

\section{Effect of heparins}

When heparin (international standard) is added to platelet rich plasma in concentrations of up to $0.5 \mathrm{~J} / \mathrm{ml}$ the lag phase is prolonged but surprisingly, hardly any decrease is seen of the amount of thrombin eventualiy produced in the burst (Fig. 6). In contrast, heparin, when added to platelet poor plasina in these concentrations causes an important inhibition of the amount of thrombin formed (chapter III). This difference between the action of heparin on platelet rich plasma and on platelet poor plasma might be caused by platelet factor 4 , released by the triggered platelets, that neutralizes the heparin added.

In fig. 7 it is shown that the release reaction provoked by $\mathrm{Ca}^{++}$ ionophore makes the reaction mixture capable of neutralizing important amounts of heparin. Also somication of platelets set free heparin binding material. 


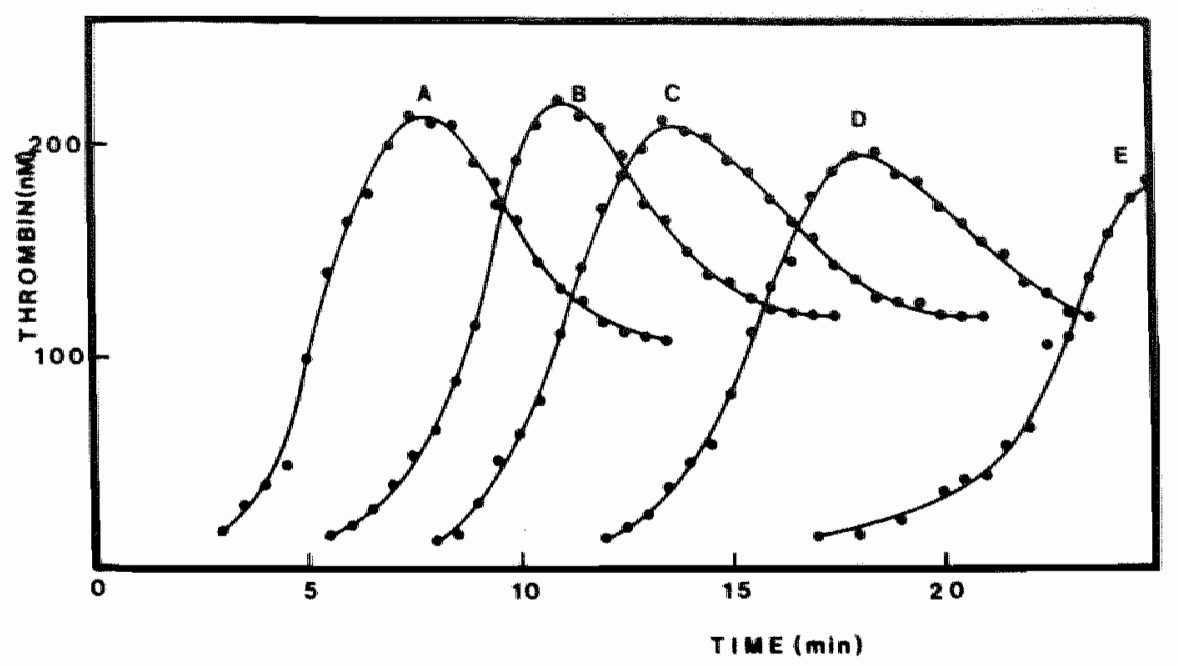

Fig. 6. INFLUENCE OF HEPARIN ON THE THROMBIN GENERATION IN PLATELET RTCH PLASMA.

Reaction mixture as in fig. 1; thromboplastin $1: 2400$

A: no heparin. B: $0.1 \mathrm{U} / \mathrm{mL}$ heparin; C: no thromboplastin;

D: $0.2 \mathrm{U} / \mathrm{ml}$ heparin; $E: 0.3 \mathrm{U} / \mathrm{ml}$ heparin.

The poor efficiency of classical heparin in inhibiting thrombin fomation in platelet rich plasma can thus in all probability be explained by the (thrombin-induced) activation of blood platelets and the subsequent release of platelet factor 4 .

We also investigated the behaviour of some law molecular weight heparins (figs. 8-11). It is seen that most of them, in contrast to heparin, both prolong the lag time and inhibit the peak of thrombin formation. Further research will have to show whether this is due to the fact that these drugs in comparison to heparin are less subject to binding platelet factor 4. 


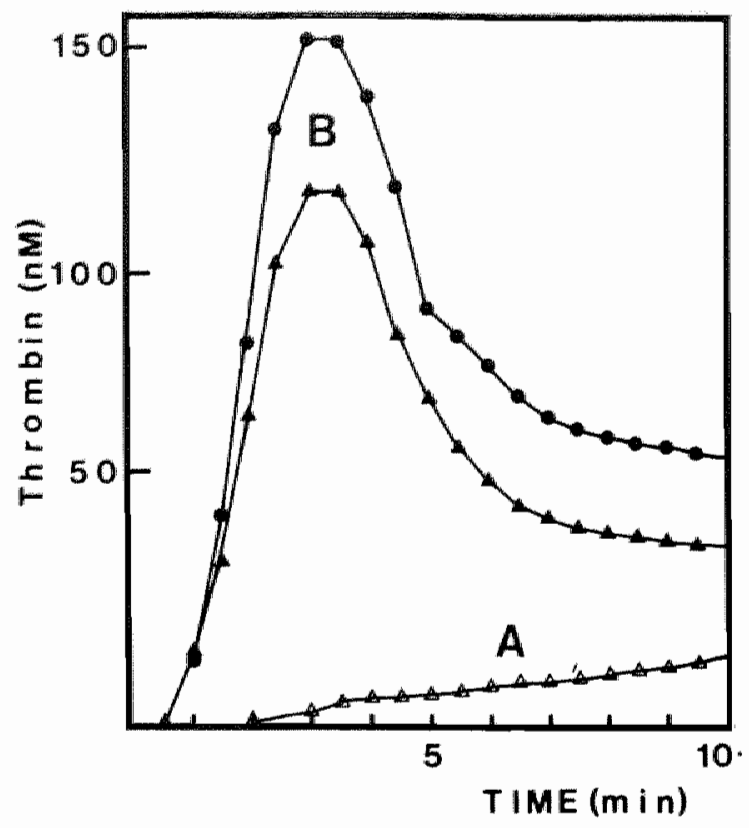

Fig. 7. THE INFLUENCE OP PF4 IN PLATELET POOR PLASMA

A) PPP with $5 \mu M$ A23187 and $0.1 \mathrm{U} / \mathrm{ml}$ heparin

B) $P P P$ prepared from $P R P$ to which $5 \mu M$ A23187 have been added

- no heparin

$\Delta 0.4 \mathrm{U} / \mathrm{ml}$ heparin

Fig. 8. INFLUENCE OF

PENTASACCHARIDE ON THE

THROMBIN GENERATION IN

PRP.

- control

- pentasacchamide

$1.2 \mu \mathrm{g} / \mathrm{ml}$

thromboplastin 1:3400

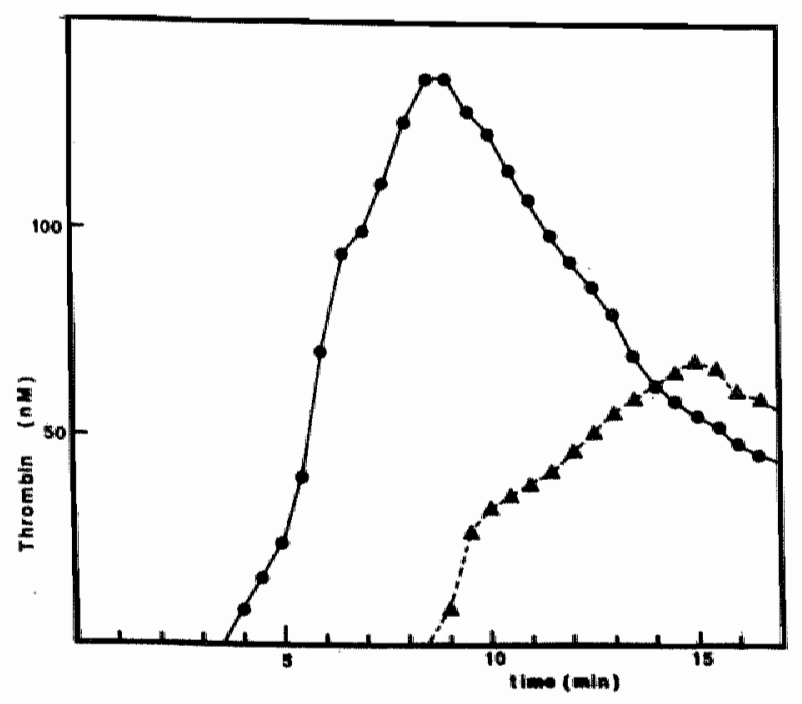


Fig. 9.

INELUENCE OF CY

216 AND CY 222

ON THE THROMBIN

GENERATION IN

PRP.

Thromboplastin

$1: 2400$

A: - econtrol

B:- $\rightarrow$ CY 222

$5 \mu g / m \tau$

C: $\square$ CY 216

$5 \mu g / m 2$
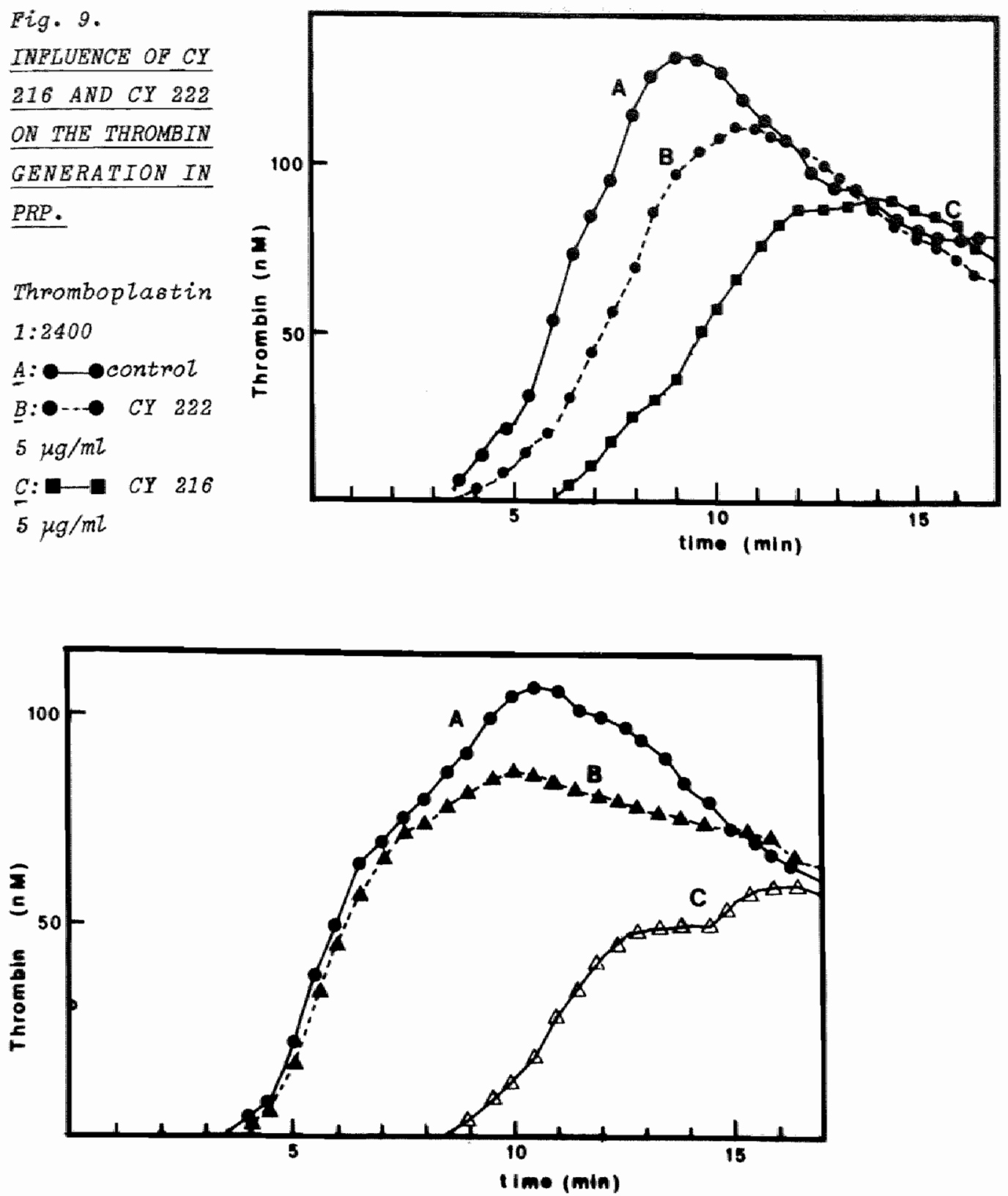

Fig. 10. INFLUENCE OF PK 101069 ON THE THROMBIN GENERATION IN PRP.

Thromboplastin 1:2400; A: -control; B:A..APK $10169 \mathrm{1 \mu g} / \mathrm{ml}$; C:D- $\triangle P K 101695 \mathrm{\mu g} / \mathrm{mL}$. 


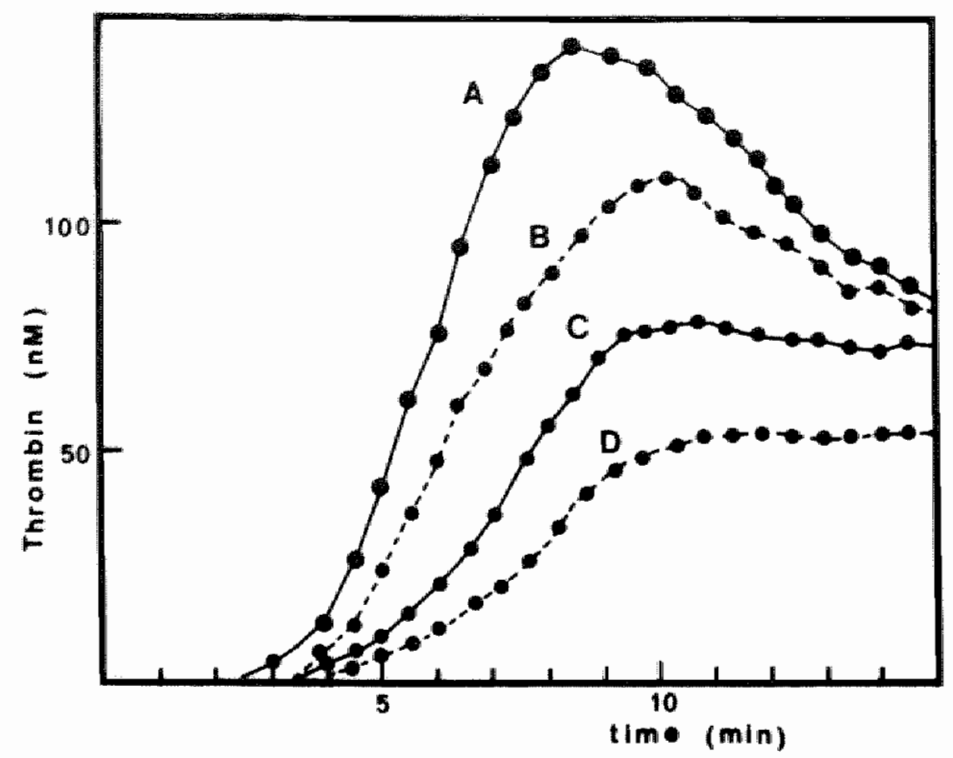

Fig. 11. INELUENCE OF EMT 966 AND EMT 967 ON THE THROMBIN GENERATION IN PRP.

Thromboplastin 1:2400; A: Control; B: EMT $9661 \mu \mathrm{g} / \mathrm{ml} ;$ C: EMT $9675 \mu \mathrm{g} / \mathrm{ml}$; D: EMT $96710 \mu g / m Z$.

Effect of other antithrombotic drugs and platelet inhibitors

We could not resist the temptation to see whether other antithrombotic drugs than heparin have an influence on the cooperativity between thromboplastin and platelets.

i. Oral anticoagulation

Marcoumar treatment causes a decrease of the amount of thrombin formed as well as a prolongation of the $\mathrm{lag}$ time of thrombin appearance when compared to normal plasma (fig. 12). It was surprising to see that the presence of platelets not only causes an increase of the peak anount of thrombin fomed but al so seems to retard thrombin formation, as if early formed thrombin is bound to platelets and remains inactive towards the chromogenic substrate. 
Fig. 12. INFLUENCE

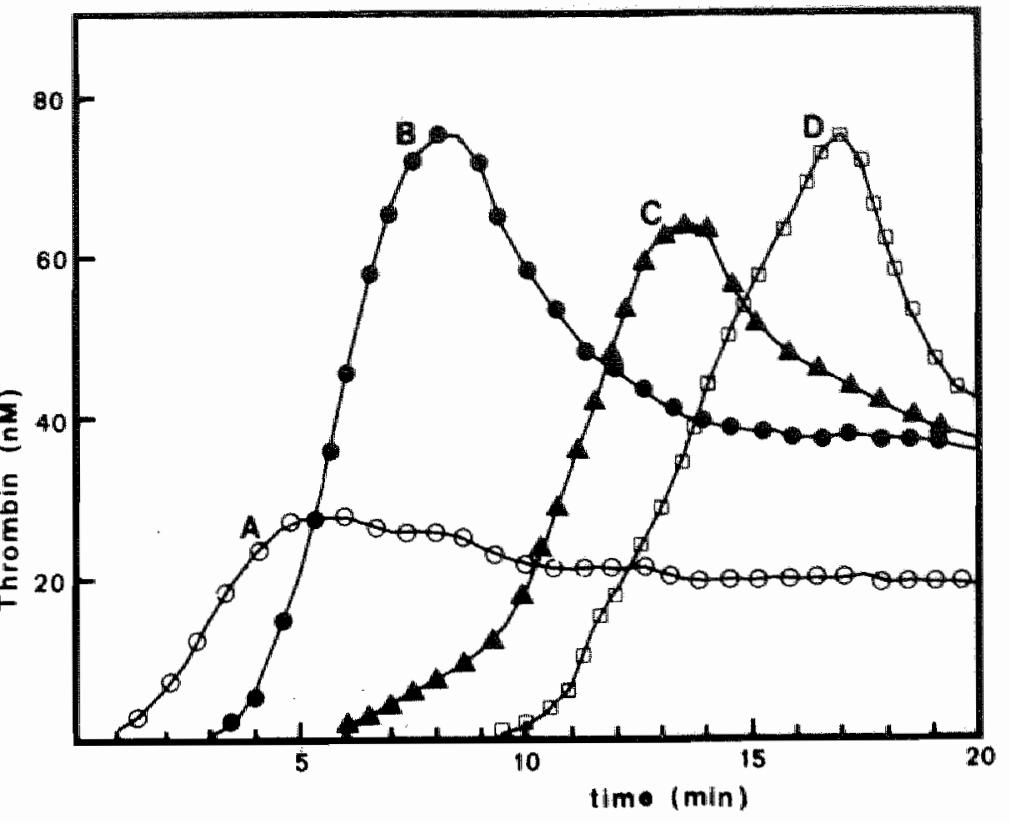

A: OPPP, thromboplastin 1:240

$B:-P R P$, thromboplastin 1:240

$C: \triangle P R P$, thromboplastin 1:2400 D: $\square P R P$, no thromboplastin

time $(\mathrm{min})$

Fig. 13. INELUENCE OF PGE1 ON THROMBIM GENERATION IN PRP.

Alocontrol, thromboplastin 1:2400

B: $\bullet 5 \mu M$ PGE1 added, thromboplastin $1: 2400$

c: 4 control, no $f$ thromboplastin

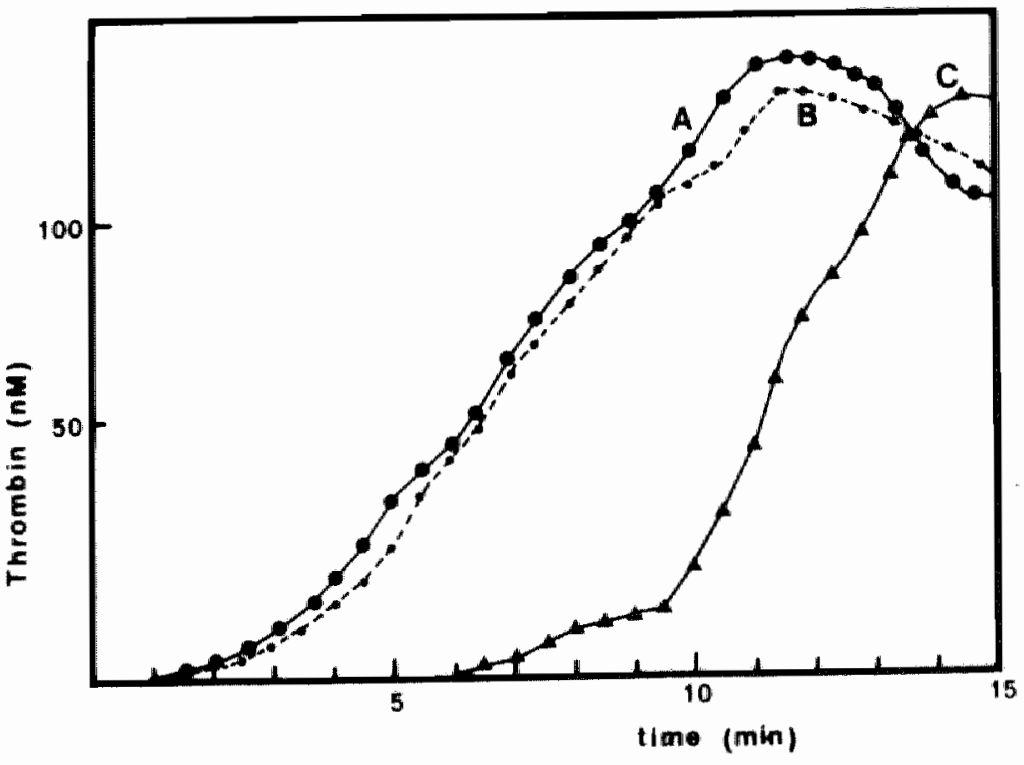

ii. Miscellaneous inhibitors

Because of the instability in $\mathrm{plasma}$ of prostacyclin $\left(\mathrm{PGI}_{2}\right)$ we did not test this substance. $\mathrm{PGE}_{1}$, at concentrations that did completely inhibit platelet aggregation, were without effect on thrombin generation (fig. 13). 


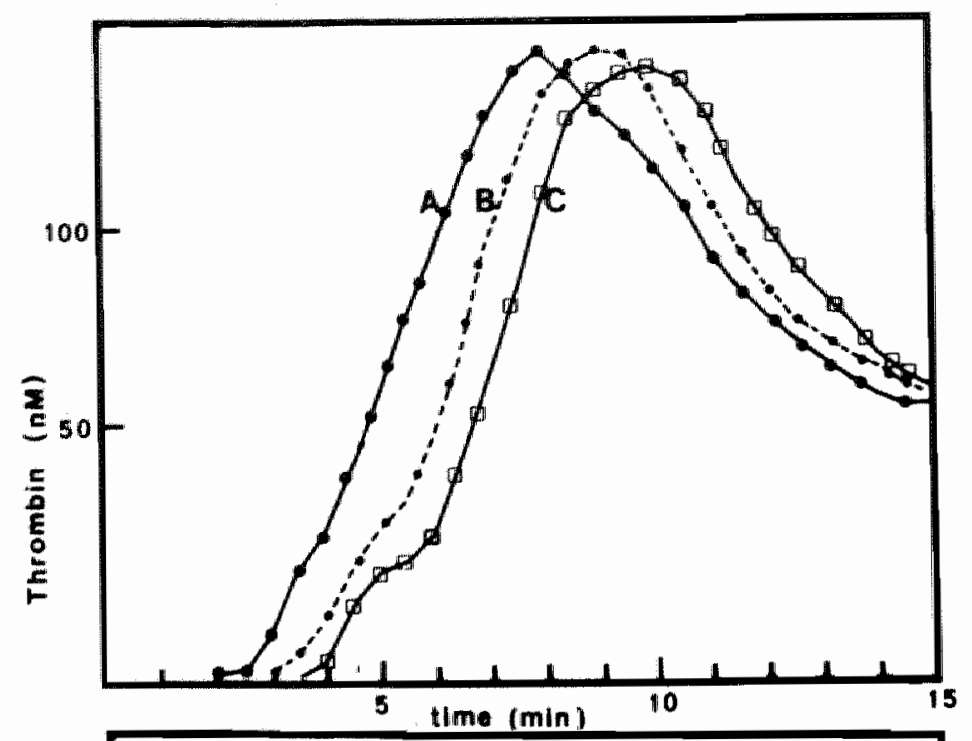

Fig. 14. INELUEWCE OF THE PROSTACYCLIN AMALOG $2 K \quad 36374$ ON THE THROMBIN GENERATION IN PRP.

A and C: controls, with thromboplastin 1:2400:(A), and without thromboplastin: (C)

B: thromboplatin $1: 2400,2 K 36374$

$5 \mathrm{nM}$

Pig. 15. INELUENCE OF ASPIRIN ON THE THROMBIN GENERATION IN PRP.

A: thromboplastin 1:2400

B: no thromboplastin drawn lines: control

dotted lines: aepimin 20 pM.

The stable prostacyclin analogue $2 K 36374$ however did cause a prolongation of the lag time in the presence of thromboplastin (fig. 14). Aspirin also caused such a prolongation both in the presence and the absence of thromboplastin (fig. 15). Interesting enough this effect was not or hardly dose dependent in the concentration range of 5-100 $\mu \mathrm{M}$. 
Fig. 16. INELUENCE OF

VASCULAR ANTICOA-

GULANT (VAC) ON THE

THROMBIN GENERATION

IN PPP.

Thromboptastin 1:480

Controz:

VAC:
$41 \mathrm{nM}$
$\Delta 5 \mathrm{nM}$
$1.0 \mathrm{nM}$
$\square 2 \rho \mathrm{nM}$
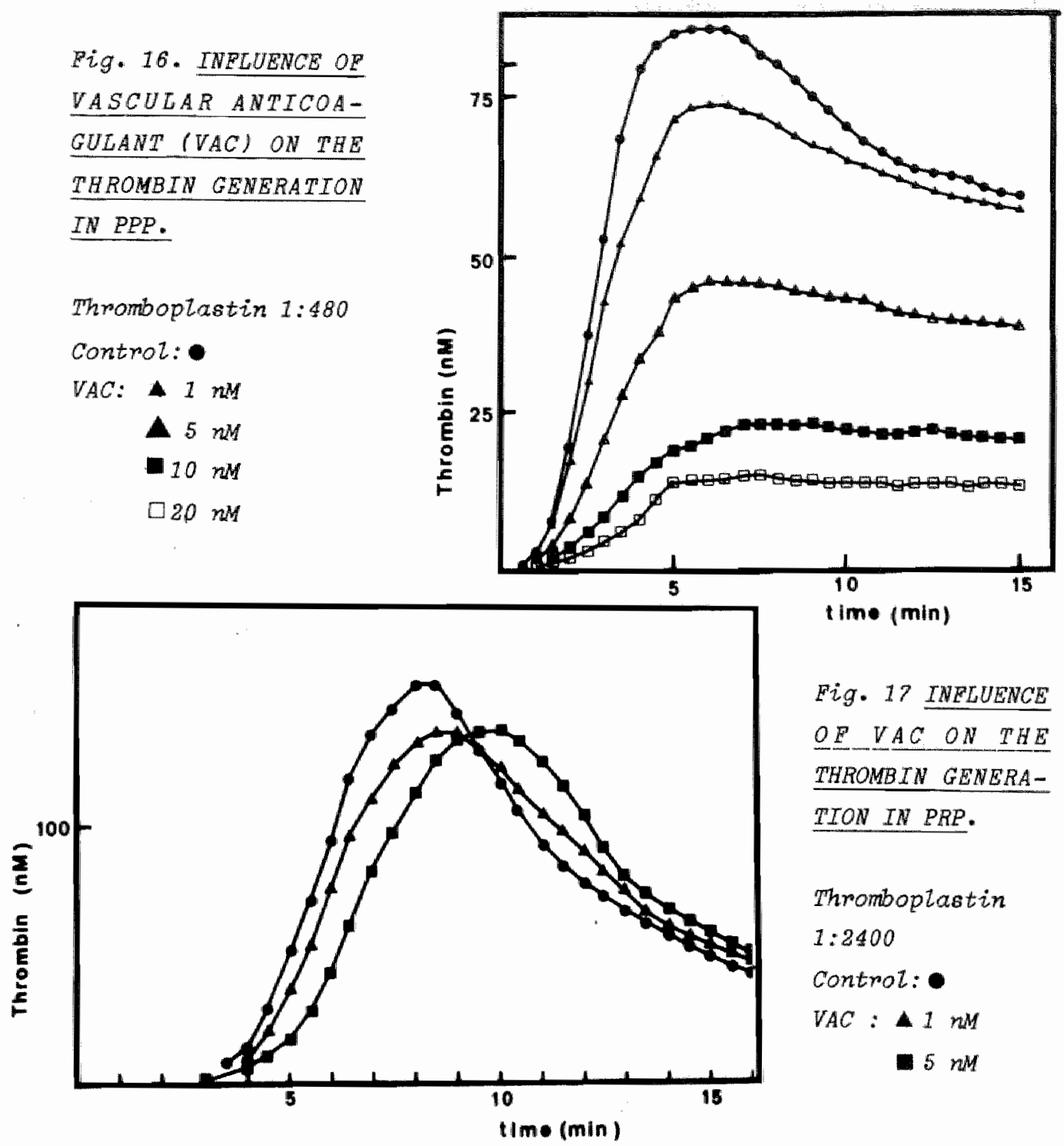

Fig. 17 INRLUENCE

OF VAC ON THE

THROMBIN GENERA-

TION IN PRP.

Thromboplastin

1.:2400

Controt:

$V A C: \Delta 1 \mathrm{nM}$

$5 \mathrm{mal}$

The vascular anticoagulant (VAC) a strongly anticoagulant protein present in the wall of normal arteria (11), at low concentrations (1-5 nM) already caused a retardation of the appearance of thrombin as well as a diminution of the peak amount of thrombin formed. Again, as with heparin the peak amount of thrombin is primarily inhibited when no platelets are present, whereas in the presence of platelets the start of thrombin fomation is retarded (figs. 16 and 17 ). 


\section{Platelets, thrombaplastin and thrombin formation}

The procoagulant effect of blood platelets is known since the earliest days of modern coagulation research. It was indeed postulated by Bizzozero in his first description of the blood platelets (14). Many later observations confirmed the role of platelets in coagulation (15) It was observed that a congenital platelet defect like Bernard-Soulier disease brings a disorder of prothrombin consumption (16).

The modern research of platelet function as it started in the first half of the sixties with the study of platelet aggregation (17) took a turn towards the cell biology of the platelet and the study of its procoagulant properties tended to disappear in the background. Apart from an occasional exception (18-24), it was not until membrane biochemistry discovered the platelet that the interest in their procoagulant activities reappeared (25).

The very nature of these studies necessitated platelet isolation and the use of purified clotting factors. They disclosed that the platelet, upon simultaneous triggering by thrombin and collagen is capable to expose procoagulant phospholipids at the outside of the intact cell ("flip-flop") (see 2,3 and 26 for further references). The platelet, when activated by collagen or thrombin as well as by a variety other stimulators, will release a multitude of compounds from various cell organelles. Here we only mention the release of two proteins that are directly pertinent to the discussion to follow: coagulation clotting factor $V$ and platelet factor 4 (4-7). Platelet factor 4, or heparin neutralizing factor, is a protein that binds strongly to (classical, high molecular weight)-heparin.

In the light of the existing knowledge it seems almost trivial to assume that in vivo there is a close interaction between blood clotting on the one hand and platelet reactions on the other. Yet, since the early sixties, the platelet and blood coagulation very often appeared as two entirely separate donains of investigation. It therefore seemed interesting to try and bring them together again by studying the generation of thrombin in platelet rich plasma. 
This appeared to be relatively difficult. Not only are there technical problems such as the disturbance of sampling by the fibrin formed, but also the reproducibility of the experiments is intrinsically less then that of the experiments with platelet poor plasma. For the latter frozen plasma may be used that, when well stored, remains practically stable in the course of several months. With platelet rich plasma a different donor has to be used every day. It also appeared that the procoagulant properties of platelets are more labile than many other functions. They deteriorate importantly in the course of 2 hours after venipuncture. Our experiments had therefore to be excecuted in parallel in three samples not later then 75 min after venipuncture. At three ocasions we isolated platelets according to ref. 2 and reconstituted platelet rich plasma from platelet poor plasma and the isolated platelets. The thrombin generation curves with the native and the reconstituted platelet rich plasma were indistinguishable. We concluded that the isolation procedure per se does not significantly change the procoagulant properties of platelets from citrated plasma.

We first detemined the amount of thromboplastin that in platelet poor plasma would have no significant influence on thrombin formation in the time course of our experiments. This threshold concentration was about 1 : 2000 under our circumstances. In platelet rich plasma recalcification causes a burst of thrombin formation after a lag time of 8-10 min. According to our impressions, the better the quality of the ventpuncture is, the longer the lag time if no thromboplastin is added. The "spontaneous" thrombin generation may be due to small amounts of tissue thromboplastin present in the blood. We have not been able to test this, because as yet we could not obtain inhibiting antibodies aginst tissue thromboplastin that would not contain traces of activated clotting factors, so that we could not completely inhibit tissue thromboplastin.

The presence of a subthreshold concentration of thromboplastin

(1: 2400) advanced the burst of thrombin formation by $3-5$ mim. This means that there is a cooperative effect of thromboplastin and platelets. Hirudin, which is a specific inhibitor of thrombin without known effect on platelets per se is able to prolong the lag time both in the presence of thromboplastin (fig. 2) and its absence (results not shown). Thrombin on the other hand shortens the liag time (fig. 3). These observations indicate that the effect of thromboplastin on the lag time is mediated by thrombin. 
Two reactions of platelets may contribute directly to thrombin generation: "flip-flop" and factor V release. We simulated both of then by adding procaagulant phospholipid or factor $V$ (in activated and unactivated form) in quantities that could be thought to be roughiy equivalent to the contribution of $3.10^{8}$ platelets per $\mathrm{ml}$. The effect of factor $V_{a}$ was minor compared to that of phospholipids (fig. 4). We tend to conclude that it is rather the phospholipid than the factor $V$ produced by the platelets that triggers thrombin formation. Also a release trigger like ADP (5 $\mu M)$ had no significant influence on the the cooperatiwity whereas a Ca-ionophore that induces a flip-flop reaction of the platelet membrane $(13,26)$ did cause a burst of thrombin fomation (fig. 5 ).

It remains surprising that, unlike the experiments with isolated platelets, ours required neither collagen nor stirring for the platelets to show their activity. It must be kept in mind however that our experimental conditions differ considerably from those of Bevers et al. in which the potentiation of collagen and thrombin was shown because in our case: a) the concentration of platelets in $100 \mathrm{x}$ higher b) plasma proteins are present, c) fibrin formation and clot retraction may have an effect on the platelets.

It has already been found that increasing the concentration of platelets will expunge the cooperative effect of collagen and thrombin on the flip-flop reaction in isolated platelets. The effect of thrombin alone, that, at around $10^{6}$ platelets $/ \mathrm{mr}$, is $10 \%$ of that of collagen and thrombin together, will, at $10^{6}$ platelets/ml be hardly less than the combined effect (3).

We can summarize our view of the course of events as follows: in platelet rich plasma, when coagulation is triggered by $\mathrm{Ca}^{++}$and a low concentration of thromboplastin, the system immediately after recalcification can be regarded as platelet poor plasma, in which inactive platelets are suspended. Thromboplastin causes small amounts of thrombin to be formed. These induce a release and a "flip-flop" reaction in the platelets, which makes them supply the phosphalipid necessary for starting explosive thrombin fomation. The factor $V$ contributed by the platelets seems less inportant for thrombin generation then the phospholipid is.

The phenomenon of vessel wall induced coagulation of platelet rich plasma observed by Hornstra \& Hemker (28) may well be explained by the 
small amounts of thromboplastin that were inevitably added to the plasma in their experiments together with the punched pieces of vessel wall.

\section{Heparins}

The effect of classical heparin on the thrombin generation in platelet rich plasma is significantly different from that in platelet poor plasma. If we compare fig. 4 from chapter III and fig. 6 of this chapter, it is clear that in platelet rich plasma the main feature of heparin addition is a prolongation of the lag time of thrombin formation whereas in platelet poor plasma the decrease of the peak amount of thrombin is the predoninant phenomenon.

From fig. 7 it follows that platelets at a physiological concentration contain amounts of heparin neutralizing material that are capable of a virtually complete annihilation of $0.5 \mathrm{U} / \mathrm{ml}$ of heparin. This represents a heparin concentration that in rigorously platelet and of 4 poor plasma will cause $>95 \%$ inhibition of the peak velocity of thrombin formation. It has been shown that mere venipuncture, if carried out under routine conditions, induces platelets ta produce a quantity of pf 4 that neutralizes $0,183 \pm 0.067 \mathrm{U} / \mathrm{ml}$ of heparin (29). The amount of heparin neutralized in our experiments therefore do not seem to be a unrealisticaliy high. The fact that plasma may readily contain significant amounts of heparin neutralizing material might explain why, in our experiments carried out with carefully prepared platelet free plasma (chapter III), we obtain important inhibition of the thrombin generation velocity at concentrations of heparin $(0.01-0.10 \mathrm{~J} / \mathrm{ml})$ that are low compared to those sometimes cited in the literature $(30,31)$.

Dur results demonstrate that heparin in platelet rich plasma retards the fomation of thrombin rather then diminishing the amount of thrombin eventually formed. It therefore seems unlikely that its antithrombotic effect in vivo is due to inhibition of the bulk of thrombin fomation, especially if the doses given do not result in plasma levels of $>0.5 \mathrm{U} / \mathrm{ml}$. It has been shown that the activation of the blood clotting system is an important cause of thrombosis (32). Tissue factor, the physiological activator of coagulation may therefore play a key role in this process. Heparin disrupts the cooperativity between tissue factor and platelets, 
thus retarding the appearance of thrombin. In fiowing blood, under the conditions of thrombus formation in vivo, this retardation might favaurably shift the balance between prothrombotic and antithrombotic forces.

We think that our results suggest a mode of action of low dose heparin therapy. From fig. 6 it is clear that an inportant retardation of thrombin formation can follow from concentrations as low as $0.1-0.15$ $\mathrm{U} / \mathrm{mi}$. We postulate that this retardation is instrumental in obtaining an antithrombotic effect. On basis of the data of van Putten (29) we can assume that a circulating concentration of $0.1-0.15 \mathrm{U} / \mathrm{ml}$ of heparin will rarely be detected by routine laboratory methods. This accounts for the difficulty in finding a laboratory correlate to the antithrombotic action of low dose heparin.

When we compare the behaviour of low molecular weight heparins in platelet rich plasma to that in platelet poor plasma, we see different patterns. In general these arugs cause both a retardation of thrombin fonation and, in constrast to classical heparin, a significant decrease of the amount of thrombin formed. Probabiy low molecular weight heparins are less subject to neutrallization by platelet factor 4 then classical heparin is.

Yet the inhibitions abtained with a given concentration af low nolecular weight heparin in platelet rich plasma are on the whole less important then those seen in platelet poor plasma (cf. Table IV of chapter IV with figs. 8-11 of this chapter). The difference is important for $\mathrm{Cr}$ 216, CY 222, PK10169 and EMT 966 and less important for the pentasaccharide and EMT 967. It is clear from our results that some, if not all, low molecular heparins are more efficient in inhibiting thrombin generation in platelet rich plasma then classical heparin is.

At this moment we cannot forward an explanation for the differences between the various heparins, apart from the different susceptibility to platelet factor 4 (27). Further studies will be necessary to disclose the details of the mode of action of 10 molecular heparin in platelet rich plasina. An abvious first step would be to determine the effect of these drugs on the generation of prothrombinase in platelet rich plasma. From the literature and from preliminary experiments it is clear that there is an important influence of fibrinogen and platelets on the inactivation of thrombin. This precluded direct application on platelet rich plasma of the nethod developed in chapter $I$. 
Besides heparin there are two other drugs with a well established antithrombotic actions: oral anticoaqulants and aspirin. It came as no surprise that oral anticoagulation to a mean lewel of vitamin $k$ dependent coagulation factors of $20 \%$, both retards and diminishes thrombin generation in platelet rich plasma (fig. 12). Yet this observation includes an unforseen features such as the fact that the presence of platelets, after triggering with thromboplastin 1: 240 increases the lag phase, but also the amount of thrombin fonmed (curves A and B, fig. 12). Again, further experiments will be necessary.

\section{Miscellaneous inhibitors}

It is still a matter of debate whether prostacyclin and its analogues will fom efficient antithrombotic drugs. In our experiments PGE 1 had no influence on the thrombin formation in $p l a t e l e t$ rich plasma whereas $Z K$ 36374 (12) had. Prostacycl in itself (PGI $)$ could not be tested because of its instability in plasma. In isolated platelets it does inhibit the "flip-flop" reaction (33). The experiment with $\mathbb{Z K} 36374$ opens the exiting possibility that there may exist antiplatelet drugs that exert their action via their ability to inhibit platelet procoagulant activity (fig. 14). The experiments with aspirin (fig. 15) may be a hint in the same direction. It has by no means been proven, however, that aspirin acts here by favour of its inhibition of cyclo-oxigenase. Again, the pilot experiments shown open a field of new inwestigations, rather then suggesting solutions.

The vessel wall contains a potent anticoagulant protein that acts by preventing clotting factors from interaction with procoagulant phospholipid surfaces (11). Its action on platelet poor plasma is shown in filg. 17. The action in platelet rich plasma shows less inhibition but a retardation of the explosion of thrombin formation (fig. 18). In this case probably caused by neutralization of the first amounts of procoagulant phospholipids produced by the platelets. We conclude that the antithrombotics that have been proven to be effective, i.e. heparin, oral anticoagulation and aspirin all three cause an inhibition of the cooperative effect between platelets and thromboplastin. It is an exciting possibility that this inhibition is a 
common feature of antithrombatic drugs, whether they act primarily on the platelet or on the coagulation system. 


\section{REFERENCES}

1. Kloprogge, E., de Has, G.M., Gorter, G., Akkerman, U.W.N.: Properties of PAF-acether-induced platelet aggregation and secretion. Studies in gel-filtered platelets. Thromb. Res. 29, 595-609 1983

2. Bevers, E.M., Comfurius, P., van Rijn, J.L.M.L., Hemker, H.C.. Zwaal, R.F.A.: Generation of prothrombin converting activity and the exposure of phosphatidylserine at the outer surface of platelets. Eur. J. Biochem. 122, 429-436 1982

3. Rosing, J., van Rijn, J.L.M.L., Bevers, E.M., van Dieijen, G., Comfurius, P., Zwaal, R.F.A.: The role of activated human platelets in prothrombin and factor X activation. Blood 65, 319-332 1985

4. Kane, W.H., Lindhout, T., Jackson, C.M., Majerus, P.W.: Factor $V_{a}$ dependent binding of factor $x_{a}$ to human platelets. J. Biol. Chem. 255, $1170-1174 \quad 1980$

5. Poplawski, A., Niewarowski, S.: Method for determining antiheparin activity of platelets and erytrocytes. Thromb. Diath. Haemorr. 13, $149-154,1965$

6. Breederveld, K., Giddings, J.C., ten Cate, J. W., Bloam, A.L.: The localization of factor $V$ within normal human platelets and the demonstration of a platelet-factor $V$ antigen in congenital factor $V$ deficiency. Br. J. Haematol. 29,405-412, 1975

7. Deutsch, E., Johnson, S.A., Seegers, W.H.: Differentiation of certain platelet factors related to blood coagulation. Circulat. Res. 3 , $110-118,1955$

8. Jesty, J., Nemerson, Y.: Purification of factor VII from bovine plasma. Reaction with tissue factor and activation of factor $x$. J. Biol. Chem. $249,509-515,1974$

9. Dwren, P.A., Aas, K.: The control of dicumarol therapy and the quantitative detemination of prothrombin and proconvertin. Scand. $J$. C1 in. Lab. Inv. 3, 201-218, 1951

10. van Dam-Mieras, M.C.E. Muller, A.D., Hemker, H.C.: Proenzymes, Enzymes, Inhibitors, Cofactors. Blaod coagulation factors II, V, VII, IX, X and $X I$. Determination by clotting assays. Meth. Enzym. Analysis V, 352-365 1984 
11. Reutelingsperger, C.P.M., Hornstra, G., Hemker, H.C.: Isolation and partial purification of a novel anticoagulant from arteries of human umbilical cord. Eur. J. Biochem. 151, 625-629, 1985

12. Gryglewski, R.J., Stock, J. edts.: Prostacyclin and its stable analogue lloprost. Springer-Verlag, Berlin, 1986

13. van Rijn, J., Rosing, J., van Dieijen, G.: Activity of human blood platelets in prothrombin and in factor $x$ activation induced by fonophore A23187. Eur. J. Biochem. 133, 1-10, 1983

14. Bizzozero, G.: Sur un nouvel ëlément morpholagique du sang chez les mammiferes et son importance dans la thrombose et dans la caagulation. Archiv. Ital. Biol. 345-362, 1882

15. Biggs, R. Macfarlane, R.G.: Human blood coagulation, Blackwell Scientific Publications, Oxford, 1953

16. Bernard, J., Soulier, J.P.: Sur une nouvelle variété de dystrophie thrombocytaire hémorragipare congénitale. Sem. Hôp. 24, 3217-3222, 1948

17. Born, G.V.R.: Aggregation of blood platelets by adenosine disphosphate and its reversal. Nature. 194, 927-929, 1962

18. Walsh, P.N.: Platelet coagulants activities and hemostasis: An hypothesis. Blood 43, 597-605, 1974

19. Joist, J.H., Dolezel, G., Lloyd, J.V., Kinlough-Rathbone, R.L., Mustard, F.d.: Platelet factor 3 avallibility and the platelet release reaction. J. Lab. Clin. Med. $84,474,1974$

20. Horawitz, H.I. Papayoanou, M.F.: Release of non-sedimentable platelet factor 3 during coagulation. J. C1in. Lab. Med. 69, 1003, 1967

21. White, J.G. Krivit, W.: The ultrastructural localization and release of platelet Tipids. Blood 27, 167, 1966

22. Webber, A.J., Johnson, S.A.: Platelet participation in blood coagulatijon aspects of hemostasis. Am. J. Pathol. 60, 19-42, 1970

23. Wu, V.Y., Johnson, S.A., MCCoy, L.E.: Platelet factor 3: Quantitation and characterization. Thromb. Res. 11, 581, 1977

24. Sandberg, H.: Platelet factor 3. The Link between platelets and plasma coagulation. Thesis. 1979

25. Zwaal, R.F.A., Comfurius, P., van Deenen, L.L.M.: Membrane asymetry and blood coaguitation. Nature 268, 358-360, 1977 
26. Zwal, R.F.A., Bevers, E.M., Comfurtus, P.: Platelets and coagulation. In: Blood Coagulation, Chapter 6,141-169, 1986, edited by R.F.A. Zwa i and H.C. Henker, Elsevier Sicience Publishers B.V.

27. Lane, D.A., Denton, J., Flynn, A.M.: Anticoagulant activities of heparin oligo-saccharides and their neutralization by platelet factor 4. Biachem. J. 21, 725-732, 1984

28. Harnstra, G. Hemker, H.C.: Clot promoting effect of platelet-vesse] wall interaction: influence of dietary fats and relation to arterial thrombus formation in rats. Haemostasis, 8, 211-226, 1979

29. van Putten, J.J., wan de Ruit, M., Beunis, H., Henker, H.C.: Heparin neutralization during collection and processing of blood inhlibited by pyridoxa 1 5-phosphate. Haemostasis, 14, 253-261, 1984

30. Teitel, J.M., Rosenberg, R.D.: Protection of factor $X_{\text {a }}$ from neutralization by the heparin-antithrombin complex. J. Clin. Invest. 71 , $1383-1391,1983$

31. Dfosu, F., Blajchman, M.A., Hirsh, J.: The inhibition by heparin of the intrinsic pathway activation of factor $X$ in the absence of antithrombin-III. Thromb. Res. 20, 391-403, 1980

32. Aronson, D.L., Thomas, D.P.: Experimental studies on venous thrombosis: effect of coagulants, procoagulants and vessel contusion. Thromb. Haemostas. 54, 856-870, 1985

33. Iwal, R.F.A., Comfurius, P.. Hemker, H.C., Bevers, E.M.: The inhibition of platelet prothrombinase activity by prostacyclin. Haemostasis, $14,320-324,1984$ 

In this thesis we want to contribute to the understanding of the mechanisms that underly thrombin generation in plasma and of the ways in which these mechanisms can be interfered with by drugs of the heparin family.

We first developed a method to determine the course of thrombin formation and disappearance under conditions as near as possible to the physiological situation and with enough precision to allow calculation of the course of prothrombinase activity. The method can be applied to defibrinated or non defibrinated platelet poor-as well as platelet rich plasma.

In essence this method is the time honoured thrombin generation test. Thrombin concentrations were estimated spectrophotometrically by their amidolytic action on a chromogenic substrate. At any moment during such a test the velocity of thrombin generation is the resultant of the activation of prothrombin by prothrombinase and the inactivation of thrombin by antithrombins. We determined the velocity of prothrombin activation (prothrombinase activity) by adding the calculated breakdown velocity of thrombin to the experimentally assessed rate of thrombin formation or disappearance. The breakdown velocity was computed by multiplication of the free thrombin concentration by the pseudo first order rate constant of decay. This constant was determined by measuring the rate of thrombin disappearance after blocking prothrombinase activity. It is the sum of the rate constants of each of the individual antithrombins. Of these the inactivation by $\alpha 2$ Macroglobutin ( $\alpha 2 M)$ requires separate determination because the thrombin- $\propto 2 M$ complex has a residual amidolytic activity. We called the rate constant of the non $\alpha 2 M$ antithrombins (mainly antithrombin III (AT III)) $k_{1}$ and that of $\alpha 2 M . k_{2}$. The ratio of $k_{1}$ to $k_{2}$ could be abtained from the ratio of the amounts of AT III bound thrombin to $\propto 2 M$ bound thrombin at the end of the experiment. It could be shown that $k_{1}$ and $k_{2}$ can be regarded as constant during in the course of the experiment.

once $k_{1}$ and $k_{2}$ are known it is possible to calculate the breakdown velocity of thrombin and the velocity of the formation of $\alpha 2 M$-thrombin at any sampling moment. Hence the prothrombin conversion rate can be calculated at any mament and the time course of prothrombinase activity can be 
obtained. A computer program was written to carry out these calculations.

The method was validated in two different ways. First we determined experimentally the time course of the concentrations of prathrombin, thrombin and $\alpha 2 M$ bound thrombin in plasma after triggering with thromboplastin. Then we calculated the time course of prothrombin and $\alpha 2 M$-thrombin from the thrombin activities. A close similarity between the experimental and the calculated values was observed.

Secondly, we made plasma deficient in AT III, and/or $\alpha 2 M$ by immunoadsorption. The time course of prothrombinase obtained in the absence of an antithrombin was shown to be indistinguishable from that in its presence if in the calculations the corresponding decay constants were put to zero. These experiments allowed us to calculate the relative importance of the different antithrombins for the decay of thrombin in plasma. We found that AT III, $\alpha 2 M$, and non AT III - non $\alpha 2 M$ (probably mainly $\alpha_{1}$ antitrypsin) contributed respectively $64 \%, 23 \%$ and $14 \%$ to the velocity of thrombin decay.

Although apparently sophisticated, our technique can be easily applied in any laboratory provided with a spectrophotometer and a personal computer. The computer showed to be a valuable aid in these experiments not only for the above mentioned calculations but also because it was used for the automatic registration of sampling times and of incubation times with the chromogenic substrate. This allowed us to sample at 3-4 seconds intervals if necessary. In this way we could reliably determine half-life times of endogenous thrombin as short as $6 \mathrm{sec}$, such as they are seen when heparin is added to plasma in therapeutic concentrations.

As far as we know our experiments are the first to approach the time course of prothrombinase in plasma. They allowed us to confirm the important role of traces of thrombin in the initial phase of coagulation postulated by $A$. Hurlet - Birk Jensen, F. Josso and ourselves in 1976 and ta obtain a better insight in the mode of action of heparins.

Contrary to the generally accepted view it appeared to us that classical unfractionated heparin (UFH) has hardly any influence on prothrombinase formation triggered via the extrinsic pathway i.e. by recalcification in the presence of thromboplastin. Its role is essentially that of an catalyst of AT III dependent thrombin inactivation only.

When prothrombinase activity is triggered via the intrinsic system 
When prothrombinase activity is triggered via the intrinsic system (recalcification in the presence of phospholipids and kaolin), heparin does influence prothrombinase fomation because, in that case, the decrease of available thrombin slows down the thrombin dependent feedback activation of factor VIII. This results in a prolongation of the 1 ag time as well as in a decrease of the amount of prothrombinase formed. The latter phenomenon can be explained by the rapid AT III- and heparin dependent inactivation of free factor $I X_{a}$ that we observed. If the generation of factor WIII is slow, factor $I X_{a}$ cannot be protected from this inactivation and is partly consumed before adequate factor VIII a levels are available. This activation of factor VIII by thrombin thus is of prime importance for the formation of the factor $x$ activating complex (tenase) and therefore for the formation of prothrombinase via the intrinsic pathway. Indeed, if tenase is added ready made to the system, heparin will not inhibit the prothrombinase formed.

We conclude that AT III-heparin in plasma does not act at the level of factor $X_{a}$. Dur abservations corroborate the conclusions of Marciniack (1973) and of Josso and Bëguin reported in 1981 on the protection of factor $x_{a}$ from the action of AT III and heparin by factor $V_{a}$ and phospholipid. Moreover, they allow us to conclude that this protection must be virtually complete. Not only is factor $x_{a}$ protected in prothrombinase but al so factor IX $X_{a}$ in tenase.

These results justify an interest in new pharmaceuticals of the heparin family that may be able to inhibit at the level of factor Xa. In the last 5 years there has been a rapidly growing body of knowledge on the mode of action of fragments and fractions of heparin. The consensus is that low molecular weight heparins (LMWH) have a decreased activity against thrombin but remain active against factor $x_{a}$.

This conclusion stems from observations in which (partially) purffied factors have been used. The mode of action of LMWH on the endogenously activated factors of clotting plasma is still unknown. Since in the case of unfractionated heparin there are apreciable differences between the action of heparin on endogenous factor II,$I X_{a}$ on $x_{a}$ and on free factors, we also tested the effect of a series of LMNH on prothrombinase fomation in plasma

It appeared that two classes of LMWH can be distinguished. One class that we called $\underline{S}$ type after its prototype Standard heparin, does induce a dose dependent increase of the inactivation of endogenous thrombin. The 
other class, the p type, of which the choay Pentasaccharide (cy 234 ) is the prototype, has no influence whatsoever on thrombin decay. The $S$ type heparins do not or hardly inhibit prothrombinase activity whereas the $P$ type heparins do. Apart from standard unfractionated heparin CY 216 (Fraxiparine ${ }^{P}$ ) and $C Y 222$ belong to the $S$ class. The $P$ class comparises the pentasaccharide, EMT 966 and EMT 967. PK 10169 (Enoxaparine) is a mixed type, possibly a mixture of a $P$ and an $S$ type heparin.

The recognition of two types af heparins has important consequences for the standardization of heparin preparations. On the one hand every 5 type heparin can now be easily compared to a standard unfractionated heparin. The AT III dependent decay of endogenous thrombin, the only primary effect of these heparins in plasma, should be used as a yardstick. On the other hand heparins of the $P$ type as well as the mixed type heparins have a mechanism of action that is fundamentaly different from classical heparin. Therefore, no rational comparison with a standard unfractionated heparin is possible.

The same holds mutatis mutandis for the clinical situation. If indeed unfractionated heparin exerts its action via the inhibition of thrombin then the $S$ type heparins will act like UFH, be it with different and probably much more favourable phamacokinetic properties. P type heparins an the contrary are of a completely different type and should be considered new drugs with unkmown effects on thrombosis and hamostasis.

We also investigated the semisynthetic heparin-like drug pentosane polysulphate (PPS, Hémoclar ${ }^{R}$ ). Like heparin it causes a dose dependent increase of the decay of thrombin, $1 \mu \mathrm{g}$ PPS having the effect of $0.045 \mu \mathrm{g}$ UFH. This effect is completely dependent upon plasma cofactors. About 35\% of the cofactor activity can not be attributed to AT III. Probably heparin cofactor II is the responsible cofactor for that part.

The inhibition of factor VIII activation by PPS, demonstrated by Wagenvoord et al. with purified factors, also sems to occur in whole plasina. The inhibition could be shown not to be due to an action on factor $I_{\mathrm{x}}$, contrary to the conclusion of Fischer et al.

We tried to use PPS as a means to demonstrate the existence of the Josso loop, i.e. a thromboplastin induced factor VIII and IX dependent. pathway of factor $x$ activation. This pathway is thought to become important if there is not enough thromboplastin to ensure the direct rapid activation 
of factor $X$ by factor VII and thromboplastin. Indeed it was observed that the inhibition by PPS of the extrinsic prothrombinase generation is dependent upon the potency of the thromboplastin used. With thromboplastin concentrations up to 1 : 10 there is no inhibition to speak of. If the dilution is 1: 40 or higher, inhibition approaches $20 \%$, independent of the PPS concentration between 1 and $10 \mu \mathrm{g} / \mathrm{ml}$.

A second indication for the existence of the Josso loop is the fact that in haemophilia A or B plasma, contrary to normal plasma, PPS does not inhibit thromboplastin induced prothrombinase generation. Surprisingly, in haemophilia plasma, PPS induced an increase of prothombinase activity. Heparin has the same effect. We were unable to find an explanation for this phenomenon. There are indications that it also occurs in normal plasma. If PPS shows both an inhibiting and an activating action in nomal plasma than the inhibition of prothrombinase observed $(\sim 20 \%)$ cannot be used to quantify the contribution of the Josso Loop but must be regarded as its lower limit.

In an attempt to further approach physiological conditions we also studied platelet-rich plasma. This involved the solution of technicali difficulties caused by the presence of fibrinogen and the unstability of the platelets. We adapted our technique so that it was possible to measure the course of thrombin formation in plasma containing a fixed number of platelets $(300.000 / 41)$ within two hours after venipuncture. A spontaneous burst of thrombin generation is seen in platelet rich plasma after a lag time of 8 - $10 \mathrm{~min}$. In platelet poor plasma this is not seen. We were surprised to find that neither stirring nor the presence of callagen influenced the lag time or the amount of thrombin fomed. Thromboplastin in a dilution so high as not to influences thrombin generation during 20 min in a sample of platelet poor plasma decreases the lag time in platelet rich plasma by $3-5$ min.

This cooperative effect of platelet and tissue factor to our knowledge has not been described before. We could show that it was mediated by trace amounts of thrombin, as it was inhibited by low concentrations of hirudin $(0.2-2 U / m 1)$ and simulated by low amounts of thrombin $(0.5-5$ nM). The effect could not be obtained by the addition of factor $W$ or factor $V_{a}$. Procoagulant phospholipids, however, did cause a shortening of the lag time. It seems probable that the production of procoagulant phospholipids 
by platelets, triggered by trace anounts of thrombin formed during the lag time, suplies the rate linting reactant necessary for the explasive formation of thrombin. This idea is supported by the fact that $5 \mu$ of the ca ${ }^{+*}$ ionophore, known to induce the appearance of procoagulant phospholipids. shortens to 2 min the lag time of thrombin formation in platelet rich plasma.

We demonstrated that heparin in concentrations that almost completely inhibit thrombin generation in platelet poor plasma $(0.1-0.3 \mathrm{U} / \mathrm{ml})$ will postpone the generation of thrombin in platelet rich plasma but will hardly influence the amount of thrombin fomed. This can be explained by the release of platelet factor 4 from the activated platelets. It was found that in the supernatant of platelet rich plasma, in which the platelets were activated by $\mathrm{Ca}^{++}$ionophore $(5 \mu \mathrm{M})$ or were destructed by sonication, up to $0.5 \mathrm{U} / \mathrm{ml}$ of heparin can be neutralized.

Contrary to unfractionated heparin, the low molecular weight heparins investigated did inhibit thrombin generation in platelet rich plasma, probably because they are less effectively neutralized by platelet factor 4. The different LMW heparins tested show different inhibition patterns, probably because of differences in their interaction with AT III, prothrombinase and platelet factor 4. Further studies will be necessary to define these effects more precisely.

We also did a series of preliminary experiments on the effect of drugs with a recognized or supposed antithrombotic action on the cooperation between thromboplastin and platelets. Dral anticoagulation, as could be expected, had an inhibitory effect. More surprisingly Aspirin also appeared to cause a slight inhibition. The stable prostacyclin analogue ZK 36374 did increase the lag time but PGE1, in concentrations that completely inhibited aggregation, did not. The vascular anticoagulant protein described by Reutellingsperger et a1. also caused inhibition of the cooperative effect.

In summary, by taking up again the old tool of coagulation that is the thrombin generation test and adapting it to modern requirements of precision and sampling frequency we were able to do a detailed study of thrombin generation in platelet poor and platelet rich plasma and of the influence of heparins and heparin like drugs thereon. The availability of highly purified human clotting factors made it possible to gain more insight in the mechanisms involved, We were able to demonstrate the importance in 
clotting plasma of three amplifying mechanisms: The Josso 10op, the feedback activation of factor VIII by thrombin and the activation of platelets by thrombin. The main effect of the latter seems to be the exposure of procoagulant phospholipids and, for clotting in the presence of heparin; the release of platelet factor 4.

We observed a cooperative effect of low concentrations of thromboplastin and platelets that may important in vivo if thrombin is generated as a result of by limited tissue damage. We demonstrated that classical heparin in plasma acts primarily on the decay of thrombin and that decay of factor $X_{a}$ and $I X_{a}$ virtually completely prevented by the presence of phospholipids and factor $V_{a}$ and VIII ${ }_{a}$. The action of heparin-AT III on thrombin entails inhibition of the feedback activations of factor VIII and platelets. We were able to show that one class of low molecular weight heparins (the $S$ type heparins) acts essentially like classical heparin does, whereas others, the $P$ type heparins, do inhibit prothrombinase and have no action on thrombin.

We hope to have demonstrated that experiments in whole plasma, with or without platelets, are a necessary link between biochemical studies on purified factors and in vivo experiments on the physiology and pharmacology of haemostasis and thrombosis.

Many ideas in this thesis originated from my long cooperation with Francois Josso. I am grateful that I had the opportunity to pursue them in his spirit. 


\section{SAMENWATTING EN CONCLUSIES}

Dit proefschrift wil een bijdrage leveren tot de kennis van het mechanisme van de voming van trombine in plasma en van de reming daarvan door heparine en heparineachtige stoffen.

Eerst ontwikkiden wij een methode om het verloop van de trombine activiteit in plasma te meten onder onstandigheden die de fysiologisch situatie dicht benaderen. De nauwkeurigheid en de frequentie van bemonstering makten het mogelijk om uit de trombineconcentraties de protrombinase aktiviteit te berekenen. De methode kan worden toegepast op al dan niet gedefibrineerd, plaatjesarm of plaatjesrijk plasma.

In wezen gat het om de wanouds bekende trombine generatie test warbij de trombine concentraties spectrofotometrisch bepald worden m.b.v. een chromogeen substraat. Op ieder tijdstip gedurende $z 0^{\prime} n$ proef is de gemeten trombinevormingssnelheid de resultante van de prothrombinase activiteit en de snelheid wan inactivering t.g.v. antitrombines. Wij verkregen de afbraaksnelheid van trombine door deze te berekenen uit de trombineconcentratie en de pseudo eerste order afbraak constante wan trombine. Deze afbraak constante werd bepald door de trombine verdwijning te meten na het blokkeren van de prothrombinase activiteft. De zo gevonden constante is de som van de individuele constantes de verschillende antitrombines in het plasma. De constante van $\alpha-2$ macroglobul ine $(\alpha 2 M)$ moet apart bepaald worden ondat het trombine $\alpha-2 M$ complex een amidolytische activiteit heeft.

$k_{1}$ noemden wij de snelheidsconstante van de niet $\mathcal{Y}$ M afhankelijke afbraakconstante (d.i. voornamelijk t.g.v. antitrombine III (AT III)), de $\alpha 2 M$ afhankelijke afbraakconstante werd $k_{2}$ genoemd. De verhouding van $k_{1}$ en $k_{2}$ kan bepaald worden door de verhouding te meten van de hoeveelheden trombine die na afloop van de proef aan AT III en a an $\alpha 2 M$ gebonden zijn. Wij toonden aan dat $k_{1}$ en $k_{2}$ constant zijn gedurende de loop valn het experiment. Bij bekende $k_{1}$ en $k_{2}$ kan men op ieder tijdstip waarop een monster getrokken is de vomingssnelheid van At III- trombine en $\alpha 2 M-t r o m b i n e ~ b e r e k e n e n$.

De protrombine amzettingssnelheid kan dan op ieder mament berekend worden door de experimenteel gemeten snelheid en de afbraaksnelheden op te tellen. Er werd een computerprogramma geschreven on deze berekeningen uit te voeren. 
De julistheid van de procedure werd op twee verschillende manieren getoetst. In de eerste plaats bepaalden wij experimenteel het verloop van

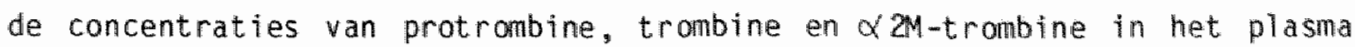
nadat de trombinevorming in gang gezet was door recalcificatie in aanwezigheid van tromboplastine. Vanuit de gevonden waarden voor trombine werden daarna het verloop vam de protrombine en de $\alpha 2 M-t r o m b i n e ~ c o n c e n-$ traties berekend en vergeleken met de experimenteel verkregen waarden. Er bleek een nawwe overeenstemming te bestaan. Ten tweede maakten wij plasma deficient in $\alpha 2 M$ en AT III of beide door immunadsorptie. Het bleek dat de berekende protrombinase activiteiten in deficiente plasmas goed avereenkomen met die verkregen uit nomaal plasma als de constante(s) behorende bij de afwezige remmer(s) gelijk gesteld werden a an nul. Met deze experimenten konden wij ook de relative invloed van de verschillende trombine remmers in plasma bepalen. Wij vonden dat AT III, $\alpha 2 M$ en de restactiviteit (waarschijnlijk $\alpha_{1}$-antitrypsine) respectivelijk $64 \%, 23 \%$ en $14 \%$ aan de snelheid van trombine inactivering bijdroegen.

Dfschoon ogenschijnlijk ingewikkeld, kan onze techniek gemakkelijk worden toegepast in ieder laboratorium war een spectrofotometer en een huiscomputer a anwezig zijn. De computer is nitet alleen nodig voor de berekeningen, maar ook voor de automatische registratie van monster- en incubatietijden via van drukcontacten voorziene pipetten. Hiemee konden monsterfrequenties $v a n$ eens per 3 a 4 seconden bereikt worden, zodat trombine-halfwaardetijden van 6 seconden en hoger, zoals die bij therapeutische heparineconcentraties voorkomen, met voldoende nauwkeurigheld gemeten kanden worden.

Voorzover wij weten zijn onze proeven de eerste die het ver loop van de protrombinase activiteit in plasma weergeven. Zij stelden ons in stat on de belangrijke rol te bevestigen van sporen trombine in de woorfase van de stolling en om nadere infomatie te krijgen over de werkingswijze van heparines.

In tegenstelling tat wat algemeen wordt aangenomen bleek dat het klassieke ongefractioneerde heparine (UFH) nauwelijks invloed heeft op de activiteit en de vorming van protrombinase, dus van factor $x_{a}$. De rol wan het heparine lijkt beperkt tot die van katalysator van AT III-afhankelijke trombineinactivering. In het extrinsieke systeem (d.w.z. recalcificatie in aanwezigheid van tromboplastine) blijft de hoeveelheid protrombinase on- 
gewijzigd in aanwezigheid wan hoeweelheden heparine die de trombinevoming sterk ( 285\%) remmen. Als de protrombinase aciviteit in gang wordt gezet via het intrinsieke systeem (recalcificatie in aanwezigheid van phospholipide en kaoline) beinvloedt heparine haar wel, zij het indirect. De veminderde hoeveelheid vrij trombine brengt in dat geval een vertragde activitering wan factor VIII met zich mee, zodat de factor IX $x_{a}$, die via het contact activeringssysteem gevormd is, wijn activiteit niet tot uitdruking kan brengen. Dit veroorzaakt een verlenging van de latentietijd voorafgaande aan de explosieve trombinevorming maar ook een vermindering van de protrombinase activiteit. Dit laatste kan verklaard worden doordat vrij factor IX dat niet met factor VIII a an phospholipide gebonden wordt snel o.i.v. heparine en AT III wordt geînactiveerd. De activering van factor VIII door trombine is dus van groot belang woor de vorming van het factor $x$ activerende complex ("tenase") via de intrinsieke weg. Als de reactie door uit zuivere factoren samengesteld tenase gestart wordt, remt heparine de protrombinase antwikkeling niet. Onze warnemingen bevestigen de conclusies van Marciniak (1973) en Josso en Béguin (1980) over de beschemende werking wan phospholipide en factor $V_{(a)}$ op factor $x_{a}$ tegen AT III en heparine. Bovendien mogen wij concluderen dat deze bescheming practisch volledig is en dat er een analoge bescherming van factor I $X_{a}$ door factor VIII en phosphol ipide bestaat.

In de laatste jaren is er veel omderzoek gedaan naar fracties en derivaten van heparine met een laag moleculair gewicht. Men is het er algemeen over eens dat laag moleculair gewicht heparines (LMWH) een verhoudingsgewijs geringere activiteit hebben tegenower trombine dan tegenover factor $x_{a}$. Dit berust op waarnemingen warbij de werking van heparines op (gedeeltelijk) gezuiverde geactiveerde factoren werd onderzocht. De werking van LMWH op geactiveerde factoren die gedurende het stollingsproces in het plasma ontstaan (endogene factoren) is nog onbekend.

Daar wij hebben kunnen aantonen dat er in het geval van UFH belangrijke verschillen bestaan tussen de werking op de endogeen geactiveerde factoren II ${ }_{a}$. I $X_{a}$ en $X_{a}$ en op dezelfde factoren als zij van buitenaf aan het plasma worden toegevoegd, 1 ag het in de rede na te gaan wat het effect van LMWH op de protrombinaseactiviteit is. Het bleek dat er twee klassen van heparines bestaan. De eerste, die wij het $s$ type noemden (naar standaard heparine) bevat heparines die niet wezenlijk van UFH verschillen. Deze heparines 
(CY 216, CY 222) versnellen de inactivering van trombine door AT III maar hebben geen directe werking op het protrombinase. De tweede klasse, het $\mathbb{P}$ type, vernoemd naar Choays Pentasaccharide (cy 234) heeft geen werking op de AT III -trombine interactie, mar pemt het protrombinase wel. Tot deze groep behoren naast het pentasaccharide de stoffen EMT 966 en EMT 967. PK 10169 is van een gemerngd type, mogelijk inderdaad een mengsel van twee of meer heparines.

Het onderkennen van twee klasses heparine heeft belangrijke gevolgen voor de standaardisering van heparinepreparaten. Enerzijds kan men de heparines van het $s$ type ongedwongen met een standaardheparine vergelijken. De enige parameter die in plasma door toevoeging van deze heparines verandert, $n l$. de afbraak constante van endogeen trombine, moet daarbij de matstaf zijn. Anderijds kunner heparines van het $P$ type niet met die van het $S$ type worden vergeleken ondat zij een geheel verschillend werkingsmechanisme hebben. Iedere vergelijking zal wan het meetsysteem afhankelijk en dus arbitrair blijven. Hetzelfide geldt mutatis mutandis voor de therapeutische situatie. Indien UFH werkt via de reming van trombine, dan zullen $S$ type heparines net zo werken, zij het dat ze andere - en waarschijnlijk gunstiger - famacodynamische eigenschappen bezitten. Heparines van het $P$ type daarentegen moeten beschouwd worden als nieuwe geneesmiddelen met onbekende werking.

Wij onderzochten ook het semisynthetische heparinoide pentosan polysulfaat (PPS, Hëmoclar ${ }^{R}$ ). Evenals heparine veroorzaakt het een dosisafhankelijke toename van de trambine inactivering in plasma. 1 Hg PPS heeft hetzelfde effect als $0.045 \mathrm{pg}$ UFH. Het effect is volledig afhankelijk van de cofactoren in het plasma. Ongeveer $2 / 3$ van de cofactor activiteit wordt uitgeoefend door AT III, de rest door ëen of meer andere cofactorem. Hoogstwaarschijnlijk betreft het hier heparine cofactor $\mathbb{I}$.

Wagenvoord e.a. hebben aangetoond dat PPS de activering van factor VIII door trombine remt in een cofactor onafhankelijk proces. Wij konden aantomen dat PPS de extrinsieke en intrinsieke protrombinase activiteit (c.q. de vorming daarvan) remt en dat deze remming, i.t.t. de conclusie van Fischer e.a. niet berust op reming van factor $I X_{7}$. Wij namen war dat de reming in het extrinsieke systeem toeneemt bij afnemende concentratie tromboplastine. Bij tromboplastineverdunningen van 1:40 of hoger bereikt de reming een plafond van $20 \%$ onafhankelijk van de PPS concentrate tussen 
I en $10 \mu \mathrm{g} / \mathrm{ml}$. Dit gedrag is te verwachten indien er een tromboplastine- en factor VIII afhankelijke reactieweg bestat voor de activering van factor $x_{a}$, d.w.z. als de tromboplastineafhankelijke factor I $x_{\text {activering bijdraagt }}$ aan de extrinsieke protrombinase vorming m.a.w. als de Josso lus in werking treedt. Onze resultaten doen vemoeden dat dit bij tromboplastine verdunningen tussen $1: 10$ en $1: 40$ het geval is. Bij hogere verdunningen stijgt de reming door PPS niet boven $20 \%$ en $11 j k t$ de bijdragen van het cofactor VIII afhankelijke proces niet toe te nemen.

Een duidelijke aanwijzing van het bestaan van de dosso lus windt men in het feit, dat de extrinsieke protrombinase vorming in hemofiel plasma (A en B) in tegenstelling tot die in normaal plasma, niet wordt geremd. Het is verleidelijk om de 20\% reming door PPS van het extrinsieke systeem met verdund tromboplastine te zien als de maximale bijdrage van de factor VIII en $I X$ afhankelijke factor $X$ activering. Het is echter eerder een ondergrens, want PPS blijkt in hemofiel plasma een stimulerende invloed op het protrombinase te hebben. Er zijn aanwijzingen dat dit proces, waarvan wij de oorzaak niet kennen, ook in normal plasma voorkomt. In dat geval is de waargenomen reming de som van een reming en een activatie zodat de echte remming groter dan 20\% moet zijn. De bijdrage van de Josso lus zou dan evemeens meer dan $20 \%$ bedragen.

In een poging om de fysiologische situatie dichter te benaderen, bestudeerden we naast plaatjesarm plasma ook plaatjesrijk plasma. Dit bracht practische problemen met zich mee vanwege de onmogelijkheid om de monsters te defibrineren en door de onstabiliteit van de plaatjes. Om onderling vergelijkbare resultaten te verkrijgen maesten de trombinegeneratiecurves paralel worden uitgevoerd binnen twee uur na venepunctie. Indien geen tromboplastine werd toegevoegd werd een trombine explosie gezien na een latentie fase van 10-12 minuten. In plaatjesarm plasma duurde het langer dan 20 minuten voordat de eerste, lage concentraties van trombine waarneembalar waren. Noch roeren, noch de anwezigheid wan collageen beinvloedde de latentietijd of de hoogte van de trombinepiek. Tromboplastine toegevoegd in zo grote verdunning $(1: 400)$ dat de trombinevoming in plaatjesam plasma niet noemensward wordt verhoogd veroorzaakt een verkorting van de latentietijd van de trombinevoming in het plaatjesrijke plasma van 3 à 5 minuten. Dit cooperatieve effect van plaatjes en weefselfactor is voor zover wij weten nog nilet eerder beschreven. Wij konden aantonen dat het 
wordt bewerkstelligd door sporen van trombine. Het wordt $n$. gerend door hirudine $(0.2$ - 2 U/ml) en nagebootst door kleine hoeveelheden trombine $(0.5$ - $5 \mathrm{nM})$. Toevoeging van factor $V$ of factor $V_{a}$, in concentraties zoals die door geactiveerde plaatjes worden wrijgegeven, beinvloedt de latentietijd niet significant. Procoagulante phospholipiden daarentegen veroorzaakten een sterke verkorting van de latentietijd.

Het lijkt niet onwarschijnlijk dat het beschikbaar komen van procoagulante phospholipiden uit bloedplaatjes de reactie is die de trombineexplosie veroorzaakt. De bloedplaatjes reactie zou dan worden geģnduceerd door sporen trombine die gedurende de latentietijd warden gevormd. Deze gedachte wordt ondersteund door het feit dat $5 \mu \mathrm{M} \mathrm{Ca}^{\text {t+ }}$ ionofoor, waarvan bekend is dat het de flip-flop reactie in platjes teweeg brengt, de latentietijd van de trombinevoming in plaatjesrijk plasma tot 2 minuten terugbrengt.

Wij konden aantonen dat heparine, in concentraties die de trombine vorming in plaatjesarm plasma praktisch geheel uitdowen $(0.1-0.3 \mathrm{U} / \mathrm{m} / \mathrm{l}) \mathrm{de}$ trombinewarming in plaatjesrijk plasma wel uitstellen maar niet remmen. Dit kan verklaard worden door het vrijkomen van de heparine bindende plaatjesfactor 4 wit geactiveerde bloedplaatjes. Wij vonden het in supernatant van plaatjesrijk plasma waaraan $\mathrm{Ca}^{++}$ionophoor $(5 \mu \mathrm{M})$ als activator was toegevoegd, voldoende plaatjesfactor 4 aanwezig was om tot $0.5 \mathrm{U} / \mathrm{ml}$ heparine te neutraliseren. Sonicatie had hetzelfde effect als toevoegen van $\mathrm{Ca}^{++}$ ionophoor.

In tegenstelling tot UFH remmen LMWH de trombine vorming in plaatjesrijk plasma wel, waarschijnlijk omdat ze minder effectief door plaatjesfactor 4 worden geneutraliseerd. De verschillende soorten LMWH tonen verschillende remingspatronen warschijnlijk afhankelijk van hun interactie met AT III, protrombinase en plaatjesfactor 4. Verdere experimenten zijn noodzakelijk on deze patronen te ontrafelen.

Wij deden ook een aantal voorbereidende proeven over het effect van andere antitrombotische famaca op de trombinevoming in plaatjesrijk plasma.

Drale antistolling remt het cooperatieve effect van tromboplastine en plaatjes. Verrassenderwijs werd ook met aspirin een zekere remming bereikt. Het stabiele prostacyclineanaloog ZK 36374 verlengde de latentietijd maar prostaglandine $E 1$ deed dit niet, ook niet in concentraties die de aggre- 
gatie volledig remden. Het vasculair anticoagulans beschreven door Reutel ingsperger et al. rende de trombine vorming in platjesarm plasma en ook het cooperat leve effect van bloedplaatjes en tromboplastine.

Wij kunnen onze resultaten a.h.v. Samenvatten: wij hebben een experimentele methode ontwikkeld die het mogelijk makt de protrombinase activitelt in plasma te verwolgen. Wij hebben deze gebruikt voor een gedetailleerde bestudering vam de trombine vorming in plaatjesam en platijesrijk plasma en van de invioed van heparine en heparineachtige stoffen daarop. De beschikbaarheid van zuivere preparaten wan menselijke stolligsfactoren maakte het mogelijk de darbij betrokken mechanismen gedetailleerd te bestuderen. Wij konden laten zien dat drie versterkingsmechanismen in stollend plasma wan groot belang zijn: De Josso lus en de activering door trombine van factor WIII en van bloedplaatjes. Dit laatste effect is vooral te danken aan het beschikbaar komen van stollingsbevorderende phopholipiden. Als er heparine aanwezig is, heeft ook het vrijkomen van plaatjesfactor 4 uit geactiveerde trombocyten een belangrijk effect op de trombinevoming. Wij vonden een cooperatief effect van lage concentraties tromboplastine en bloedplaatjes dat van belang kan zijn als de trombinevorming in viva door beperkte weefsel schade wordt opgewekt.

Wij konden aantonen dat het klassieke heparine in plasma voornamelijk werkt via op de inactivering van trombine en dat de inactivering van factor $X_{a}$ en factor $\mathbb{I} X_{a}$ praktisch geheel wordt voorkomen door de aanwezigheid van fosfolipide en factor $V_{a}$ en factor VIII . Wel brengt de werking van heparine - AT III op trombine remming van de product-activatie via factor VIII en bloedplaatjes met zich mee. De laagmoleculairgewicht heparines blijken voor te komen in twee verschillende soorten, de type-s heparines die niet wezenlijk anders werken dan het klassieke heparine en de type-p heparines die niet op trombine werken maar wel het protrombinase remmen.

Wij hopen te hebben laten zien dat experimenten op ongefractioneerd plasma, met of zonder bloedplaatjes een noodzakelijke schakel vormen tussen biochemische studies met zuivere factoren enerzijds en in vivo experimenten op het gebied van pathophysiologie en pharmacologie van haemostase en trombose anderzijds.

Vele van de ideeën in dit proefschrift vonden hun oorsprong in mijn jarenlange samenwerking met François Josso. Ik ben dankbaar een proefschrift te mogen afsluiten waruit zijn geest nog duidelijk spreekt. 
Les ëtudes présentëes dans ce mémoire ont eu pour objectif d'apporter notre contribution à la compréhension des mécanismes qui, dans le plasma procèdent à la fomation de la thrombine ainsï qu'à la compréhension des processus d'inhibition induits par certaines substances telles que 1 'hëparine, ses dérivés et le polysulfate de pentosane. Pour ce faire, nous avons en premier lieu mis au point une méthode permettant d'observer avec une grande prëcision, au cours de la coagulation plasmatique la fomation de la thrombine et 1 'activité de la prothrombinase dans un système se rapprochant le plus possible de la situation physiologique. Cette technique peut aussi bien s'appliquer au plasma dépourvu de plaquettes, dëfibriné ou non, qu "au plasma riche en plaquettes.

Le principe de la mëthode étant celui du test de génération de thrombine, la quantité de thrombine observẻe est la rësultante de deux vitesses: vitesse d'activation de la prothrombine par la prothrombinase et vitesse d"inactivation de la thrombine par les antiprotéases. Une mëthode a étë développée pour mesurer les constantes de dégradation de la thrombine par $1^{\prime} \alpha_{2}$ macroglabuline $\left(k_{2}\right)$ et par 7 'antithrombine III $\left(k_{1}\right)$. La détemination de ces constantes, à diffërents moments de la gënëration de thrombine nous a démontré que leurs valeurs sont invariables pour un plasma donné.

Connaissant ces constantes, $i 1$ est possible par un procédé mathématique (présenté en annexe du chapitre II) de calculer pour chaque point de la courbe la vitesse réelle de la formation de la thrombine, de méme que sa vitesse de disparition. La some de ces deux vitesses représente la vitesse d'activation de la prothrombine ce qui correspond à l'activitë de la prothrombinase. Pour affinmer la validité de cette méthode nous avons comparé les valeurs thëoriques obtenues mathématiquement, aux valeurs trouvëes expérimentalement. Cette vērification a ēté effectuēe de deux manières différentes: d'une part en dēterminant expérimentalement l'activitë amidolytique glabale en même temps que le taux $d \alpha_{2} M-I_{a}$, ou la quantité de prothrombine convertie en thrombine, d'autre part en comparant les vitesses expērimentales et calculëes dans le plasma sélectivement dépourvu d' $\alpha_{2}$ macroglobuline ou d'antithrombine III par immunoadsorption. Les courbes obtenues à l'aide des valeurs expérimentalles d"une part et des valeurs 
theoriques d'autre part, sont etroitement superposables. Ce résultat prouve la vallidié de notre methode.

Bien qu'apparemment "sophistiquẻe" cette technique peut être utilisée facilement ausí bien dans les laboratoires de recherche clinique que dans les laboratoires de recherche fondamentale, ëquipës seulement d'un spectraphotametre et d'un ordinateur personnel pourwu des programes correspondants. L'ordinateur s'est révélé un outil précieux, non seulement pour le traitement informatique des données mais aussi come enregistreur des temps de prélèvement des échantilians tout au long du test de génération de thrombine et des temps d'incubation de la thrombine avec le substrat chromogëne, nous permettant de multiplier les prélèvements et les mesures. Nous awons ainsi pu effectuer des prélèvements espacês de deux à quatre secondes et estimer des deni-vies de la thrombine de 1 'ordre de six secondes dans des plasmas contenant des concentrations thérapeutiques d'héparine.

La grande précision obtenue grâce à ce programme et à l'utilisation des substrats chromogènes nous a pemis d'ëtudier la fomation des premiēres traces de thrombine. Nous avons pu en particulier "matérialiser" le rôle primordial de la thrombine dans la phase initiale de la coagulation et par 1a-mēne confirmer les observations de A. Hurlet-Birk Jensen, F. Josso et nous-même en 1976. La dëtemination rigoureuse des constantes d'inhibition des antiprotéases majeures telles que $I^{\prime \prime}$ antithrombine II et $I^{\prime} \alpha_{2}$ macroglobuline a permis d'évaluer pour la premiēre fois l'activité de la prothrambinase en miliew plasmatique. L'estimation précise de l'activité prothrombinase nous a conduit à une mellileure comprëhension du mode d'action de certains inhibiteurs thërapeutiques de la coagulation.

Contrairement à ce que 1 'on pensait jusqu'a présent, il nous est apparu que 1 "hepparine classique quelle qu'en soit 1 'origine n'a presque pas d"action sur la prothrombinase formée dans le plasma recalfié en présence de facteur tissuläire c'est à dire dans le système extrinsèque de lla coagulation. Son rôle se limite alors essentiellement à celui de catalyseur de 1 'antithrombine III dans ses fonctions inhibitrices de la thrombine. Cependant: l'activitë inhibitrice du complexe AT III Héparine à l"ëgard de la prothrombinase se manifeste clairement lorsque que la coagulation est dëclenchëe par le système intrinsèque (phospholipides, activateur du contact: kaolin), et que le facteur VIII ne peut être activé par les 
pramières traces de thrombine èliminées par le complexe AT III Hêparine. Ceci se traduit par un allongement du temps de latence pour la formation du pic de thrombine et par une diminution de l'activite prothrombinase. L"activation du facteur VIII est donc primordiale pour la formation du complexe activateur du facteur $x$ ("tenase") et par conséquent de la prothrombinase. En effet, si la tenase est formèe extemporanement en dehors du systēme, puis ajoutée au plasma héparinē. la fomation de la prothrombinase est normale. Ces observations corroborent les conclusions des travaux de Marciniak ainsi que les résultats obtenus en milieu purifië par Josso et Béguin, et rapportés au congrës de Toronto en 1981. De plus, elles nous permettent d'apprëcier le degré de protection des facteurs $I_{a}$ et $x_{a}$, au sein de leurs complexes respectifs: tenase et prothrombinase. En effet, ces facteurs semblent être entiērement protëgës de l'action inhibitrice de 1 "antithrombine III, en présence de concentrations d'héparine pouvant inhiber jusqu'à $80 \%$ de la quantité de thrombine formée.

Ces résultats peuvent justifier l'intêrêt croissant des laboratoires phamaceutiques à l'égard des fragments de faible masse molëculaire provenant de 1 'héparine. Si l'on commence à bien connaftre le conportement de ces inhibiteurs en système purifié et leurs rôles respectifs vis à vis de chacune des protéines de la coagulation, la connaissance de leur mode d"action dans les sytèmes globaux en plasma total est assez floue. Aussi après avoir démontré (par notre mëthode) que 1 'effet anti $x_{a} d u$ complaxe AT-III Hëparine classique avait peu de retentissement sur la prothrombinase, avons nous entrepris d'étudier certains fragments d'héparine de faible masse moléculaire afin de déterminer si leur activité anti $x_{a}$ abondamment décrite dans la littérature avait ou non une influence sur la prothrombinase.

La discrimination possible entre activité thrombine et activitë prothrombinase a fait apparaitre la possibilité de classer les fragments en deux grandes catégories: 1 'une que nous avons appelée $S$ par rëfërence a l'héparine Standard et l'autre, $\underline{P}$, selon le modèle type fourni par le Pentasaccharide (CY 234). Ainsï, dans la catégorie S ont êté classës les produits CY 216 (Fraxiparine) et CY 222 prësentant les mêmes caractërístiques biologiques que celles de l"hëparine standard c'est-ä-dire: inhibition de la thrombine ( $k_{1}$ modifiē) sans activité significative sur la prothrombinase. Dans la catëgorie $\underline{p}$ ont ëtë classés les produits EMT 966 et 
BMT 967 par analogie avec le Pentasaccharide qui présente une activité antithrombique nulle ( $k_{1}$ constant) et une activité inhibitrice à l'égard de la prothrombinase (en raison de son effet anti $x_{a}$ ).

En rafson du caractère mixte de ses propriétés le PK 10169 (Enoxaparine), n"a pu être classé que dans une catégorie intermédiaire, ne pouvant appartenir préfërentiellement ni à l'une ni à l'autre des deux classes.

La mise en évidence de deux catégories d'héparines soulève le problème du choix d'un standard de comparaison. En effet, s'il est logique actuellement de comparer les fragments d'hêparine de type $S$ à 1 'héparine standard international, voire même d'établifr à partir de notre méthode une équivalence par la relation concentration/ $k$, il serait irrationnel de comparer à ce mëme standard les héparines de type $P$, en raison de leurs mécanismes d'action fondamentalement différents. Le Pentasaccharide (CY 234) chimiquement bien défini pourrait constituer un madèle de référence pour la seconde catégarie.

Ces données d'ordre général obtenues par notre méthode seraient bien évidenment incomplètes, sans les données fondamentales fournies par les biochimistes; néanmoins, pour le clinicien elles peuvent constituer un camplénent précieux d'information pour l'usage thérapeutique des produits qui lui sont proposés, en se rapprochant le plus possible des problèmes auxquels $i 1$ se trouve confronté quotidiennement en raison des nombreuses réactions croisées qui interfèrent in vivo.

Nous avons également étudié le rôle d'un héparinoide, le polysulfate de pentosane (Hếmoclar $r^{R}$, P.P.S). Nous avons pu démontrer que dans le plasma ce prodult corme 1'hëparine exerce sur la thrombine générée in situ une activité antithrombique non négligeable $\left(1 \mu \mathrm{g} \mathrm{d}^{\prime} \mathrm{Hëmoclar}^{\mathrm{R}}\right.$ équivaut à 0.045 $\mu g$ d"hêparinel.

Cette activite antithrombique disparait lorsque la thrombine est génērëe dans les euglobulines plasmatiques en présence d'Hémoclar ${ }^{R}$. Ceci implique que 1 'effet antithrombique est entiērement dēpendant de cofacteurs plasmatiques, à savoir: l'antithrombine III (pour les 2/3) et très vraisemblablement le 2e cofacteur de l'héparine (1/3). Cependant, si l'Hémoclar $^{R} s^{\prime}$ apparente à l'héparine par son activité antithrombique plasmatique, il en diffère par une activitē antiprothrombinase supplémentaire dẻpendante de la vitesse de fomation de la thrombine. En effet, pour le polysulfate 
de pentosane nous avons observé que si pour une faible dilution de la thromboplastine (1/10) 1'inhibition de la prothrombinase est négligeable, 11 apparait pour une dilution de thromboplastine egale ou supërieure au $1 / 40$, une inhibition modérée (voisine de $20 \%$ ) et constante quelle que soit la concentration du produit. (au dela de $1 \mu g / m i)$.

Cette inhibition ne semble pas 1 iée à l'imhibition du facteur IXa, observẻe par Fischer et col. en mileu purifië. En effet, lorsque dans le plasma en 1 'absence d'activation par le contact, la coagulation a été declenchēe par le facteur IX ajoutë extemporanänent en prësence de calcium et de phospholipides, 4 $\mu \mathrm{g}$ d'Hëmoclar m'ont pas modifié la prothrombinase, alors que la concentration équivalente d'héparine $(0.03 \mathrm{U} / \mathrm{ml})$ a inhtbë presque entièrement la thrombinoformation. Cet effet imhibiteur de 1 Hémoclar ${ }^{\mathbb{R}}$ sur la prothrombinase peut être attribué à l'inhibition de l'activation du facteur VIII par la thronbine, dëmontré en systëme purifië par Wagenvoord et al.

Ces observations nous ont conduit à utiliser le polysulfate de pentosane en tant qu'inhibiteur d"activation du facteur VIII, pour étudier le rôle des facteurs VIII et IX dans la voie extrinsèque (boucle Josso). En I"absence de facteur VIII ou IX (plasma d'hëmophilies) il n'y a pas d"inhibition de la gënération de prothrombinase par $4 \mu \mathrm{g} \mathrm{d}^{\text {"Hëmoclar }}{ }^{R}$, contrairement aux expériences réalisées dans le plasma nomal. Cependant 1 interprétration de nos résultats s'est révélée compliquèe par une augmentation d"activité de la prothrombinase dans le plasma d"hëmophile, lors de l'addition d'hëmoclar. Ce mêne phënomène ëgalement observé dans le prasna nomal en présence d'hëparine dans le système extrinsèque reste mytérieux. Ainsi, I'Hëmoclar ${ }^{R}$ nous a permis de falle appara tre l'extstence de la boucle Josso sans toutefois nous permettre de la quantifier.

Selon notre abjectif initial de nous rapprocher le plus possible des conditions physiologiques, nous rapportons dans le dermier chapitre de ce travail les résultats concernant l'étude de la formation de la thrombine dans le plasma riche en plaquettes. Confronté à de nouveaux problëmes principalement liés à la présence du fibrinogène et à linstabilité des plaquettes nous avons été amené à madifier notre technique pour pouvolr effectuer simultanément (contrôle inclus) des expëriences comparatives, dans le plasma non défibriné contenant 300000 plaquettes/fl moins de deux heures après le prélèvement sanguin. 
Aprês recalcification du plasma riche en plaquettes, nous avons observe de facon constante un temps de latence de 8 a 10 minutes avant I"apparition explosive du pic de thrombine. Nous avons eu la surprise de constater que le collagène indispensable pour l'action procoagulante des plaquettes lisolëes et "lavées" n'avait aucun effet sur l'activité coagulante de celles-ci en milieu plasmatique, cecl indëpendemment de la nature du collagëne et des conditions experimentales (avec ou sans agitation). $L$ "addition de traces de thromboplastine (1/2400, concentration finale) insuffisantes pour influencer la gënëration de thrombine du plasma pauvre en plaquettes raccourcit de 3 a 5 minutes ce temps de latence. Nous avons dënontré que ce phénomène observé pour la première fais, est la conséquence d'un effet coopératif des plaquettes avec le facteur tissulaire, induisant un mécanisme d'accélération par l'apparition de traces de thrombine ( $5 n M$ ). En effet, l'addition au plasma riche en plaquettes, d'un inhibiteur spéciflque de la thrombine: l'hirudina, sous fome de traces linsuffisantes pour madifier la quantitë de thrombine gënērée dans le plasma pauvre en plaquettes) conduit à la disparition du phénomène coopératif alors que 1 'addition de nanomales de thrombine, en l'absence de thromboplastine, fait apparaiture ce même phénamène, c'est-à-dire le raccourcissement du temps de latence. Cet effet coopëratif n'est pas lié au facteur $V$ relargué par les plaquettes, car l'addition de facteur $V$ ou $V_{a}$, s'est avérée sans effet sur le temps de latence. Par contre, la gënération de thrombine du plasma riche en plaquettes, obtenue après 1'addition de phospholipides et en l'absence de thromboplastine s'est montrée similaire à celle réalisée en présence de traces de thromboplastine, révēlant ainsi la nature phospholipidique du phénomēne, indiquant ëgalement que dans le plasma, les phospholipides provenant de l'activation des plaquettes par la thrombine déteminent sa vitesse de formation.

Ainsi, 11 est possible que les traces de thrombine induites par les traces de facteur tissulaire (thromboplastine), en déclenchant la 1 ibëration des phospholipides plaquettaires, favorisent la formation de la prothrombinase. Ce phénamène s'apparente-t-il au phénamène de "flip-flop" induit par l'ionophore de calcium qui en exposant les phospholipides plaquettaires les rend immëdiatement disponibles? Cela est vraisemblable, car 1 "addition extemporanée, au plasma riche en plaquettes, de 5 pMolaire d'iomophore de calcium a reporté à 2 minutes le temps de latence précédant 


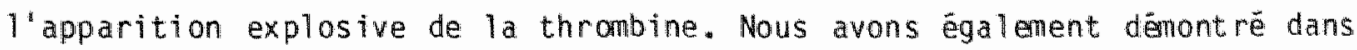
le dernier chapitre que I'hëparine standard qui dans le plasma pauvre en plaquettes, à des concentrations de $0,2 \mathrm{U} / \mathrm{ml}$ abaisse très fortenent le pic de thrombine, n'a eu pour effet dans le plasma riche en plaquettes que d'allanger le temps de latence du pic de thrombine sans toutefois en modifier la hauteur. Cette dernière constatation peut être expliquée par la présence dans les plaquettes du facteur 4 antihéparinique. En effet, nous avons dĕnontré que lorsque celui est libëré dans le plasma soit par sonication des plaquettes soit par leur activation préalable par $5 \mu \mathrm{M}$ d'ionophore de calcium, et après élimination des cellules par centrifugation, l'action inhibitrice de 0,5 unité d'hēparine standard est entièrement neutralisēe tandis que l'allongement du temps de latence disparait également.

Enfin nous nous sommes intéressé aux fragments hépariniques de faỉble masse moléculaîre. A 1 "encontre de 1 "héparine, ces fragments, de type P ou de type $S$, en fonction de leur concentration inhibent à des degrés variables la formation de la thrombine dans le plasma riche en plaquettes. Cependant les BMT 966 et 967 appartenant a la classe P du pentasaccharide, moins inhibiteurs que celui-ci (comparés en poids) ne prolongent que modérément la phase de latence, alars que le pentasaccharide à un degré voisin d'inhibition, allonge d'environ deux fois le temps de latence, ceci étant lié à la faible production de thrombine (en raison du caractère antiprothrombinase du pentasaccharide).

Les CY 216 et 222 appartenant à la classe 5, utilisés dans le plasma riche en plaquettes à des concentrations de $5 \mu \mathrm{g} / \mathrm{ml}$, sont essentiellenent antithrombiques, $11 \mathrm{~s}$ allongent la phase de latence. Cependant, en inhibant faiblement la hauteur du pic de thrombine, ils diffërent des hëparines 5. Le PK $n$ 'appartenant à aucune des deux classes s'est montrë une foís encore, diffërent des autres fragnents: 11 inhibe la quantitë de thrombine formée sans modifier le temps de latence.

Bien évidemment ces données concernant les fragments de faible masse molëculaire mériteraient un plus grand dēveloppement, aussti n"apparałssent-elles dans ce travail que conme exemples d'application de notre méthode, et en préliminaire d'études plus approfondies qui seront poursuivies ultérieurement dans le plasma riche en plaquettes.

D'autres substances antithrombotiques, plus spécifiques des thrombocytes, mais non anticoagulantes telles que 1'aspirine, la prostacycline et 
ses dërivës, ont une influence sur l'effet coopēratif thromboplastine/plaquettes. Des expëriences préliminaires ont dëmontré que ces drogues retardent la fomation explosive de la thrombine. ce mêne effet retard a éte observé pour l'anticoagulation orale; cependant la diminution de la production maximale de thrombine (lièe à la diminution de la synthèse du facteur II) est molns importante en présence de plaquettes qu'en leur absence, cette dernière observation est non nëgligeabie pour l'établissement d'une thérapeutique anticoagulante efficace.

En résumé, en reprenant dans son principe le vieil outil des biologistes: le test de gënëration de thrombine, mais en 1 'adaptant aux mëthodes actueiles, en nous servant des protēines purifiées nous avons dëmontrë qu'il est possible d'ëtudier trẻs prëcisëment la formation de la thrombine dans le plasma, de mesurer la prothrombinase. Nous avons fait apparaitre 1 'importance de trois boucles de renforcement dans le plasma: la boucle Josso, la rétroactivation du facteur VIII par la thrombine, 1 'activation par la thrombine des plaquettes qui libèrent leur facteur 4. L'effet coopēratif de la thromboplastine et des plaquettes nous parait important in vivo pour expliquer la coagulation "extrinsèque" qui peut survenir lors de la libération de facteur tissulaire par des cellules lésées. En dëmontrant que T'hëparine standard est essentiellement "antithrombique" nous avoms limité son rôle dans les processus qui aboutissent à la coagulation, à celui d'inhibiteur de la rétroactivation par la thrombine.

Nous avons pu confirmer que dans le plasma, certains fragments de falble masse molëculaire en inhibant la prothrombinase ainsi que sa formation avaient une action fondamentalement diffërente de l'héparine classtique.

D'autre part 11 nous est apparu que selon le mode expérimental (système purifië ou milieu plasmatique) ces substances pouvaient avoir un comportement different. Ce point nous semble primordial lors de l'utilisation de ces drogues à des fins thërapeutiques.

Par nos études effectuées en plasma total nous espérons avaîr démontré que notre approche constitue un trait d'union entre la biochimie et la pathophysiologive de 1 "hëmostase. Nous sommes heureuse d'avoir pu inener ce travail selon une voie que notre maitre François Josso aurait aimé nous voir prendre. 


\section{REMERCIEMENTS}

Mes remerciements s'adressent:

Au professeur F. Josso qui fit de moi le chercheur que j'ëtais en commençant cette thèse

A monsieur le professeur P. Cornu qui fut le premier à m'aíder dans l'entreprise de ce travail et favorisa ma venue à Maastricht dans le département de biochimie, que cette thèse soit un têmoignage de ma gratitude.

Ma profonde gratitude $S^{\prime}$ adresse ensuite et avant tout au professeur H.C. Henker qui, à la disparition de $F$. Josso, sut me redonner le goût du travail et la joie de la recherche scientifique. Sa grande patience, son dynamisme communicatif, ses connaissances innombrables dans de nombreux domaines $n$ 'ont eu d'égal que celles de mon maitre François Josso. Rares sont les directeurs de thèse qui participent aux expériences autrement qu'avec leur tête; Coen Hemker, après trois longues anneés de charges administratives ne put résister à la tentation de "mettre la main à la pâte", aussi le vit-on bien souvent à la paillasse, qu'il trouve ici le témoignage de ma profonde reconnaissance. Qu'il soit également remercié pour m'avoir introduite dans son laboratoire dans lequel un accueil sympathique me fut accordë.

Ce travail n'aurait pu exister sous cette forme sans la participation mathëmatique de George Willems, qu'il en reçoive mes remerciements.

La grande gentillesse de Paul Devilée, son aide constante factlitèrent mon travail en aplanissant les difficultés quotidiennes, qu'elles soient lieés aux expériences ou aux difficultés de langage. Qu'il reçoive ici avec mes remerciements le témoignage de mon amitié.

Je remercie également Theo Lindhout qui depuis plusieurs années m"aide par ses précieux conseils, de mêne que par sa contribution étroite à ce travail. Sa grande compétence n'a d'ëgal que sa gentillesse et son extrème simplicité. 
Dans de numbreuses expériences j"à pu apprécier la chance infinie et rarissine d"utiliser des protëines purifiées humaines données très gënëreusenent par Ron Budë, Chris Reutelingsperger, Guido Tans et Rob Wagenvoard qu'ils trouvent ici l'expression de ma profonde gratitude.

Je romercie ëglement Edouard Bevers, Karly Hamulyäk, Jean Pieters, Pieter Schoen, Hans Soons pour leur participation ä ce travaill.

Enfin, je remercie tous ceux quit dans ce département de biochimie m'aidērent, de près ou de laîn, à reälïser ce mémoire, en particulier Mariet Molenaar et Fieke Verschueren.

Grâce au service technique les expëriences me furent grandement facil itëes, je remercie Bert van der Steld et son équipe et en particulier Casper Kouw. Je me dols de remercier le professeur J. Caen de nous avair accueillis à Paris dans son service de l'höpital Lariboisière, ainsi que Madame le professeur $\mathrm{Claudine}$ Soria qui avec ses collaborateurs nous reçut avec une très grande gentillesse dans son laboratolre.

Enfin mes derniers remerciements non des moins chaleureux vont à Trees Camphuisen, qui inlassablement et avec une extrème et constante gentillesse accepta de remanier indëfiniment la frappe du manuscrit avant d"assurer avec beaucoup de talent la mise en page de cette thèse qu'elle trouve ici 1 "expression de mon affectueuse amitié. 
Suzette Bëguin was born july $10^{\text {th }} 1939$ in Saint-0uen (France). In 1960 she finished her studies of bacteriology and biochemistry at the Ecole Nationale de Chimie de Paris. In 1963 she obtained a certificate in Parasitology and in Haematology of the Medical Faculty of Paris. In 1975 she presented a thesis: "Etude du rôle des leucocytes dans le déclenchement des phénomènes de coagulation observēs au cours des réactions inflammatoires et de certaines réactions immunitaires" at the Ecole Pratique des Hautes Etudes, (Sorbonne) Paris, which is roughly equivalent to obtaining a B.SC. degree.

From 1961-1970 she worked in the research department of the Centre National de Transfusion Sanguine (Paris) a national reference laboratory for disorders in haemostasis and thrombosis where she was in charge of the diagnostic procedures for classifying disorders of haemostasis under the guidance of Prof. J.P. Soulier.

In 1970 under the supervision of Prof. F. Josso she founded the laboratory for haemostasis and thrombosis research at the Centre HospitaloUniversitaire of the new medical Faculty Necker-Enfants Malades (Universite Descartes). She is (co)author of 30 articles and communications on subjects in haemostasis and thrombosis studied there. She was al so responsible for the laboratory training in haematology of students, technical and medical staff. In 1984 she was admitted to the preparation of a Ph.D. degree in the Netherlands by the Dutch Ministery of Education.

Since October 1985 she is on leave of absence from the University of Paris $V$ and working at the department of biochemistry of Rijksuniversiteit Limburg, Maastricht, where the main part of the present thesis was written. During a three months stay in 1986 at the Department of Haematology of the Lariboisiere Hospital in Paris (head Prof. J. Caen), the experiments described in chapter $V 1$ have been carried out. 